\title{
REALISM OF THE SENSES
}

\section{A TENDENCY IN CONTEMPORARY WORLD CINEMA}

Tiago Magalhães de Luca

Submitted in accordance with the requirements for the degree of Doctor of Philosophy

University of Leeds

School of Modern Languages and Cultures

Centre for World Cinemas

June 2011 
The candidate confirms that the work submitted is his own and that appropriate credit has been given where reference has been made to the work of others.

This copy has been supplied on the understanding that it is copyright material and that no quotation from the thesis may be published without proper acknowledgment.

(C) June 2011

The University of Leeds

Tiago Magalhães de Luca 
To my dear parents, Roney de Luca and Angela Maria Magalhães de Luca, with all my love and affection 


\section{Acknowledgements}

The seeds of this project began germinating back in 2006, during my MA degree in Film Studies at UCL (University College London). At that time, I attended classes and seminars that were fundamental to the development of the ideas which would become the central focus of this thesis. My heartfelt thanks go in particular to Claire Thomson, who was the tutor and coordinator of the brilliant module on Nordic Cinema and supervised my MA dissertation. Her intellectual generosity, encouragement and personal support were crucial in my decision to embark on a PhD.

In 2007, I was offered a place at the Centre for World Cinemas (CWC), University of Leeds, and granted an Overseas Research Student Award (ORSAS) scholarship, which fully supported my doctorate. During my period at Leeds, CWC offered me the opportunity to attend and participate in numerous workshops, conferences and seminars with world-renowned scholars, which made it a vibrant and exciting research environment.

I thank the group Abbey Santander, which in 2009 provided me with funding for a trip to Mexico where I carried out research on the work of Carlos Reygadas. I am grateful to Fiorella Moretti and all staff at Mantarraya Produciones, who made my research at the company's archives a truly enjoyable experience. Special thanks go to Reygadas, who generously provided me with the complete storyboards of his films and other precious materials. Thanks are also due to Tsai Ming-liang who took time to give me a long interview during his busy visit to the University of Leeds in November 2010.

Many friends helped me along the way. Thanks go to Cecilia Lara for putting me in touch with Mantarraya Produciones; to Victor Antonio Leão, for his unfailing support on technical matters; to Cecília Mello, who always had the best advices; to Harry James Attwell, Maina Cardoso, Robson Barreto, as well as many other friends in Brazil, for putting up with my interminable rants.

Paul Cooke, my co-supervisor, was a great reader and I am thankful for his insightful comments. In particular, my deepest thanks go to my supervisor Lúcia Nagib, who could not have read my drafts more attentively and whose unparalleled expertise in cinematic realism continuously challenged and inspired me. No less importantly, Lúcia became a dear friend. Thanks are finally due to my precious parents, whose unrestricted devotion to their sons never fails to touch me. With all my gratitude, I dedicate this thesis to them. 


\begin{abstract}
This thesis proposes to examine the production of sensory realism in world cinema by using as case studies the cinemas of Carlos Reygadas (Mexico), Tsai Ming-liang (Taiwan) and Gus Van Sant (US). These cinemas are bound together through the hyperbolic application of the long take, which promotes a sensory viewing experience anchored in duration and the pure phenomenological presence of animate and inanimate matter. The theoretical underpinnings of the project are laid out in the Introduction, which addresses the alleged demise of realism in light of the emergence of digital technology and provides an overview of the ways the realist style has been historically theorised as connected to the sensory character of the cinematic experience. It further investigates the main aesthetic principles governing contemporary realist cinema and proposes a theorisation of its distinctive sensory mode of address. The thesis is divided into three different parts, which focus separately on each of the aforementioned filmmakers and their distinct realist projects, with emphasis given on their political impact and social significance. Part I is dedicated to Carlos Reygadas's oeuvre, which, indebted to the transcendental cinemas of Tarkovsky, Bresson and Dreyer, complicates spirituality through a quasi-scientific take on materiality and carnality. Tsai Ming-liang is the subject of Part II, which examines his cinema's auteurist, ultra-reflexive realist approach as recycling an aesthetics of the everyday in film through a focus on the sheer physicality of domestic spaces and the physiology of a grotesque body. Part III investigates Gus Van Sant's recent incursion into an experimental-realist style as producing sensory explorations of mental processes of perception in line with the American avant-garde cinema 'visionary' tradition. The Conclusion contextualises and evaluates the aesthetic and political contribution of these cinemas as perpetuating, and reconfiguring, cinematic realism.
\end{abstract}




\section{REALISM OF THE SENSES \\ A TENDENCY IN CONTEMPORARY WORLD CINEMA}

Tiago Magalhães de Luca

\section{TABLE OF CONTENTS}

$\begin{array}{ll}\text { INTRODUCTION } & 9\end{array}$

$\begin{array}{ll}\text { The Real and the Digital } & 10\end{array}$

$\begin{array}{ll}\text { Sensory Realism } & 15\end{array}$

$\begin{array}{ll}\text { A Cinema of Contemplation } & 20\end{array}$

$\begin{array}{ll}\text { Time and Image } & 27\end{array}$

$\begin{array}{ll}\text { Pure Presence } & 30\end{array}$

PART I - CARLOS REYGADAS: CINEMA OF THE IMPOSSIBLE 36

$\begin{array}{lll}\text { Chapter } 1 \text { Transcendental Realism } & 38\end{array}$

$\begin{array}{ll}\text { Spiritual Supremacy } & 38\end{array}$

Metaphysical Obscenity 43

Japón 43

Battle in Heaven $\quad 54$

$\begin{array}{ll}\text { Silent Light } & 62\end{array}$

$\begin{array}{ll}\text { Chapter } 2 \text { Material Surfaces } & 72\end{array}$ 
$\begin{array}{ll}\text { Fleshly Geographies } & 74\end{array}$

$\begin{array}{ll}\text { Earthly Geographies } & 83\end{array}$

Chapter 3 Formal Realism 93

Chapter 4 Producing the Impossible 101

$\begin{array}{ll}\text { Incoherent Narratives } & 101\end{array}$

$\begin{array}{lr}\text { Unlikely Couples } & 107\end{array}$

PART II - TSAI MING-LIANG: CINEMA OF BODIES 117

$\begin{array}{lr}\text { Chapter } 5 \text { The Real City } & 119\end{array}$

$\begin{array}{ll}\text { Chapter } 6 \text { Same Difference } & 126\end{array}$

$\begin{array}{ll}\text { Chapter } 7 \text { Sensory Everyday } & 139\end{array}$

$\begin{array}{ll}\text { Domestic Spaces } & 139\end{array}$

$\begin{array}{ll}\text { A (Bath)room of One's Own } & 155\end{array}$

$\begin{array}{ll}\text { Chapter } 8 \text { Undomesticated Bodies } & 171\end{array}$

$\begin{array}{ll}\text { Grotesque Bodies } & 173\end{array}$

$\begin{array}{lr}\text { Performative Realism } & 188\end{array}$

$\begin{array}{ll}\text { Becoming Animal } & 197\end{array}$

PART III - GUS VAN SANT AND VISIONARY REALISM 204

$\begin{array}{ll}\text { Chapter } 9 \text { Realism and Postmodernism } & 206\end{array}$

$\begin{array}{ll}\text { Chapter } 10 \text { Gerry } & 215\end{array}$

$\begin{array}{ll}\text { Improvisational Realism } & 215\end{array}$ 
$\begin{array}{ll}\text { Contemplating Landscapes } & 222\end{array}$

$\begin{array}{ll}\text { Visionary Images } & 229\end{array}$

$\begin{array}{ll}\text { Chapter } 11 \text { Elephant } & 238\end{array}$

$\begin{array}{ll}\text { Observational Realism } & 240\end{array}$

$\begin{array}{ll}\text { The Reality of Trauma } & 246\end{array}$

$\begin{array}{ll}\text { A Complex Reality } & 260\end{array}$

$\begin{array}{lll}\text { Chapter } 12 \text { Last Days } & 268\end{array}$

Death, Drugs and Rock and Roll 276

$\begin{array}{ll}\text { The Doors of Perception } & 281\end{array}$

$\begin{array}{ll}\text { CONCLUSION } & 297\end{array}$

$\begin{array}{ll}\text { Bibliography } & 306\end{array}$ 


\section{INTRODUCTION}

There is not one realism, but several realisms. Each period looks for its own, the technique and the aesthetics that will capture, retain, and render best what one wants

from reality.

André Bazin

This thesis proposes to examine the production of sensory realism in contemporary world cinema by using as case studies the cinemas of Carlos Reygadas (Mexico), Tsai Mingliang (Taiwan) and Gus Van Sant (US). I will argue that these are cinemas highly representative of a tendency across the globe that purports to restore the traditional tenets of cinematic realism, such as location shooting, non-professional acting and depth of field. More remarkably, this new realist aesthetics is steeped in the hyperbolic application of the long take, which promotes a contemplative viewing experience anchored in phenomenological presence and duration. In other words, these are cinemas characterised by a sensory mode of address based on the protracted inspection of physical reality.

I will delineate in more detail the aesthetic features of this tendency below, as well as the rationale of my choice of directors; for now some words on 'realism' is in order. My use of the term has nothing to do with the 'transparent' style of narrative realism as allegedly produced by Hollywood cinema, which conceals its discursive features and material conditions so as to produce an 'impression of reality' (Baudry 
1974) and, consequently, a bourgeois and phallocentric view of the world, as theorised by semiotic and psychoanalytic film theories of the 1970s. Rather, my take on realism as a methodological and theoretical tool accords to an arguably more basic definition: films that make full use of the camera's recording ability, derived from its photographic foundations, so as to foreground the materiality of the cinematic event and, as a result, that of the medium itself. And yet, realism understood in this light has been under the threat of extinction due to the emergence of digital technology, which has caused a stepchange in film practice as well as theory, asking for some elaboration.

\section{The Real and the Digital}

Debates concerning the demise of realism in cinema have proliferated in film studies in the last two decades. Due to digital's ability to elicit simulation, what is today largely known as the indexicality of photography was deemed lost. As is well known, the term indexicality gained currency in film studies through Peter Wollen's assessment of André Bazin's concept of the 'ontology of the photographic image' (more of which shortly) in the light of Peirce's theory of signs (Wollen 1976: ch. 3). Wollen translated Bazin's ontology into Peirce's definition of the index, that is, the sign that connects to its object through an existential link, as observed in the photographic image. With the emergence of digital technology, indexicality, it appeared, was no longer inherent to the photographic image, prompting theorisations that either celebrated or lamented the digital turn.

In 1996, for instance, Stephen Prince observed that the 'perceptual realism' of 
films such as Jurassic Park (Steven Spielberg, 1993) and Forrest Gump (Robert Zemeckis, 1994) were 'referentially fictional', that is to say, created entirely through digital processes while conserving an isomorphic correspondence to the physical properties and Cartesian coordinates of the real world. Digitisation, Prince argued, gave a new flexibility to the cinematic image which in turn invalidated the application of classical film theories to contemporary cinematic phenomena (Prince 1996). This idea was later reinforced by Lev Manovich, who contended that cinema was 'no longer an indexical media technology, but, rather, a subgenre of painting' (Manovich 2001: 295), due to the fact that cinematic images could be digitally manipulated. More recently, Daniel Frampton has struck a similar note, arguing that the increase of virtual images in film or, in his words, the fluidity of 'this new digitally manipulatable film image' prompts a reconceptualisation of film away from notions of 'automatic photography' and direct 'reproduction of reality' (Frampton 2006: 4-5).

The idea that realist theories were no longer adequate to account for current film phenomena also took nostalgic overtones. In the introduction to the new edition of Siegfried Kracauer's Theory of Film: the Redemption of Physical Reality, Miriam Bratu Hansen argued that Kracauer's realist theory elucidated an indexically grounded cinema which belonged to 'a period that may well be past', helping us 'understand the experience that cinema once was' (Hansen1997: xxxv, my emphasis). Subsequently, Mary Ann Doane observed that Hansen's nostalgic take on indexicality resonated with Paul Willemen (Doane 2002: 227), for whom cinephilia, or 'cinephiliac moments' are intrinsically linked to the film's indexical dimension. As Willemen explains, the surfeit of details recorded by the camera enables the unprogrammed contingent to 'shine through' 
the image, allowing the spectator 'to glimpse something else that you are not meant to see' (Willemen 1994: 241). In this way, 'the less the image has a Bazinian ontological relation to the real...the less appropriate cinephilia becomes' (Willemen 1994: 243).

Both in the celebratory and nostalgic keys, indexicality is seen as a thing of 'the past'. Closer inspection of contemporary audiovisual practices, however, suggests that this may not be entirely true. In fact, the digital often makes the recording of the real, as well as its dissemination, much easier and cheaper. Our 'obsession with realism' (Bazin 2005a: 12), as Bazin put it some fifty years ago, rather than diminished by the digital, seems greater than ever. Consider for instance the boom of reality shows and documentary-style programmes in television in recent years (as pointed out by Nagib and Mello 2009: xv). Take also video websites such as YouTube, which have prompted the massive circulation of domestic videos on the Internet and whose emblematic slogan is 'Broadcast Yourself'. Concerning cinema, it is symptomatic that the documentary genre has seen its levels of popularity and critical acclaim soar in the last years.

Frampton argues that 'it is hard to find a film that does not include some images or people that were never in front of the camera' nowadays (Frampton 2006: 5). But what kind of cinema are we talking about? Dudley Andrew, for example, disagrees with this view, arguing that 'amidst digital confections tempting filmmakers and audiences to escape to the land of the virtual, world cinema brings us back...to Earth, on which many worlds are lived and perceived concurrently' (Andrew 2006: 28). Of course, this does not mean that world cinema is immune to simulation. On the contrary, digital manipulation of the plastic qualities of the image have become widespread thanks to the digital, an example being Alexander Sokurov's Russian Ark (Russkiy kovcheg, 2003), the first 
feature-length film shot in a single long take thanks to digital technology, which, on the other hand, also allowed its images to be retouched in post-production.

As Lúcia Nagib and Cecília Mello note, 'the digital has been more often than not resorted to as a facilitator of the recording of real locations and characters, as well as a means to expand the application of techniques traditionally identified with realism' (Nagib \& Mello 2009: xv). As has historically been the case, such techniques are primarily used to express social concerns, as exemplified by contemporary realisms. An unscripted film such as Abbas Kiarostami's Ten (2002), for example, easily proves this point, as it was entirely shot on two portable cameras mounted on the dashboard of a car in movement, without directorial intervention, a method only made possible by the unobtrusive digital equipment. Drawing on observational time and averse to all didacticism, this method allowed non-professional actors to behave naturally and provided the director with plenty of footage for the editing work, aimed at producing a powerful plea for women's rights. The work of Jia Zhangke is another telling example of social concern expressed through digital technology, and indeed an evidence of the revolution caused by this format in Chinese filmmaking over the last decade, as filmmakers have turned to it in order to sidestep censorship and document the environmental transformation effected by the country's economic boom. Portuguese Pedro Costa also opts for the digital as a means to closely document social inequality, in his case, the slum inhabitants on the periphery of Lisbon, as seen in two of his films, In Vanda's Room (No quarto de Vanda, 2000) and Colossal Youth (Juventude em marcha, 2006), which he shot entirely by himself with a portable Panasonic DV.

And yet, though the digital and the indexical are not antithetical terms, a digital 
camera does not capture information in the same way a non-digital does. The defining feature of a photograph is the reflection of rays of light which cause a chemical reaction on the film emulsion through the camera lens. Hence Bazin's famous metaphor of the photograph as a death mask. In digital capture, however, this physical link is less evident given that the light that passes through the lens is encoded into numerical data. To a film theorist such as D.W. Rodowick, indexicality is therefore 'weakened' in digital capture when compared to analogical photography, because in the latter 'the process of transcription is continuous in space and time, producing an isomorphic record that is indivisible and counterfactually dependent on its source' (Rodowick 2007: 113). This means that photography captures actual blocs of space and time which are dissipated into immaterial algorithms in the digital image. Other theorists, such as Tom Gunning, however, question the notion of a watershed introduced by the digital technology:

The translation of photographic information into a number-based system certainly represents a revolutionary moment in photography, but one not unlike the replacement of wet collodion process by the dry plate, or the conquering of exposure time with instantaneous photography, or the introduction of the hand camera. Like these earlier transformations in photographic history, the digital revolution will change the way photographs are made, who makes them, and how they are used - but they will still be photographs (Gunning 2004: 48).

Philip Rosen has used the term 'digital utopia' to refer to the perception that the emergence of digital technology marks a watershed in audiovisual practices. For him, this 
wrongly 'defines its novelty in opposition to precedent media, identifies precedent media with indexicality, and makes indexicality into a monolithic unity characterized by fixity of world, of representation, of subject' (Rosen 2001: 348). Moreover, Rosen suggests, indexicality is more flexible than recent arguments hinging on its disappearance imply, and for this reason the novelty introduced by the digital as a simulation tool is only in degree, not in kind. And indeed the digital's transformative power has many precedents. Cinematographers, as well as photographers, have always had at their disposal a plethora of formal devices so as to mould the image according to their whims, such as filters, lenses, exposure time, multiple printing, chemicals, etc. No doubt, digital technology intensifies, accelerates and facilitates simulation and manipulation to an unprecedented degree, but this gives continuation to the natural evolution of photography, rather than entailing its end. Foregrounding reality in film has always been a matter of choice, that is to say, the result of deliberate strategies, and this long before the emergence of the digital.

\section{Sensory Realism}

As stated earlier, I would contend that this new realist peak in world cinema is defined above all by a sensory mode of address. Realist styles, and related theories, have always relied on the world's sensory and phenomenological dimensions. Bazin's pioneering realist theory, launched in the 1950s, stated that photography, and consequently film, had an 'ontological' relation with the real derived from its automatic nature. Therefore, in his defence of realism, he praised those directors who, rather than manipulating objective reality, as in the Soviet montage tradition or in German expressionism, highlighted it 
through choices such as location shooting, deep-focus cinematography and nonprofessional acting. Indebted to a phenomenological approach to the real, Bazin revelled in those moments in which the profilmic contingent disrupted the narrative flow, enhancing instead the materiality of the image and thereby triggering a sensual response on the part of the viewer. His writings are freighted with celebrations of the tactile, physical reality of objects. Take for instance his analysis of the final scene of Jean Renoir's Boudu Saved from Drowning (Boudu sauvé des eaux, 1932):

The water is no longer 'water' but more specifically the water of the Marne in August, yellow and glaucous. Michel Simon floats on it, turns over, sprays like a seal; and as he plays we begin to perceive the depth, the quality, even the tepid warmth of that water. When he comes up on the bank, an extraordinarily slow 360-degree pan shows us the countryside before him...At the end of the pan, the camera picks up a bit of grass where, in close-up, one can see distinctly the white dust that the heat and wind have lifted from the past. One can almost feel it between one's fingers (Bazin 1974: 85-86).

Bazin's rhetoric - the 'tepid warmth of the water', the grass which 'one can almost feel between one's fingers' - emphasises the image's sensory effects on the spectator (as noted by Keathley 2006: 66). As Rosen has recently noted, Bazin's theorisation of objective reality as conveyed by film presupposes a subjective investment in the phenomenological real onscreen (Rosen 2003: 41), a subjectivity which I believe has an embodied character. 
The notion that the realist style 'affect[s] primarily the spectator's senses' was also put forward in 1960 by Siegfried Kracauer (1997: 158), who, like Bazin, theorised realism as a property intrinsic to the film medium thanks to its photographic foundations:

[Film] records physical reality for its own sake. Struck by the reality character of the resultant image, the spectator cannot help reacting to them as he would to the material aspects of nature in the raw which these photographic images reproduce. Hence their appeal to his sensitivity. It is as if they urged him through their sheer presence unthinkingly to assimilate their indeterminate and often amorphous patterns (Kracauer 1997: 158).

Kracauer argued that film's 'affinity' with the material world elicits a corporeal mode of spectatorship: 'The material elements that present themselves in film directly stimulate the material layers of the human being: his nerves, his senses, his entire physiological substance' (Kracauer apud Hansen 1997: xxi). In her assessment of Kracauer's theory of realism, Hansen would argue that this corporeal approach could not be further away 'from cognitivist conceptions of film viewing as an operation of "scanning", of processing hypotheses relevant for the construction of a story from the film's representational materials' (Hansen 1997: xxi).

It is interesting to examine how this resonates (or not) with 'body' theories of cinema, which started to emerge in the early 1990s with reference to modes of reception and spectatorship. This was kick-started by Linda Williams, who focused on the physical responses elicited by the 'bodily excess' on display in " gross" genres' such as the 
melodrama, pornography and horror films (Williams 1991: 4). In 1993 Steven Shaviro argued for a film theory based on 'the bodily agitations, the movements of fascination, the reactions of attraction and repulsion, of which they are the extension and the elaboration' (Shaviro 1993: 9). Several theoretical approaches hinging on the 'sensuous', 'tactile' and visceral' dimensions of film viewing followed in his footsteps. Laura U. Marks, for example, has theorised on the ways in which materiality can impact the viewer in a tactile manner. This she calls 'haptic visuality', that is, images which foreground 'material presence' through extreme close-ups and unusual framings, strategies identified in the cinema of Reygadas, as will be analysed in Part I. To Marks, haptic images engender a mode of spectatorship in which 'the eyes themselves function like organs of touch' (Marks 2000: 163).

Under the influence of Gilles Deleuze's philosophical approach to cinema, which will be discussed later, these new takes on spectatorship have, by and large, proposed to replace the ideal, transcendental spectator of psychoanalytic and semiotic approaches with a corporeal one, and the concomitant recognition of the bodily pleasures intrinsic to film viewing. In 2000 Vivian Sobchack, drawing on Maurice Merleau-Ponty’s phenomenology, attributed this theoretical turn to a dissatisfaction with the way the 'spectator's identification with the cinema has been constituted almost exclusively as a specular and psychical process abstracted from the body and mediated through language' (Sobchack 2000).

Parallel to this, new theories drawing on Bazin's foundational views on realism continued to thrive. Onscreen death and sex, events whose re-presentation Bazin deemed an 'ontological obscenity' (Bazin 2003: 30), as well as physical exertion and animal 
cruelty, offered new grounds for theorisations on the physicality of the cinematic experience. Ivone Margulies, for example, expounded on what she called 'corporeal cinema', which she defines as films that reproduce the 'original urgency' of an event through 'their close association with the carnality of the body and decay...realities such as possession rituals, animal sacrifice, torture, or physical disability' (Margulies 2003: 1), some of which comprise the bulk of Reygadas's films (Part I). Sobchack also elaborated from a spectatorial perspective on this physical excess, which in her view ruptures the spectator's investment in the diegesis. This she calls 'the charge of the real', which she illustrates with the famous scene of the killing of a rabbit in Renoir's The Rules of the Game (La Règle du jeu, 1939). She compares the physical quality of this scene with that of the death of a fiction character in Renoir's film, arguing that the latter cannot 'elicit the same level of subjective and physical shiver we feel as our very bodies "know" the existential difference between the character's and the rabbit's...death' (Sobchack 2004: 271). In tune with this focus on physicality but moving away from modes of reception and into those of production and address, Nagib has theorised on the notion of "bodily enactment' performed by cast and crew in the recording of the real in the fiction film. She discusses those films which 'give evidence of an actor's physical engagement with the cinematic event' (Nagib 2011: 19), an aspect which, as we will see, is prevalent, in different measures, in the cinemas of Tsai (Part II) and Van Sant (Part III). Nagib cites, among others, Glauber Rocha's Black God, White Devil (Deus e o diabo na terra do sol, 1964), in which Manuel's race at the end of the film, performed in reality by actor Geraldo Del Rey in the arid backlands of the Brazilian Northeast, entails for the actor a 'painful, bodily experience' of 'a harsh, cruel soil, under an unrelenting sun' (Nagib 
2011: 64).

In common with, and indebted to, many aspects of these theories, my take on sensory realism presupposes an embodied spectator 'with skin and hair', to cite Kracauer's famous expression, that is, the spectator's phenomenological investment in the onscreen reality. However, my approach claims no position in the debates on modes of cinematic reception. Rather, my purpose is to identify and analyse sensory modes of production and address in contemporary realist cinema, to which I will now turn.

\section{A Cinema of Contemplation}

In a sparsely furnished room, a white, young woman is having real sex with an obese, Mexican Indian man. At first static, the camera turns away from the event and pulls out of the room through an open window to perform a slow $360^{\circ}$ pan, capturing in the process two men fixing a house aerial, a busy street, kids playing in the garden of another house, storeys of a luxurious building, a dripping tap, until it makes its way back into the room and find the couple resting, after no less than five minutes. Cut. A limping woman, with a broom in hands, walks into an empty cinema's auditorium framed in a static long shot. She enters the frame from the right, walks up the stairs while sweeping the floor, crosses the upper part of the auditorium, then climbs down the stairs and leaves the auditorium from the left, an action which she takes over three minutes to perform. The camera remains imperturbably immobile recording the now empty auditorium for nearly three minutes. Cut. Outside a stately home the camera, seemingly static, focuses on a room whose half-open window reveals several music instruments. On the upper half of this 
window, the glass reflects the branches of a robust tree whose leaves flutter with the heavy wind. A blond, frail man enters the room, and consequently the frame, and starts playing, one by one, these musical instruments: the bass, the guitar, the drums and so on. The camera unhurriedly starts to recede, taking no less than five minutes to unveil the house's façade, its front area and the tree in front of it.

These three sequence shots, drawn respectively from Reygadas's Battle in Heaven (Batalla en el cielo, 2005), Tsai's Goodbye Dragon Inn (Bu san, 2003) and Van Sant's Last Days (2005), epitomise the similar kind of realism embraced by these cinemas. Despite their widely differing settings and objects of attention, they proceed through a similarly protracted and mute contemplation of reality as enabled by the long take. In them, the narrative is not only rarefied through unbroken shots which quickly exhaust diegetic motivation, if ever there was one, but is blatantly averted. Whether through a camera which literally turns away from the main event to record chance occurrences in the city; or a stubbornly stationary camera that remains firmly in place after a character has left the screen; or a slow-moving camera which ostensibly recedes from the main event while framing a much wider visual field, these are cinemas in which the act of recording takes the upper hand over narrative progression thanks to a camera which seems in awe of its own ability to capture overstretched blocs of space and time.

If, as the quote from Bazin which opens this thesis states, each realism 'looks for the technique and the aesthetics that will capture, retain, and render best what one wants from reality' (Bazin 1997: 6), the contemporary realist tendency as represented by these three filmmakers has to be defined above all by its hyperbolic use of the long take. It is my contention that these cinemas foreground reality primarily as a perceptual, sensible 
and experiential phenomenon. Their phenomenological irreducibility can only be perceived and conveyed through sensory experience. At first glance, this superabundant materiality as enabled by the long take might seem to accord with the kind of realism championed by Bazin's phenomenology (see, in this respect, Flanagan 2008). If that may be the case in many respects, there is also a crucial difference, relating to the way these realisms far extrapolate the representational imperatives informing Bazin's view of realist cinema. A brief sample of his writings will help me substantiate this claim.

Bazin's thought is traditionally associated with the long take, and yet his defence of this technique is only tangential to it. More than an end in itself, as is often the case in the cinemas of Reygadas, Tsai and Van Sant, the sequence shot in Bazinian terms is the direct consequence of another technique, namely depth of field, which, as Wollen notes, is in turn subordinated to dramaturgic efficiency (Wollen 2004: 252). For example, expounding on William Wyler's The Best Year of Our Lives (1948), Bazin justifies its lengthy shots with the fact that they are 'necessary to convey the narrative clearly' (Bazin 1997: 11). Similar justifications are given in his analyses of Citizen Kane (Orson Welles, 1942) and Renoir's films, whose use of deep focus is examined on the basis of their ability to conflate simultaneous events. Even when praising Umberto $D(1952)$ for its focus on a character's eventless life, Bazin would speak, as Wollen notes, 'of a "dramaturgy of everyday life"” (Wollen 2004: 253). His analysis of this film also gives him the opportunity to expound on the Bergsonian tenets of his realist theory. In his famous analysis of the scene in which the maid gets up and potters about in the kitchen, he identifies glimpses 'of what a truly realist cinema of time could be, a cinema of “duration"”, or durée, in Bergson's term (Bazin 2005b: 77). However, this scene does not 
unfold in a single shot, which prompts one to conclude, as does Margulies, that for Bazin 'what matters is no longer the actual physical integrity of representation - its lack of cuts but that it appears to be physically integral' (Margulies 1996: 39). But nowhere is this representational prescription more overtly formulated than in his appraisal of Luchino Visconti's La Terra Trema (1948), whose 'unusually long' and aestheticised shots 'must be applicable to dramatic ends if it is to be of service in the evolution of cinema' (Bazin 2005b: 45). Quite explicitly, Bazin argues that Visconti's 'disinclination to sacrifice anything to drama has one obvious and serious consequence: La Terra Trema bores the public. A film with a limited action, it lasts longer than three hours' (Bazin 2005b: 45). In fact, if Bazin was impressed with the fact that The Best Years of Our Lives does not have 'more than 190 shots per hour' with 'shots of more than two minutes in duration' (Bazin 1997: 11), he may have been underwhelmed by a 100-minute film such as Gerry (2002) which, as investigated in Part III (Chapter 10), is composed of approximately 100 shots, a large portion of which simply limited to following characters as they traverse desert landscapes, sometimes for nearly five minutes. Or Tsai's What Time Is It There? (Ni na bian ji dian, 2001), a two-hour film made up of 106 shots foregrounding private and absurdist situations often devoid of dramatic significance, as examined in Part II. Or indeed a film such as Reygadas's Japón (2002), analysed in Part I: shot entirely on location in a small rural village in Mexico, the film devotes most of its time to following an unnamed man as he perambulates across rugged landscapes and considers committing suicide for unexplained reasons. The scenes of his solitary wanderings undermine narrative momentum, inviting the viewer to contemplate, in silent, overstretched long takes, images of the empty landscapes he traverses. In this kind of 
realism, spatial and temporal integrity is preserved to hyperbolic extremes. As a result, in spectatorial terms, narrative interaction is dissipated in favour of contemplation and sensory experience. We as viewers are invited to adopt the point of view of the camera and protractedly study images as they appear on the screen in their unexplained literalness. This frontally contradicts the Bazinian rules, as the temporal elongation of the shot surpasses by far the demands of the story, leaving the spectator unguided as to how to read that particular scene hermeneutically.

Now, as mentioned earlier, this hyperbolic and protracted stress on materiality is not restricted to the cinemas of Reygadas, Tsai and Van Sant. On the contrary, sensory realism is currently found in all corners of the globe, as exemplified, among others, by the aforementioned cinemas of Abbas Kiarostami, Pedro Costa, Jia Zhangke, as well as those of Apichatpong Weerasethakul (Thailand), Béla Tarr (Hungary), Lisandro Alonso (Argentina), Nuri Bilge Ceylan (Turkey), José Luis Guerin (Spain), to cite a few more cinemas equally interested in foregrounding material phenomena as enabled by the long take. And yet, this is not a structured film movement. While it is not my intention to locate the reasons behind this aesthetic phenomenon, some speculative commentary can be offered. It is revealing, for example, that this cinematic tendency has emerged, as mentioned earlier, at the moment digital technology has the potential to obliterate film's indexical support, which suggests a reaction to simulation processes. Similarly, these are cinemas whose contemplative-sensory mode of address is strictly premised on the viewing conditions of the theatrical experience - a larger-than-life screen, silence, darkness, an enveloping sound system - which seems to respond to the revolution which the video and, more recently, the digital, have introduced into film viewing habits, 
increasingly displaced onto the private sphere of home and ever-smaller screens. As if to confirm this, the theatrical experience itself has been reflexively explored by some of these cinemas, an obvious example being Tsai's Goodbye Dragon Inn, entirely shot in a crumbling cinema in Taipei, as examined in Part II. ${ }^{1}$

It is also telling that these directors are all habitués of international film festivals whose 'global proliferation...during the 1980s and 1990s resulted in the creation of a worldwide alternative film circuit' (Valck 2005: 101) that enabled a direct aesthetic interchange in the formal and narrative economy of films. Likewise, these are films whose aesthetics of 'slowness', as suggested by Song Hwee Lim, chime with 'slow movements' currently gathering momentum worldwide and which champion the slowing down of life in the context of a world in frantic speed ${ }^{2}$. In fact, in the process of writing this thesis, the slow tempo of this trend has been continually stressed in film criticism (see, for example, Flanagan 2008; James 2009; Romney 2010; James 2010). My approach certainly takes into account slowness, as crystallised in these films' dedramatised mise-en-scène, slow and/or static camerawork and protracted shot length. However, my aim here is to analyse these perceptual and durational strategies through the prism of cinematic realism, an aspect which in my view is in need of theorising.

I would also stop short of adhering to a binary model which sees this tendency as 'a way of saying No to mainstream Hollywood's current fast-edit...style', as suggested by Steven Shaviro (2010) and others (see James 2010). To my mind, these discussions

\footnotetext{
${ }^{1}$ The theatrical experience has also been the focus of Alonso's Fantasma (2006), filmed in the Cinemateca Argentina, as well as Kiarostami's Shirin (2008), a 90-minutes film entirely made up of protracted closeups of over one hundred Iranian actresses (with the exception of French Juliette Binoche) while they watch, enraptured, the film of the title.

${ }^{2}$ I thank Song Hwee Lim for bringing this to my attention during a symposium on Tsai Ming-liang at the University of Leeds, October 2010.
} 
have often incurred the lumping together of these different cinemas as producing an ossified and formulaic style that allegedly purports to oppose the Hollywood model - and this is why in-depth and contextual analyses is here of the essence. In fact, this is my first reason for restricting my focus to the cinemas of Reygadas, Tsai and Van Sant. Theirs are realist projects that, despite their formal similarities, are indebted to entirely dissimilar traditions, enabling us to see different facets of this cinematic phenomenon.

This includes breaking with the Hollywood model, as exemplified, for instance, by Van Sant's cinema, whose 'visionary realism', as Part III examines, stemmed from a rupture with narrative film as materialised, in the director's view, in Tarr's contemplative cinema. He further conflates traditional realist devices, such as non-professional acting and improvisational modes of production, with strategies associated with the American avant-garde cinema, and even the horror film, producing sensory explorations of altered modes of perception. Reygadas, in his turn, owes nothing to Hollywood, giving a new dimension to the 'transcendental realism' of directors such as Tarkovsky, Bresson, Rossellini and Dreyer, whose revelation of physical reality, as discussed in Part I, aimed at the disclosure of metaphysics. Recycling and expanding upon tropes and devices associated with these filmmakers, his realism consists, among other things, in complicating metaphysics through a quasi-scientific take on carnality and materiality. As for Tsai's realist project, it is avowedly indebted to auteurist cinemas typical of the 1960s and 1970s, as well as Brechtian precepts, mobilising an ultra-reflexive style grounded in the exaggeration of depth of field, duration and camera fixity. Not to mention his solid theatrical background, resonant with performance theory and practice (Bao 2007), and translated in his 'cinema of bodies' into a physical acting style embedded in serialised 
and exaggerated movements, as investigated in Part II.

But there is another reason for choosing these cinemas, which is their political impact and social significance. In line with the realist tradition, they are in constant and overt dialogue with their own local realities, despite their being in most cases transnational productions. Indeed, their focus on the class and ethnic divide of Mexico (Reygadas), marginalised populations in rapidly urbanising, late-capitalist cities such as Taipei and Kuala Lumpur (Tsai), and traumatic events in the US such as the Columbine massacre (Van Sant), among others, are cogent cinematic expressions of some of the most pressing social issues of our time. As I will argue, in these three cases these social realities are not only unveiled in revelatory fashion but, even more so, reframed and restructured through sensory audiovisual experiences that, averse to normative representational logic, acknowledge the overwhelming complexity of these realities and, in so doing, enable us to look at them anew.

\section{Time and Image}

Binding together these distinct realist programmes is a desire to convey existing, contextual and material realities through sensory experience. One could say that this is a cinema on the frontier between storytelling and sheer recording, the latter constantly undermining the former. By being delayed, the cut ceases to serve dramatic purposes. In their turn, characters, often played by amateur actors, are devoid of psychological traits: they are laconic, listless, impassive. More than their psychology, it is their physical characteristics and physiology which is on display. Narratives are elusive, sometimes 
mysterious, often deprived of causal logic, its smooth progression truncated by overstretched images depleted of dramaticity. Time ceases to serve the demands of the story: the duration of each shot, diegetically unjustified, makes itself felt. And here we are compelled to revisit Gilles Deleuze's notion of modern cinema, which he defines as the time-image regime.

Deleuze published Cinema 1: The Movement-Image in 1983 and Cinema 2: The Time Image in 1985, before the emergence of the realist trend addressed in this thesis. And yet, as one reads the philosopher's description of a cinema in which action and narrative causality are weakened; and in which the act of seeing takes on the greatest importance for characters and, consequently, spectators, one has the uncanny impression that, more than referring to the dozens of filmmakers of his own pantheon (many of whom are entirely reliant on montage and storytelling, such as Ozu and Rossellini), Deleuze is prophesying a cinema which would take a few years to fully materialise. For him, the time-image cinema requires a new type of character that no longer acts in perpetual motion and according to a causal logic, as was the case in classical cinema. The actions carried out within the diegesis tend not to have an aim. They are those of walking, strolling, wandering, eliciting a contemplative stance which is perfectly illustrated by the cinemas of Reygadas, Tsai and Van Sant, as will be examined in the following chapters. For Deleuze, in the time-image, the character 'has become a kind of viewer...the situation he is in outstrips his motor capacities on all sides, and makes him see and hear what is no longer subject to the rule of a response or an action' (Deleuze 2005b: 3). This 'cinema of the seer and no longer of the agent' (Deleuze 2005b: 2) decentres the representational dimension of the image, now appearing as "pure optical and sound 
situations', which Deleuze explains thus:

These are pure optical and sound situations, in which the character does not know how to respond, abandoned spaces in which he ceases to experience and to act so that he enters into flight, goes on a trip, comes and goes, vaguely indifferent to what happens to him, undecided as to what must be done. But he has gained in an ability to see what he has lost in action or reaction: he SEES so that the viewer's problem becomes 'What is there to see in the image?' (and not now 'What are we going to see in the next image?') (Deleuze 2005b: 261).

Granted, Deleuze emphasises that his is not a realist film theory, arguing that the special power of the time-image is not its ontological force, as defended by Bazin apropos of Italian Neorealism, but its ability to 'prevent perception being extended into action in order to put it in contact with thought' (Deleuze 2005b: 1). Rather than with realism, he is concerned with the way time is rendered non-chronologically within the diegesis in modern cinema. And yet, underlying his approach, it is easy to identify a realist foundation, given its stress on the objectivity of recording. Elaborating on the 'cinema of delay' of Kiarostami, Laura Mulvey notes its conformity to the tenets of the time-image, as a film aesthetic which starts by

deriving images from whatever the camera observed rather than a narrative aspiration to order and organization. With the decline of action, an evacuated cinematic space fills the gap, registering the empty images of landscape and 
cityscape...This cinema of record, observation and delay tends to work with elongated shots, enabling the presence of time to appear on the screen (Mulvey 2006: 129).

As well as the autonomy of time, this de-dramatised cinema conveys a sense of pure material and sensible presence which translates, at least in principle, into a sensory mode of spectatorship.

\section{Pure Presence}

Taking up Roland Barthes’ essay 'The Third Meaning', Kristin Thompson has examined the conflict arising from 'the materiality of a film and the unifying structures within it' (Thompson 1986: 132), that is, those moments when the material dimension of the image escapes and exceeds narrative motivation and structural patterns, calling attention to its own perceptual fabric as such. Though not mentioning the long take, Thompson concludes that material excess is particularly prone to irrupt when a device remains onscreen for too long, which exhausts its functional purpose within the narrative:

Motivation is insufficient to determine how long a device needs to be on the screen in order to serve its purpose...We may notice a device immediately and understand its function, but it may then continue to be visible or audible for some time past this recognition. In this case, we may be inclined to study or contemplate it apart from its narrative or compositional function; such 
contemplation necessarily distracts from narrative progression (Thompson 1986: $135)$.

This material surplus has also been analysed from a spectatorial perspective. Christian Keathley, for instance, argues that the cinephiliac practice stems from a particular way of watching films which involves scanning the image through what he calls "panoramic perception'. Looking for every detail, the cinephile studies the image beyond their narrative functionality, thereby reanimating 'the repressed materiality of the film' (Keathley 2006: 53). The sequence shot, for Keathley, is the device ideally placed to elicit this kind of perception (Keathley 2006: 47).

But how can we theorise cinemas in which materiality is not in excess of a causally chained narrative but quite simply what there is? The above formulations are only in part applicable to the cinemas addressed in this thesis insofar as these theorists characterise materiality as a diegetic surplus: the superabundance of details which, locked in a dominant dramatic structure, posit the danger of calling attention to themselves rather than advancing the plot. Here, on the contrary, materiality is not 'repressed' by the film's structure and subsequently perceived as the epiphanic, fragmentary moments theorised by cinephiliac discourses, as described by Keathley (2006) and Willemen (1994). On the contrary, through the hyperbolic application of the long take and other time-stretching devices, materiality is primarily conveyed as non-conceptual, sensual phenomena.

Before Deleuze, Pier Paolo Pasolini had already attempted to establish a connection between cinema's empirical and temporal dimensions as achieved by the long take. For Pasolini, the long take is by definition 'in the present tense' (Pasolini 1980: 3). 
Reality as it is lived, he argues, is always from a single vantage point and unrepresentable: it 'makes no sense, or if it does, it does so only subjectively, in an incomplete, uncertain, mysterious way' (Pasolini 1980: 4). For him, only the long take is able to convey the sensuous indeterminacy of lived reality:

The substance of cinema is... an endless long take, as is reality to our senses for as long as we are able to see and feel (a long take that ends with the end of our lives); and this long take is nothing but the reproduction of the language of reality. In other words it is the reproduction of the present (Pasolini 1980: 5).

Only when montage intervenes is this present tense transformed into past, for it systematises what is otherwise non-symbolic, purely experiential, indeterminate; it gives a meaningful trajectory to that which essentially lacks signification, namely reality. In this way, Pasolini concludes, the cut in cinema is the embodiment of death, because it organises one's life according to sense-making patterns, retroactively providing it with a definite and irrevocable meaning.

Now it is obvious, as Pasolini himself stresses, that no film escapes montage, as no life escapes death. Moreover, if we take montage in a broader sense, it also includes the manipulation and arrangement of elements onscreen, camera movements which change frames in time without the need of editing, lighting, mise-en-scène, etc., all of which are intended to produce meaning. In filmmaking practice, however, the long take is understood as far less authoritative in making meaning. More than any representational function it may serve, "its fundamental and dominant proposition...is: "All this 
is"'(Pasolini 2005: 240). In other words, the long take highlights the sheer expressiveness of the sensible, as it presentifies the material world. This is best exemplified by the opening of Reygadas's Silent Light (Stellet Licht, 2007), a seven-minute shot of a dawn which shows, through imperceptible time-lapse, the gradual rise of the sun in the horizon. At first pitch-black, the screen gradually lightens, revealing the countryside and the immense sky above. As the sun rises up, a myriad of changing colours appear in the sky, evoking brushstrokes of an abstract painting which has seemingly come into life. Here, an image of the world appears as phenomenological and aesthetic presence, that is to say, as realism of the senses.

Part I looks at the 'cinema of the impossible' of Carlos Reygadas. A self-taught filmmaker and avowed cinephile, his work offers a fascinating case study of a transcendental film aesthetics. Indebted to directors such as Tarkovsky, Bresson and Dreyer, Reygadas complicates spirituality through a naturalist approach, as exemplified by his focus on onscreen death, animal cruelty and graphic sex. His is a realism concerned with the pure materiality of urban and rural environments, as well as the carnality and facticity of bodies, producing a rich mosaic of 'fleshly' and 'earthly' geographies. His work is further characterised by implausible fictional constructions which are, on the other hand, authenticated by realist modes of production, as observed in the unlikely couples of his two first films: a septuagenarian Indian woman and a middleaged white man in Japón, and an obese Indian man and a white young girl in Battle in Heaven. Played by non-professional actors engaged in real sexual encounters, these are 
couples whose unlikely and improbable formation contravenes not only regulatory cultural codes such as age and physical appearance but, more importantly, the rigid social norms animating the socio-ethnic divide of Mexico. While these are 'impossible' fictions, I argue that Reygadas makes them possible in reality.

Part II examines Taiwan-based filmmaker Tsai Ming-liang, whose 'cinema of bodies', impresses for its formal and thematic uniformity. Featuring the same actors, episodic structure and formal style, his films intermingle with one another into one intricate corpus, comprising a limit-case of auteurist filmmaking. In symmetry with that, realism is here also stretched to its limits through the exaggeration of Bazinian spatiotemporal unity, which, decentring representation, highlights instead the concreteness of domestic spaces and the physicality of the human body. In my analysis, I argue that Tsai perpetuates a cinematic tradition of the everyday while opening the doors of domestic privacy wide open. Here, characters are constantly depicted in physiological situations, not to mention their voracious sexual appetite, unorthodox physical movements and idiosyncratic behaviour. Drawing on grotesque repertoire, Tsai challenges prevailing models of normality, gender expectations and discourses on sexuality, affirming instead an undisciplined body that is flexible, inventive and open.

In Part III, I investigate Gus Van Sant's move into an experimental-realist cinema. In contrast with Tsai's work, Van Sant's oeuvre is devoid of formal unity, oscillating between the aesthetics of realism and postmodernism. In 2002 the director embarked on the ‘trilogy of death' - Gerry, Elephant and Last Days (2005) - films based on real life young deaths on the basis of improvisational scripts and modes of production and anchored in the application of the long take. Yet, Van Sant's realist project is hardly 
straightforward. As will be argued in this part, these three films complicate their focus on the objective real through experimental strategies that evoke, through their form, mental processes of perception and cognition, that is to say, altered states of mind. While Gerry seems to convey desert mirages in the modes of a 'visionary' cinematic tradition, Elephant frames the Columbine killings through what I call 'the reality of trauma', unveiling its social complexity and shedding a new light on current American youth. In its turn, Last Days emulates a drug-induced state of mind in its rendition of Kurt Cobain's death, incorporating strategies from the American avant-garde cinema, as well as surrealism and minimal art. In these three films, altered states are conveyed through a hyperbolic assertion of the film medium's recording ability, which, coupled with traditional realist devices as well as conceptual strategies, yields sensory cinematic experiences that testify to the continuous reinvention of cinematic realism.

In the Conclusion, I spell out the aesthetic and political contribution of these cinemas in the context of our stimuli-saturated and technologically-mediated era. 


\section{PART I}

\section{CARLOS REYGADAS: CINEMA OF THE IMPOSSIBLE}

With only three feature-length films in his oeuvre, Carlos Reygadas has arguably become one of the most prominent directors in contemporary world cinema. Born in 1971 in Mexico City, Reygadas dropped a promising career in law and became an entirely selftaught filmmaker. At the age of 28, he completed his debut feature-length Japón (2002), which, premiered at the Rotterdam Film Festival, wowed audiences for its uncompromising realism and formal flair. This was followed by Battle in Heaven (Batalla en el cielo, 2005) and Silent Light (Stellet Licht, 2007), films which cemented the director on the world cinema map and confirmed his interest in distinct yet coexistent Mexican realities. As will be my contention here, what immediately stands out in his oeuvre is the implausibility of fictions, which, paradoxically, are wholly authenticated by realist modes of production. This is best exemplified by his first two films, at the centre of which stand couples - a septuagenarian Indian woman and a middle-aged white man in Japón; an obese Indian man and a white, sculptural young girl in Battle in Heaven whose unlikely, improbable formation glaringly contravenes the wide social segregation of Mexico. Hence, they are what I call 'the impossible'. And yet, their audiovisual materialisation eschews representational artifice, played as they are by amateur actors 
engaged in real sex onscreen. I will argue that Reygadas appropriates the film medium so as to indeed produce the impossible in reality.

Far from restricted to the above, however, this singular realist project encompasses many facets, as the following chapters will hopefully illustrate. Chapter 1 analyses Reygadas's avowed debt to the 'transcendental-realist' cinemas of Dreyer, Bresson and Tarkovsky, directors whose focus on physical reality envisaged the transcendence of the material world. Complicating transcendentalism in his work, however, is a quasi-scientific scrutiny of carnality and materiality, which, anchored in the application of extreme close-ups and the interplay of scale, generates sensory cinematic geographies, as examined in Chapter 2. Chapter 3 investigates the tension between formalism and authenticity informing Reygadas's oeuvre, the combination of which also accounts for its sensory realism. Displaying a rigorous and predetermined concern with form, his films privilege, on the other hand, the pure presence of the sensible and contingent real as enabled by long takes, location shooting and untrained nonprofessional acting. Entirely averse to representational logic and moral didacticism, his is a cinema that mobilises the impossible in the real world and right before the camera lens. This, I conclude in Chapter 4, is political. 


\section{Chapter 1}

\section{Transcendental Realism}

\section{Spiritual Supremacy}

The critical understanding of Reygadas's work seems to be unanimous at least in one respect: that it is informed by a metaphysical impulse, in its turn the consequence of specific cinematic influences, namely Robert Bresson, Carl Theodor Dreyer, Andrei Tarkovsky, and to a lesser extent, Roberto Rossellini (see, for example: Dargis 2003; Butcher 2005; James 2005; Romney 2005; Teodoro 2009). In fact Reygadas himself acknowledges these influences:

I like Roberto Rossellini very much, and the conditions in which he had to shoot with whatever was there. Rossellini was a master at using the world as it is to create everything he needed for his stories. For me, Dreyer is also great. Ordet [1955] is one of the most moving films I've ever seen in my life, a miracle of film. Bresson is also a master, especially in the way he works with non-actors and uses sound. A Man Escaped (1956) is a personal favourite. Tarkovsky was the one to really open my eyes. When I saw his films I realized that emotion could come directly out of the sound and the image, and not necessarily from the story-telling (Reygadas apud Wood 2006: 117-8). 
The realist techniques adopted by these directors are, furthermore, easily found in Reygadas's films. His use of real locations and events, for example, can be viewed as reminiscent of Rossellini's. One needs only consider the scenes of a real religious procession in Rossellini's Journey to Italy (Viaggio in Italia, 1953), which is evoked in Reygadas's Battle in Heaven. The undramatic acting style of his work, reliant as it is on non-professional actors and averse to psychology, is reminiscent of the work of Bresson and his 'models'. His adherence to slow-moving long takes, open landscapes and religious music evokes the hallmarks of Tarkovsky's cinema. No less importantly, Reygadas dialogues with the aforementioned filmmakers through citations, an obvious example being the way he replays Ordet's ending in Silent Light, as will be later analysed.

Like most of their work, Reygadas's three films focus on religion, faith and spirituality. Above all, the contemplative vein of films such as Japón, Battle in Heaven and Silent Light, displaying as they do a certain reverence to the material world through lingering long takes, would seem to replicate the metaphysical thrust of Dreyer, Bresson, Rossellini and Tarkovsky. Yet, exactly how close is Reygadas to these directors? Despite their huge differences, their work has often been grouped together under the rubric of 'transcendental cinema'. Their focus on the physical world aimed at reaching into a spiritual realm and, in so doing, disclosing 'the essence' of things through their material surface. In other words, they subscribed to the notion that the film medium's recording ability could open up a gateway to the metaphysical dimension lurking underneath material reality. This was in fact openly voiced by these directors. For example, Dreyer maintained that 'it is not the things in reality that the director should be interested in but, 
rather, the spirit in and behind the things' (Dreyer apud Carney 1989: 65). Similarly, Bresson postulated that 'your film's beauty will not be in the images (postcardism) but in the ineffable that they will disengage' (Bresson 1986: 109). In his turn, Tarkovsky argued that ' $[\mathrm{t}]$ he image is tied to the concrete and the material, yet reaches out along mysterious paths to regions beyond the spirit' (Tarkovsky 2005: 116).

Rossellini holds crucial importance in the emergence of Italian Neorealism thanks, among other things, to his transcendental discourse. As Millicent Marcus tells us, the realist programme mobilised by Italian Neorealism, of which the director was a foundational figure, was the fruit of amalgamated realist tendencies. Though inflected with the scientific drive of nineteenth-century French Naturalism, and I will return to this in due course, it retained the 'Aristotelian belief in a permanent, ideal order inherent in the world of matter and men' (Marcus 1986: 14). Hence, the neorealist project 'lives in the simultaneous claims of absolute, scientific objectivity on the one hand, and a quest for underlying patterns of significance on the other' (Marcus 1986: 14). With a view to combining these opposing traditions, Neorealism rejected the anti-metaphysical stance of naturalism so as to invest the material world with a higher, morally significant, order. It is this moral impetus that compels Rossellini to say, in order to define 'the realist film', that it 'does not stop at surface appearances, but seeks out the most subtle strands of the soul' (Rossellini apud Forgacs et al 2000: 150).

This moral thrust in film would find in Bazin its most eloquent defender. His well-known praise of neorealist films stemmed from the fact that they materialised his philosophical and spiritual beliefs. As Peter Wollen notes, the critic 'was deeply influenced by [Roger] Mounier's insistence that the interior and the exterior, the spiritual 
and the physical, the ideal and the material were indissolubly linked' (Wollen 1976: 132). Therefore, expounding on Dreyer's The Passion of Joan of Arc (Le Passion de Jeanne d'Arc, 1928), Bazin's praise of this 'documentary of faces' was justified on the grounds of 'the extreme spiritual purification' such 'scrupulous realism of the camera as microscope' offers (Bazin 1982: 20). In the films of Rossellini he saw 'a world of pure acts, unimportant in themselves but preparing the way (as if unbeknownst to God himself) for the sudden dazzling revelation of their meaning' (Bazin 2005b: 100); in those of Bresson 'the outward revelation of an interior destiny' (Bazin 2005a: 133). Yet, Bazin's interest in film remained primarily within the realm of aesthetics. But his belief in the metaphysical qualities of film, informed by a phenomenological approach, was expanded in the work of his disciple, the Catholic priest Amédée Ayfre, who goes on to equate a phenomenological apprehension of the world through film with religious experience. As Jim Hillier contends, ‘Ayfre draws heavily on Bazin’s significant insights... while trying to draw out some of the underlying assumptions which Bazin does not make explicit' (Hillier 1985: 176). For Ayfre, neorealist films' focus on material reality discloses 'the human face of the transcendent Mystery of God' (Ayfre 1985: 190); Rossellini's 'concrete attitude' takes the viewer to the realm of 'metaphysics' and proposes 'the mystery of existence' (Ayfre 1985: 184); in the work of Bresson '[b]eyond the surface...one can glimpse another dimension: that of the soul' (Ayfre 1969: 11). Phenomenological and religious experience were further conflated by Henri Agel, who also expanded on many ideas pioneered by Bazin. For example, elaborating on Dreyer's Jeanne D'Arc, Agel goes on to state that 'it is because Dreyer is concerned with this "physicality" of his characters...that the transfiguration of a tormented human 
substance can become a Christ-substance' (Agel apud Bird 2007: 394).

Cinematic transcendentalism also gained theoretical currency in Anglo-Saxon film studies in the 1970s through Paul Schrader's Transcendental Style in Film, in which Bresson and Dreyer (as well as Yasujiro Ozu) were deemed representative of an aesthetics that draws 'the viewer from the familiar world to the other world' (Schrader 1972: 159). More recently, Michael Bird has theorised the metaphysical in film as 'hierophany'. Borrowing this term from Mircea Eliade - 'the disclosure of the transcendent or sacred precisely through the material of reality' - Bird, following the steps of Ayfre and Agel, coins the term 'spiritual realism' for films 'in which cinema's technical properties become the vehicle of meditation' and 'the sacred is sought at the depth in reality itself' (Bird 2007: 393-4).

Does Reygadas attempt to replicate the spiritual thrust of this cohort of directors? For, though entirely averse to parochialism, the fact remains that a Christian morality is arguably discernable in the work of these filmmakers, the physical being their means to arrive at metaphysics. As far as Reygadas is concerned, his oeuvre seems to pose a different problem: though the idea of transcendence is certainly in evidence in his work, there is here what I call a 'surplus of physicality' that cannot point to the ineffable insofar as it cannot but affirm a purely material and carnal world. Here the material often ceases to be the means for the attainment of a spiritual dimension to become itself the centre of attention, a physical excess encapsulated in the notion of flesh. It is this extreme carnality that complicates his transcendentalism and sets him apart from his cinematic influences, as will now be examined in each of his films. 


\section{Metaphysical Obscenity}

\section{Japón}

Reygadas's cinematic debut, Japón, was shot entirely on location in Ayacatzintla, a small village peopled by less than 170 inhabitants in the Mexican state of Hidalgo. It tells the story of a white, middle-aged, unnamed man (Alejandro Ferretis), presumably an artist, who leaves Mexico City in order to end his life in this remote village. There he seeks lodging and encounters Ascen (Magdalena Flores), a septuagenarian Indian widow who agrees to shelter him in the hut attached to her ramshackle house overlooking the Canyon landscapes. Devoid of narrative momentum, the film unfolds episodically, showing its two protagonists in mundane activities: the man having his breakfast in Ascen's house, sitting in the sun observing the vast mountains, climbing up and down the hillsides; Ascen washing her clothes on the edge of a river, cleaning up the house, etc. In fact Japón devotes most of its time to simply following the man's wanderings across the rugged landscapes. These are prolonged shots taking in the immensity of the Canyons, which, accompanied by religious scores such as Johan Sebastian Bach's 'Mattheus Passion', underline the man's spiritual dilemma and lends the film metaphysical overtones. However, as the man seems to settle in the arid region, spirituality becomes inextricably conflated with carnality, as he finds himself with a strong sexual desire in need of satiation.

Sexual impulses are highlighted, for example, when we see the man observing two horses copulating in a vast field. This three-minute long scene, remarkable for its documentary quality, alternates shots of the two animals, one mounting over the other, 
with a group of giggly children observing the act. The horses are then framed in extreme close-ups that emphasise the penetrative act, as well as their tactile texture, calling to mind what George Bataille, speaking of the lack of subjectivity in animal sex, calls an ‘unashamed sexuality' (Bataille 2001: 31).

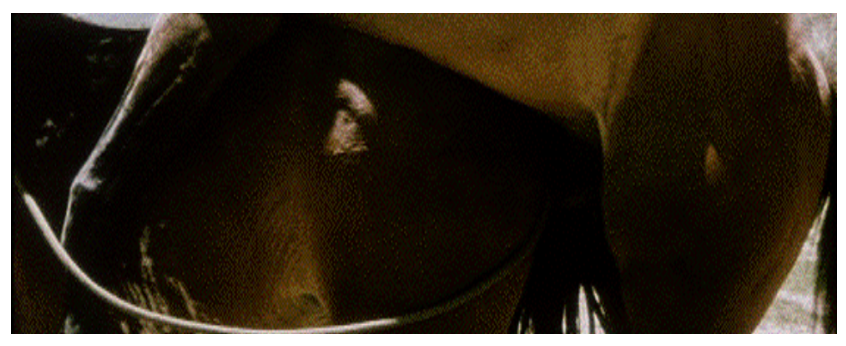

Unashamed sex in Japón

The man's sexual desires are further underlined through subjective shots that convey his staring at Ascen's buttocks and breast. In one particular scene, he is shown masturbating and picturing in his mind Ascen kissing a younger woman in a deserted beach (the film leaves unexplained who this woman is). While these occurrences would seem to disclose a desire directed exclusively towards Ascen, this proves not to be the case. In another scene we see him in a bar transfixed by the attendant's buttocks, as well as by a picture of a naked woman in a newspaper. Towards the end of the film, the man asks Ascen whether she would be willing to have sexual intercourse with him, stressing the need of such an act as a means to obtain the spiritual appeasement he longs for. Inexplicably, Ascen complies with the man and the two of them have sex the following day. 

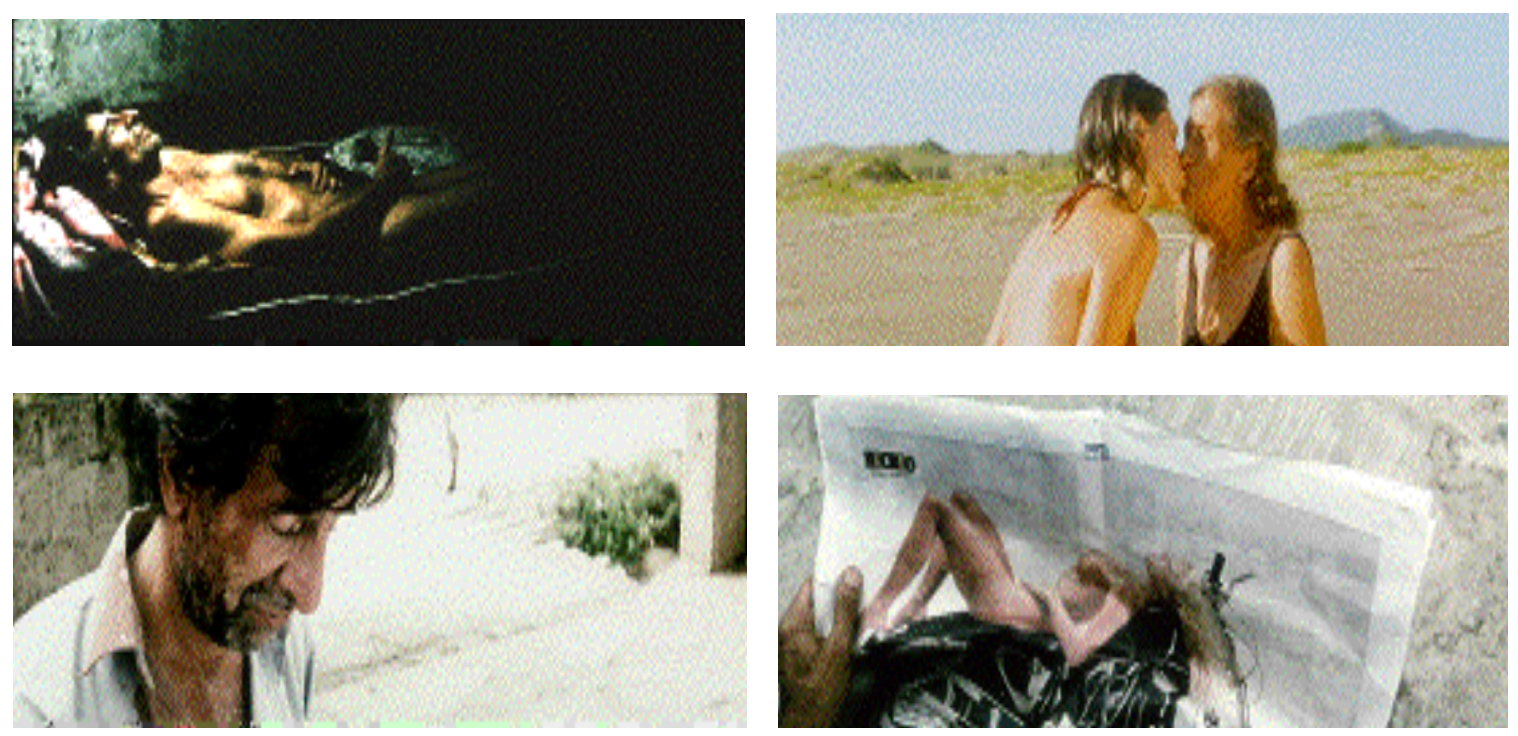

The man's uncontrollable sexual desires

In her turn, Ascen is characterised as incarnating the man's salvation, being moreover constantly associated with Christ. When she first appears, for example, Ascen emphatically instructs the man that her name is not 'Asuncion', as he mistakenly calls her, but 'Ascension', which means, she stresses, 'Christ ascending into heaven with nobody's help'. She is further shown in a series of events that underline her bond with Jesus: pictures of Christ abound in her house; she tells the man she collects Catholic comic books; she goes to the church with a friend as the scene proceeds by interweaving close-ups of her face and the statue of the crucified Jesus. In one particular shot, she is framed in a close-up whose composition even resembles that of a picture of Jesus shown earlier in the house, as the pictures below illustrate. 

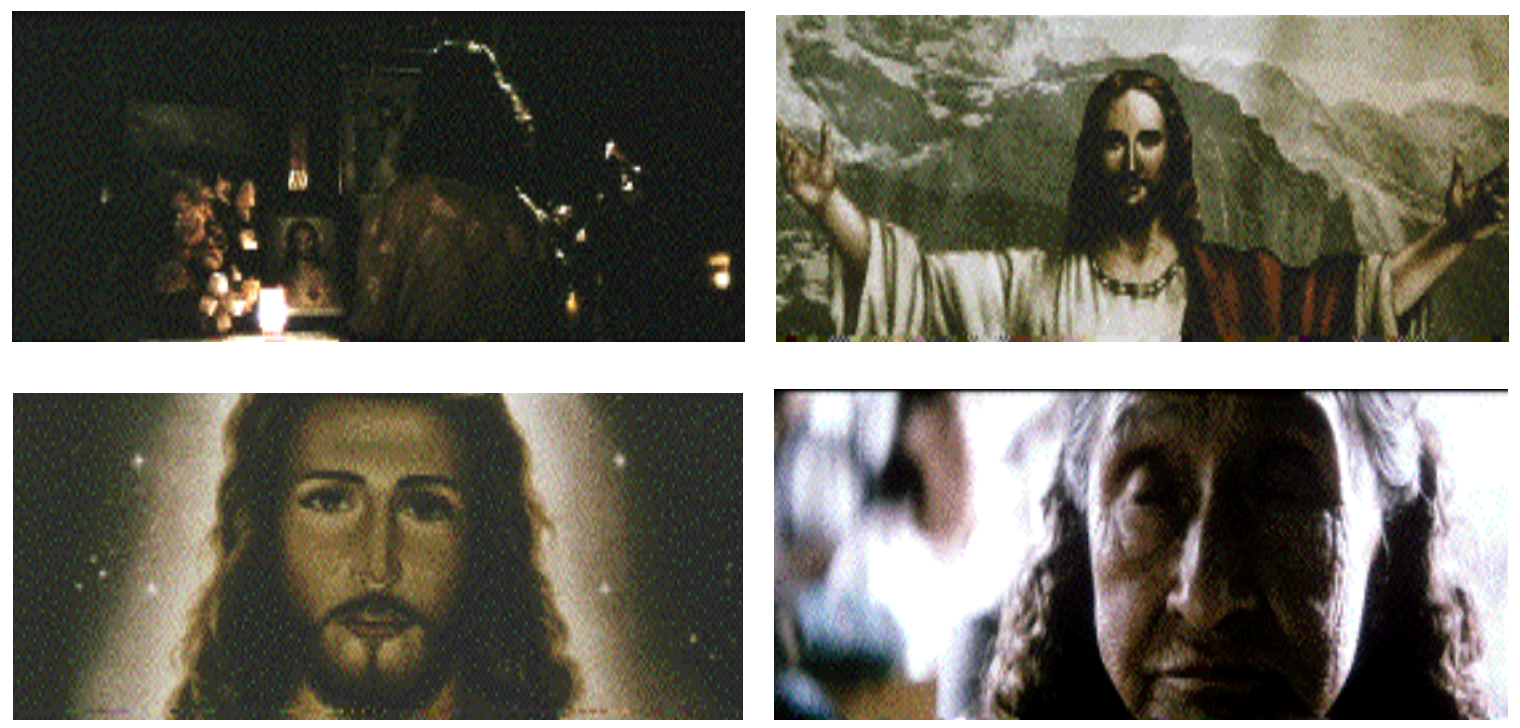

Ascen and Jesus

Ascen also embodies saintly attributes: she is humble, good and generous. We repeatedly see her taking care of her guest: she washes his clothes, cleans his room and waits for him outside her house holding a tray with iced tea and fruits. In a telling scene, she inexplicably holds her hands out to then grip those of the man without uttering a word, a gesture that connotes her desire to appease him. Her accepting to have sex with him, moreover, confirms her willingness to sacrifice herself for him. At first, the man responds to this friendly subservience with asperity. However, as he spends more time with her, he is gradually won over by her kindness, changing his cold attitude as they become closer. In any case, the film continuously emphasises their differences, such as her religious fervour, which frontally clashes with his scepticism. For example, Ascen learns with surprise about the man's disbelief in Jesus or the Virgin of Guadalupe (he disdainfully claims 'they're all the same thing'), assuring him she will pray on his behalf. 
The parallelism between Ascen and Jesus Christ comes to a head in Japón's ending, with her mysterious death while in the back of her nephew's truck, an accident which follows up on her sexual encounter with the man. The film does not show the accident but only its aftermath: this remarkable scene, a six-minute tracking shot taken from a camera carrying out continual $360^{\circ}$ movements and timed to Arvo Part's 'Cantus in Memory of Benjamin Britten', gradually reveals the vestiges of the accident and Ascen's dead body. The film leaves in suspension whether the man, still living in her house, will commit his planned suicide as he sobs upon learning of the accident. We could thus say that there is a biblical parable running through Japón as her death seems to evoke the foundation myth of Christianity: like Jesus, Ascen dies in order to save the man's soul. But what should be noted is that the man's spiritual regeneration is effected through a (simulated) sexual intercourse, the physicality of which is emphasised in Japón by the atypical sight of a septuagenarian peasant woman and a middle-aged man in their unglamourised nakedness. Indeed, this scene is remarkable for its documentary quality and unrehearsed nature, as both non-professional actors are visibly ill at ease and uncertain as to how to proceed, where to put their hands and which position to go for.

This conflation of sexual encounter with spiritual salvation seems to have been lifted from Tarkovsky's The Sacrifice (Offret, 1986). Japón's textual dialogue with this film is in fact evident in its featuring the same extract of Johan Sebastian Bach's 'Mattheus Passion', played at the end of The Sacrifice. Similarly, one of Japón's first scenes, in which the man is framed with a child by an enormous tree, evokes the opening of Tarkovsky's film, as the pictures below illustrate. In The Sacrifice we follow the story of Alexander (Erland Josephson), a Professor of aesthetics who, faced with an imminent 
nuclear war, implores God to avert the catastrophe and promises that, should He realise his wish, he will sacrifice all that is dearest to him. Later, informed by his friend Otto (Allan Edwall) that his servant Maria (Gudrún Gísladóttir) is a 'good witch', Alexander goes to her house and sleeps with her as a means to rediscover his spirituality as their attached bodies inexplicably float up in the room. This scene introduces an ambiguous element into the film as its intimations of witchcraft complicate its otherwise straightforward Christian parable of self-sacrifice. It is unclear, later in the film, whether the restored normality resulted from the sexual act or from Alexander's prayer, or from both, or whether it was all a dream.
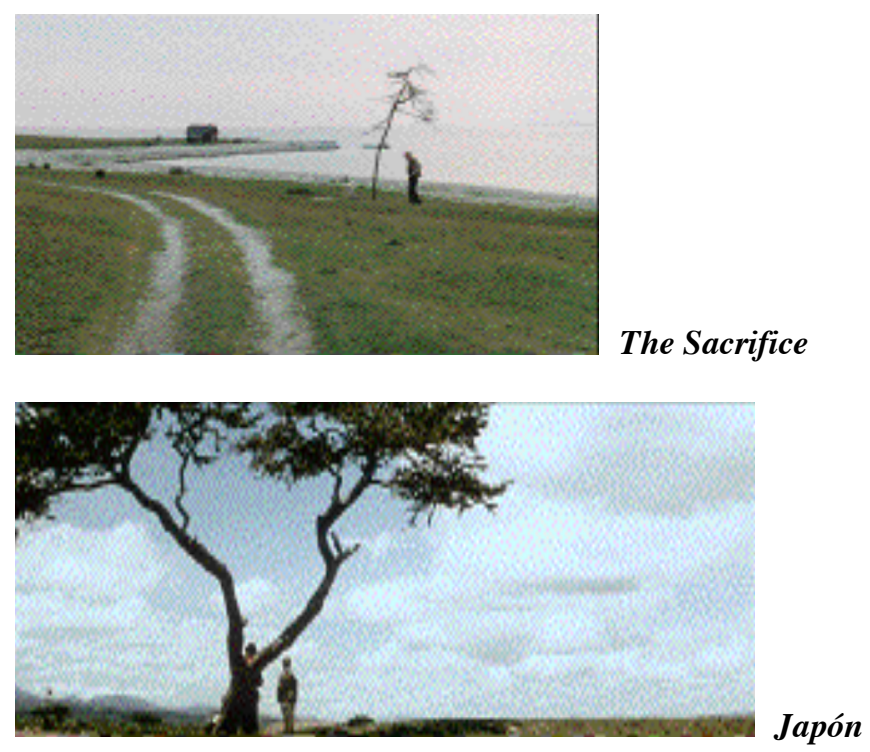

Whatever the case, Tarkovsky is careful to tone down the sexual act in the scene so as to stress its symbolic aspect: not only is this scene devoid of real sex but it also highlights a maternal bond between the two characters, as Maria cuddles Alexander's head and reassures him that 'everything is going to be alright'. Tarkovsky's words on this 
scene are elucidating for, according to him, it was the need to represent a superior kind of love that prompted him to refrain from focusing on the sexual act itself. As he puts it: 'Love for me is the supreme demonstration of mutual understanding, something that the representation of the sexual act can't express... The sexual act is for every one, for every couple something unique. When it is put into films, it's the inverse' (Tarkovsky apud de Brantes 2006: 183), a statement which, as we will shortly see, strongly resonates with Bazin's views on real sex onscreen. By comparison, in Japón the viewer is, firstly, unable to ascertain that there is love between Ascen and the man: we need only remember the aforementioned occurrences which indicate that the man's sexual drive is not directed exclusively at Ascen but a purely physiological impulse. Secondly, by means of its graphic frankness the sexual event on display here calls attention to its indexical carnality, which overrides its metaphorical dimension.
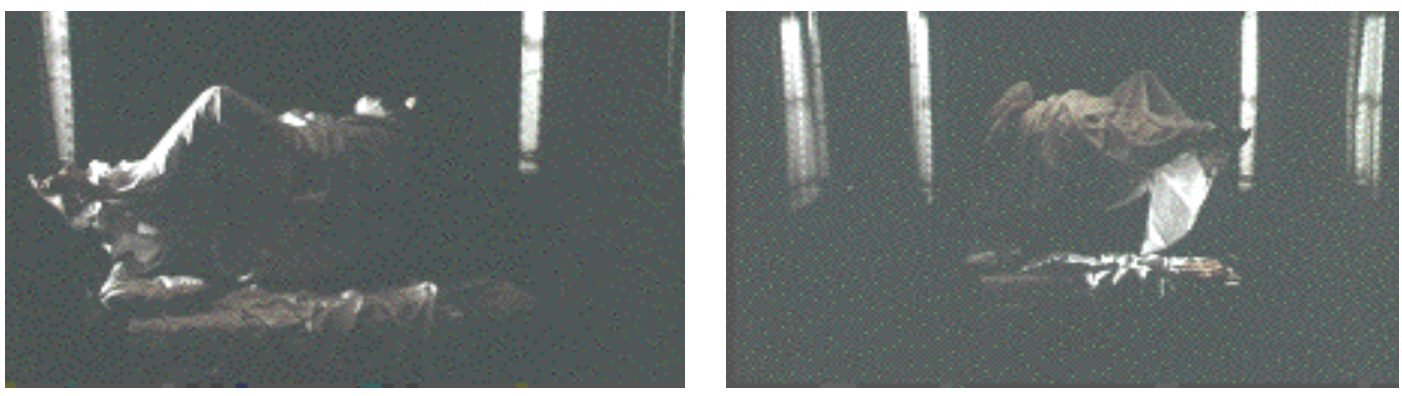

The spiritual-sexual act in The Sacrifice (above) and Japón (below)
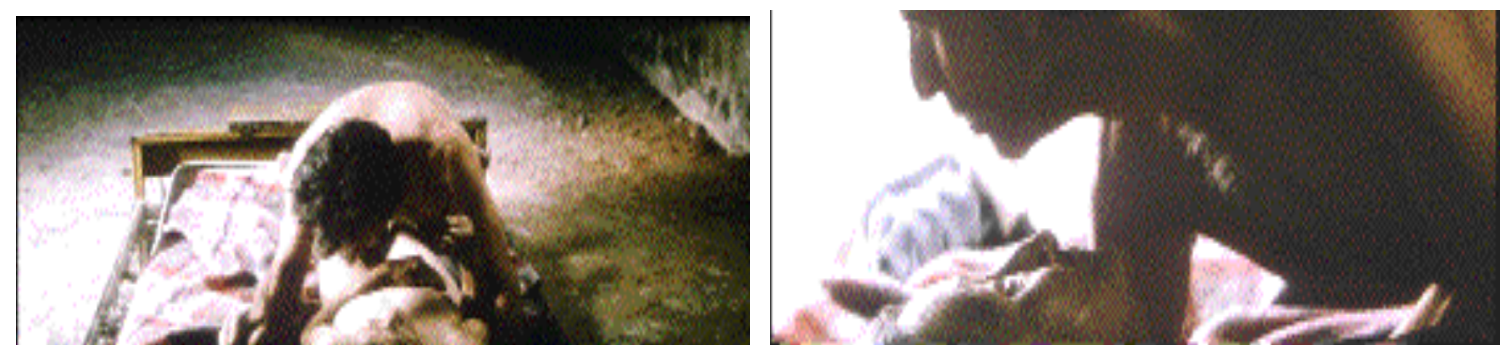
The relationship between Christianity and sexuality is an intricate one. On the one hand, we could say that aversion to the flesh lies at the core of Christian discourses. Brian Turner, for example, contends that while the notion of the flesh as 'the vehicle or vessel of unruly, ungovernable, and irrational passions, desires and emotions' goes back to classical Greek culture, Christianity 'gave this view of the body a darker meaning', viewing the flesh as the source of evil and 'the Christian's duty to master this threatening nature (this wilderness within order) to maintain the life of the soul and of the mind' (Turner 1997: 21-2). In this perspective, by likening the sexual act with spiritual salvation, Japón transgresses Christian codes, according to which sexual abstinence or indeed celibacy is a basic prerogative for spiritual purification. Yet, on the other hand, the flesh is in fact an indispensable element of Christian metaphors, especially in Catholicism. As Donna Haraway points out, Catholic signifiers are so powerful due to their indissolubility with the physicality of the human flesh, as seen, for example, in the doctrines of incarnation and transubstantiation (Haraway 2000: 86). The so-called 'religious ecstasy' in Christianity, characterised as a state of spiritual rapture, also carries sexual connotations. Japón's spiritual-sexual act resonates with a tradition within Christianity in which the perfect communion with a male-gendered God, or Jesus Christ, is rendered in terms reminiscent of an orgasm. One of the most notable examples is that of Santa Teresa of Ávila who in the sixteenth century described her spiritual encounter with Jesus Christ in strictly bodily terms. Around a century later, Baroque sculptor Gian Lorenzo Bernini translated her sensual description into a marble sculpture which conveyed her spiritual ecstasy as one of sexual fulfilment. Another example is the erotic 
poems of San Juan de la Cruz, St. Teresa's confrere, which describe his encounters with God as one of intense physical pleasures.

Conflation of carnality and spirituality is not only restricted to the sexual encounter between Ascen and the man but a recurring motif in Japón, as the gendered and personified symbols of Catholicism are further depicted as sexually arousing. In one ambiguous scene, for example, we see Ascen, standing before a small altar in her house, unhurriedly kissing a Jesus Christ painting on his mouth. Even more significant is the scene in which she nonchalantly tells the man that in the village men tend to like more Virgin Mary while women prefer Jesus. She concludes by citing a story of an imprisoned nephew who was caught masturbating on a picture of the Virgin that she had given him.

Overall, the world portrayed in Japón is one in which impulses of the flesh reigns supreme. The carnality of beings is ultimately emphasised through the foregrounding of real animal death. We have seen that the man's sexual awakening is crystallised in the film by two copulating horses that leave him transfixed, mirroring his own ungovernable animality. In addition, events involving animal death reflect his suicidal thoughts and underline the film's central themes: life, death and rebirth. Yet, more than conveying metaphysics, these scenes emphasise the fragility and finitude of physical life. An eloquent example is the scene, at the film's beginning, in which the man helps a boy pluck a bird's head off. The bird's decapitated head, shot in close-up, is kept in full view while it gulps for breath for a few seconds until it ceases to twitch. Elaborating on the visual taboos informing the re-presentation of death onscreen, Sobchack notes how it challenges 'both the unity and security of the subject' through 'particular bodily signs that indexically point to and foreground the essential mystery of bodily being and 
nonbeing' (Sobchack 2004: 232). She cites, for example, how 'the inanimate human corpse serve as [a] radical sign of the "matter" of human being', what Lawrence L. Langer calls one's “creatureliness"”(Sobchack 2004: 233). Though Sobchack's remarks are not entirely applicable here, given the less shocking sight of a bird's death, this scene brings into central view the tension between physical being and nonbeing by focusing on the animal's transformation from animate to inanimate 'matter'.

Physical fragility and animal death recur in other scenes. We see the man inside a butcher shop as the camera hovers over the raw meat on display; his encounter with a horse's half-eaten carcass atop a hill; a beetle, in close-up, struggling to survive as it starts to rain; a spider, also in close-up, pinched and crushed to death by Ascen. In a particularly disorienting scene, we hear the agonising groans of a pig being slaughtered while the screen remains pitch-black. The camera pans out of the dark room, reaches the daylight and tilts down, revealing the pig's blood spreading over the floor.
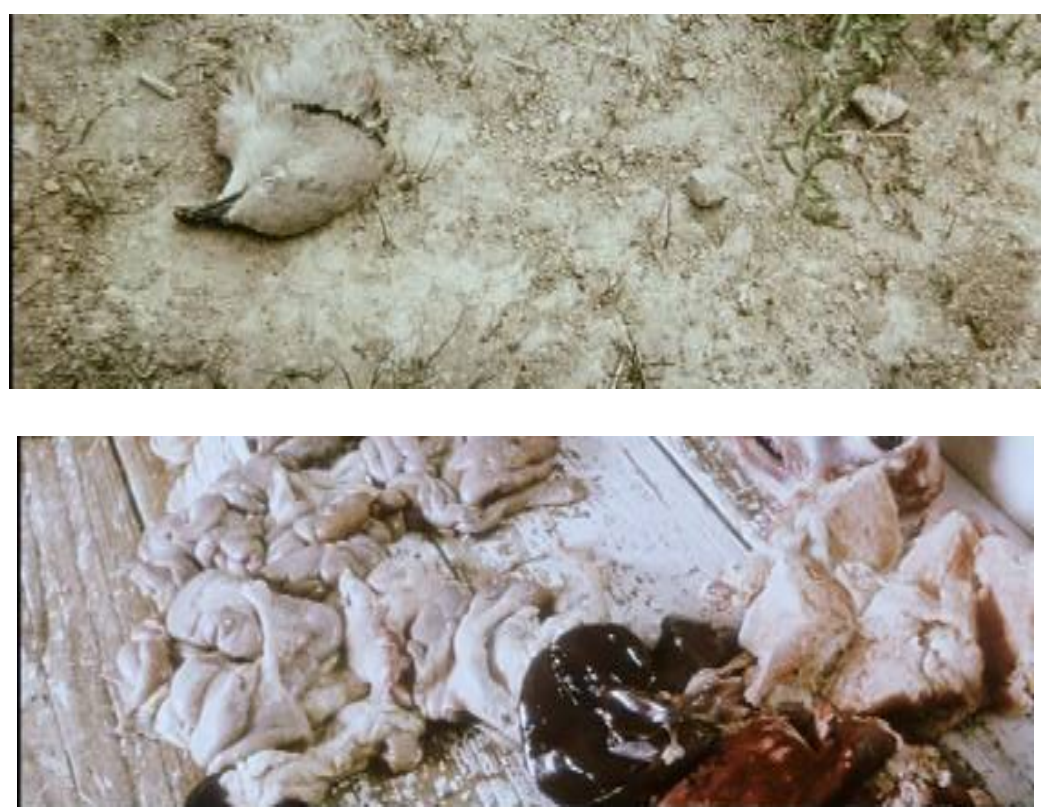


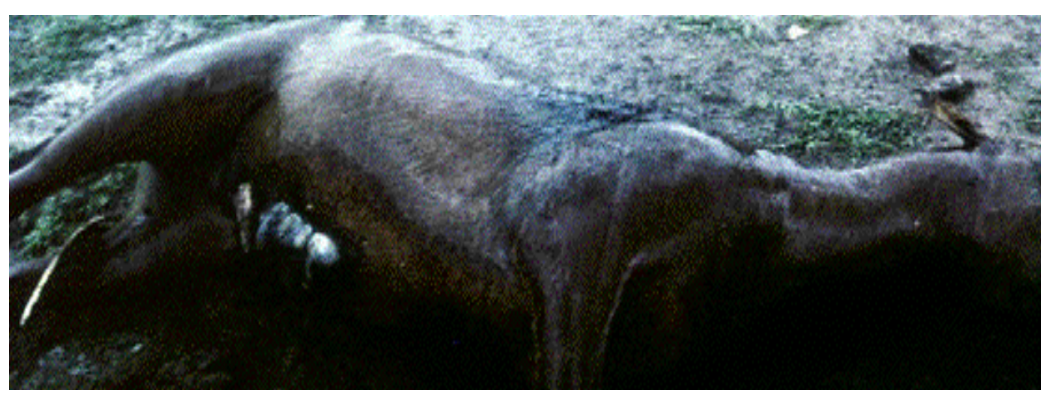

The undisguised flesh

In her review of Japón, Manohla Dargis concludes that its realism would have pleased Bazin: 'For Bazin, Rossellini's films were a way of seeing the world's glory. I think he would have thought the same of "Japón"' (Dargis 2003). However, from the onset Japón is in discordance with a Bazinian realism at least in two respects. In more than one occasion, Bazin, informed by his moral and spiritual convictions, articulated what for him constituted an 'ontological obscenity', namely, the re-presentation of sex and death onscreen. Indebted to the Bergsonian notion of durée, according to which time is qualitative, immeasurable and experiential, Bazin saw these events as the 'absolute negation of the objectivity of time, the qualitative instant in its purest form', hence:

Like death, love must be experienced and cannot be represented (it is not called little death for nothing) without violating its nature. This violation is called obscenity. The representation of a real death is also an obscenity, no longer a moral one, as in love, but metaphysical. We do not die twice (Bazin 2003: 30).

Reygadas's realist project thus extrapolates Bazin's moral imperatives on the representational limits of the film medium. In Japón, metaphysics is constantly thwarted by 
events whose supreme carnality affirms an excessively physical, crude and, not least, amoral world. This obscene metaphysics would gain equally visible contours in Reygadas's second feature-length film.

\section{Battle in Heaven}

Battle in Heaven furthers Reygadas's explorations of flesh and spirit, as epitomised by its shocking opening: a fellatio scene between its main protagonists, Ana (Anapola Mushkadiz) and Marcos (Marcos Hernández), accompanied by a solemn score of strong religious overtones, an original composition by Sir John Tavener. Like Japón, the film has a male protagonist who seems unable to contain his sexual desires while in search of spiritual purification. We follow the story of Marcos, an obese, native Mexican Indian in his mid-30s who works as a driver to a general in Mexico City. He has been involved in the kidnap of his friend's child and the baby has died (the reasons for the death, as well as the kidnap, are left unexplained). He now faces the dilemma of turning himself in to the police and confides the whole story to Ana, his employer's daughter and with whom he has occasional sexual encounters. As the film unfolds against the backdrop of the Virgin of Guadalupe week in Mexico City, Marcos falls into a downward spiral. After inexplicably stabbing Ana to death, he embarks on a flagellation ritual in a religious procession, ultimately collapsing dead inside the Basilica of Guadalupe.

In her turn, Ana is a wealthy, young and beautiful girl who prostitutes herself apparently for the sake of pleasure, a situation thus evocative of Luis Buñuel's surrealist landmark Belle de Jour (1967). In fact, Reygadas bears some interesting analogies with 
the Spanish iconoclast. Buñuel worked in Mexico from 1946 to 1965, making nearly 20 films in the country. It is interesting to note some coincidences between Reygadas's films and those of Buñuel's Mexican phase. Like Simon of the Desert (Simón del desierto, 1965), Buñuel's last Mexican film, Japón was shot in the state of Hidalgo. Battle in Heaven's title, in Spanish Batalla en el cielo, evokes Buñuel's Ascent to Heaven (1951), originally titled Subida al cielo. More significantly, Buñuel's obsessive focus on Catholic symbols and rituals, and their transfiguration into sexual iconography in his work, would seem to resonate with the work of Reygadas - albeit without the corrosive humour. In Viridiana (1961), for example, the female protagonist is raped to the sound of 'Hallelujah Chorus' (as noted by Stam 1995: 175), an audiovisual dissonance which can be found in the work of Reygadas, for instance in Battle in Heaven's aforementioned opening. Yet, while Buñuel's thrust is, arguably, blatantly iconoclastic and ironic, being moreover informed by a love for fetish, this is not entirely applicable to Reygadas.

In any case, there are some important similarities between these two filmmakers. Elaborating on the 'transcendental pornography' of Buñuel's work, Robert Stam, for example, notes how 'saint meets voluptuary in a world which celebrates all that introduces a note of "excess" into the orderly round of respectable activity' (Stam 1995: 175), going on to argue that, in his films, '[s]exual pleasure...exists only in a religious context', as 'religion becomes the trampoline for desire' (Stam 1995: 177). Deleuze, in his turn, contends that 'in Buñuel, the discovery of impulses proper to the soul - as strong as hunger and sexuality and made up of them - was to give perversion a spiritual role' (Deleuze 2005a: 135). Something along these lines happens in Battle in Heaven, in which, as with the man in Japón, Marcos's spiritual and sexual impulses go hand in hand. 
Marcos changes his sceptical attitude towards religion while becoming more sexually attached to Ana. At first, he lacks spiritual convictions, as observed in the scene in which he chances upon a large religious procession and comments to the gas station attendant that 'they're all sheep'. This is further underscored by his reluctance to partake in the Sunday's pilgrimage with his wife, who repeatedly asks him to accompany her. However, as the film progresses, the weight of his criminal deed, it appears, compels him to rethink this anti-spiritual stance.

Spiritual growth is particularly emphasised in the sequence in which he is away in the countryside for the day. After complying with his wife that he will attend the Sunday's procession, Marcos makes his way into the woods. With his back to the screen, he recedes from the camera as fog starts rapidly drifting in until the sight of the woods farther away becomes no longer visible. As with many occurrences in this film, the sudden setting of the fog is left unexplained, lending itself to a metaphysical reading: as Marcos becomes the only discernable figure in the frame and walks into the mist, one cannot but infer an allusion to the Heaven of the film's title. This is then reinforced when, a few shots later, we see Marcos climbing up a high hill, atop of which a wooden cross stands facing the countryside. Marcos stops and looks pensively into the horizon in the manner of a Romantic hero, in a visual composition emulating Caspar David Friedrich's Wanderer above the Sea of Fog (Der Wanderer über dem Nebelmeer, 1818), a painting famously informed by a metaphysical thrust (see pictures below). 

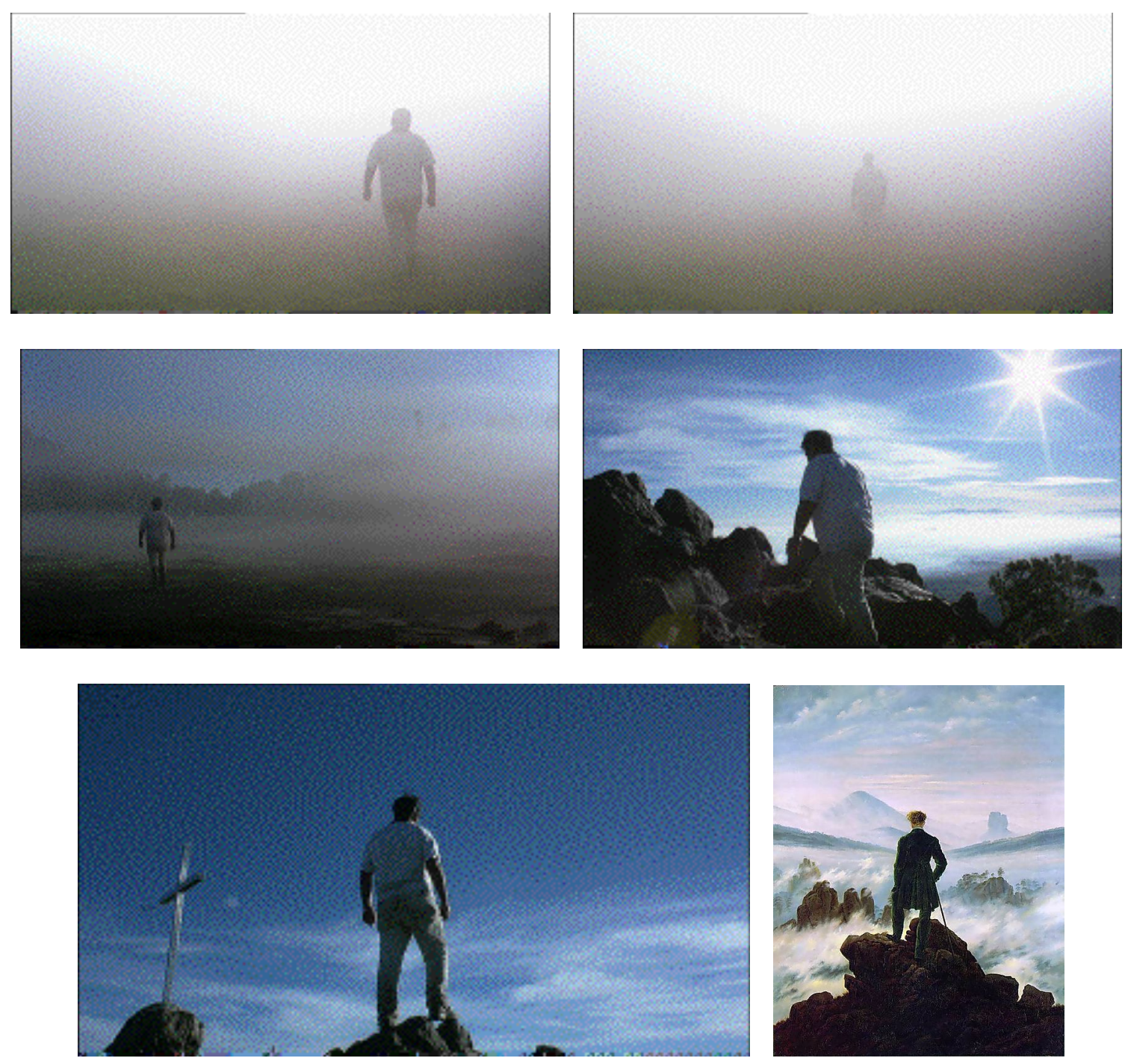

Towards the transcendent

And yet, if anything, Battle in Heaven brings to the fore Reygadas's interest in the human flesh while again likening it to the ritualistic arena of religion. This is what happens when Marcos, presumably wishing to purify himself of his sins, embarks on the Guadalupe procession and falls into a self-flagellation trance: on his knees, topless and hooded, he makes his way to the Basilica and there he collapses dead. A constitutive element of Christian religions and in particular Catholicism, the act of flagellation, whose physical suffering is meant to replicate that of Christ, is still common practice during 
religious festivities in Latin American countries such as Mexico and Brazil. And like the equation of sex with religious rapture seen in Japón, the carnality intrinsic to this practice reveals the profound reliance of Catholic metaphors upon bodily experiences.

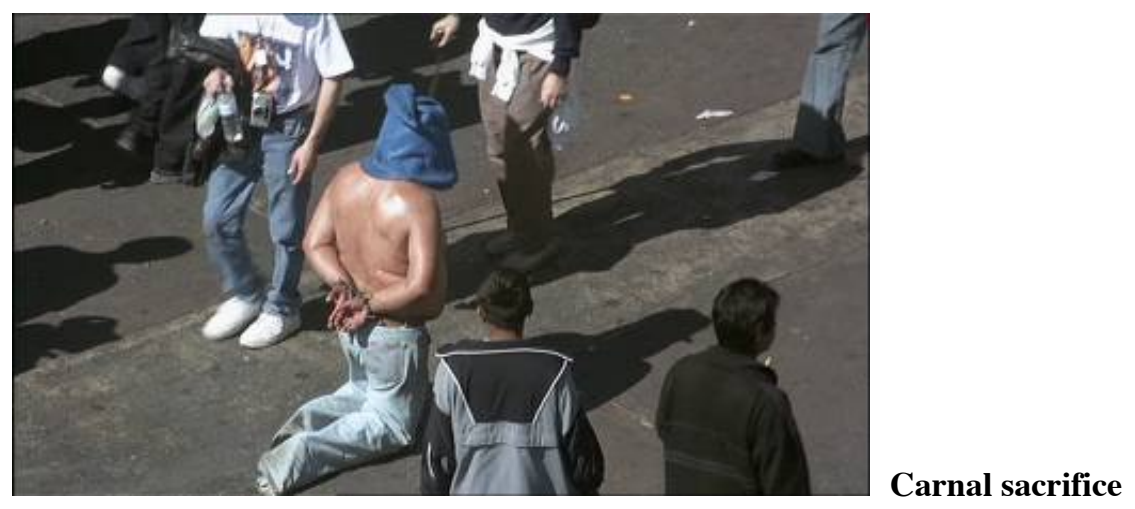

Battle in Heaven's emphasis on carnality is further mobilised through the pivotal role played by sexual desires in Marcos's life. He is seen not only having sex with Ana and with his wife but also masturbating, and all these events are depicted in graphic detail. In fact we could say that the film's carnal impulse is literally materialised in the corpulent figures of Marcos Hernandez and Berta Ruiz, who plays his wife in the film. It could be argued, moreover, that the decision to use these real, obese people aimed at unveiling a prominent aspect of Mexico's reality. Marcos's obesity, as well as his wife's, attests to a growing and large-scale disease in Mexico, the second most obese country in the world, behind only the US. While malnutrition has always plagued the poorest in Mexico, this surge in obesity, growing mainly among the deprived in the big cities, reflects radical changes in the country's diet where the consumption of cheap junk food has risen considerably and obesity, once a mark of health and wealth, becomes a sign of poverty. 
Yet, while this may explain one aspect of the presence of Hernandez and Ruiz in the film, it does not fully account for the way their bodies are foregrounded. When Marcos and his wife are having sex, for example, the film employs extreme close-ups that scrutinise and magnify their excess of flesh, and I will return to this in the next chapter. Additionally, this scene encapsulates the theme at the heart of Reygadas's oeuvre as it proceeds by juxtaposing the sexual act with shots of a semi-naked Jesus Christ painting hung on the bedroom's wall, which yet again reveals the carnality constituent of Catholicism bloody, fleshly imagery. By alternating extreme close-ups of the flesh of Christ's wounded body, from which blood gushes out, with those of Marcos's and his wife's rotund figures, moreover, this scene establishes an interesting analogy between the pious and the grotesque. Indeed, the obese figures of Marcos and his wife conform to Mikhail Bakhtin's definition of the grotesque body as a corporeal mass in constant outgrowth, hyperbolic, excessive; 'the body enlarged to gigantic dimensions' (1984: 328).
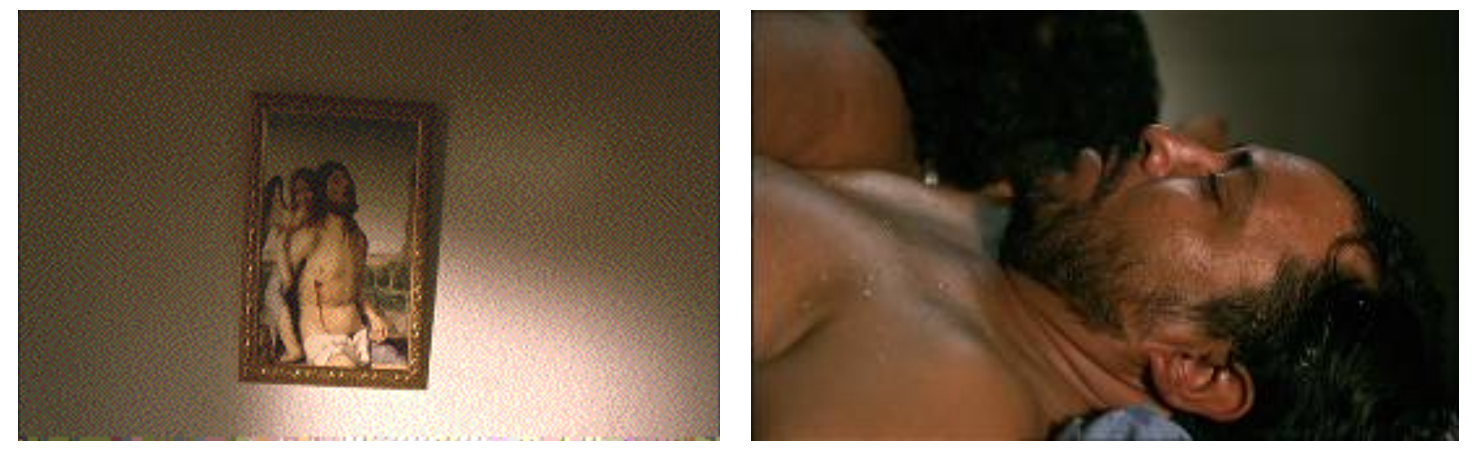

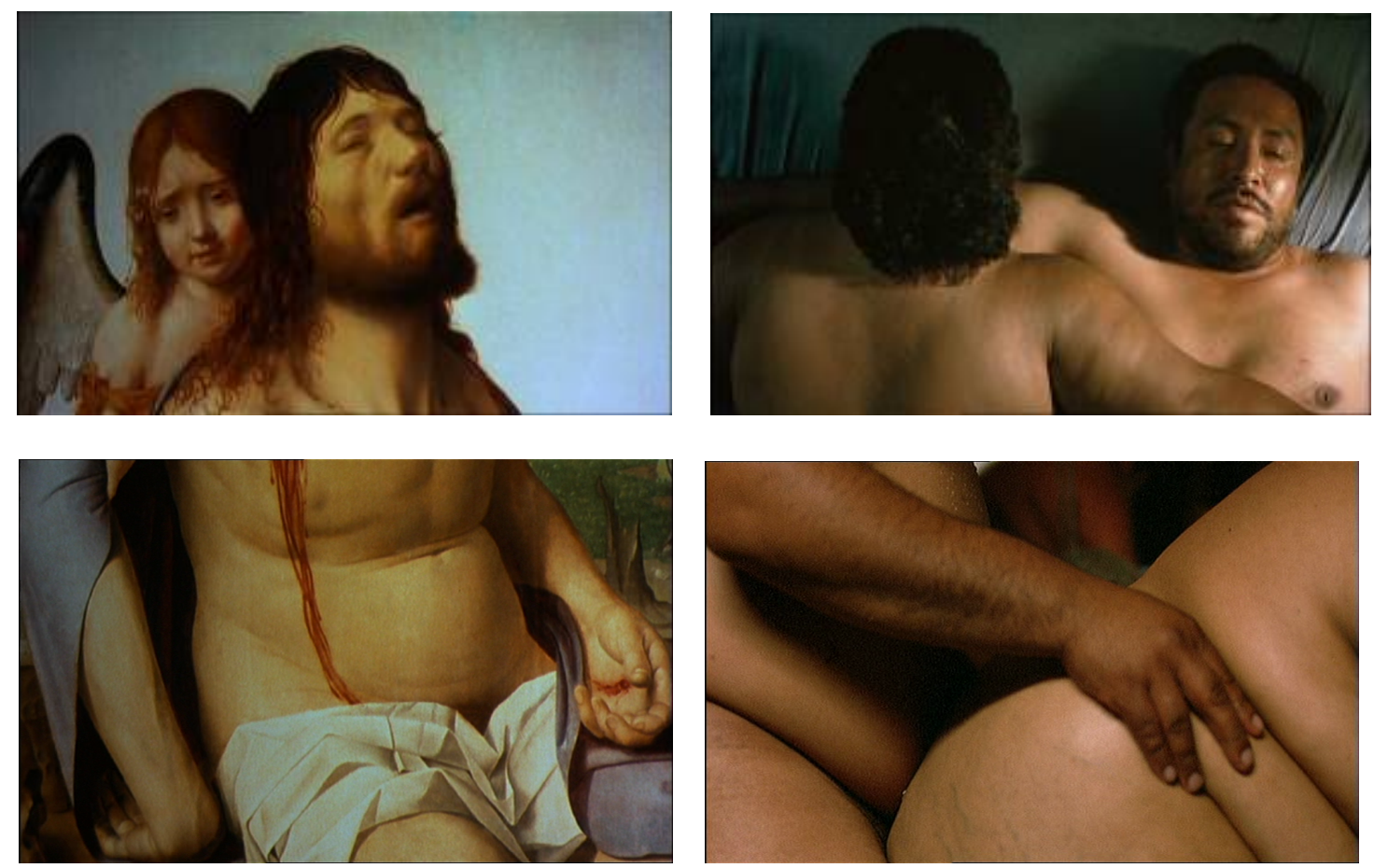

The body of Christ, the grotesque body

This surplus of carnality also brings to mind what Jean-Paul Sartre once defined as 'the obscene body', which he opposes to the 'graceful body'. 'In grace', Sartre argues, the body appears as a psychic being in situation. It reveals above all its transcendence' (Sartre 2003: 422). In its turn, the obscene appears when the body discloses 'the inertia of its flesh... either by some sort of flabbiness...or by a deformity in its structure (for example the proliferation of the fat cells) which exhibits a super-abundant facticity' (Sartre 2003: 423). What is so interesting about these two types of corporeal obscenity described by Sartre - the flabby and the obese - is that these are the very bodies respectively foregrounded in Japón and Battle in Heaven. Whether through the septuagenarian body of the peasant Magdalena Flores, defined as it is by muscular flabbiness, or the hyperbolic bodies of Hernandez and Ruiz, these films foreground bodies made pure flesh, an extreme carnality devoid of transcendence. 

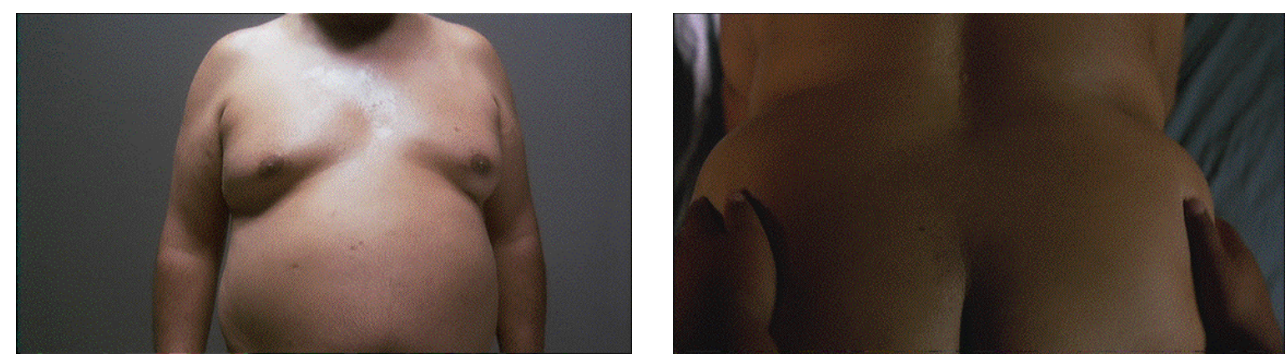

'The Obscene'

Yet it could be argued that transcendental directors such as Dreyer and Bresson were also interested in exploring the human flesh. And this is doubtless true, not least if we consider Dreyer's Jeanne D'arc, whose obsession with Falconetti's epidermis is well documented, and even more so the work of Bresson, whose corporeal fragmentation through close-ups is also well known, and I will come back to this. However, not only Reygadas's casting choices are obviously more shocking and unusual, but the frontal nudity and real sex we find in his films extrapolate the moral imperatives animating the work of these other directors.

In keeping with their moral code, Bresson and Dreyer foregrounded human carnality as the vehicle for transcendence. Bazin is one, for example, who repeatedly highlighted this aspect in their films, a notable example being his aforementioned appraisal of Dreyer's Jeanne D'arc, in his words 'a documentary of faces' which offers an 'extreme spiritual purification' (Bazin 1982: 20), an idea recently reworded by Deleuze, who sees Falconetti close-ups as the ultimate expression of his concept of 'affect', with the image opening itself onto a fourth and fifth dimension, 'Time' and 'Spirit' respectively (Deleuze 2005a: 11). Elaborating on Bresson's Diary of a Country Priest (Journal d'un cure de campagne, 1951), Bazin had also struck the same note: 'Naturally, Bresson, like Dreyer, is only concerned with the countenance as flesh, which 
when not involved in playing a role, is a man's true imprint, the most visible mark of his soul. It is then that the countenance takes on the dignity of a sign' (Bazin 2005a: 133). Taking up Bazin's insights, Raymond Durgnat once said of Bresson's The Diary of Country Priest: 'the spiritual has devoured the flesh' (Durgnat 1969: 48). In Reygadas, on the contrary, it is the flesh that devours the spiritual.

\section{Silent Light}

Reygadas's third feature-length film, Silent Light, rather than provoking the divided critical reception of its predecessors, was hailed as a more mature work (see, for example, Bradshaw 2007; Romney 2008) and, in particular, one in which a transcendental aesthetics was taken to a more earnest level in the director's career. Freighted with overextended shots of beautiful pastoral landscapes, such as its much-commented opening shot of a dawn in the countryside, the film was viewed as gesturing more firmly towards metaphysics. This was epitomised, for example, by José Teodoro, who argued that the film 'brings the transcendental metaphysics of Mexican provocateur Carlos Reygadas out into the open' through his 'renunciation of shock value' (Teodoro 2009: 49). At stake here was the fact that Silent Light refrained from the crude physical excess of his previous films, such as animal death, real sex and bodily obesity. In addition, the film's dialogue with Dreyer's Ordet (1955), as observed in its depiction of a traditional rural religious sect and miraculous finale, came to congeal the idea that Reygadas was now exploring the transcendental with a hitherto unseen forthrightness. Yet, as I will now 
endeavour to demonstrate, this metaphysical shift is not so clear-cut or resolute as it appears. On the contrary, it remains ambiguous and inextricably fused with carnality. In terms of storyline, Silent Light reiterates the thematic unity of Reygadas's oeuvre: once again, we are offered a mature man faced with a carnal dilemma which in turn leads him to rethink his spirituality. The film tells the story of Johan (Cornelio Wall Fehr), the head of a family in a Mennonite community, who falls in love with another woman, Marianne (María Pankratz), finding himself in the middle of a moral conflict. Though Johan is honest about the romance with his wife, Esther (Miriam Toews), who suffers in silence and waits for her husband to make his own decision, he has also to confront his religious community, which condemns adultery. This leads Johan and Marianne to end the romance. But the grief set in motion by this affair causes Esther to unexpectedly die under torrential rain. It is then that, with Esther in the coffin and her funeral under way, the miracle happens: upon being kissed by Marianne, she inexplicably awakes from death.

That this story is set in a Mennonite community means that it eschews, in principle, themes related to a specific Mexican context, which is in contrast with Reygadas's previous films, at the heart of which lies the ethnic and social divide of the country, as will be later analysed. The director acknowledges that, in his quest to depict a perennial love story, he searched for 'something as timeless and placeless as possible' as well as a 'uniform society', in which issues of social scale, appearance and class would be inexistent (Reygadas apud Romney 2008: 43). However, this community indeed exists in the state of Chihuahua in Mexico. Threatened by the loss of their German language with the approval of a new law that mandated the use of English in all schools in 
Manitoba, Mennonite groups living in Canada left for Mexico from 1922 to 1926, settling in Chihuahua as farmers (Dyck 1993: 322). Silent Light features real Mennonites from the community, as well as from outside, an example being the Canadian novelist Miriam Toews, who plays Esther.

It is certainly telling, in the context of Reygadas's oeuvre, that this adultery tale is set in a religious community characterised by rigorous asceticism and whose ethics of marriage vehemently condemns divorce, let alone adultery. Named after the leader Menno Simons, the Mennonites' origin goes back to the emergence of Christian Anabaptism during the Protestant Reformation in the sixteenth century. Although generally linked with Protestantism in that it shared 'the more revolutionary aspects of a "Protestant" Reformation, including the break with papal primacy, traditional ecclesiastical authority, and the scholastically defined sacramental-sacerdotal system', Anabaptism, as Kenneth Ronald Davis clarifies, was part of a dissenting faction of the Reformation, holding an essentially distinct project grounded in the principles of an ‘ascetically-orientated' religious reform (Davis 1974: 294). Rather than a 'spiritually passive' ideology, legitimised by 'institutionalized rites and submission to ecclesiastical authority', Anabaptism put forward an active, perfectionist theology, based on 'the practical, daily, outward struggle for the mortification of sin and the flesh' (Davis 1974: 130-1).

In Silent Light, Johan finds himself torn apart between the duties his religion entails, the asceticism to which he must obey if he is to be a spiritually purified man, and the carnal temptations that have suddenly erupted in his life in the figure of a new woman, Marianne, and which are equated with evil as his father warns him that it is the 
work of the enemy'. Asceticism and carnality are further opposed in the contrast between the relationships of Johan and Esther, and Johan and Marianne. Johan and Esther are depicted in familial situations indicative of a wedlock consumed by a rigorous routine and work ethics, prescribed by the Anabaptist doctrines. We see them praying and having breakfast with their children in the early hours of the day, as the whole family gets ready to go out for work; washing their children in the margins of a lake; picking up the corn harvest with their oldest daughter and son; coming back home in the car after a long day of work.

The encounters of Johan and Marianne, conversely, are characterised by intense physical contact. In the scene in which they furtively meet in an open field, for example, no word is exchanged between the two as the non-professional actors clumsily embrace and kiss each other. In particular, the sound of their kiss is remarkable for its raw, heightened physical quality. Entirely shot with direct sound, Silent Light preserves the sounds that are usually eliminated in the mainstream film ${ }^{3}$. The actors' mouths pressing against each other, as well as their breathing, is so limpidly heard that it highlights the physiological aspect of the act, undermining its romantic connotations. This scene also holds a crucial importance in the film as it is later echoed by that of Esther's death. As Marianne and Johan kiss each other against the sun, the sunlight creates 'lens flares' in the image, with the light, instead of refracting and helping form the image, producing hexagonal-shaped patterns across it. This normally undesirable effect, caused by an

\footnotetext{
${ }^{3}$ Reygadas himself provided me with this information. As he puts it: 'I tend to do all direct sound, being it direct proper or some wild tracks. Very, very little in post synchro [sic]. In Silent Light, nothing at all...Our ear is so used to the processed sound in cinema so whenever it is very raw, thus natural, it may seem unnaturally enhanced' (De Luca 2009).
} 
excessively bright source, can of course be prevented and the decision to maintain it seems deliberate. To begin with, these flares directly refer to the film's title, being as they are nothing but indices of pure light, that is, light that is not transformed into image. On a symbolic level, they further highlight such encounter as one of sheer joy. Interestingly, this scene lends itself to an analogy with that of Esther's death, as she leans on to a trunk and sobs under torrential rain. Her burst of tears (convincingly conjured by Toews), the physical culmination of her repressed pain, is therefore doubled and magnified in the pouring rain under which she sobs. At the same time, the camera lens is gradually covered by drops of water, which, as well as exposing the physicality of the camera itself, echoes the flares that highlighted the passionate encounter. True enough, this unoriginal use of sunlight and rain as signifiers of joy and pain could risk being taken as formulaic. What prevents this from being the case is the phenomenological density inscribed in these scenes, which attenuates the blatancy of its signifying gestures and authenticates it with a superabundant material quality.
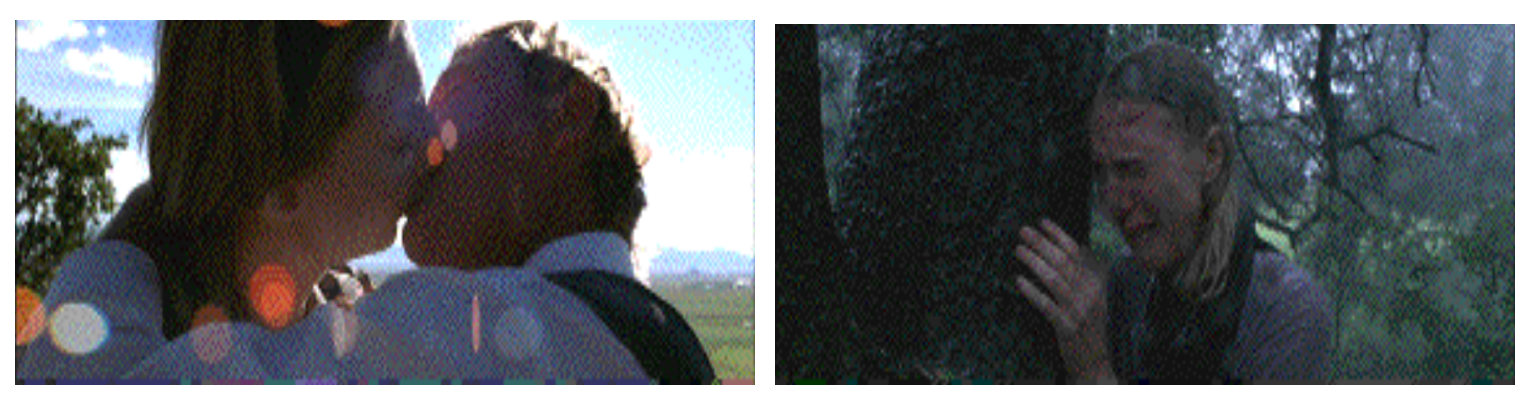

Joy and Pain in Silent Light

The carnal relationship of Johan and Marianne is further underlined when they have their last sexual encounter. Though this is not graphically depicted, it is certainly 
charged with physicality. To start with, it is evident that Pankratz and Fehr are not entirely at ease to perform, being noticeably conscious about their half-uncovered bodies while embracing each other. The scene proceeds with a high angle shot over Marianne lying in bed, which provides the viewer with Johan's point-of-view. As the camera erratically moves back and forth, simulating a penetration, Pankratz looks into the camera and grunts. What is remarkable here is not only the audacity contained in Pankratz, a Mennonite non-professional actress, simulating an orgasm directly to the 'viewer', put in the position of the man who is penetrating her. It is also the proximity of her flesh enabled by the camera, which closely reveals her skin bathed in sweat. The scene ends by alternating facial close-ups of both characters, drops of sweat exuding through the magnified pores of Fehr's reddened skin. No doubt, Silent Light shuns away from frontal nudity and sexual explicitness. The flesh however remains.
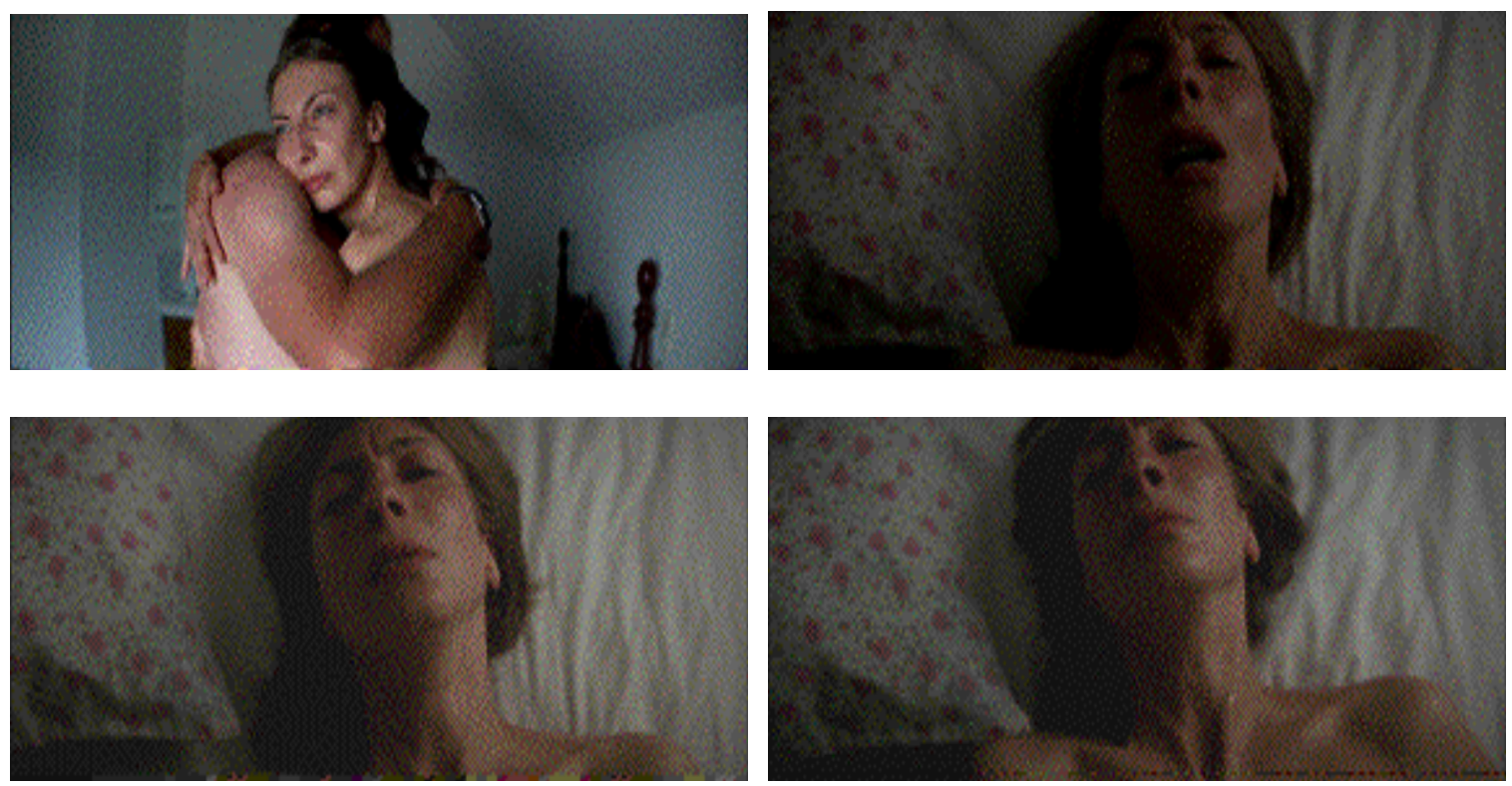

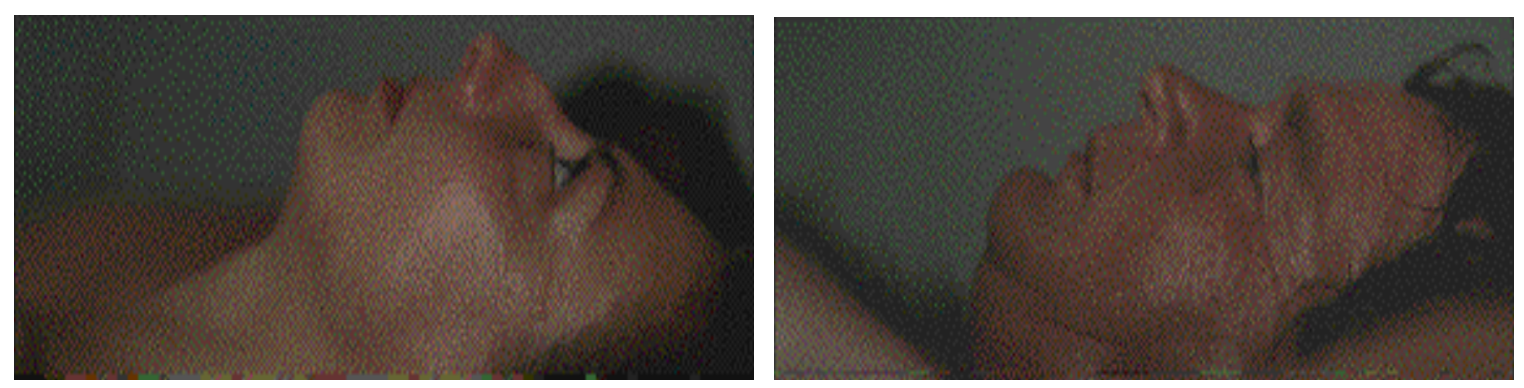

The flesh remains

We are now equipped to turn to Silent Light's citation of Ordet. As stated earlier, this intertextual gesture was largely viewed as an attempt to endow the film with the spiritual credibility lacking in Japón and Battle in Heaven. And, indeed, Dreyer's film the screen adaptation of a 1932 play by Danish priest Kaj Munk - is a strong, and serious, exercise in cinematic metaphysics. In every subplot of Ordet we encounter the theme of religious faith: we follow the classical tale of two families with opposing religious views - Inner Mission and Grundtvigism - and whose respective youngest children, Anne Skraedder (Gerda Nielsen) and Anders Borgen (Cay Kristiansen), fall in love with each other, bringing out their parents' deep-seated rivalry. Centred on Borgen's patriarchal figure, Morten (Henrik Malberg), religion is thematised through all familial links: Morten's oldest son, Mikkel (Emil Hass Christensen), is an agnostic, to his father's disappointment; Johannes (Preben Lerdorff Rye), the mentally ill middle son, believes he is the reincarnation of Jesus Christ; Inger (Brigitte Federspiel), Mikkel's wife, holds religious views in accordance with those of Morten. More remarkably, Ordet embraces spirituality through its exploration of the Christian idea of resurrection. As Inger dies from a miscarriage, Johannes, inexplicably cured of his insanity, accuses everyone on lacking faith in God's power to bring Inger back to life. Upon the insistence of Maren 
(Ann Elisabeth Rud), Inger's daughter, Johannes pleads to God to perform the miracle, as Inger subsequently rises up in the coffin.

Silent Light dialogues with Ordet throughout: Johan's name alludes to the character of Johannes in Dreyer's film; we see Johan's father stopping a ticking clock, which echoes the exact same gesture performed by Anders in Ordet's final scene; the sequence of Esther's funeral, in which the community mourns her death singing religious songs, evokes the same occurrence in Ordet. However, these similarities acquire full visibility in retrospect, for it is the image of Esther's dead body in the coffin, and the ensuing miracle, that unmistakably reveals this intertextuality. The visual composition is almost identical to that of Ordet's most famous shot: at the centre of the screen, the coffin is positioned between two tall candle sticks in a fully white room, emulating Ordet's celebrated 'milky whiteness', as once described by François Truffaut (1971: 310).
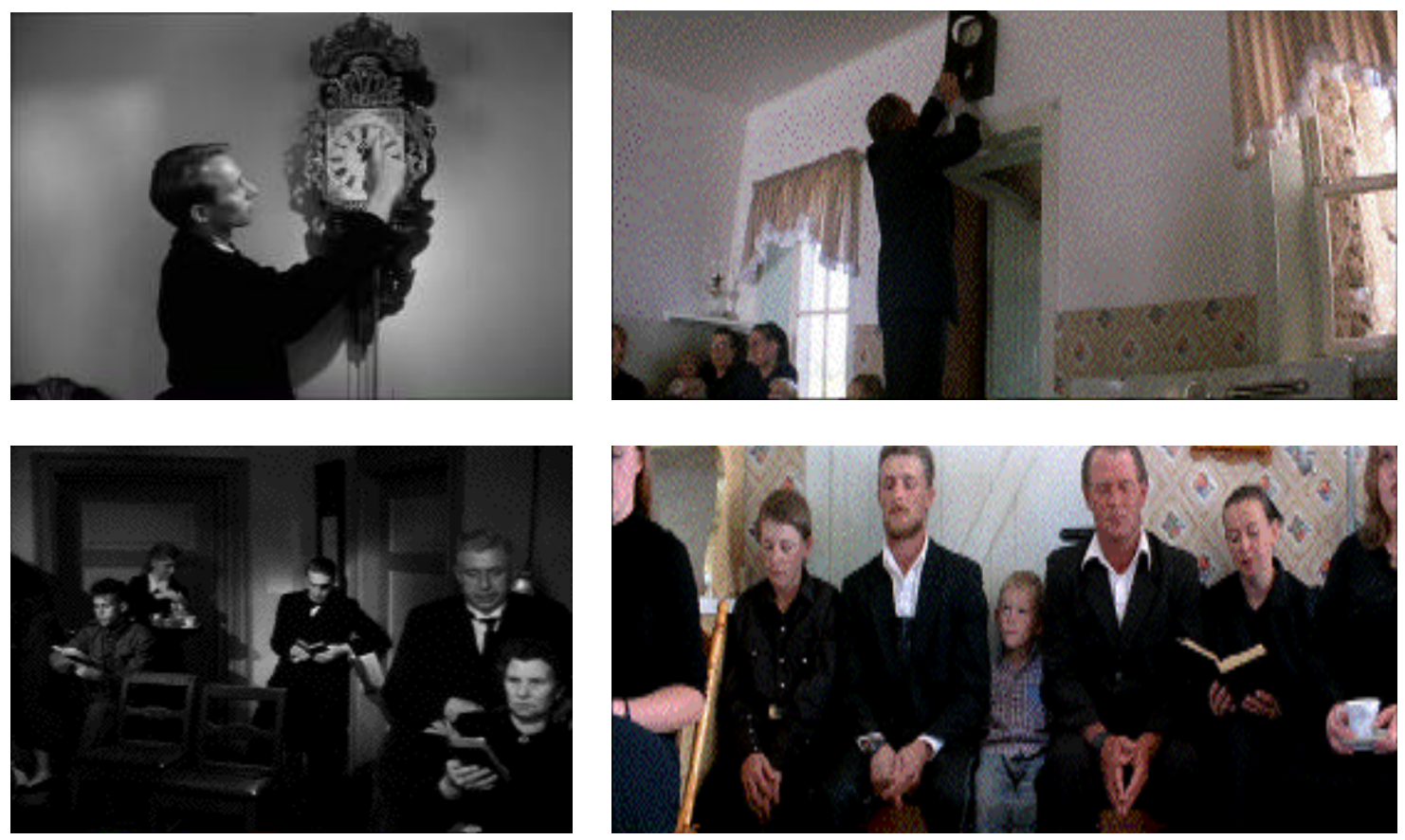

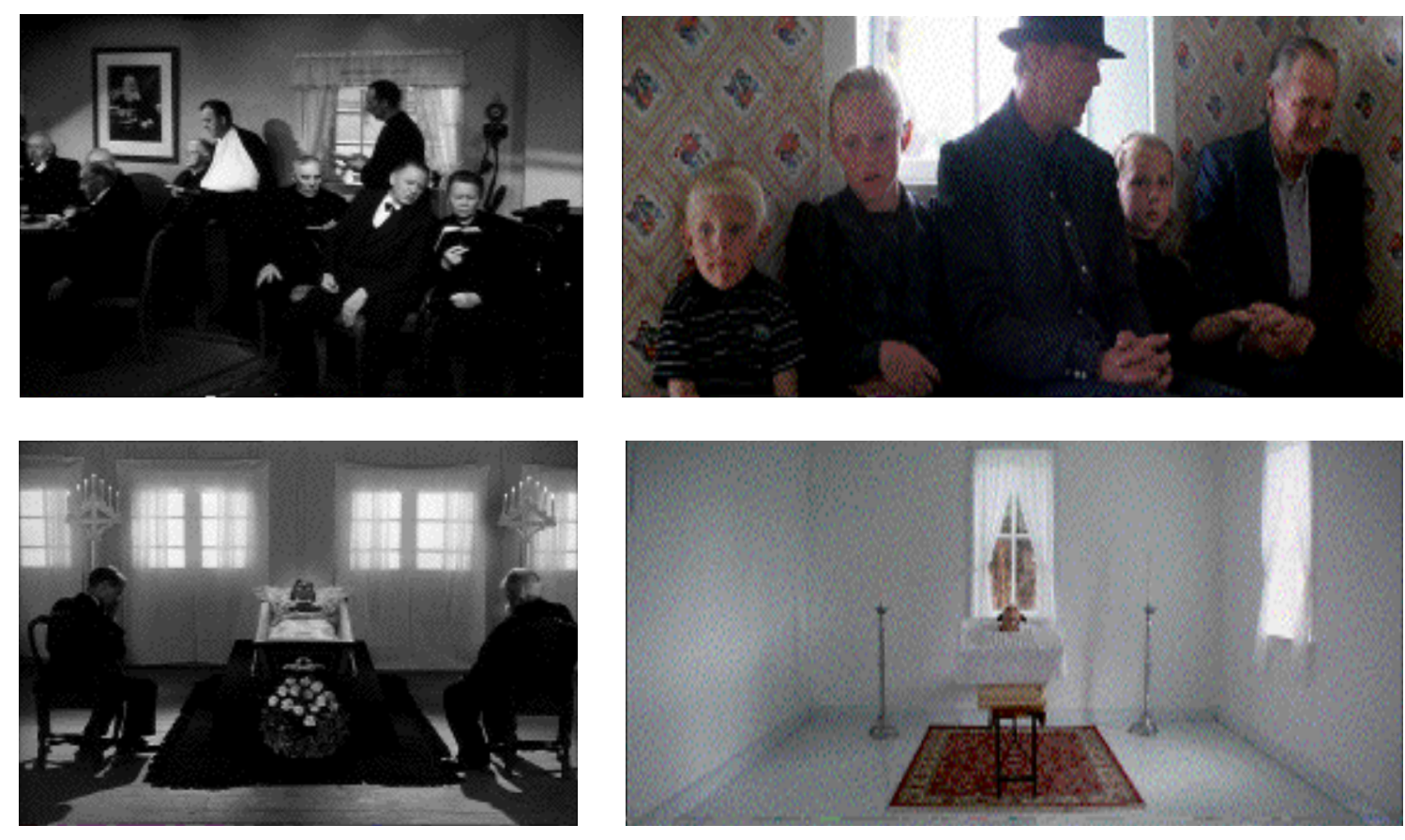

Silent Light's citation of Ordet

But if this citation is indisputable, one must also note the differences between these films. Ordet's fundamentally religious plot, its emphasis on the power of faith, in short, its endorsement of a Christian theology, are entirely absent in Silent Light. While religion is present in Reygadas's film, it figures as the backdrop against which an adultery tale unfolds. Unlike Ordet, nowhere in Silent Light the characters' belief in God or their faith in religion will be put to test or brought to the fore. Consider also the miraculous ending in both films. In Ordet it is the logical culmination of the theme of religious faith. In Silent Light this is not only de-contextualised as the film also introduces new, and telling, elements. Esther's resurrection inexplicably takes place upon Marianne's kissing her on her mouth. This means that the obviousness of Ordet's ultimate Christian allusion is thwarted in favour of a gesture that connotes a twisted version of this miracle. Indeed, more than the idea of resurrection, this scene evokes a 
fairy tale trope - the prince who awakens the sleeping beauty with a kiss - which is itself twisted, tinged as it is with homosexual connotations.
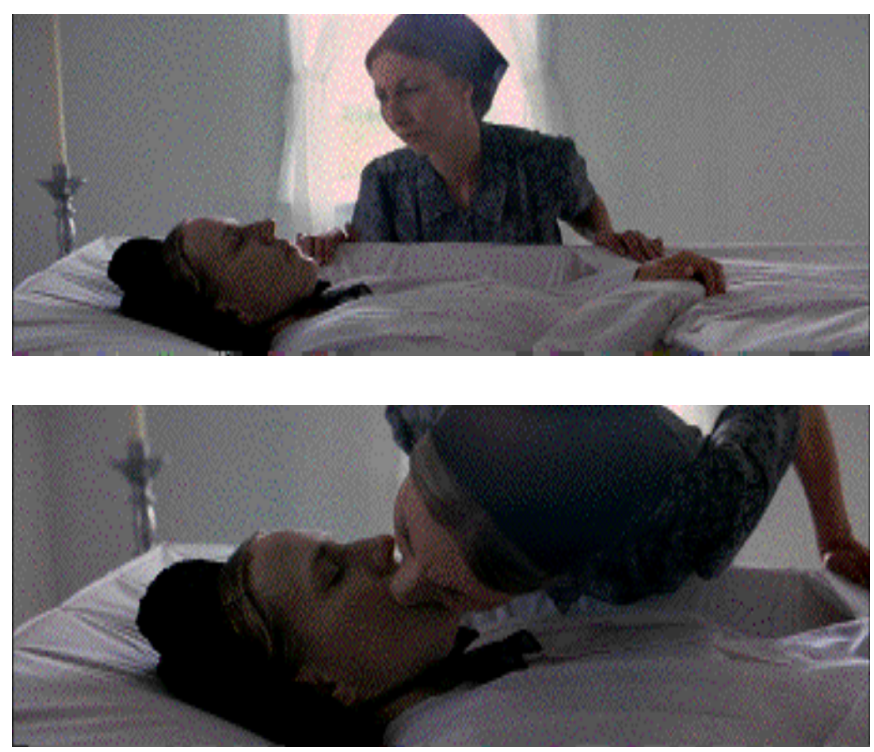

The miraculous kiss

Like Reygadas's previous films, Silent Light is thus filled with Christian signifiers that are either twisted or else presented with an indifference to their moral codes. It appropriates the ending of a film in which, as David Bordwell puts it, 'virtually every gesture...is freighted with Christian significance' (Bordwell 1981: 146) so as to render it elusive and ambiguous. Metaphysical obscenity is here materialised in the homosexual kiss between these two women, as it enters into dissonance with the Christian symbolism in which it is steeped. It certainly is a milder version of Reygadas's previously more explicit and shocking choices. But rather than representing a more earnest move towards the metaphysical, Silent Light reiterates a transcendentalism always already tainted with carnality. 


\section{Chapter 2}

\section{Material Surfaces}

On the one hand, the work of Reygadas is indebted to a cinematic realist tradition that envisaged the transcendence of physical reality. On the other, its metaphysical impetus is contradicted through an excessive carnality that draws forth a purely physical world. Is it thus not the case that this metaphysical obscenity results from the coalescence of two very different, often opposing, but nonetheless long-established aesthetics of realism? One that aspires to transcendental, ideal forms while the other negates metaphysics through a firmly empirical approach? One that is, in effect, Aristotelian, because 'unwilling to remain at the level of surface appearances' while the other, naturalist, comprises 'a strictly materialistic approach to the human condition' (Marcus 1986: 7-8)? As I will argue in this chapter, naturalism provides, at least in principle, a useful framework upon which to grasp Reygadas's carnal metaphysics. To this end, I begin with an overview of the main tenets governing the naturalist school of thought, moving on to examine its translation, as well as its aesthetic extrapolation, in Reygadas's 'fleshly' and 'earthly' cinematic geographies.

The term 'naturalism', like 'realism', encompasses divergent meanings, having coined from philosophical schools, through fine arts to literary movements (see Furst \& Skrine 1971). My usage of the term refers to the nineteenth-century French literary movement and, more specifically, to the notions formulated by its leading figure, Émile 
Zola, who championed a rationalist, empirical and scientific mode of thought. Man and nature were to be studied according to observational methods, in turn deemed sufficient to explain the laws of the universe. As Lilian R. Furst and Peter N. Skrine explain, a naturalist world in a philosophical sense is essentially 'a world devoid of transcendental, metaphysical or divine forces' (Furst \& Skrine 1971: 2). In the preface to the second edition of Thérèse Raquin, the founding novel of the movement, Zola stressed its eminently physical world in which 'there is a total absence of the soul' (Zola 1992: 2). Of course, Reygadas does not strictly reproduce a naturalist aesthetics, given that metaphysics also plays a part in his films. Further, naturalism was itself the fruit of a particular historical conjecture: the Industrial Revolution, the emergence of positivism in philosophy, Darwin's evolutionist theories, etc. Still, his work shows some affinities with the movement that begs elaboration.

In line with a naturalist aesthetics, for example, Reygadas's work is centred on 'individuals existing under the sovereign dominion of their nerves and blood, devoid of free will and drawn into every act of their lives by the inescapable promptings of the flesh' (Zola 1992: 1). At the core of his three films, as previously analysed, there stands a man unable to tame his lust. Not to mention the character of Ana in Battle in Heaven who seems equally driven by sexual desires, as observed in her sensual demeanour and, notably, the fact that she prostitutes herself seemingly for pleasure. Adherence to naturalism can also be found in the formal techniques of Reygadas's films. Indeed, their style lends itself to an interesting case of analogy with naturalist literary techniques which were, in effect, photographic. As Furst \& Skrine point out, in their materialist quest, the naturalists employed a rhetoric aimed at conveying 'photographic details' of 
the physical world (Furst \& Skrine 1971: 7). To this end, they resorted to descriptive expression and language that scrutinised the microscopic nuances of things and beings so as to reveal their purely material reality. Himself an amateur photographer, Zola would declare in 1901 that 'you cannot claim to have really seen something until you have photographed it' (Zola apud Sontag 2002: 87). A surface observation maxim is fully materialised in Reygadas's work through what I call its 'fleshly' and 'earthly' geographies. Let us turn to the former.

\section{Fleshly Geographies}

Reygadas's cinematography, operated by Diego Martínez Vignatti in Japón and Battle in Heaven and Alexis Zabe in Silent Light, seems in principle to realise the scientific character of a naturalist aesthetics by emulating an inquisitive microscope, fragmenting, scrutinising and magnifying parts of the human body. In this respect, a name such as Bresson immediately springs to mind, in view of his well-documented aesthetics of fragmentation as achieved by close-ups. Yet, in Bresson, not only the fragmented body fully conserves its legibility, as we clearly recognise its members, but corporeal fragmentation is predominantly restricted to human limbs, especially hands. Moreover, as Jacques Rancière has recently suggested, fragmentation in Bresson serves an important narrative purpose, 'intensifying the coordination between the visual and the dramatic: we seize with our hands, no need to represent the whole body'. This brings 'into sharp focus what is essential in the action, what classical theories of painting used to call the pregnant moment of the story' (Rancière 2006: 122). By contrast, in Reygadas not only body 
fragmentation involves the foregrounding of intimate human parts such as genitalia and buttocks, but these entirely exceed narrative motivation and, as a result, take on a purely aesthetic quality. Here, moreover, close-ups are characterised by an excessive proximity to the human flesh, which more often than not threatens to disfigure the legibility of the image. Unlike Bresson's, these shots mutilate the flesh into unexpected and unusual shapes and forms, playing on the geography and movement of the body.

Consider for instance the (real) sex scene between Ana and Marcos in Battle in Heaven, which opens with an extreme close-up of Mushkadiz's dreadlocked hair. At first glance, the viewer is unable to identify the object of attention, given that the actress's hair, seen at such close range, mutates itself into an entangled web of gigantic and tactile strands. As they finish the sexual act, the viewer is subsequently offered a series of extreme close-ups whose microscopic and geometric fragmentation of the actors' bodies, framed moreover in idiosyncratic positions, discloses a malleable geography of fleshy forms. We see, for example, Mushkadiz, naked and mounted on top of Hernandez, from a high angle which, focused on her buttocks and back, slices her body off into an unfamiliar, new shape. We are then offered their hands, feet and even their genitalia, all magnified by close-ups. This is followed by an extreme close-up of the actress's vagina, which, occupying the entire screen, threatens to overflow the borders of the figurative, her skin porosity and the texture of her pubic hair taking on an excessively tactile quality, as the pictures bellow illustrate. In this respect, these images resonate with what Laura U. Marks has recently theorised as 'haptic visuality', as mentioned in the Introduction, which she defines as images that emphasise 'material presence' through the tactility of beings. While 'optical' images, Marks claims, frame a given object at a certain range so 
as to preserve its recognisability, a haptic framing abolishes such distance and, in so doing, foreground a purely material reality. This, she concludes, promotes a sensuous mode of spectatorship, as 'the eyes themselves function like organs of touch' (Marks 2000: 163).
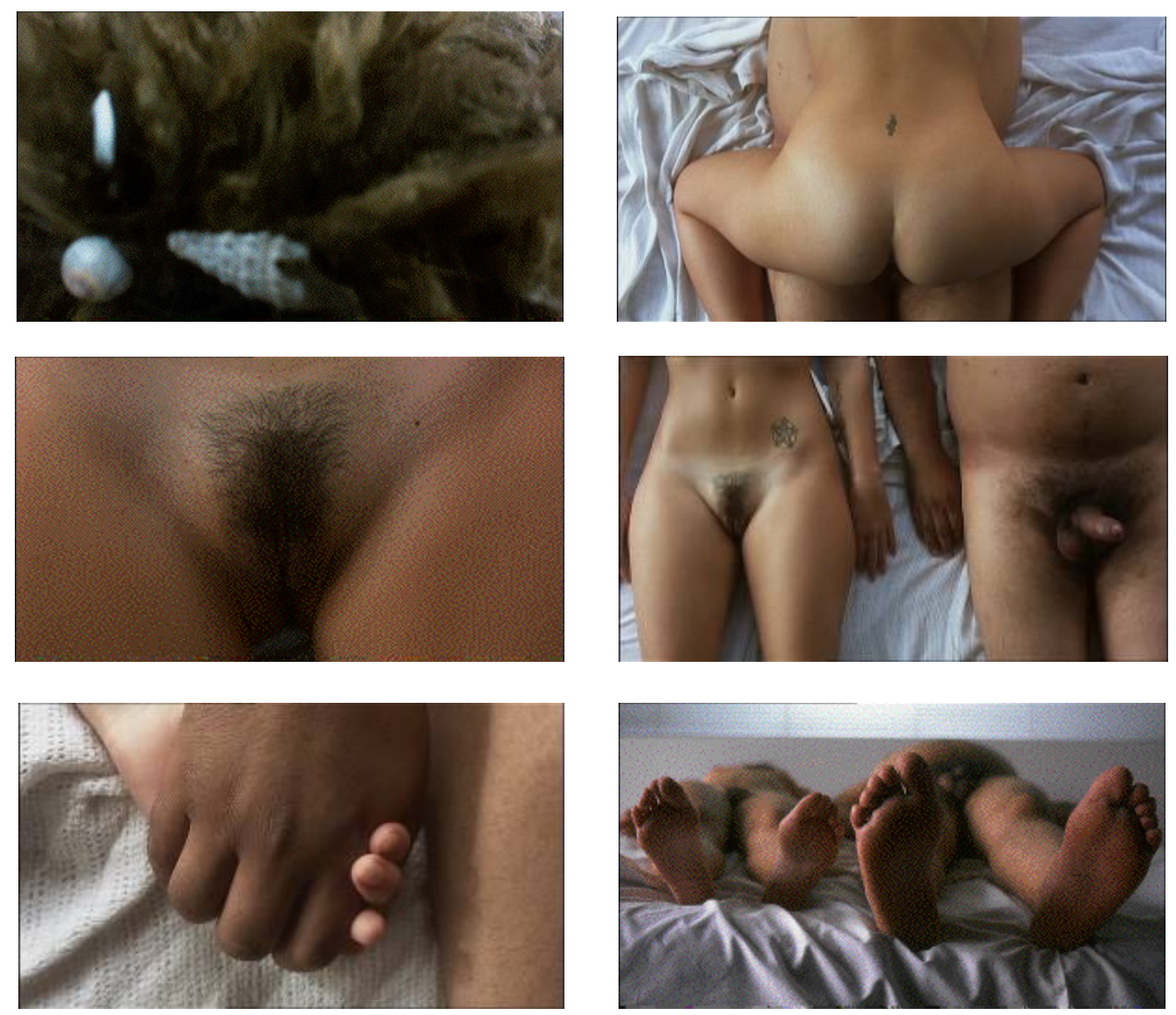

Camera as microscope: dissecting the body

Long before Marks, Kracauer had already attempted to elaborate on the sensory dimension of the extreme close-up. To the German film theorist, 'any huge close-up reveals new and unsuspected formations of matter; skin textures are reminiscent of aerial photographs, eyes turn into lakes or volcanic craters' (Kracauer 1997: 48). These 
'unknown shapes [the viewer] encounters involve not so much his power of reasoning as his visceral faculties. Arousing his innate curiosity, they lure him into dimensions where sense impressions are all important' (Kracauer 1997: 159). More recently, Doane has elaborated on the notion of cinematic scale and its relation to realism. She notes the 'hyperbolic affects' of the close-up in early cinema:

The close-up presented two threats to the norm of the mimetic body: first, it was perceived as aesthetically offensive in extreme ways - as monstrous or grotesque, an excessive display of disproportion in scale; and second, as an untenable fragmentation of the human body (Doane 2009: 64).

With the emergence of narrative cinema, the close-up, though still 'carrying the threat of a certain monstrosity', becomes primarily associated with the human face, being systematised into, and rationalised by, 'continuity editing, which struggles to preserve the logic of a space that must be kept intact, homogenous and continuous' (Doane 2009: 73). Doane goes on to analyse a film such as Wong Kar-wai's In the Mood for Love (Fa yeung nin wa, 2000), in which such logic is disrupted through 'an excessive and sustained proximity to bodies', which in turn undermines 'the expectation that the face is the privileged content of the close-up. The possibility of expressivity and of legibility is shifted from the face to the other parts of the body, resituating affect' (Doane 2009: 79). What is so interesting about Reygadas's work, and Battle in Heaven in particular, is that such disruption is even more radical, for in it the proximity to bodies is indeed much more extreme than that of Wong's film, in which, as Doane herself points out, the body 
still preserves its 'legibility'. Through hyperbolisation, Battle in Heaven unveils and highlights the fragmental impulse and, even more so, the sense of monstrosity inherent in the close-up, overblown as it is by the voluptuous bodies of Hernandez and Ruiz, themselves disproportionate in scale and representative of the grotesque. Framed in extreme close-ups whose proximity threatens to preclude legibility, their carnality inundates the screen.
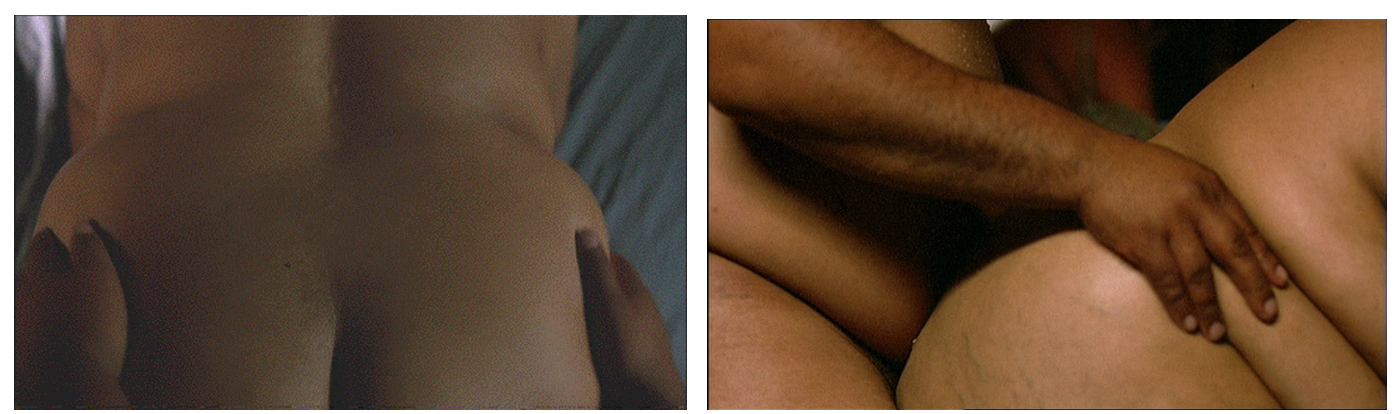

The monstrosity of the close-up

Now, this use of close-up as a tool to play on the scale, proportion and fragmentation of the body, and the creative geographies of the flesh it produces, extrapolates the scientific and empirical imperatives of a naturalist stance. More than naturalism, they are indeed exemplary of aesthetic modernism, displaying the photographic sensibility of someone such as Edward Weston, who in the 1920s and 1930s understood photography in its ability to reveal an unseen reality. Imbued with the modernist spirit of these decades, Weston resorted to techniques such as arbitrary croppings and microscopic framings in his vanguardist work with nudes, disclosing unfamiliar shapes out of the human body. In the late 1940s, fashion photographer Irving Penn, in what became known as his 'Earthly Bodies' series, employed similar techniques 
when photographing voluptuous women, with which Battle in Heaven's obese bodies resonate even more strongly, as the pictures below illustrate.
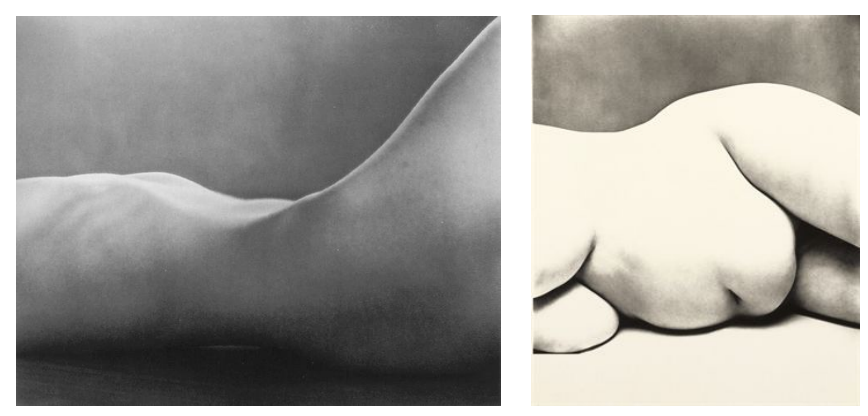

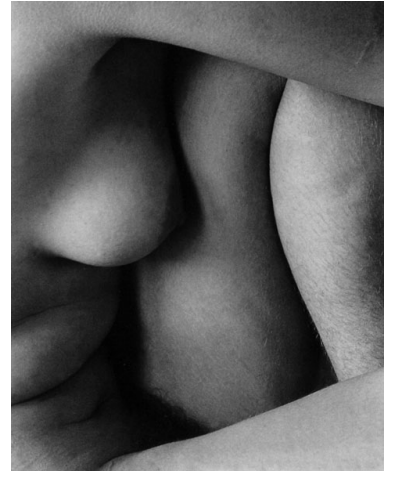

Weston's nudes

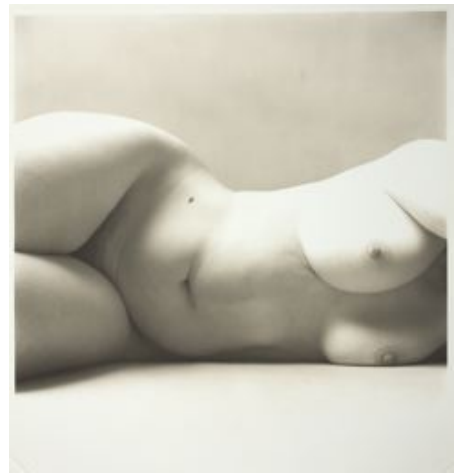

Penn's 'Earthly Bodies'

However, gigantism of scale through close-ups is not restricted to body fragmentation in Reygadas's films. Even when framing faces - the institutionalised object of this technique - the close-up is also appropriated for hyperbolic ends, calling attention to its microscopic and fragmental effect. This is what happens in Silent Light when the faces of Pankratz and Fehr are framed at such close range that it is their porous and reddened epidermis that stand out, as mentioned in the previous chapter. Taking up the whole screen, their gigantic profiles, like the bodies of Hernandez and Ruiz, evoke the form and geography of rocks. Even more emblematic are the extremely tight shots employed in Japón on the faces of Ferretis and Flores. Such is the proximity of the 
camera here that, occasionally (as in the scene in which they have sexual intercourse), their eyes occupy the entire widescreen, a visual composition echoed in Battle in Heaven's opening, in which the camera steadfastly closes in on Mushkadiz's face in a movement which seems to disclose an urge to penetrate her flesh.
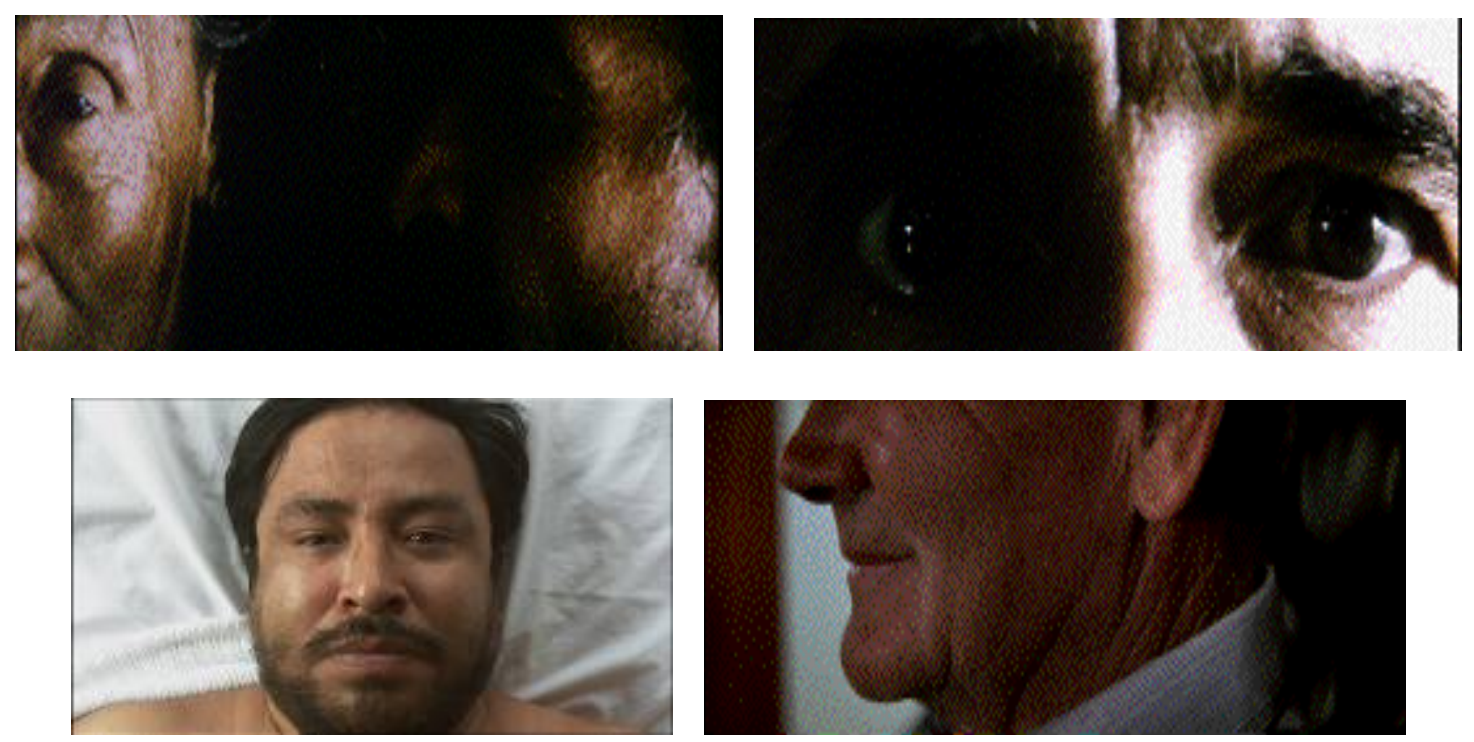

Tactile faces (in clockwise order): Ascen and the man in Japón; the man in Japón; Marcos in Battle in Heaven; Johan's father in Silent Light

In particular, the tactile shots of Flores's wrinkled epidermis, when set against the recurring establishing shots of the rugged Canyons in Japón, establishes a beautiful connection between the topography of her face and that of her environment: Flores' skin reproduces in its very flesh the physical features of the landscape which she inhabits. Both herself and the Canyons, subjected to a castigating sun, attest, through their changing forms, to a transient materiality. And while these forms vary in size and could go unnoticed to the bare human eye, the film medium, by ignoring the natural scale of things and peoples, brings micro and macro together, revealing the remarkable similarity of their material surfaces. 

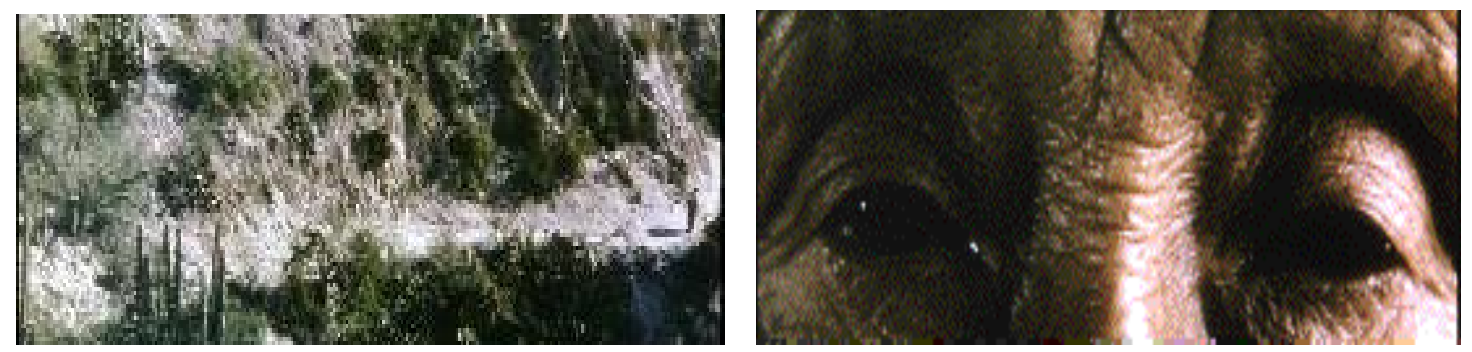

Rough Canyon, rough skin

This in turn resonates with what Deleuze defines as 'deterritorialisation', namely the film medium's ability to play on the scale of material reality. He writes:

[T]he screen, as the frame of frames, gives a common standard of measurement to things which do not have one - long shots of countryside and close-ups of the face, an astronomical system and a single drop of water - parts which do not have the same denominator or distance, relief or light. In all these senses the frame ensures a deterrorialisation of the image (Deleuze 2005a: 16).

This interplay of scale and distance is a crucial feature of Reygadas's work, as further epitomised by a particular shot in Silent Light. As Marianne embraces Johan, the sunlight hits her eyes and she raises her arm so as to block the light hindering her vision. Her hand and forearm, framed in extreme close-up, diagonally take up the entire screen, as if 'enveloping' the sun, whose light gives her hand a radiant contour. The resulting image has supernatural overtones as it evokes an eclipse, with her human limb standing for a celestial body of gigantic proportions. In a similar vein, we find in Reygadas's films long distance shots that transform the natural shape of landscapes, an eloquent example being the bird's-eye view shot of a confluence of highways in Mexico City in Battle in Heaven. 
By alternating close-ups of the human flesh with establishing shots of vast landscapes, Reygadas accords to both the same significance: all is geography, all is materiality. Reygadas is a topographical filmmaker for what we have here are geographies of the earth and geographies of the flesh, and the crossroads at which these geographies overlap. Let us now turn to his work's environmental focus.
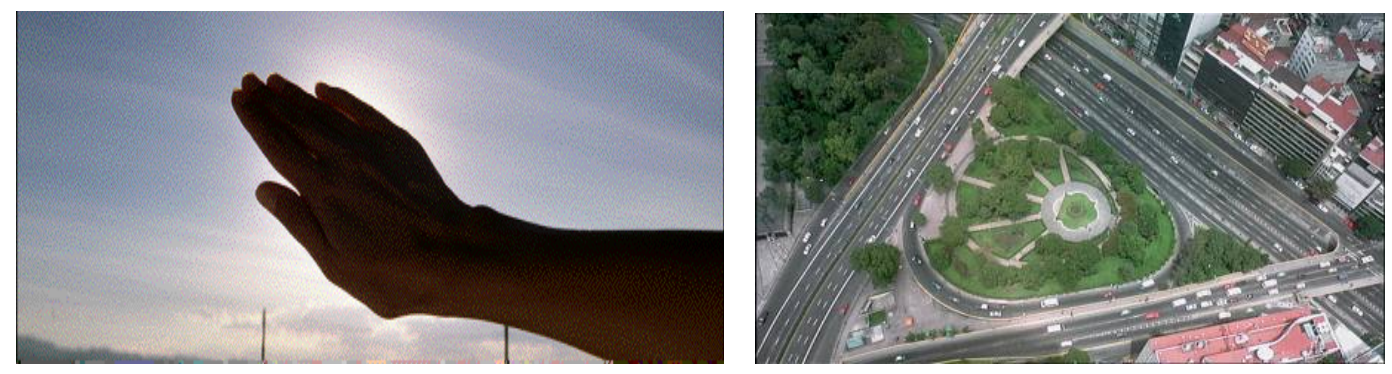

Deterrorialisation in Silent Light (left) and Battle in Heaven

\section{Earthly Geographies}

We have seen that the microscopic attention to the human flesh one encounters in Reygadas's work connects it, in principle, to a naturalist aesthetics. This is also corroborated by the materiality of environments insistently on show here. In this respect, moreover, the places displayed in Japón and Battle in Heaven - Ayacatzintla and Mexico City respectively - are not depicted romantically or idealistically but, rather, in true naturalist fashion, as places whose social and environmental determinism is indeed discernable on the actors' physique. One could indeed argue that Flores's wrinkled and dried-out skin, as well as Hernandez and Ruiz's obesity, are the direct result of their habitats, in the former a scorching sun and miserable living conditions, in the latter bad 
eating habits which become the cultural norm in the megalopolis. As far as fiction is concerned, one could equally argue that Marcos's criminal deed in Battle in Heaven also stems from the social inequality animating his place of living: like obesity, kidnapping is currently a very pressing issue in Mexico.

More remarkably, as will be now analysed, the extremely dissimilar geographies on display in each Reygadas film disclose the coexistence of very distinct Mexican realities. In Japón, for example, contrast between urban and rural milieus is established in the film's opening. We are offered a series of shots, taken from the front window of a car in movement, showing in succession the car-stricken streets and tunnels of Mexico City, empty and asphalted highways and, then, precarious, unpaved roads cutting across vast and deserted landscapes. The shots of Mexico City's highways and tunnels, in particular, evoke the famous 'city of the future' sequence of Tarkovsky's Solaris (Solyaris, 1972), which, interestingly, was shot on the Tokyo Metropolitan Highway. Is the enigmatic title of Reygadas's film - in English, 'Japan' - a citation of this particular sequence? Or does it refer instead to the enormous divide between the industrialised Mexico City and the rudimentary, rural Ayacatzintla, a place only a few hours away from the capital, and yet an entirely different world $?^{4}$ For, indeed, this move from the city into the countryside, as well as reflecting the man's desire to escape the urban chaos in search of a place to commit suicide, reveals the contrasting realities of a country in which geography stands as one of the markers of ethnic and socio-economical disparities.

\footnotetext{
${ }^{4}$ Reygadas has later confessed to me that this was indeed the main reasoning behind the film's title. This interview remains unpublished (De Luca 2009).
} 

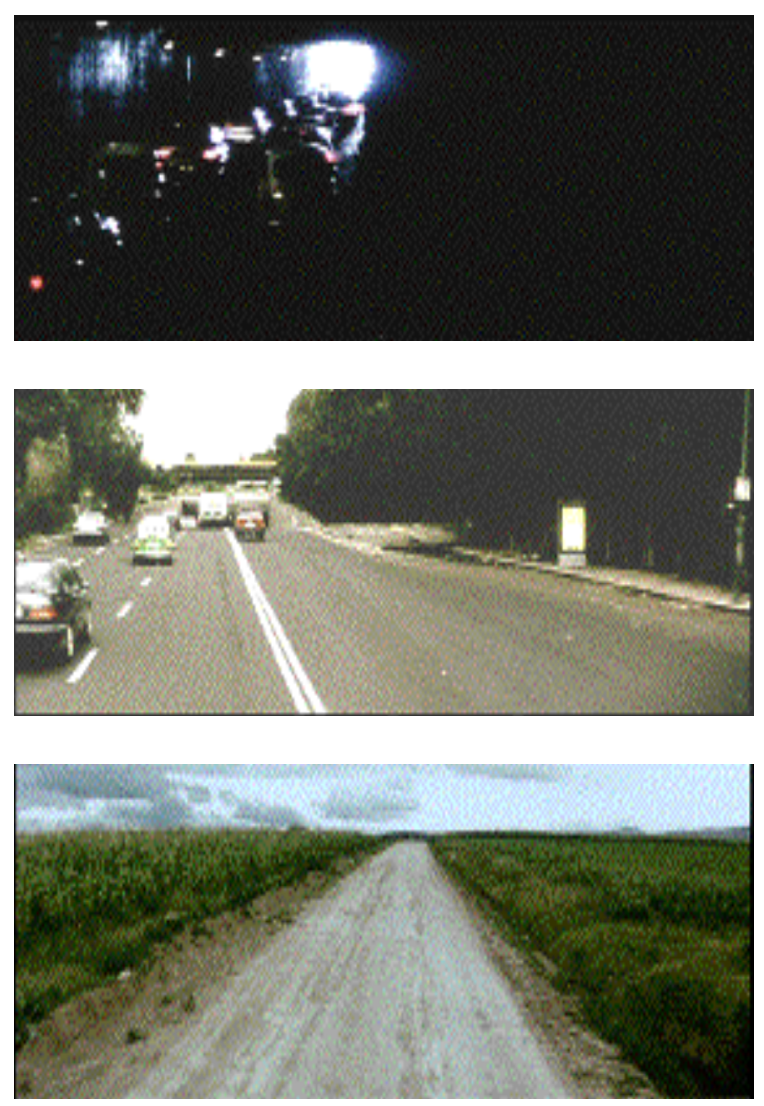

From the city to the countryside

The city-countryside opposition is in fact a recurring theme in the cinematic history of Mexico. As Miriam Haddu points out, arid, cactus-filled, vast landscapes, alongside depictions of urban spaces (notably Mexico City), in 'Mexican cinematic geographies', have acquired throughout the last century the status of 'visual signifiers of Mexican national identity' (Haddu 2007: 206). These rural settings, she goes on, often appear masked as an idyllic backdrop against which the Indian is romanticised as a mythical figure living in 'a long lost paradise location' (Haddu 2007: 209). By contrast, in Japón Ayacatzintla is portrayed naturalistically, that is, as a poor, harsh and hostile milieu. The village's isolation, both in geographical and economic terms, is underlined right at the beginning, when the man, upon running into a group of men shooting birds in the area, is told that 'it is very difficult to go down by foot' and that 'not even cats make 
it by night'. When he arrives at the village, he is further told that he should go to Metztitlan if he wants a hotel to stay, as he will not find any in the area. When asking Ascen if he could stay in her barn, he is then forewarned that her house, high up on the hill, has no running water, which must be brought up with a donkey. Throughout the film Ascen and the man only eat fruit, which seems to be the only food available. In one suggestive scene, Ascen mechanically stirs a pan with nothing inside (the reasons for this are not explained), which further underscores the state of deep poverty in which she lives, already apparent in the sordid conditions of her house.

As far as the film's form is concerned, it also lends itself to the depiction of Nature not as a bucolic realm but as a crude, cruel force. The merciless sun, the harsh cactus-filled expanses and the rudimentary way of life of its inhabitants are all emphasised. Shot on $16 \mathrm{~mm}$ with anamorphic lens, which gives it a Cinemascope ratio - a visual style the director claims to have borrowed from Gaspar Noé's I Stand Alone (Seul contre tous, 1998) - the film appropriates horizontality so as to highlight, in silent and contemplative long takes, the immensity of the Canyons. The use of $16 \mathrm{~mm}$ film stock later blown up to $35 \mathrm{~mm}$, further gives the film a grainy, rough look, as well as dull, washed-out and de-saturated colours, which sensuously convey the material harshness of the environment, as does the use of natural lighting, through which the scorching sun is translated into bleached photography. The erratic, handheld camera when following the man's wanderings on the steep hillsides also contributes to the naturalistic depiction of the area, its jittery movements suggesting the physical exertion to which both actors and film crew were subjected during the shoot. Finally, a cacophony of animal sounds such as clucking, crowing and braying, usually accompanied by buzzing insects, reverberates in 
the film, underlining the wildness of the location. Not to mention the abundance of scenes in which, as mentioned in Chapter 1, animal sex and death are shown with quasiscientific detachment.

By contrast, Battle in Heaven shuns away from nature, focusing instead on the cityscapes of the biggest city in the world. In fact, Mexico City is a character in itself in the film, its recognisable landmarks on constant display, including the Zócalo (the main plaza in the historic centre of the city with a gigantic Mexican flag) and the Basilica of Guadalupe, one of the largest churches in the world. Above all, the frenzied, chaotic and awkward aspects of the city are emphasised here. This is primarily conveyed through recurring images of the city's busy expressways (including a bird's-eye view shot that effectively conveys its gigantic proportions, as mentioned earlier), as the character of Marcos, a chauffer driving incessantly across the megalopolis, provides the cue for shots of car-stricken streets filled with the capital's recognisable green Volkswagen taxis. In addition, the film highlights the mammoth population of Mexico City, such as in the scene of an extremely packed subway train in which Marcos loses his spectacles; or in the recurring shots of the thousands of pilgrims making their way to a crammed Basilica.
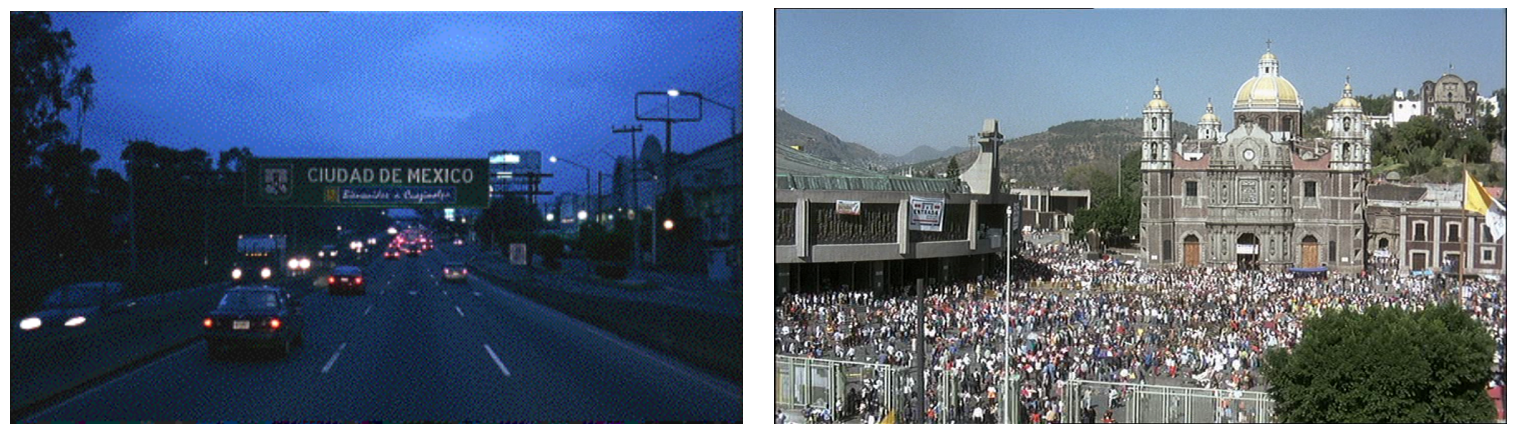

The gigantic city 
However, the film contrasts this overwhelming volume of people and cars in the busiest parts of the city with its wealthy and comparatively peaceful quarters, underlining the divide between rich and poor in the capital and, like Japón, stressing the geographical line marking them out. Unlike recent Mexican films such as Sólo con tu pareja (1991, Alfonso Cuarón), Cilantro y Perejil (1996, Rafael Montero) and Sex, Shame and Tears (Sexo, pudor y lágrimas, 1999, Antonio Serrano) which, as Armida de la Garza contends, depict Mexico as a 'developed metropolis' through an emphasis on the 'upmarket neighbourhoods of Mexico City' (De la Garza 2006: 147), here it is the case of a geographical contextualisation of these neighbourhoods within the disorganised, chaotic and sprawling megalopolis. This is what happens, for example, in the scene in which Marcos, after picking up Ana at the airport, drives her home. In some ways reminiscent of Japón's aforementioned opening, the viewer is gradually transported, through a series of shots taken from the front window of a car, from the busy areas of the city to its rich and quiet areas, in reality the residential district of Las Lomas, home to the wealthiest people in the capital.

But while in Japón this transition mobilises a dichotomy between city and countryside, here it discloses a geographical discrepancy within the city itself, made evident through the juxtaposition of shots of ugly, dirty and jam-packed roads with quiet, suburban, green avenues lined with nicely trimmed trees, stately houses and expensive cars. This opposition is moreover emphasised through the use of sound. In contrast to the concatenation of car engines and beeping horns heard throughout the film, this trafficfree area is acoustically translated into an idyllic atmosphere. This is best demonstrated in two prolonged shots, when Marcos stands outside Ana's house and, through his point-of- 
view, the film shows trees against the backdrop of mansions in which the bucolic singing of birds is the only audible sound. While Japón refrains from a bucolic depiction of nature, focusing instead on its crudeness, Battle in Heaven underlines the existence of a haven within the city itself, a world in which nature is meticulously trimmed, domesticated and tamed. And this glaring opposition between the wealthy districts and 'the rest' of the city comments on the notion that Mexico, like many of its Latin American neighbours, 'is in effect a two-class system: the elite and everyone else, the haves and varying gradations of have-nots' (Berg 1992: 24).

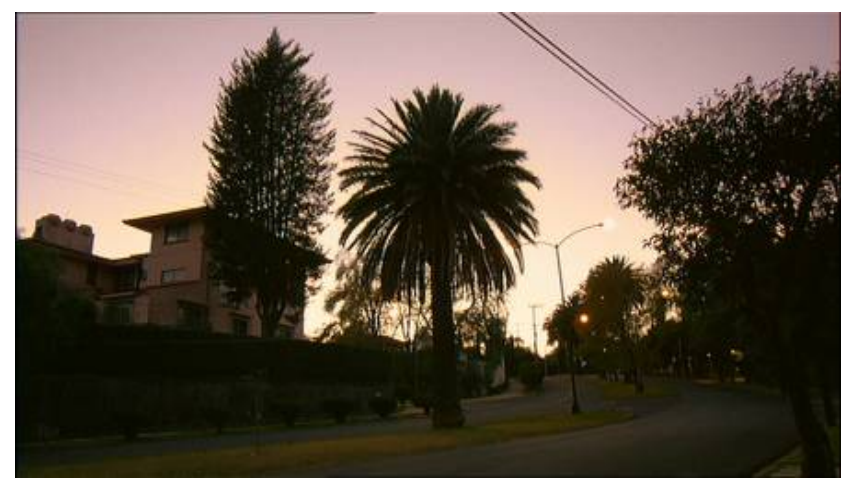

The bucolic façade of the rich

In its turn, Silent Light witnessed Reygadas's return to a rural setting. The film was shot in the northern Mexican state of Chihuahua, famous for its desert landscapes and semi-arid climate. At first, this region offered inappropriate conditions for the Mennonites' agricultural aspirations, when they settled in Mexico in 1920. But it eventually proved a good spot thanks to its torrential summer rains, which, providing irrigation to the soil, enabled the harvesting of staple crops, wheat and corn in the mechanised farming process to be developed by the newly arrived settlers (see Sawatzky 
1971). This channelling of natural forces into economical profit changed the face of those lands, which gradually acquired a distinctive, 'healthier' look in the midst of arid landscapes. In Silent Light, this primarily agricultural form of subsistence of the Mennonites, and the distinctive landscapes resulted from this process, is highlighted through shots of flat, vast cornfields, as in the scene in which Esther drives a threshing machine; or when she and Johan, along with their oldest children, stop working and have lunch in the middle of the fields.

In many ways, furthermore, Silent Light puts forward a more sympathetic depiction of nature, stopping short of employing the very techniques that contributed to Japón's raw naturalism, such as handheld camera, grainy image and washed-out colours. The film has indeed a more austere tone, being without a doubt Reygadas's most restrained film thus far, in terms of camerawork, editing pace and use of sound. Significantly, Reygadas worked with a new crew here: the cinematography and sound of his previous films, in the hands of Diego Martínez Vignatti and Gilles Laurent respectively, was operated by Alexis Zabé and Raúl Locatelli, among other changes. In addition, after the experience of Battle in Heaven's sizeable crew, Reygadas opted for a much smaller-scale production and a more intimate shooting style, with the crew amounting to no more than 11 people.

In contrast to Japón and Battle in Heaven, which feature religious and grandiose musical scores (often to surrealist effect, as will be later analysed), Silent Light opts for diegetic sound only. In fact, as previously stated, the film was shot with direct sound, which emphasises the physicality of noises normally edited out in the conventional narrative film, such as that of the kissing between Fehr and Pankratz. In symmetry with 
that, the materiality of these landscapes is acoustically highlighted through a symphony of animal sounds, such as crickets, cicadas and lowing cattle. As far as its cinematography is concerned, the film opts mostly for overextended, stationary and establishing shots, which, coupled with the film's widescreen ratio, highlight the flat landscapes characteristic of the state of Chihuahua, as well as the 'weight' of the immense sky upon them (see pictures below), contributing to the film's metaphysical overtones.
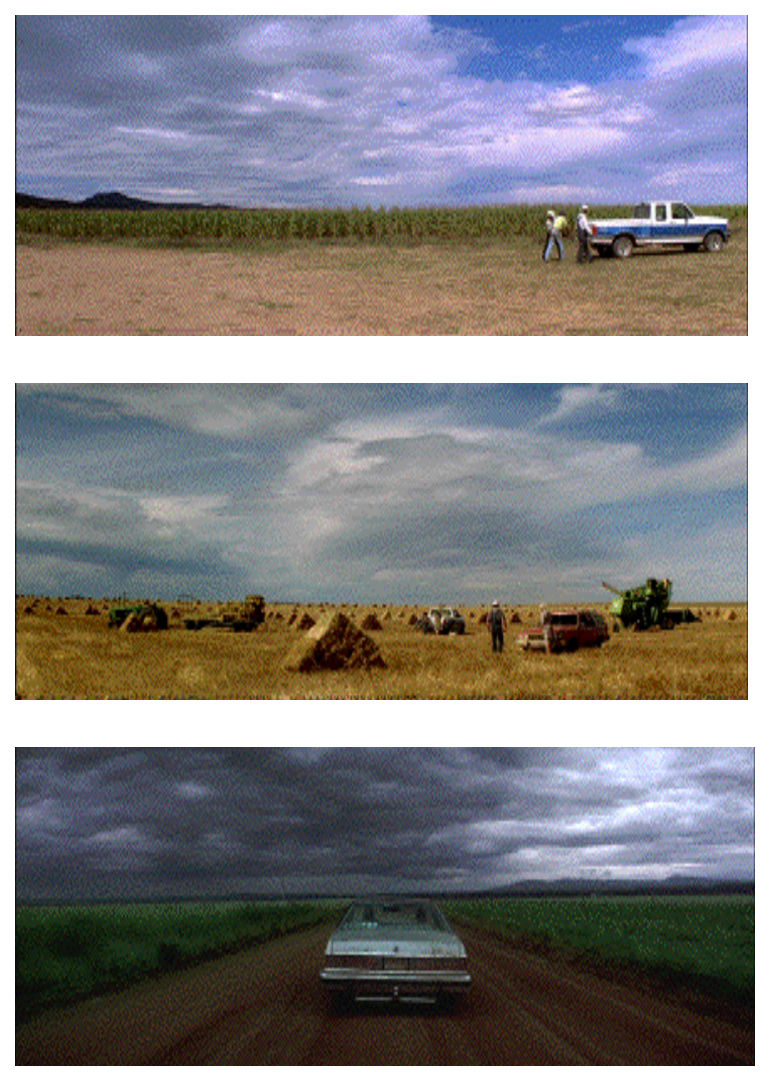

The weight of the sky: metaphysical overtones in Silent Light

Indeed, closer inspection of Silent Light's take on nature helps us understand its critical reception, which, as mentioned in Chapter 1, highlighted its metaphysical 
assertion when compared to its cinematic predecessors. And, no doubt, Silent Light puts forward a depiction of nature more akin to the commonly held notions of beauty in the transcendental sense of the term. An eloquent example is its astonishing opening, described in the Introduction, in which we are offered a time-lapsed dawn in the countryside (the film's ending, in its turn, features a time-lapsed dusk filmed in the same spot). Overall, the recurring shots of flat, vast green fields under portentous blue skies, framed in geometric and precise arrangements, evoke painterly compositions, doubtless a hallmark of Reygadas's work but one which is here pushed to new heights in terms of formal perfectionism. In fact, some of these compositions are so visually striking that they were thought to have been digitally manipulated. This is what happened, for example, with the film's aforementioned opening, which raised doubts as to whether Zabe had resorted to CGI, which, according to Reygadas, was not the case (Romney 2008: 43).
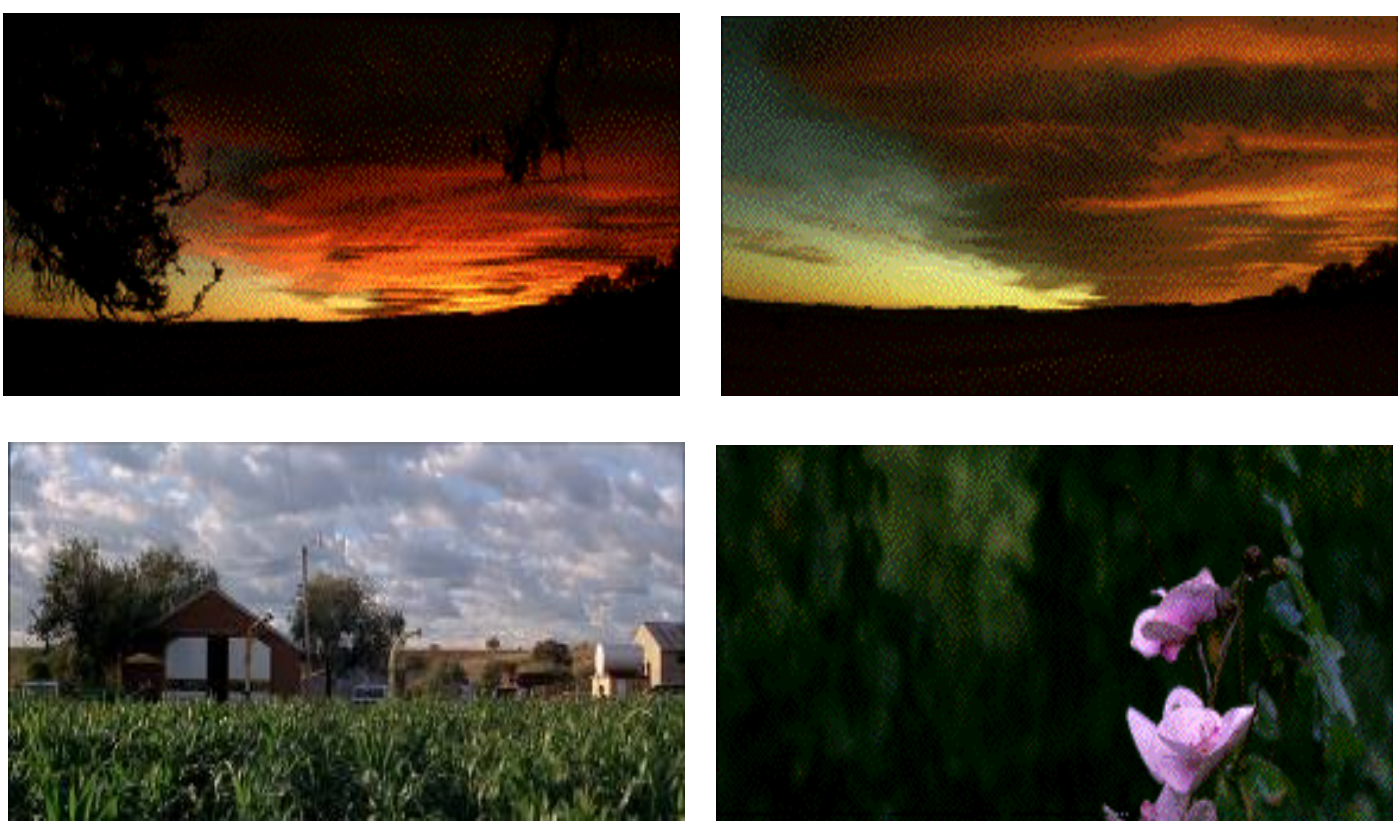

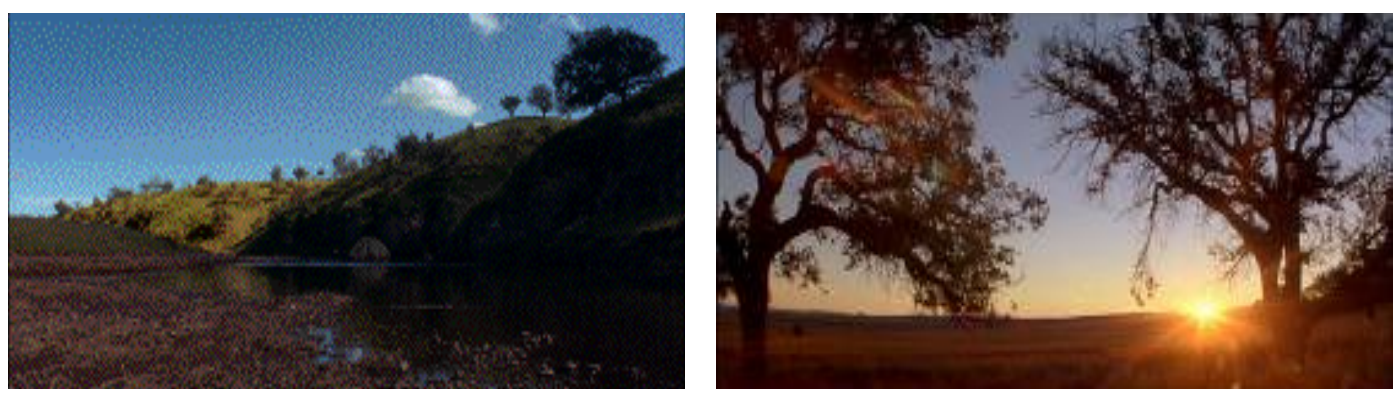

Painterly compositions in Silent Light

In short, the environmental sensibility of Reygadas's work, as observed in their focus on highly dissimilar geographies, reveals the Mexican topographical diversity, granting audiovisual expression to what Lesley Simpson Byrd, in his book Many Mexicos, defines as the country's absence of 'geographical unity', 'since any generalization about [its topography and climate] is likely to break down locally' (Byrd 1967: 11). More specifically, this laying bare of Mexico as a locus devoid of topographical uniformity discloses the inextricability of geography and socioeconomic/ethnic disparities. And since Reygadas mainly works with people from the environments in which his films are set, these in turn document the many faces populating the country: from the predominantly Indian-descending inhabitants of Ayacatzintla through the melting pot of Mexico City to the Mennonites of Chihuahua. The relationship between fiction and document in Reygadas's work is, however, far more complex. 


\section{Chapter 3}

\section{Formal Realism}

An ethnographic quality is attained in Reygadas's films through their location shooting and use of local people. His three films indeed convey what Nagib, elaborating on the Brazilian film City of God (Cidade de deus, Fernando Meirelles, 2003), defines as 'the revelatory quality of a "hidden reality" intrinsic to realist peaks in film history such as Italian Neorealism or Brazilian Cinema Novo (Nagib 2007: 106). Nowhere is revelatory realism more fully materialised than in Silent Light, unveiling with scientific curiosity the hitherto unexplored Mennonite universe in Mexican territory (it is not without surprise that most viewers learn that this film is actually set in Mexico). However, documentary ethnography is here complicated by geometric formalism, a stylistic clash that produces sensory realism and now asks for further elaboration.

On the one hand, Reygadas is a meticulous formalist, planning his films in minute detail. This includes punctilious storyboards, drawn by the director himself, which details the framing as well as the camerawork of each shot. This even compels him to claim, à la Hitchcock, that 'if you see my storyboard, you see the film' (Reygadas apud Matheou 2003: 12), a statement indeed readily confirmed upon inspection of his drawings ${ }^{5}$. His films, moreover, containing as they do acrobatic, sweeping camera movements, as well as

\footnotetext{
${ }^{5}$ Reygadas has provided me with the complete storyboards of his three films, for which I am thankful.
} 
geometric framing compositions, give further evidence of a studied and controlled filmmaking process.

And yet, formal rigour is here thwarted by strategies that, on the other hand, propitiate the unpredictable real to emerge. A comparison with the work of Alfred Hitchcock and Yasujiro Ozu is helpful. These masters of cinema also made films derived from minutely detailed storyboards. Writing on Ozu, Bordwell notes his 'near-obsessive concern with controlling every aspect of the image', which prompted him to sketch drawings of every shot (Bordwell 1988: 74). These directors' obsession with control was further extended into the shoot. Not only were they adept at studio filming, which enabled greater control over mise-en-scène dynamics, but their rigour concerning the gestures and expressions delivered by actors is well documented in film history. In both cases, one identifies a consistency running from storyboard through to filming, all aimed at preventing unprogrammed contingencies in the filmmaking process.

This would not apply to Reygadas in which formal control is thwarted by the phenomenological presence of the spontaneous real. This is observed, first of all, in the way he handles amateur actors, who are not at all trained. On the contrary, it is their unprofessional quality and spontaneous response to the presence of the camera, in short, the unpredictable 'reality' produced by such encounter, that is at stake here. Actually, these non-professional actors are not even given the film scripts. Further, they are not told how to deliver lines or pull particular facial expressions but simply instructed as to their (often statuesque-like) posture, positioning and what to say only minutes prior to the actual shoot, thereby enabling a scene dynamics which include elements beyond the director's control. One of the direct consequences of this, for example, is that these 
amateur actors more often than not look into the camera, breaking the self-sufficiency of the diegesis and, in so doing, enabling the profilmic event to emerge. In fact, Reygadas has declared in many interviews that, precisely because of its more spontaneous and unpredictable quality, he often chooses the first take when editing his films.
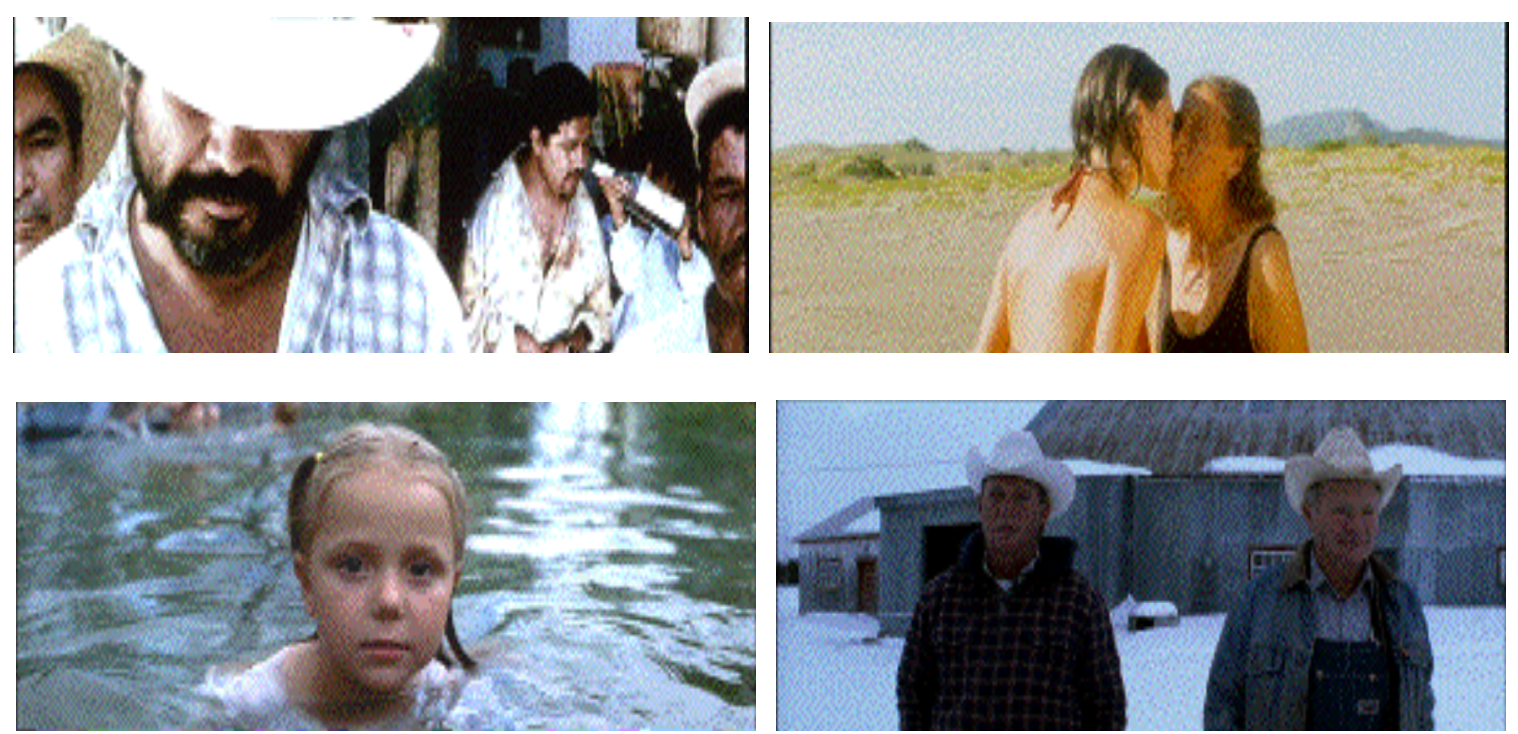

Breaking the fourth wall: non-actors looking into the camera in Japón (above) and Silent Light (below)

Reygadas articulates this aversion to rehearsal and dramatic performance as a 'concern for the actual human presence', equating himself to a portrait photographer, to whom 'it's the [actual] person that means everything' (Reygadas apud Marlow 2006). In addition, he cites Bresson's directorial approach to acting as influential on the way he himself came to direct amateur actors in his films. However, it must be noted, Reygadas's method is in some important respects quite dissimilar to Bresson's, which famously consisted of a rigid and repetitious training of posture, gestures, speech and movements with amateur actors - his 'models' as he describes them - with a view to rendering their acts and lines automatic and purposeless (see Cunneen 2004: 60). Seeing standard acting 
as a gross simplification of human emotion, Bresson believed that by preventing dramatic expressivity, the model could reveal, through physical presence, his or her true depth.

Admittedly, it is hard to articulate the difference between the results of Bresson's laborious method and that of Reygadas, since both privilege de-dramatisation as a means to enhance the material presence of human beings. Yet, I would argue that Bresson's models are defined by a more robotic quality, as observed, for example, in their trained monotone speech. The lack of acting training in Reygadas's work, in its turn, allows each non-professional actor to bring his or her singularity into play in a more spontaneous fashion. (Re)acting before the camera each in their own way, they reinforce the ethnographic quality of these films. While Alejandro Ferretis and Anapola Mushkadiz, for example, seem more at ease before the camera, delivering performances more tantamount to standard, if occasionally poor, acting, Marcos Hernandez and Magdalena Flores, on the other hand, stand out for their highly impassive faces. In their turn, the children featured in Silent Light are remarkable for their fresh spontaneity.

This rehearsal-free method thus results in an acting style that not only is uneven but dramatically unconvincing, insufficient to give the narrative psychological depth. As we watch these amateur actors uttering lines devoid of dramaticity, their speech takes on a purely citational and, therefore, material, quality. This brings to mind Bertolt Brecht's call for a type of acting that defies spectatorial identification as the utterance of lines reveals the actor's process of constructing his or her character while performing that character, 'the tone of the subject [being] demonstrated with a certain reserve, with detachment' (Brecht 1964: 125). Add to this that dialogue is punctuated by inexplicably lengthy pauses, as Reygadas is very meticulous with tempo. To this end, he even attaches 
strings to the actors' legs, pulling them at the exact moment they are expected to deliver their lines. As a result, the sense of physical presence of these actors, who are moreover often static, is heightened, contributing to these films' arresting quality, that is, their production of sensory realism. Sontag has elaborated on how silence in speech is sensuously translated into physicality:

Everyone has experienced how, when punctuated by long silences, words weigh more; they become almost palpable. Or how, when one talks less, one begins feeling more fully one's physical presence in a given space. Silence undermines 'bad speech', by which I mean dissociated speech - speech dissociated from the body (and, therefore, from feeling), speech not organically informed by the sensuous presence and concrete particularity of the speaker and by the individual occasion for using language (Sontag 2009: 20).

Here, speech has this concrete and autonomous quality, enhancing, as a result, the sheer physical presence of actors rather than representational performance.

As well as by untrained acting, formalism is here contradicted by profilmic contingency. To be perfectly accurate, we could say that with each new film, Reygadas became formally more rigorous. In retrospect, Japón displays a more spontaneous style, shot in part with handheld cameras and featuring scenes that could not have been scripted or planned beforehand. An example is when we see a gathering of approximately ten men drinking together, friends of Ascen's nephew in the filmic diegesis. Entirely untrained, these real peasants repeatedly look into the camera. At one point, one of them speculates 
who is going to provide them with more drinks, to which another man, visibly intoxicated, replies: 'They don't give us much, the people from the film'. A few shots later, we see this same man, now in close-up, singing a local song but hardly able to articulate its lyrics such is his drunken state, to the amusement of his friends who burst out laughing. This statement about the film crew thus reveals the intertwinement of documentary and fiction in Japón's hybrid style.

In any case, even when Reygadas is faithful to his storyboards, his preference for non-professional acting and location shooting destabilises formal rigour by infusing it with the spontaneous real. In the scene in Battle in Heaven in which Marcos is on a packed subway train, for example, the onscreen visual composition is entirely in keeping with the storyboard drawing, which attests to the director's control. This however does not prevent the profilmic real to surface in this scene through the number of real passengers that openly acknowledge the presence of the camera on the train. This is also what happens, in Silent Light, when Johan's children potter about and swim in a lake, constantly looking into the camera. Taking its time, the camera seems enraptured by pure materiality and movement, lingering on the flowing water, the green vegetation and even the wind in the trees. We also see the kids being washed, one by one, by Esther and Johan, the material sound of their hands scrubbing the children's hair and the running water limpidly rendered through direct sound.

In addition, the camera does not restrict itself to following characters but, at times, remains autonomous from them, keeping in view seemingly insignificant details or even disengaging from situations altogether and going on unexpected courses so as to highlight phenomenological reality. In one scene in Japón, for example, Vignatti's camera follows 
the man walking through a field in a lateral travelling to suddenly overtake him, continuing to move forwards. Then, in a continuous take, it frames Ascen from a distance picking up vegetables, a pile of cluttered logs, the open landscape, to 'find' the man again, after one minute has elapsed. These autonomous camera wanderings further recur during the film in the form of $360^{\circ}$ pans which move away from characters so as to, for example, take in the vastness of the Canyons in lingering sequence shots.

These $360^{\circ}$ pans are in fact a hallmark of Reygadas's films. As mentioned in the Introduction, in the scene in which Marcos and Ana are having sex in Battle in Heaven, the camera turns away from the sexual act and pans out of the room through the open window to slowly turn back on itself, framing two men fixing an aerial in the house next door, a busy street, kids playing in the garden of a house, three storeys of a luxurious building to then make its way back into the room. On the one hand, what stands out in this scene is its carefully predetermined form, as crystallised by a convoluted camera acrobatics that underline the materiality of the medium itself. Yet, as the camera gradually brings into view these random occurrences in the city (when panning across the building, for example, we even get a glimpse of some maids engaged in cleaning duties inside the apartments), the viewer's attention is split between the reflexive camerawork and these chance events, which, entirely devoid of narrative purpose and onscreen for nearly five minutes, are presentified as a superabundant phenomenological reality.

Thus, while Reygadas meticulously plans his films in terms of mise-en-scène dynamics, tempo and framing, he paradoxically privileges strategies seemingly at odds with such formal control, such as untrained amateur acting, preference for spontaneous first takes and long takes that presentify the phenomenological and contingent real. Were 
we to use Bazin's famous distinction between 'those directors who put their faith in the image and those who put their faith in reality' (Bazin 2005a: 24), we would have to place the director at the crossroads of these opposing aesthetic trends. His work indeed seems to give cinematic form to what Rancière calls 'the aesthetic regime of art', which in his view is 'distributed between two extremes: a pure creative activity... and the pure passivity of the expressive power inscribed on the very surface of things, independently of every desire to signify or create' (Rancière 2006: 8). This is an art thus divided between formal control and the expressiveness of reality, which, escaping intentionality, asserts itself as a purely sensible presence, that is to say, as realism of the senses. 


\section{Chapter 4}

\section{Producing the Impossible}

One of the key aspects of Reygadas's aesthetics thus resides in its conflictual character: metaphysics is thwarted by a purely materialist impulse, formalism is contradicted by phenomenological presence and authenticity. As will be my contention in this chapter, rather than with mimesis and representational verisimilitude, these are films concerned with producing a new reality whose incoherent logic and unexpected, shocking social configuration - what I call 'the impossible' - exposes the shackles of the social divide in Mexico and complicate the notion of national identity in the country. This is epitomised by the 'unlikely couples' of his first two films: Ascen and the man in Japón, and Ana and Marcos in Battle in Heaven. In what follows, I examine the way in which impossible realism is mobilised in the diegeses of Reygadas's films, what I call their 'incoherent narratives'. I move on to examine the way these implausible fictions are authenticated by realist modes of production, arguing that these are films that produce the impossible in reality. I conclude by highlighting their political significance.

\section{Incoherent Narratives}

From the outset, Reygadas's narratives are replete with irresolvable holes which prevent, 
in principle, spectatorial identification. In Japón, as we have seen, the viewer is left with unanswerable questions: Who is this unnamed man? Why does he want to end his life? Why does he need to have sexual intercourse with a septuagenarian woman in order to attain the spiritual appeasement he speaks of? Is this woman a saint? Is it really spiritual salvation he is looking for with this act or simply the satiation of a carnal desire? In its turn, Silent Light, though endowed with a tighter narrative structure, lacks psychological reasoning, presenting a miraculous ending that resists a facile Christian interpretation and remains highly ambiguous. But, without a doubt, it is Battle in Heaven that offers the most obscure and baffling of narratives. Ana's behaviour remains opaque and elusive throughout: does she prostitute herself for the sake of pleasure? The film refrains from conveying much information about her character, restraining itself to show her only when with Marcos and, in so doing, restricting the spectator's knowledge to that of his. Yet Marcos's behaviour strikes a similar note. We never learn, for example, the reason why he kidnapped his friend Vicky's baby. His stabbing of Ana at the end of the film remains equally unexplained in psychological terms.

As well as by withholding of information, Battle in Heaven's narrative is characterised by an absurdist quality, materialised in events bereft of diegetic motivation and meaning. It is not, however, only the case that these events are merely inconsequential, halting the narrative flow. More specifically, these are scenes resistant to logical interpretation. A privileged example is the football match sequence, shot in a stadium and inexplicably accompanied by the film's funereal march song theme. Though the next scene in part justifies its motivation, as we see Marcos masturbating in front of a television on which the match is being broadcast, this event remains utterly nonsensical. 
This is in fact reflexively highlighted by Marcos himself, who utters out loud, while masturbating: 'This a fantasy. This a fantasy'. Another example occurs when Marcos has his car's engine checked at the gas station, a scene whose grandiose musical accompaniment - Bach's concerto No. 1 in D minor - is oddly superimposed on the trivial occurrence being shown. More specifically, this scene confounds the spectator as to whether the composition is located inside or outside the diegetic universe. When Marcos drives into the station, the piece seems to come from the inside of his car. But as he leaves the car and the music continues being played, the viewer concludes it to be nondiegetic. The scene ends with Magdalena Flores, in a cameo appearance, getting out of a car in the station after none other than nine people. Then, she bemusedly asks 'where does that music come from?', confounding the viewer yet again.

Nonsense is also mobilised when Marcos waits for Ana outside her stately house, a sequence which oscillates between dream and reality and begs a detailed description. Marcos, framed in close-up, leans on the wall and observes the trees opposite him. As the sun comes out, the chromatic image gradually changes into a warm, artificial sepia tone that lends it a dreamlike quality, a strategy reminiscent of Tarkovsky's oneiric imagery. Two incidents then take place in succession, both of which entirely defying commonsense logic: a car packed with several youngsters parks at the house next door and the driver, seemingly drunk and accompanied by another young men, inexplicably urinates over the suitcases in the car's boot. As Marcos and Ana, who has now left the house, walk down the street, they run into a blond, fair-skinned woman in a nurse uniform, pushing an invalid old man in a wheelchair. The viewer is offered prolonged and silent close-ups of Marco's and the old man's faces, and then of Ana's uncovered, 
tattooed belly as the camera unhurriedly pans up to her face; all of them in static positions. In a close-up, the nurse looks into the camera and says, in English, 'I am sorry' to then add, this time in Spanish with a foreign accent, 'He likes to listen to the birds'. All of the above occurrences, strongly resistant to meaning-making as they are, take on a dreamlike quality, casting doubt on the diegetic objectivity of events.

Gillen Laurent's anti-naturalistic use of sound further enhances this dreamlike atmosphere in Battle in Heaven. This is what happens, for example, in the scene in which Marcos follows Ana in the airport, as we can only hear the sharp clicking of her highheeled shoes onto the floor at the expense of other ambient sounds. Similarly, when Marcos watches the football match on television, the ticking of a wall clock gradually superimposes itself onto the television sound, even though the latter remains on. This use of sound, which also echoes that of Tarkovsky, deprives events of the ambient sounds that would constitute it 'in reality' and whose sources we identify onscreen: the hubbub in the crowded airport; the television sound, etc. As with the previously analysed scenes, this audiovisual disjunction confounds the viewer, prompting the diegesis to oscillate between subjective and objective perspectives.

Although not to the same extent as Battle in Heaven, Japón and Silent Light also contain events that resist meaning. One needs only remember, among others, the scene in Japón in which the man, having just arrived, talks with the village's representative. The latter is framed in a frontal close-up and discourses on the place's amenities. Curiously, in the background we discern a man with disabled arms having poured into his mouth what looks like an alcoholic drink by a young girl. This same man, later in the film, is shown eating with his feet an apple on the end of a stick. These scenes appear as entirely 
unmotivated in the diegesis. With respect to Silent Light, take the scene in which Johan's children watch on television, inside a van, Belgian cabaret singer Jacques Brel. True, this event comments on the fact that television watching is a forbidden activity in Mennonite religions, which in turn explains the children's amusement. And yet, the prolonged attention which Brel's singing receives here is somewhat befuddling. At first onscreen diegetically, his televised image takes on a non-diegetic status as we cease to hear the kids' off-screen giggles. For nearly two minutes, we are then offered extreme close-ups of the singer's pixelised, black-and-white and sweaty face, as well as of his applauding audience. The intent of these images remain elusive as the singer's caricatural performance resists a semiotic association with the Mennonite universe or the extramarital tale depicted, taking on an absurdist quality; its extended duration being misleading as it proves inconsequential to the narrative. Even more baffling is the scene in Silent Light in which Johan converses with his father in the middle of a field entirely covered in snow, which strikes as odd considering the fair weather on display throughout the rest of the film, plunging diegetic chronology into uncertain waters.

These confusing, incoherent narratives resonate with what Deleuze defines as 'the powers of the false' of the time-image cinema, which in his view opposes 'truthful narrations'. While the latter is defined by a plausible representational logic and structure, being 'developed organically, according to legal connections in space and chronological relations in time' (Deleuze 2005b: 129), a 'falsifying narration', on the other hand,

is constantly being modified, in each of its episodes, not according to subjective variations, but as a consequence of disconnected places and de-chronologized 
moments. There is a fundamental reason for this new situation: contrary to the form of the true which is unifying and tends to the identification of a character (his discovery or simply his coherence), the power of the false cannot be separated from an irreducible multiplicity. 'I is another' ['Je est un autre'] has replaced Ego $=$ Ego (Deleuze 2005b: 129)

Deleuze goes on to argue that in 'false' fictions - fictions that do not claim to be true even the notion of morality is abolished, the viewer being unable to resort to a 'system of judgement'. He cites, for example, Orson Welles, who 'constantly constructs characters who are unjudicable and who have not to be judged, who evade any possible judgment' (Deleuze 2005b: 135). Something similar happens in Reygadas's universes, which, governed by a logical system alien to causality, psychology and verisimilitude, prevent the judgment of characters based on a moral system. And it is this prevention that decisively sets it apart from the likes of Bresson, Dreyer, Tarkovsky and Rossellini, as well as Bazin's humanism, in which the notion of morality plays a significant role. Here, the traditional categories of good and evil cease to make sense. The viewer is not asked to sympathise with Esther's suffering any more than to judge Marcos's criminal deed or pity the man's existential turmoil but to contemplate these events as material presences devoid of moral value, as expressions of 'outpouring becoming' which 'is always innocent, even in crime, even in the exhausted life' (Deleuze 2005b: 137). There is no victimisation here either. In fact, characters belonging to the same poor social stratum are portrayed as shattering class unification from within: the demolition of Ascen's house at the end of Japón, for example, is carried out by her nephew, who, 
helped by the village peasants, wants to take her house. As previously stated, Marcos and his wife kidnap the baby of their close friend Vicky. (In some respects, this unsentimental portrayal again recalls the work of Buñuel, often labelled 'cruel' because unflinching in its depiction of coarse types: we need only remember, for example, the juvenile delinquents of Los Olvidados [1950] or the rowdy, greedy paupers of Viridiana, among others.)

And it is precisely because of this disregard for normative representational tenets that the work of Reygadas contains a powerful political relevance. Revoking a verisimilar logic so as to embrace its own incoherence, here 'the impossible comes from the possible' (Deleuze 2005b: 127).

\section{Unlikely Couples}

Nowhere is the impossible more fully epitomised than in the implausible sexual encounters between Ascen and the man in Japón, and Ana and Marcos in Battle in Heaven. These are couples whose formation glaringly subverts not only regulatory cultural codes such as age and physical appearance but, more significantly, the rigid social segregation animating Mexico. Marcos and Ana, and Ascen and the man, phenotypically encapsulate and, in so doing, highlight, the socio-ethnic divide of the country.

Let me briefly substantiate this claim. Social segregation in Mexico, encapsulated in the figures of the Creole (white European) and the dark-skinned Indian - as personified in Japón and Battle in Heaven - goes back to the country's Conquest era when, already 
home for three ethnicities, it was invaded and subsequently colonised by the Spaniards. This clear-cut divide, of course, does not stand close scrutiny. Both the Spaniards and the Indians were the product of syncretic civilisations themselves, a situation further complicated in Mexico after its colonisation, as 'mestizos' (mixed race) became the majority of the population. Still, as with most of its Latin American neighbours, class and ethnicity go hand in hand in Mexico, meaning that the darker one is, the poorer one is likely to be. As Charles Ramírez Berg contends, 'though numerically inferior, white creoles are [Mexico's] phenotypical ideal...institutionalized by a colonial caste system that placed the European at the pinnacle and the Indian at the bottom' (Berg 1992: 137).

It was not until the country's 1910 Revolution that a 'conscious attempt', as Anthony D. Smith puts it, 'was made to synthesize the conflicting traditions...of ancient and modern Mexico' (Smith 2003: 209). And one sphere where this construction of a national identity in Mexico is said to have found its most privileged showcase is cinema, emblematised, for example, in the number of studies on Mexican cinema grappling with this topic (see, for example, Haddu 2007; Noble 2005; Berg 1992; De la Garza 2006). Though it is not my purpose to stress their nuances and differences, it is important to note that central to these accounts is the notion of Mexican cinema as directly reflecting this conscious attempt at the construction of a national identity through coherent narratives. Thus, Berg argues that cinema in Mexico 'might be thought of as a series of attempts to assemble the Mexican experience into a complete and coherent narrative' (Berg 1992:1). De la Garza strikes a similar note by arguing that national discourses (and its construction in cinematic discourses) will 'by necessity be constructed around...the impossibility of realising a transcendental identity, which it attempts to hide through the articulation of a 
coherent narrative that provides a provisional identity, a national identity' (De la Garza 2006: 13).

It seems that the very opposite is true of Reygadas's films, intent as they are on defying and subverting the expectations bought into the image of Mexico. This is best exemplified by Silent Light, whose Mennonite universe, situated in almost complete isolation and anonymity within the country, directly contradicts any notion of Mexicanness. With each new Reygadas film, a distinct face of Mexico is highlighted, revoking the notion of an all-encompassing, consensual national identity in the country. Battle in Heaven, for example, is emblematically bookended by the ceremonial raising and lowering of the Mexican national flag, exploring subjects crucial to the country's national identity such as Catholicism, as well as touching upon pressing current issues such as kidnapping and obesity - all authenticated by a strictly realist mode of production. Yet, precisely, what is striking in this film is its incoherent, implausible and unlikely picture of Mexico, as epitomised by its central couple, which confrontationally defies representational logic. (Reygadas's original casting choice for Ana's role was the Mexican pop singer and celebrity star Paulina Rubio, which reveals the extent to which the director was willing to juxtapose diametrically opposite types. Rubio declined the offer.) Here, as in Japón, there seems to be an attempt to lay bare the extent to which any concept of national identity, or indeed any concept of identity at all, is a construction and, therefore, fiction.

It is true, unlikely couples are nothing new to storytelling, stretching as far back as Shakespeare's Romeo and Juliet and comprising a central motif in fairytales. Nor, for this matter, is the trope foreign to film. In his book Unlikely Couples Thomas E. 
Wartenberg charts the cinematic history of what he sees as a film genre in its own right, going on to analyse films as diverse as Frank Capra's It Happened One Night (1934) through to Rainer Werner Fassbinder's Fear Eats the Soul (Angst essen Seele auf, 1974) to Neil Jordan's The Crying Game (1992), among others, so as to highlight the subversive potential intrinsic to the unlikely couple motif. He argues that 'the unlikely couple film traces the difficult course of a romance between two individuals whose social status makes their involvement problematic...[as observed in] its violation of a hierarchic social norm regulating the composition of romantic couples' (Wartenberg 1999: 7). Therefore, a fundamental convention of the genre, what Wartenberg calls its 'narrative figure', is the clash of the couple with society. In his turn, Ismail Xavier, elaborating on the Brazilian cinema of the 1990s, contends that 'unexpected cross-cultural encounters', a sign of 'a new configuration of social networks', have become recurrent in film in recent decades as 'displacements in space, and the interactions between local and alien elements, have had a significant effect on the dramatic structures of cinema in several countries', from which Brazil is a prominent example (Xavier 2003: 49).

And yet, notwithstanding the cinematic history of this trope, Reygadas's take on the unlikely couple offers its originality. To begin with, Japón and Battle in Heaven entirely refrain from acknowledging the implausibility of these couples and their sociohierarchical disruption. In both films, these couples are presented as naturals, their incongruity going on unquestioned. We are not entirely sure why Ascen so easily complies with the man on having sex. Even more baffling is Ana's attraction to her chauffeur Marcos, whose defiance of commonsense logic, involving issues of class, ethnicity and physical appearance, is not even mentioned but instead presented as a 
given. To cite another film in which an equally impossible relationship occurs, Fassbinder's Fear Eats the Soul, here we have the love story of an elderly German woman, Emmi (Brigitte Mira), and a younger Moroccan Gastarbeiter, Ali (El Hedi ben Salem), and therefore a relationship also strictly informed by social and ethnic issues. But Fassbinder, revising Douglas Sirk's All that Heaven Allows (1955), overtly thematises the couple's implausibility, explaining it on grounds of love - 'an impossible love' as its commercial trailer announces - and focusing on the disruption this relationship represents to the social order in Germany. By contrast, in Japón and Battle in Heaven, we cannot even ascertain it is love that draws these couples together or simply lust, as the viewer is unaided by character psychology.

More significantly, the originality of these couples relates to the degree of exposition to which Reygadas subjected these non-professional actors - and consequently himself - for we are talking of scenes involving full frontal nudity, sex simulation and, in the case of Battle in Heaven, real, penetrative sex onscreen. Therefore, these couples are shocking not only by the way they are unenclosed by a plausible dramatic structure that would explain their incoherence. There is the greater shock of seeing these real people in explicit sexual intimacy. Which is to say that these are impossible fictions authenticated and made possible in reality. The sexual intercourse between Ana and Marcos, more than representing the unlikely encounter of different ethnicities, classes and ages, is this encounter, registered by the camera lens. To borrow Nagib's words, here the film medium is used 'as a means to produce, as well as reproduce reality' (Nagib 2011: 8), meaning that these are fictions which are also, and perhaps more importantly, facts. 

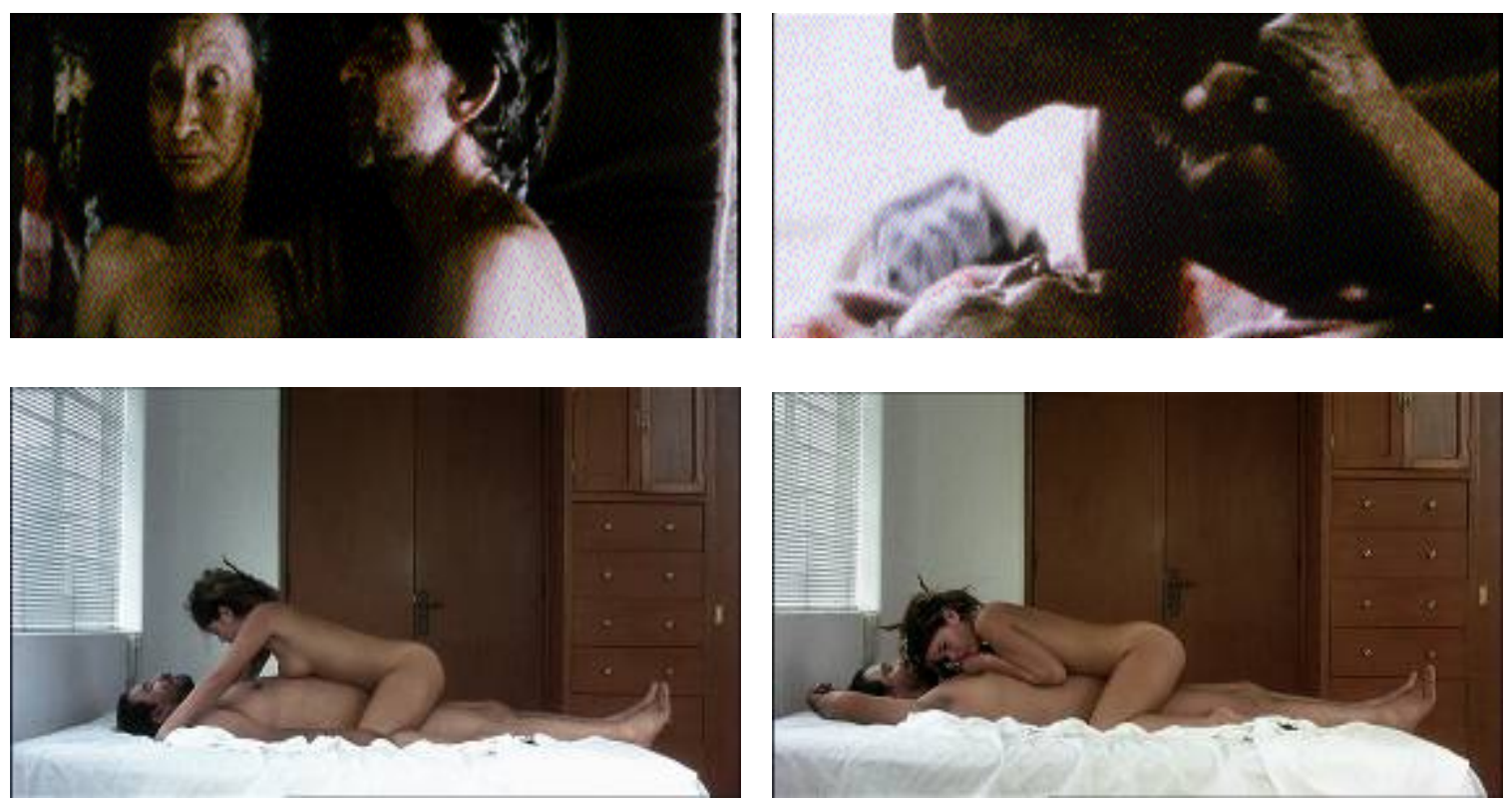

Producing the impossible: the sexual encounters of Ascen and the man in Japón (above) and Ana and Marcos in Battle in Heaven (below)

These facts take on an even more pronounced documental status if we consider that these are all non-professional actors whose real lives strictly overlap with those of the characters they play. Not only Marcos Hernandez and Anapola Mushkadiz lend their real names to their characters in Battle in Heaven but Hernandez is indeed a chauffeur while Mushkadiz, in addition to wearing her own clothes when playing Ana, has declared herself 'to be even more "excessive" than her character' (Smith 2005: 48). In the same film, we also have Marcos's wife, who, like thousands of Mexicans living in the capital, works as a self-employed vendor in a subway station. In real life, Berta Ruiz sells jellies in the city's international airport. Likewise, Magdalena Flores, like all peasants featured in Japón, indeed live in Ayacatzintla (albeit not in the hut shown in the film). Finally, the man in Japón was specifically written for Alejandro Ferretis, a personal friend of Reygadas, who has confessed the character was directly based on Ferretis's taciturn way of being. 
This conflation of fiction and reality in Reygadas's work is certainly viewed as its most controversial aspect. Upon their release, Japón and Battle in Heaven caused considerable stir mostly due to their expositional and uncompromising use of nonprofessional actors and real locations. Paul Julian Smith, for example, in his review of Japón, contended that 'Reygadas is not documenting the real here; he is intruding on it' (Smith 2003: 50), implying that the director would have appropriated the village and its inhabitants for purely aesthetic purposes. This, Smith goes on, is corroborated by the fact that Magdalena Flores was not even given the script during the shoot, which confirms the suspicion that 'it is not only within the plot that the elderly lady is being tricked' (Smith 2003: 50), an opinion which he subsequently reinforced in his review of Battle in Heaven, in which, according to him, 'the use of amateur actors raises tricky ethical questions' (Smith 2005: 48). Now, the problem underlying the deduction that these people were 'tricked' by the film's director, is the implicit notion that they would be incapable to decide for themselves. There resides here a paradox: the critic is wary of the power relations between the filmmaker and the peasant woman or, for that matter, the Indian driver. However, by insinuating that these are people unable to take responsibility for their decisions, the critic has taken up, through his words, the condemned superiority he has attributed to the film director in the first place. The power relations which the critic aims to dismantle are, on the contrary, reinforced.

Smith sees a discrepancy between Japón's highly aestheticised imprint and the poor milieu it presents, which elicits a 'kind of tension between the modesty of the film's means and the extravagance of its ambitions' (Smith 2003: 50). Informing Smith's critical method is a representational logic whose mimetic foundations spell out not only 
what kind of subjects and objects are to be represented but also the ways in which this is to be done, including their specific hierarchical configuration. It is this view of art that dictates, for example, that non-normative bodies such as those of Hernandez, Flores and Ruiz should not be uncovered at all, let alone shown engaged in explicit sexual acts; or that a poor milieu such as Ayacatzintla should not be appropriated for aesthetic ends. This Rancière calls 'the representative regime of art', which Raji Vallury cogently summarises thus:

Founded on the principle of mimesis, or the imitation of an action, the representative regime of art lays down normative forms (formes de normativité) that...define manners of expression that are most suited to the subjects represented. The representative regime of art is thus driven by a principle of adequation between action and signification, by a will to render the links between ways of being, doing and speaking causally rational and intelligible (Vallury 2009: 230).

Opposing this is what Rancière calls the 'aesthetic regime of art', which turns reality into a thoroughly expressive phenomenon, abolishing mimesis from within. In so doing, aesthetic art effects a disruption in the ways it is expected to represent subjects in a 'consensual' manner, creating instead 'dissensus'. In a rhetoric which resonates with Deleuze's 'powers of the false', Rancière writes:

What characterizes the mainstream fiction of the police order is that it passes 
itself off as real, that it feigns to draw a clear-cut line between what belongs to the self-evidence of the real and what belongs to the field of appearances, representations, opinions and utopias. Consensus means precisely that the sensory is given as univocal. Political and artistic fictions introduce dissensus by hollowing out that "real" and multiplying it in a polemical way (Rancière 2010: 148-9).

Aesthetic art, therefore, by effecting this dissensual disruption in the normal ways of reality and its representation, politically 'contributes to the constitution of a form of commonsense that is "polemical", to a new landscape of the visible, the sayable and the doable' (Rancière 2010: 149).

It is precisely in this sense that Reygadas's sensory and aestheticised realism is strongly political in essence. By presenting the controversial sexual encounters between a septuagenarian Indian woman and a white middle-aged man, as well as between an obese Indian man and a rich and attractive young girl, these are films that manufacture a new reality out of reality itself. They contribute to the production of a new social landscape and, in so doing, expose the social establishment and its mechanisms of exclusion, while at the same time upsetting the dominant cultural codes and revealing these same codes as partial, historical and contextual. Rather than inserting these couples into a plausible dramatic structure, these films unveil these bodies - non-normative bodies which the cinema has rarely focused on with such frankness - in their shocking aesthetic quality. Their political impact consists in the way they tear these bodies away from their assigned places so as to rearrange them in unexpected configurations. As such, they build 
alternative realities in which all starts up anew and change unleashes itself. 


\section{PART II}

\section{TSAI MING-LIANG: CINEMA OF BODIES}

Asked to describe the cinema of Tsai Ming-liang in a few sentences, one would probably cite its minimalist settings, static camerawork, overstretched long takes and solitary characters whose private life and eccentric behaviour are minutely dissected against the backdrop of late-industrialised Taipei. One would equally mention its lack of narrative momentum and psychology, as well as its focus on human physiology and bodily needs. Tsai's sensory realism is therefore produced through an unrelenting attention to the concreteness of domestic spaces and the physicality of bodies, which testifies, in principle, to a cinematic tradition of the 'everyday' while at the same time drawing on grotesque repertoire. As will be examined in the following chapters, his is a cinema that challenges essentialist assumptions of normative behaviour, gender expectations and discourses on sexuality, highlighting instead a political body that is unfinished, mutable and open.

Chapter 5 offers a contextual analysis of Tsai's oeuvre, whose documentary inflection provides a razor-sharp social commentary on the exclusion process intrinsic to modernisation in late-capitalist urban spaces such as Taipei and Kuala Lumpur. Yet, far from restricted to an observational method, his cinema comprises a limit-case of an auteurist, as well as a realist, approach, as analysed, respectively, in Chapter 6 and 7. Still 
in Chapter 7, I examine the way Tsai reconfigures an everyday tradition in film by enhancing the materiality of interior spaces and opening up the doors of domestic privacy through a focus on the body's physiology and intimate situations. Chapter 8 concludes this part by addressing the grotesque impulse and physical acting style animating Tsai's cinema, stressing its political assertion of a non-normative body in continuous becoming. 


\section{Chapter 5}

\section{The Real City}

During a career spanning nearly two decades, Tsai Ming-liang has cemented his position as one of world cinema's most creative and audacious directors. Tsai was born in 1957 in Kuching, Malaysia, moving to Taiwan at the age of 20 where he began his studies of film and drama at the Chinese Cultural University of Taipei. Soon he became part of Taiwan's Xiaowu Theatre group, performing the roles of actor, director and playwright to later embark on a career in television and subsequently film. The director rose to fame in the international film circuit with his second feature-length film Vive l'amour (Ai qing wan sui, 1994), which earned him the prestigious Golden Lion at the Venice Film Festival. In 1997 its follow-up The River (He liu) was awarded the Silver Bear at the Berlin Film Festival. His international success came to be viewed as part of the second wave of Taiwan New Cinema, whose representatives included, among others, Ang Lee and Stan Lai. But his cinema's observational focus on the urban face of contemporary Taipei also likened it to the late output of Taiwan New Cinema's acclaimed first new-wavers, notably Hou Hsiao-hsien and Edward Yang.

The origin of Taiwan New Cinema is generally traced back to 1982 and, more specifically, to the release of In Our Time (Guang yin de gu shi), a four-part film directed by Chang Yi, Ko I-chen, Tao Te-chen and Edward Yang. In contrast to the escapist musicals and dramas of the country's cinematic past, produced under the aegis of the Chinese Nationalist Party (KMT), new Taiwanese films strove for a stronger realist style. 
This included the use of non-professional actors, location shooting, as well as aversion to 'theatrical conflicts, meaningful characterization and purposeful dialogue' (Rawnsley 2009: 99-100) - features which Tsai's cinema stretches to its limits. In particular, these cinemas turned to Taiwan history as an openly political attempt to grasp the country's colonial past, the peasant's struggle against deprivation and its troubled national identity (Lim 2006: 128).

However, this historical drive started to fade as Taiwan entered a post-martial law era, undergoing a radical urbanisation process resulting from its 'economic miracle'. This, as Song Hwee Lim observes, led to a shift from 'a "historical I" to a "private I"' in the cultural and artistic practices of the country (Lim 2006: 128), including film, which now turned to the private aspect of everyday life and contemporary urban issues. It is precisely this depiction of a private, late-capitalist urban life in Taipei, caught up in the middle of a sweeping modernisation process, that lies at the core of Tsai's oeuvre, whose take on the trope of the everyday, as will be examined in Chapter 7, is one of its most distinctive aspects. For now, let us turn to the documentary drive which informs his work and its resulting social relevance.

Tsai's cinema is endowed with a documentary quality thanks to its location shooting. With the exception of What Time Is It There? (Ni na bian ji dian, 2001) - shot partly in Paris - and I Don't Want to Sleep Alone (Hei yan quan, 2007) - filmed on the director's native soil Malaysia - most of his films are set in and around Taipei, displaying recognisable districts for those familiar with the city. More specifically, his is a cinema that provides a commentary on the unwelcoming consequences of modernisation, such as real environmental changes and the alienation experienced by those living on the fringes 
of society, summarily excluded from this process.

This social critique is mobilised through a stress on Taipei's marginalised districts and underprivileged inhabitants. A case in point is the Ximending district, in southwest Taipei, which extensively appeared in Tsai's television work in the early 1990s, being also the main setting of Rebels of the Neon God (Qing shao nian nuo zha, 1992), the director's first feature-length film. Tsai himself lived in Ximending while studying, where he picked up Lee Kang-sheng, who went on to become the ubiquitous protagonist of all his films, Hsiao-kang (Yao 2005: 226). This neighbourhood, Taipei's displaced commercial centre, is filled with decrepit shopping malls, crowded video arcades and delinquent juveniles, all of which are depicted in Rebels of the Neon God as we follow Ah Tze (Chen Chao-jung), a young man who roams about on his motorbike stealing coins from telephone-cabins and video hard drives.

In stark contrast to Ximending, Vive l'amour is set in Taipei's wealthy quarters, as we follow three different characters 'squatting' a vacant apartment in a luxurious building. The film highlights the social disparity resulted from an unequal economic distribution in the city. As Fran Martin observes, 'each of the character's occupations represents an aspect of the underside of Taiwan's "economic miracle"” (Martin 2003: 176). Hsiao-kang (Lee Kang-sheng) is a salesman of funerary niches 'on a small island where skyrocketing land values have put a grave site in a traditional cemetery outside most people's reach' (Martin 2003: 176); Ah Rong (Chen Chao-jung) is an illegal street seller constantly running from the police and Mei-mei (Yang Kuei-mei), the state agent in charge of selling the wealthy property, lives in a flat which is nothing but shabby in comparison to the former. In fact Tsai's working-class characters live predominantly in 
bleak, drab, grey housing projects in the destitute quarters of the city. Their flats are ugly, damp and small, literally crumbling apart from within, a process further accelerated by the infiltration of extraneous elements, notably water, which, whether through leaks or drains, floods their apartments. These are deeply laconic, alienated characters, isolated within their home and longing for a connection of some sort with other people. Their jobs are low-paid: they are taxi-drivers, street-sellers, elevators' operators, cleaners. They eat junk food, canned groceries, leftovers. They wander, disaffected, through the city's neonlit corners and alleys, run-down shopping malls and cruising areas. In short, they are the marginalised inhabitants of a city in relentless transformation.

This stress on poverty, solitude and alienation in the context of urban society thus discloses a dystopian view of postmodern life, an aspect further reinforced by the use of adverse, real life environmental changes as narrative cues. This is what happens, for example, in The River in which Hsiao-kang is seized by a severe neck pain after diving into a polluted river. Though the causes of this pain remain unexplained, the river in question is the Tamsui River, situated in the northern part of Taipei and which, as KuangTien Yao tells us, has been used 'for decades as a garbage dumping ground from the metropolitan area' (Yao 2005: 234). Similarly, in I Don't Want to Sleep Alone a smoky haze besets Kuala Lumpur, forcing its inhabitants to use gas masks, which refers to a real occurrence: every year smoke is indeed produced by fires in Sumatra, Indonesia, being carried by winds to Malaysia, as farmers illegally burn their lands so as to clear it for new plantations.

Nostalgia for rapidly disappearing places due to urban expansion and industrialisation can also be found here. Goodbye Dragon Inn (Bu san, 2003) is entirely 
set in a decrepit movie house in Yonghe, in Taipei County. As the cinema was closed down, Tsai rented it for one year to shoot the film, which depicts its last opening day. More recently, Tsai has gone even further in his ruminations on the waning of the theatrical film experience. As part of the Cannes film festival $60^{\text {th }}$ anniversary, the director realised a short film entirely shot, once again, in a run-down movie theatre about to be demolished, this time in Malaysia. Entitled It's a Dream (2007), this was further showcased at the Taipei Fine Arts Museum (TFAM), for which the director turned out with a longer, 23-minute version which contains the same images, only onscreen for a longer period of time. Prior to the cinema being demolished, Tsai collected around 30 chairs from it and integrated them into the installation (which eventually became part of TFAM's permanent collection) so that people could watch the film in the actual seats of the theatre which no longer exists but is preserved in the film itself.

To be perfectly accurate, disappearing places in Tsai's oeuvre in fact goes back to the short The Skywalk Is Gone (Tian qiao bu jian le, 2002), premised on the actual demolition of a skywalk opposite Taipei's main train station, which had appeared in Tsai's preceding film, What Time Is It There?. In the latter Hsiao-kang works on the said skywalk as a vendor of wristwatches where he meets Shiang-chyi (Chen Shiang-chyi) as she purchases his own wristwatch before taking off to Paris. Upon learning about the overpass's demolition, which occurred so as to make room for more lanes in the increasingly congested avenues below, Tsai decided to further the couple's story by using the demolition itself as a narrative cue, as we follow Shiang-chyi, having just arrived from Paris and looking for Hsiao-kang, searching for the skywalk through the city's jammed streets. Overcrowded locations, incidentally, are not a recurrent feature in Tsai's 
oeuvre as the director often evacuates Taipei's busy areas while filming. These empty urban spaces have indeed become one of his many auteur trademarks, contributing to his cinema's ongoing depiction of loneliness and isolation while also attesting to his avowed debt to a director such as Michelangelo Antonioni (Kraicer 2000: 585), famous for his alienated, wandering characters and deserted urban landscapes. In the short film, by contrast, Taipei is depicted as a frenzied, bustling and chaotic urban space, shot on areas swarming with pedestrians and vehicles.

Chaotic urban spaces are likewise on display in I Don't Want to Sleep Alone, Tsai's cinematic foray in his birthplace Malaysia, as mentioned earlier. Here Kuala Lumpur is also highlighted as a busy and noisy urban centre filled with street vendors, pedestrians and cars. Focused again on the underclass, the film follows a group of Bangladesh immigrants living in a ramshackle, half-built apartment block, revealing the terrible living conditions faced by these immigrant workers. This is a real social issue in Malaysia, which received a massive number of immigrants in the early 1990s as a consequence of economic prosperity. By the end of the decade, however, the country entered into a deep financial crisis, leaving these immigrants abandoned and deprived of work. The film also mobilises political commentary through its main visual motif - a mattress found in the streets by these immigrants and which becomes the symbol of a love triangle between its main characters - which refers to a Malaysian political scandal. In 2000 Vice Prime Minister Anwar Ibrahim was sentenced to nine years for sodomy in a case forged by Prime Minister Mahathir Monhammad, whose government was openly criticised by Ibrahim (Neyrat 2007). One of the pieces of evidence faked against Anwar was, precisely, a stained mattress, with the Vice Prime Minister further appearing in court 
with his eyes severely bruised due to police violence - a fact which, as Cyril Neyrat (2007) notes, is explicitly alluded to by the film's original Chinese title (Hei yan quan, meaning 'eyes circled in black' or 'shadow under the eyes') and lost in the English translation ${ }^{6}$.

Tsai's cinema is therefore endowed with a social and political relevance thanks to its documentary quality and stress on the underprivileged, bringing out into the open the ruthless exclusion intrinsic to an unequal modernisation process in late-capitalist cities such as Taipei and Kuala Lumpur. By focusing on the detrimental environmental changes such process has so far engendered, it further prompts a deep reflection on the consequences of such changes. However, his work is not restricted to a documentary approach. As the next chapter will look at, superimposing this documentary layer is a unique, idiosyncratic and self-contained fictional universe whose immediately recognisable imprint comprises a limit-case of auteurist filmmaking.

\footnotetext{
${ }^{6}$ The film had a turbulent trajectory prior to its release in Malaysia. It was first banned, then unbanned, then censored. Tsai had to make five cuts to the film so that it could be finally released.
} 


\section{Chapter 6}

\section{Same Difference}

Among Tsai's avowed heroes, nouvelle vague frontman François Truffaut occupies a very special place, as made overt in What Time Is It There?, which, in addition to being partly filmed in Paris, incorporates actual scenes from Truffaut's milestone The 400 Blows (Le quatre cents coups, 1959). As Shiang-chyi takes off to the French city after a brief encounter with Hsiao-kang, he acquires a sudden interest in the capital and begins to search for French film classics in the pirate market of Taipei. More than a postmodern collage, the citation of this film, the direct harvest of la politique des auteurs as defended by the French magazine Cahiers du Cinéma in the 1950s, in fact exposes a crucial aspect of Tsai's oeuvre, starkly governed as it is by an auteurist approach.

The auteur policy championed by Truffaut and his colleagues in the pages of Cahiers (the 'Young Turks' as they became known due to their fiery film criticism) fought for a cinema representative of the director's personal worldview. This idea, foundationally sketched by Alexandre Astruc's 1948 defence of a 'caméra-stylo', gained momentum in 1954 with Truffaut's publication of his essay 'A Certain Tendency of the French Cinema', which rehashed and cemented many points raised by Astruc. In particular, it attacked French directors' over-reliance on literary and theatrical sources, further advocating for an individualist and low-budget filmmaking, in which the practitioner's signature would recognisably run through his or her output. Truffaut's 
filmmaking career became itself highly emblematic of auteurism as he continually revisited the same themes and motifs, incorporating autobiographical elements into his films. His auteur signature was further personified in his alter ego Antoine Doinel, the protagonist of a saga of five films played by Jean-Pierre Léaud, whose own physical appearance uncannily came to resemble that of Truffaut himself as both grew older. Indeed, in one of its references to Truffaut, What Time Is It There? features Léaud in a cameo appearance, as Shiang-chyi runs into him in a cemetery in Paris.

Tsai follows the steps of Truffaut in two respects. Like the French director, he infuses his films with autobiographical elements and references. Many of the absurdist occurrences which pervade his work are, according to the director, based on his own real life experiences, an example being the floods which he claims to have experienced in different houses and which unfailingly appear in his films. More specifically, Tsai mirrors Truffaut through his own cinematic alter ego, Hsiao-kang, the protagonist of all his films played by Lee Kang-sheng, whose own real life experiences also provide inspiration for the director. For example, the strange neck pain that seizes the character in The River, as previously stated, was allegedly based on a similar ailment experienced by Lee in real life. The same is true of his father's death in What Time Is It There?, whose cue Tsai took from Lee's own father loss (Hummel 2004). Though Lee has also worked with other directors and even directed his own feature-length films, such as The Missing (Bu jian, 2003) and Help Me Eros (Bang bang wo ai shen, 2007), the collaborative partnership between him and Tsai is such that the director has even attributed his protracted and silent directorial style as responding to Lee's taciturn demeanour (Hummel 2004). 
However, Tsai's auteurist approach is not restricted to his cinema's autobiographical layers. His is a cinema whose impressive uniformity - in part derived, of course, from the director's reliance on the same collaborators (cinematographer Liao Penjung, editor Chen Sheng-chang and scriptwriter Yang Pi-ying) - stretches auteurism to hyperbolic extremes. His films are always reverberating with one another, a fictional web which becomes more intricate and complex as his body of work grows in number. This interweaving is so pervasive that, as Lim argues, his 'oeuvre consists not so much of individual films but, rather, can be more fruitfully seen as a serial whose constituent components are never quite complete within themselves in hindsight, as elements in later films illuminate aspects of earlier ones' (Lim 2007: 227). Calling this aspect the 'intratextuality' of Tsai's films, Lim suggests that while they can of course be viewed as separate texts, 'an intratextual approach...is appropriate, as it allows for productive reading strategies that interrelate one film to another' (Lim 2007: 226). I concur that Tsai's cinema, at this stage of his consistent career, indeed demands this approach.

From the onset, the self-referential web of Tsai's work is mobilised through the same casting choices, which is not exclusively attached to Lee and includes female actors as well, what Mark Betz defines as an 'artisanal or theatrical troupe approach to casting' (Betz 2006: 162). Yang Kuei-mei, for example, plays the leading parts in Vive l'amour and The Hole (Dong, 1998), and appear in minor roles in Goodbye Dragon Inn and The Wayward Cloud (Tian bian yi duo yun, 2005). Lu Yu-ching, who plays Hsiao-kang's mother in Rebels of the Neon God, The River and What Time Is It There?, also makes brief appearances in most Tsai's films, as does Miao Tien, his father in the same films. But, no doubt, it is Chen Shiang-chyi who has acquired an omnipresence only 
comparable to Lee's: she first appeared in The River in a brief role, going on to star in What Time Is It There?, Goodbye Dragon Inn, The Wayward Cloud and I Don't Want to Sleep Alone. The constant presence of Chen and Lee as a couple of sorts in Tsai's latest features are thus telling examples of his echoing narratives. There are however different kinds of self-referential dialogue animating his oeuvre.

Firstly, Tsai's auteur signature is readily identified in the visual motifs which unfailingly recur in his films and which by now have become taken-for-granted features of his universe. Most notable is the director's famous obsession with water, which, in the form of rain, leaks and drains, prominently figures in all his films. Yet the list is far more extensive: cockroaches, cats, watermelons, hotel rooms, porn films and magazines, TV sets, cigarettes, rice cookers, long corridors, emergency stairs, bridges, ventilators, among many others, are likely to be found in any Tsai film. Though it is not infrequent that these motifs are appropriated for narrative purposes, their arbitrary repetition from film to film authoritatively reinforce the director's signature. And this panoply of recurrent individuals, objects and spaces is matched, on a thematic level, with stories whose threads insidiously weave into one another, producing a pervasive and permanent sense of déjà vu. Let me illustrate this with some examples.

Rebels of the Neon God, for instance, tells the story of the then unknown Hsiaokang, a lonely, disaffected young man who has deliberately dropped out of school and seems lost in life. His erratic behaviour leads him to clash with his concerned parents, with his mother believing he is the reincarnation of Nezha, a disobedient child-deity in folk religion who tries to kill his father (the film's original Chinese title, Qing shiao nian nиo zha, reads 'Teenage Nezha'). This same family, depicted in the same domestic 
settings, is at the centre of The River and What Time Is It There?, in which the parents acquire greater diegetic importance. The River focuses on the utter lack of communication among these three family members, following their separate and isolated routines. Hsiao-kang inexplicably develops a severe neck pain after diving into the polluted river of the title, then undergoing a series of religious and medical rituals so as to rid himself of this pain. At the same time he is shown frequenting gay saunas.

Meanwhile, his mother is having an affair with another man while his father, like Hsiaokang, is visiting gay cruising areas and saunas. It is in one of these that, at the end of the film, father and son unknowingly have non-penetrative sex in a dark room, with the film leaving in suspension the consequences of such a shocking act. What Time Is It There? returns to this same family and setting if only to depict its dissolution: the father dies at the film's opening, prompting the mother to partake in Taoist rituals as she believes his spirit remains in the house and may soon reincarnate. Hsiao-kang, now a wristwatch street-vendor, develops the peculiar mania of resetting all clocks he chances upon from Taipei to Paris time after selling his own dual-time wristwatch to Shiang-chyi, who is on her way to Paris and whose solitary wanderings in the French city we also follow.
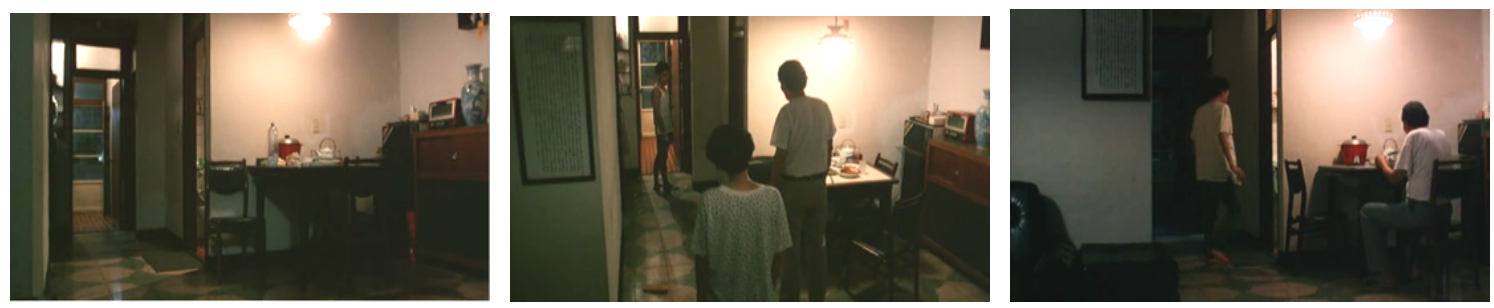

Rebels of the Neon God 

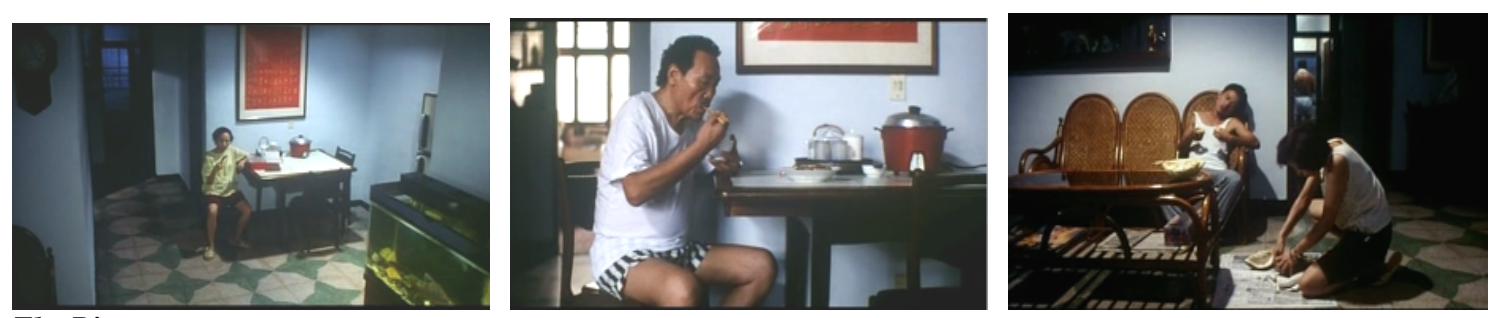

\section{The River}

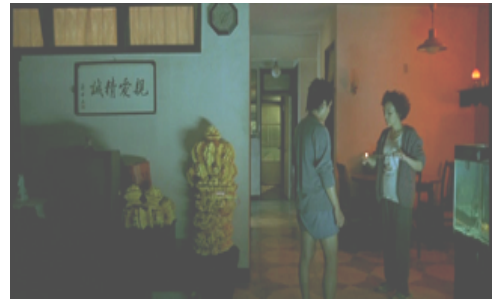

What Time Is It There?

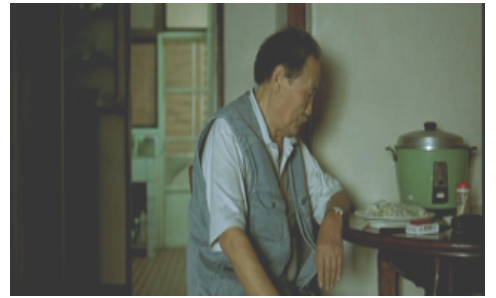

Same settings. Same family?

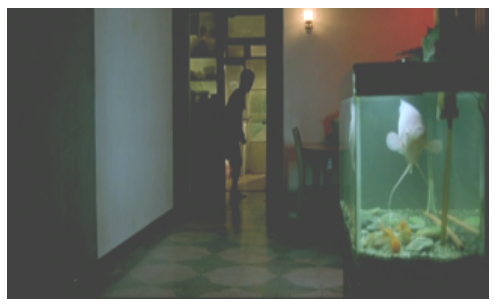

Tsai's first three works are also interlinked, albeit in less explicit fashion. In Rebels of the Neon God, Hsiao-kang starts tailing Ah Tze (Chen Chao-jung). The film leaves unexplained whether this tailing is due to envy of Ah Tze's affair with a beautiful young girl, Ah Kuei (Wang Yu-wen) or a repressed homosexual desire towards Ah Tze himself. But it is telling, as Lim notes, that Hsiao-kang's 'incessant gaze on Ah Tze in Rebels is extended in Vive l'amour, in which Chen plays Ah Rong' (Lim 2006: 138). In Vive l'amour, as previously mentioned, Hsiao-kang and Ah Rong accidentally meet in an unoccupied apartment as they steal keys from Mei-mei, the estate agent. Throughout the film, Ah Rong and Mei-mei have occasional sexual encounters while Hsiao-kang finds himself attracted to Ah Rong, as we see him, for example, masturbating under the bed where the couple is having sex, and later planting a kiss on Ah Rong as he sleeps. This linkage, as Lim goes on to note, comes to a head in The River in which Chen now plays the character to whom Hsiao-kang's father directs his gaze: they cruise in a decrepit shopping arcade and then go to a gay sauna. Later, in three successive shots, we see Chen 
and Hsiao-kang unknowingly close to each other: at the sauna's entrance, outside a convenience shop and walking across a bridge. This accidental proximity between both characters may be puzzling for the viewer unacquainted with Tsai's previous films, as it proves inconsequential to the narrative. But it takes on an added significance for those familiar with the history of these characters.

Yet, although elements of previous films are revisited and amplified in later ones in Tsai's oeuvre, this is not always openly articulated as such, leaving room for speculation. In 'the family trilogy', for example, the use of nearly identical settings and cast would seem to attest that this is the same family. Yet there is no unequivocal link between these films. This is evidenced, first, by the fact that this 'trilogy' is interspersed by two films (Vive l'amour and The Hole) and, second, by the incoherent behaviour of these characters from film to film. Take, for example, the demonstrations of grief of Hsiao-kang's mother when mourning the death of her husband throughout What Time Is It There?, which connotes a strong affection between the two. In The River the couple barely exchange a word throughout the film, being engaged in extra-marital affairs. To complicate things further, neither the mother nor the father is named in these films, which denies the definite confirmation these are the same characters (only Hsiao-kang preserves his name but this is the case in all Tsai films). In another variation, the roles played by Chen Chao-jung in Rebels of the Neon God, Vive l'amour and The River are certainly not identical, attested by his different names in each film. But it is obvious that Tsai plays on this actor-character merging for auteurist purposes.

These different examples of textual dialogue in Tsai's work, derived from the use of the same cast, are thus endowed with a sense of playful ambiguity, as they in part 
resist an indisputable linkage. This however does not apply to another trio of films in Tsai's oeuvre, namely What Time Is It There?, The Skywalk Is Gone and The Wayward Cloud. In The Skywalk Is Gone, as mentioned earlier, Shiang-chyi searches for the overpass in which she first met Hsiao-kang in What Time Is It There?. In The Wayward Cloud, both characters are finally reunited as they run into each other in a deserted playground: she asks him whether he still sells watches, a question which unmistakably bridges these three films. Moreover, The Skywalk Is Gone introduces fictional elements that are furthered in The Wayward Cloud, such as the severe drought besetting Taipei, which is hinted at in the short film as we see Shiang-chyi being told in a restaurant there is no coffee due to water rationing. Likewise, The Skywalk Is Gone's ending finds Hsiaokang auditioning for a porn film; in The Wayward Cloud he is a porn actor.

However, these three films were not released consecutively, being interspersed by Goodbye Dragon Inn, released between The Skywalk Is Gone and The Wayward Cloud. Featuring the same couple, Goodbye Dragon Inn, a film set in a decadent movie house in which Shiang-chyi works as a ticket vendor and Hsiao-kang as a film projector, could be mistaken as presenting the same characters yet again. Yet Shiang-chyi's character now has a physical disability - she wears a leg brace - which differentiates her from the others. This duplicity is similarly identified in I Don't Want to Sleep Alone, which presents the same couple yet again. But here not only is there no link with Tsai's previous films but Lee also plays two roles: a comatose man looked after by Shiang-chyi and another recovering from physical injuries and looked after by Rawang, a Malay builder. The trilogies or sequels in Tsai's oeuvre are therefore intermingled with other films, which by featuring the same cast in similar roles confounds the spectator. This is further 
complicated by these characters' lack of psychological depth and chronical laconism, which, as a result, enhance the sheer physical characteristics of actors rather than representational performance.

But even when Tsai's narratives do not perfectly connect with one another they mirror each other by revolving around recurrent themes. This is most readily identified in the domestic situations and bodily faculties unfailingly on display in his films, as will be analysed in detail in the next chapters. One could also cite the catastrophic and often absurdist backdrop against which stories unfold in his work, as observed, for example, in The Hole, The Wayward Cloud and I Don't Want to Sleep Alone. In The Hole Taipei is crippled by interminable rain and an epidemic virus that reduces its inhabitants to cockroach-like behaviour. In The Wayward Cloud, as mentioned above, Taipei faces a severe drought, prompting the authorities to encourage watermelons as an alternative to water. As for I Don't Want to Sleep Alone, it depicts Kuala Lumpur as beset by a smoky haze carried to the city by winds from Sumatra, as discussed in the previous chapter, forcing the public to use gas masks. These calamities are further depicted through similar narrative strategies, which reinforce their parallelisms. In none of these films, for example, are these incidents portrayed on a large scale but, rather, we follow their consequences to the characters' private lives: domestic entrapment in The Hole; excessive consumption of watermelons in The Wayward Cloud; and use of gas masks in I Don't Want to Sleep Alone. Likewise, in these three films we are updated on these catastrophes, alongside the characters, through television and radio broadcasts.

Tsai's auteur signature is also evidenced by shots that arbitrarily cite previous films through compositional resemblance. In What Time Is It There?, for example, Hsiao- 
kang is shown in a movie house drying his hands in a long corridor. An identical visual composition is found in Goodbye Dragon Inn, which is entirely set in this same movie house. Another example: in Vive l'amour Hsiao-kang is seen licking a watermelon as though kissing someone; in The Wayward Cloud, it is Shiang-chyi who performs this gesture. Another example: The River's opening finds Hsiao-kang and Shiang-chyi bumping into each other on the outside escalators of a department store. In The Skywalk Is Gone we see these same escalators, in a similar framing, as Shiang-chyi searches for Hsiao-kang in Taipei.
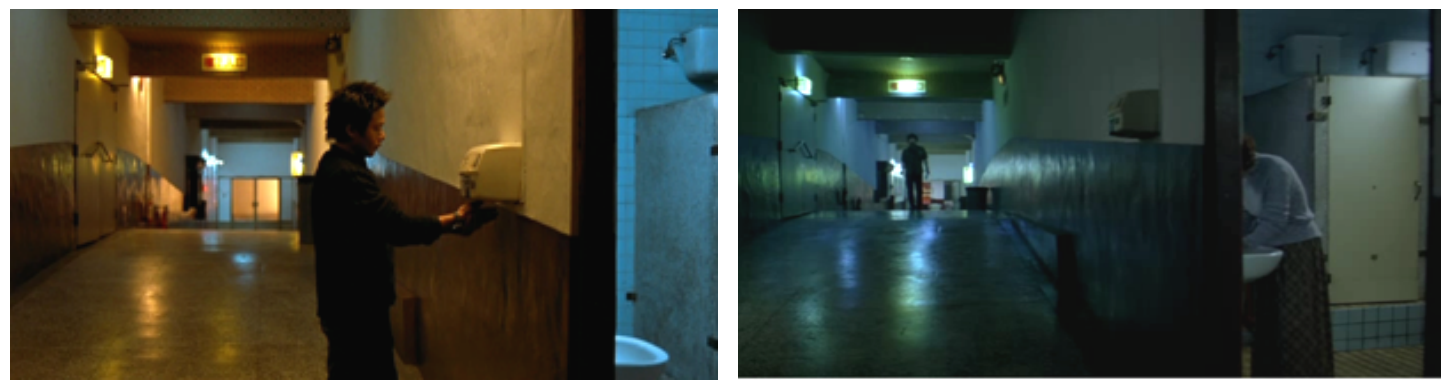

Same settings and identical visual compositions in What Time Is It There? and Goodbye Dragon Inn
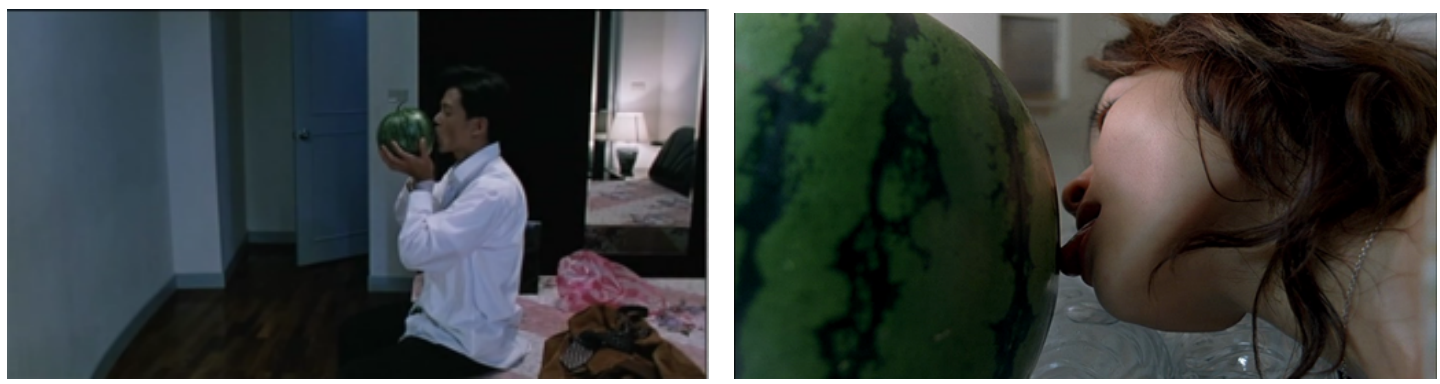

Juicy watermelons: Hsiao-kang in Vive l'amour and Shiang-chyi in The Wayward Cloud 

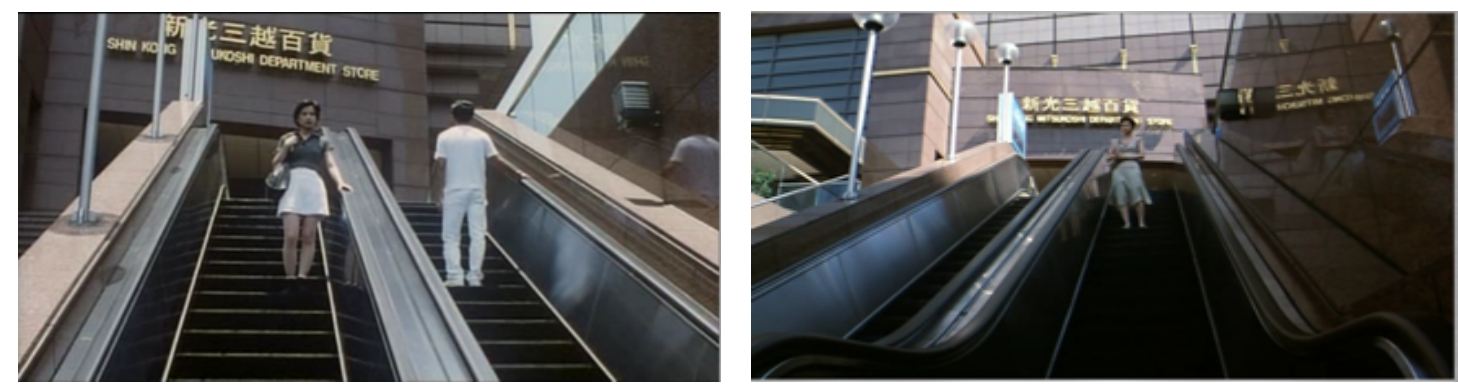

Shiang-chyi bumps into Hsiao-kang in The River... and searches for him in The Skywalk is Gone

This citational process is also identified in the replaying of arbitrary situations. For instance: in Goodbye Dragon Inn Hsiao-kang places his hand on a future-reading machine, which evokes Ah-Tze's identical gesture in Rebels of the Neon God. In other occasions, these citations are even more obvious as we see the same actor performing identical activities in different films. When Hsiao-kang's mother masturbates with a cushion tucked between her legs in What Time Is It There?, for example, she is replaying the same gesture she is shown doing in The River. An even more germane example is found in Yang Kuei-mei's single appearance in Goodbye Dragon Inn. As she watches the film in the empty movie house cracking seeds in her mouth, we cannot but be reminded of the scene in Vive l'amour in which Mei-mei, played by the same actress, is shown cracking seeds while waiting for a client in a vacant house. In this respect several situations in which Yang is depicted in Vive l'amour are also echoed in The Hole: in both films we see her moisturising her face, having a bath, urinating, eating. 

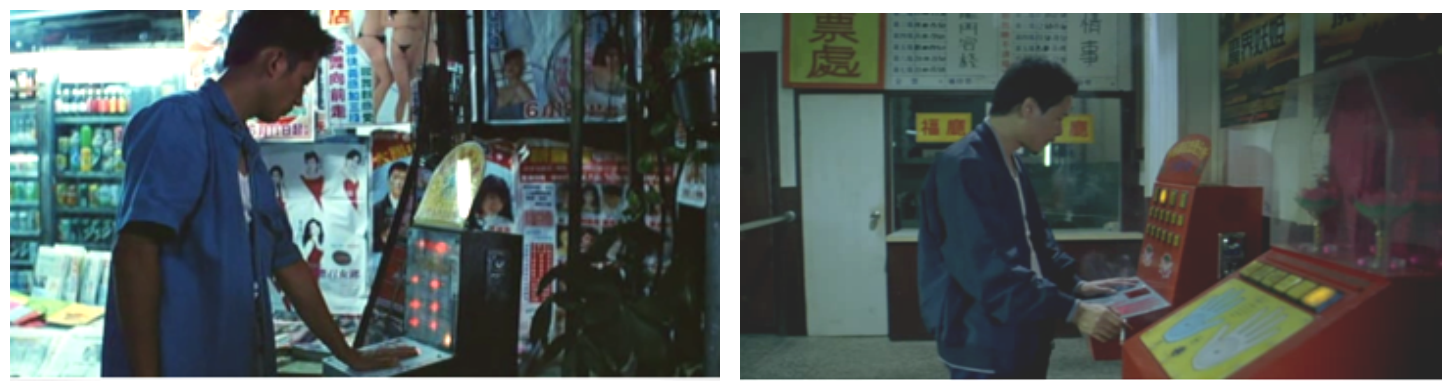

Reading the Future: Ah Tze in Rebels of the Neon God and Hsiao-kang in Goodbye Dragon Inn
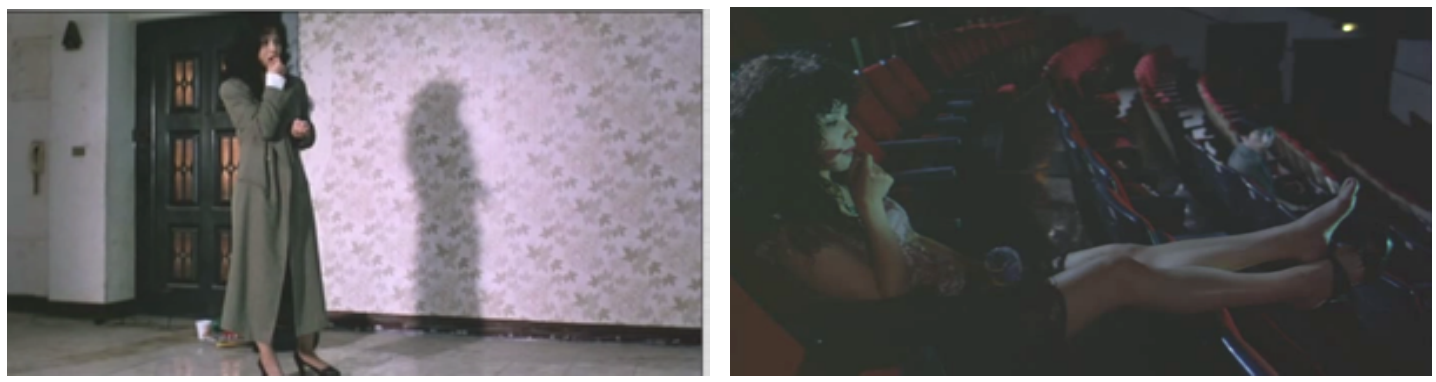

Yang Kuei-mei cracking seeds in Vive l'amour... and in Goodbye Dragon Inn
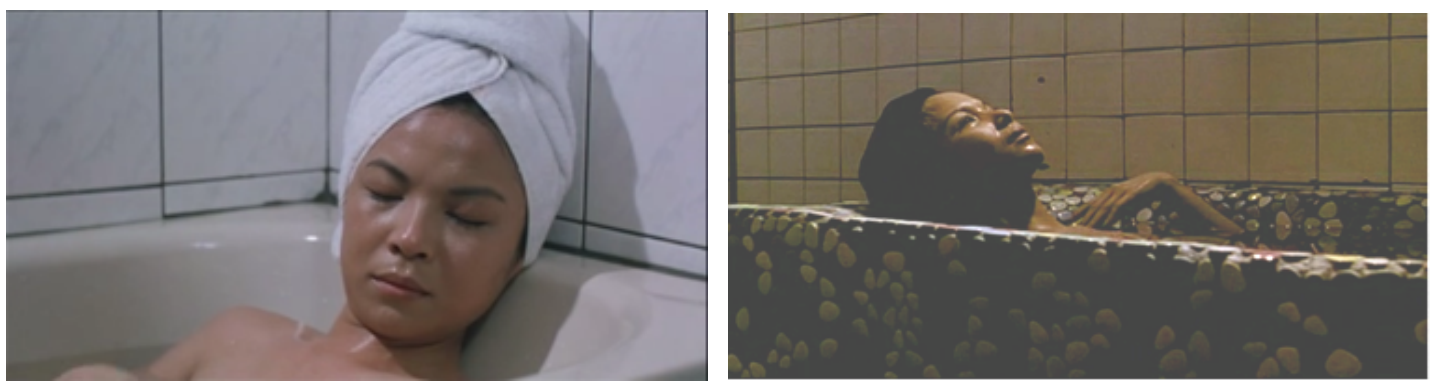

Yang Kuei-mei having a bath in Vive l'amour... and in The Hole

As these examples thus attest, Tsai's oeuvre is freighted with visual and aural cues which, replayed on different films, playfully invite the spectator to engage with his entire body of work as if in a hide-and-seek game. This highly self-referential style, typical of an auteurist approach, is incarnated by Tsai himself in Goodbye Dragon Inn in which he makes a Hitchcockian cameo appearance sitting beside Taiwanese film critic Lee You-hsin, both with their back to the screen. Not to mention that from his third film onwards, Tsai's signature is indeed literally on display, in handwritten form, in the credits 
of his films, a gesture which, as Lim notes, seems to respond directly to Alexandre Astruc's call for a 'caméra-stylo' (Lim 2007: 237). And this urge to expose his own authorial voice is further identified in the style of Tsai's work, also characterised by a remarkable formal uniformity, as we will now see. 


\section{Chapter 7}

\section{Sensory Everyday}

The self-referential narratives of Tsai's oeuvre are matched, on a formal level, by an equally reflexive style. In fact, his is an ultra-reflexive cinema, which, anchored in the hyperbolic application of traditional realist devices such as depth of field and the long take, recycles an everyday tradition in film. In this chapter, I will investigate Tsai's antiillusionist thrust in the light of Brechtian precepts, cinematic realism and Jean-Louis Baudry's apparatus theory, moving on to analyse how cinematic reflexivity is translated in his cinema into a sensory realism cathexed on the pure physical presence of domestic spaces and objects. I will then proceed to examine its distinctive troping of the everyday as opening up the doors of domestic privacy through an unwavering focus on the physiology of the human body.

\section{Domestic Spaces}

The self-reflexive style of Tsai's cinema can be immediately likened to his self-confessed admiration for the counter-cinema of the European New Waves of the 1960s and 1970s, cinemas largely inspired by Bertolt Brecht's theories of distanciation. More specifically, Tsai himself has a Brechtian theatrical background, having even choreographed one of Brecht's plays (see Rehm et al 1996: 93-4). He openly ascribes his cinematic aesthetics to 
the German dramatist's ideas:

I want the audience to be constantly reminded that they are watching a film. They are watching a film in the theater. There's a distance. They should have a viewing attitude. There's no need to be absorbed in the viewing. They can choose to be absorbed and also to pull back...It's like the writer I like very much, Brecht. When you are sitting in the theater, you should be aware of that. You should be aware of the fact that you are watching a work of art. So you wouldn't be completely absorbed. That's my ideal (Tsai apud Hui 2009).

As is widely known, Brecht defended in theatre the use of particular techniques as a means to disrupt the illusionistic world and render it unfamiliar, thereby calling attention to its material conditions of production and raising the audience's critical awareness. This he called Verfremdungseffekt, a neologism which established a variant to the concept of Entfremdung 'in the Marxist sense of a worker's alienation from the product of his/her labour' (Nagib 2011: 209) and has been variously translated into English as 'estrangement' 'distanciation' and 'alienation effect' (A-effect). He wrote: 'The A-effect consists in turning the object of which one is to be made aware, to which one's attention is to be drawn, from something ordinary, familiar, immediately accessible, into something peculiar, striking and unexpected' (Brecht 1964: 143). Hence Brecht defended that the lighting equipment, for example, should be made visible during the play so as to break fictional illusionism. In line with these precepts, Tsai's fictional universe is constantly disrupted through devices that call attention to themselves. 
Consider for example Tsai's consistent framing choices. In his films, solitary characters are constantly delimited by windows, doors, mirrors and glasses, a framewithin-frame device which calls to mind the handling of spaces as effected by Douglas Sirk's 1950s glossy melodramas and, even more so, Fassbinder's Fear Eats the Soul (Angst essen Seele auf, 1974), itself an homage to Sirk, and a film for which Tsai publicly expresses admiration. Sirk's extensive use of frame-within-frames was re-evaluated in the 1970s as being in compliance with Brechtian techniques of distanciation. This was put forward by Sirk himself and later theorised by Paul Willemen, who argued that this device served to underline the entrapment of characters in the diegesis and, on a formal level, reflexively mirror the cropping impulse intrinsic to film (see Halliday 1997; Willemen 1994: ch. 3). In 1974, Fassbinder, himself indebted to Brecht's theories, paid homage to Sirk with Fear Eats the Soul, hyperbolising this device when shooting domestic spaces. The recurrence of this strategy in Tsai's work thus immediately connects it to a Brechtian-inflected cinematic tradition, a device epitomised in the number of shots of an actual cinema screen in Goodbye Dragon Inn, which openly exposes the cinematographic image's cropped nature.

As a matter of fact, the material conditions of film production and reception are constantly in evidence in the intradiegetic universe of Tsai's metafilms. The River, for example, begins with the shooting of a film for which Hsiao-kang stunts in a polluted river. Not only we see a large crew, film equipments and follow the shooting of scenes, but the film director on show is real, Hong Kong-based Ann Hui, whose extensive filmmaking career was to later have a film - Ordinary Heroes (Qian yan wan yu, 1999) starring Lee Kang-sheng himself. The Wayward Cloud, in turn, depicts the shooting of a 
porn film, similarly exposing the material aspects of the filmmaking process. Yet, no doubt, it is Goodbye Dragon Inn, which, to this date, provides the most self-reflexive sample of Tsai's oeuvre ${ }^{7}$ : entirely set in a movie house, not only does it highlight the waning of a specific mode of film consumption, but also focuses on film projection through Hsiao-kang, who is the cinema's projectionist. In one particular scene, he is shown next to the filmstrips of King Hu's swordplay Dragon Gate Inn (Longmen kezhan, 1967) looping through the projector, which exposes yet another crucial aspect of the filmmaking process: the illusion of movement which the projector helps create as 24 still frames per second are continuously reproduced. And here one is reminded of Jean LouisBaudry, who argued that this concealed stillness - this 'difference negated' - is but one aspect of the homogeneous spectator manufactured by the "technical apparatus which he had forgotten' (Baudry 1974: 43). In Tsai, by contrast, the viewer is constantly reminded of such apparatus, notably through its highly self-evident and hyperbolic form, embedded in overstretched static shots.

Yet, seen in chronological order, Tsai's oeuvre has not always displayed the same formal rigour and unrestrained adherence to long takes. Rebels of the Neon God, for example, complies to a certain extent to analytical editing, with long takes and static camerawork being only occasionally employed. In his following features the stationary sequence shot is certainly more amply embraced but travellings, pans and reframings are also not infrequent in Vive l'amour, The River and The Hole. In fact, What Time Is It There? is the first Tsai film entirely composed of fixed long takes and devoid of decoupage within scenes. From then on, Tsai would consistently collaborate with the

\footnotetext{
${ }^{7}$ Though the synopsis of Tsai's latest film (Face) suggests this to be an equally ultra-reflexive work: Hsiao-kang plays the role of a film director who travels to the Louvre, Paris, to shoot a film about the myth of Salome.
} 
same editor, Chen Sheng-chang, although his cinematographer, Liao Pen-jung has always remained the same, with the exception of What Time Is It There?, photographed by Benôit Delhomme. Of course, some camera movements or cuts within scenes still appear in his oeuvre thereafter but, as a general rule, its aesthetic foundations become tied to the hyperbolisation of spatiotemporal integrity through extended stationary shots focused on domestic settings.

Doors, walls, windows and mirrors are objects which, as well as enclosing characters, fragment, expand and open up space into multiple planes in Tsai's cinema, offering simultaneous foci of attention within and across the frame. Rather than directing the spectator's attention to a particular point in the image, Liao's camera often chooses to multiply its portions of interest, a telling example being the shots of Shiang-chyi loitering in front of mirrored doors in The Skywalk Is Gone, which produces a disorienting effect due to the conflicting sections of its parts, as the pictures below illustrate.
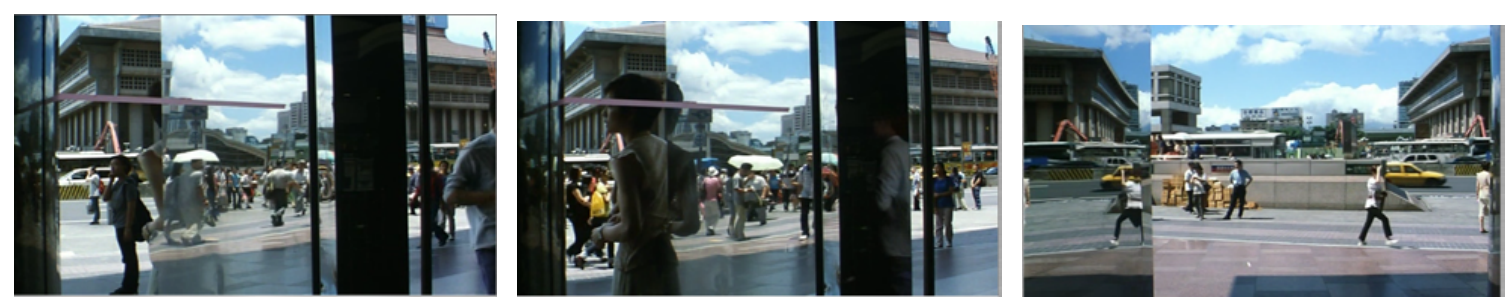

Multiple points of interest in The Skywalk is Gone

More recurrently, this expansion of space is attained through extreme deep focus, which underlines recessional planes within the image and, concomitantly, the spatial fullness and sectionality of domestic spaces. The camera is often strategically placed with a view to capturing simultaneous events occurring in different rooms in the same shot. 
Take for instance the scene in The River in which Hsiao-kang sleeps in his bed while his father speaks to a plumber at the room's window outside the house. Though the blinds are shut, we hear the characters talk outside and make out their silhouettes, and the two spaces - in and outdoors - compete for the viewer's attention. Consider also the scene, later on, in which Hsiao-kang and his parents, each engaged in a different activity, are shown in different planes across and within the frame: Hsiao-kang's mother cuts up a fruit on the floor in the foreground, Hsiao-kang sits contorting himself with pain in a chair in the middle ground and his father is seen further in the background through the kitchen door.
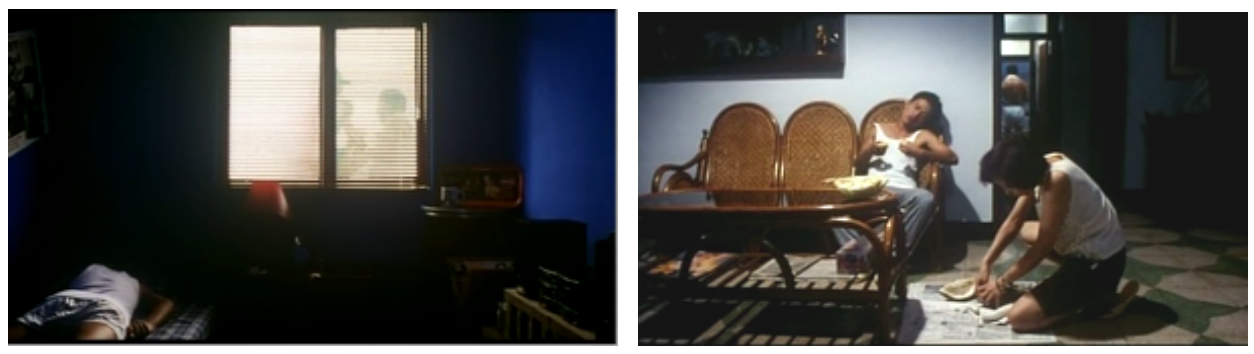

Sectional spaces in The River

In What Time Is It There? this same domestic setting is also highlighted in its sectionality. A telling example is the scene in which Hsiao-kang sits in front of a bonfire in the balcony at the back of the house. As we see him at the vanishing point, our attention is suddenly directed to his mother, whom we can also see cooking through the kitchen's window on the frame's right-hand side. Both characters carry on doing their activities without acknowledging each other's proximity. Another case in point: the scene in The Wayward Cloud in which Hsiao-kang visits Shiang-chyi in her house. The camera is placed between the living room and the kitchen, highlighting the wall, right at the 
centre of the shot, separating both spaces. This evokes a split-screen effect as we see Shiang-chyi in the kitchen pouring watermelon juice on the left and Hsiao-kang in the living room, on the right, attempting to open her suitcase.
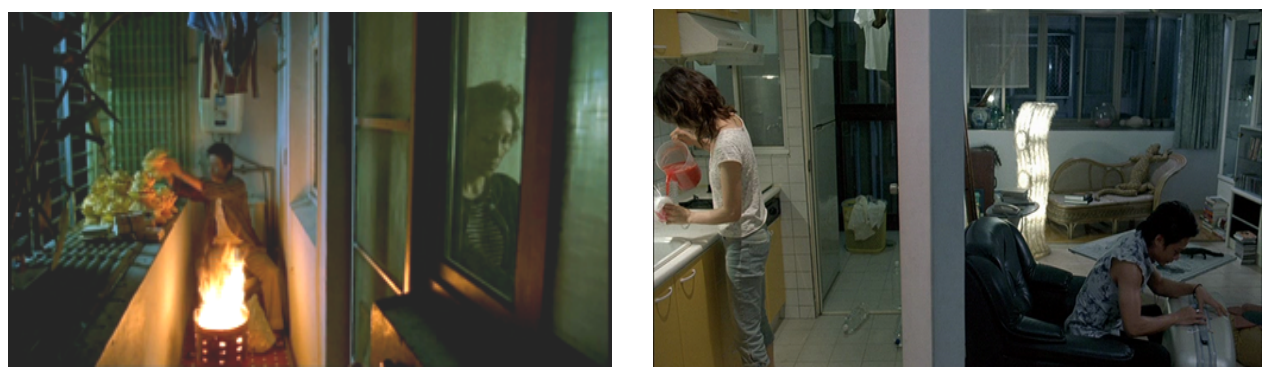

Split houses in What Time Is It There? and The Wayward Cloud

In its turn, I Don't Want to Sleep Alone shows a horizontal splitting in the scene in which Shiang-chyi's house is framed from outside and we see both storeys of the house through the window: on the ground floor, Shiang-chyi's boss (Pearlly Chua) applies moisturiser on herself while on the floor above, Shiang-chyi dries her hair with a towel. A few shots later, we see this same house filmed from within. Three sections are highlighted in extreme deep focus: on the right we see a room, its door open, where Shiang-chyi stands; on the left we see a corridor which leads onto a hall and a staircase; and further in the background we can discern the house's front door past the staircase. As the son of Shiang-chyi's boss walks into the house with his wife and son, showing the house around to possible buyers, the viewer's attention is diffused across the image as multiple characters walk into and out of rooms, go up and down the stairs and out and then back into the house through the main door. 

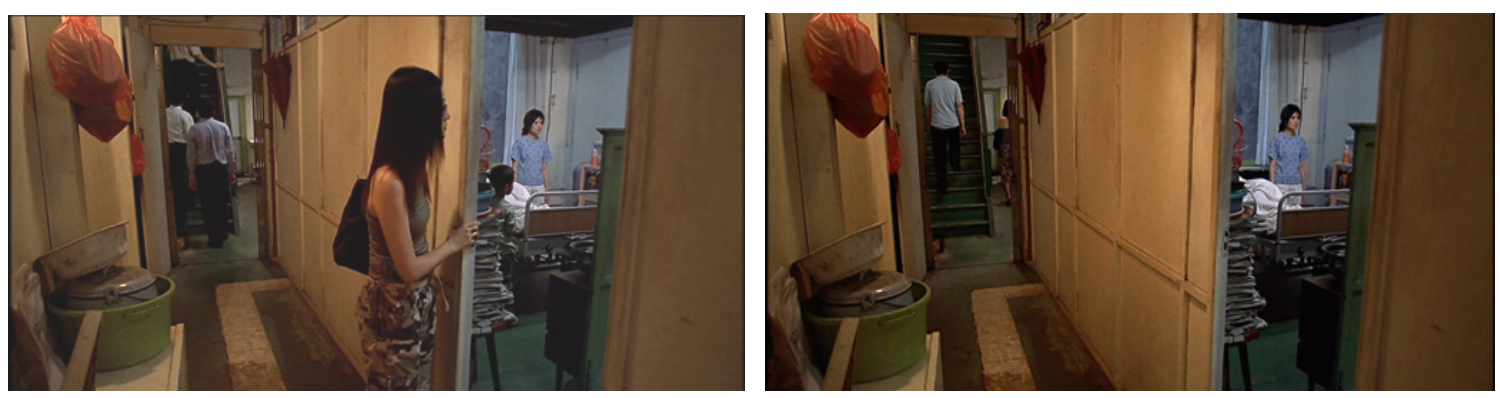

Expanding and fracturing space in I Don't Want to Sleep Alone

These examples of sectional spaces, of course, serve allegorical purposes. In The River, What Time Is It There? and I Don't Want to Sleep Alone, as in all Tsai films, these characters are portrayed in their utter incommunicability and isolation. These doors and walls, and the mise-en-scène strategies we encounter here, effectively underline these themes. In like manner, The Wayward Cloud depicts the struggle of Hsiao-kang and Shiang-chyi as they repeatedly attempt, without success, to engage in sexual intercourse. The wall literally secluding both characters suggests their inability to attain a closer, sexual intimacy. These films' conflation of simultaneous events, furthermore, resonates with Bazin's defence of the long take-deep focus as famously expressed in his analyses of Orson Welles's Citizen Kane (1942) and William Wyler's The Best Year of Our Lives (1946), films which preserved the spatial and temporal unity of phenomenological reality. According to Bazin, they prompted spectators to actively scan the image as opposed to being mere recipients of views dictated by the film: 'Obliged to exercise his liberty and his intelligence, the spectator perceives the ontological ambivalence of reality directly, in the very structure of its appearances' (Bazin 1978: 80). The critic further praised their creatively orchestrated mise-en-scène, ascribing it to their theatrical background. Bazin's remarks are, up to a point, applicable to Tsai's work, whose mise-en- 
scène strategies also preserve 'the ontological ambivalence of reality' and can be similarly attributed to the director's solid experience as a theatre director (see Bao 2007: 130; Lim 2006: 133). As the director himself puts it, 'when I started to make films I found myself pretty much influenced by the stage. It's the long [sic] concept of space and time, and the stationary camera' (Kraicer 2000: 584). However, Tsai's cinema is eager to stretch the possibilities of expansion and fragmentation of space within the shot, as well as its temporal elongation, to a more hyperbolic extent than championed by Bazin. Chris Wood, for example, notes that the defamiliarising and comic effects produced by such exaggeration depart from a Bazinian realism, which in his view aimed at 'an accurate picture of the world' (Wood 2007: 106). Though I think the realism championed by Bazin is in fact more complex ${ }^{8}$, the fact remains that Tsai extrapolates the representational imperatives animating Bazin's take on realist cinema, which, as discussed in the Introduction, is very much connected to dramaturgic efficiency. Here, by contrast, representation is obliterated through the exaggeration of these traditional realist devices, what Chris Berry sees as a kind of realism performed 'so excessively as to draw attention to itself, making it a limit-case realism' (Berry 2005: 89).

This is best exemplified by the shot in Goodbye Dragon Inn in which Shiang-chyi limps towards a door situated at the vanishing point of the image. She opens up the door and walks into another room, which increases the depth of the image as we see another stretch of space which the door previously concealed. To the viewer's surprise, she opens yet another door at the far end of the room in which she now finds herself, deepening the

\footnotetext{
${ }^{8}$ I also cannot follow Wood when he connects Bazin's defence of the long take and deep focus with neorealist films. Bazin praised neorealist films mostly due to their extensive location shooting, improvisational modes of production and amateur acting. Indeed, the long take-deep focus appear mainly in Bazin's analyses of Citizen Kane, The Best Years of Our Lives and, to a lesser extent, Renoir's films.
} 
image's vanishing point yet further - a stretching of space so excessive, which, as well as producing a comic effect (as noted by Wood 2007: 108), seems to disclose an urge to capture the materiality of interior spaces. Such yearning for spatial depth can also be found in the V-shaped corridors displayed in The Wayward Cloud. Rather than presenting a single vanishing point, these shots exhibit a two-point perspectival principle, doubling the vanishing points of the image into opposite directions and, in so doing, capturing ‘more' space.
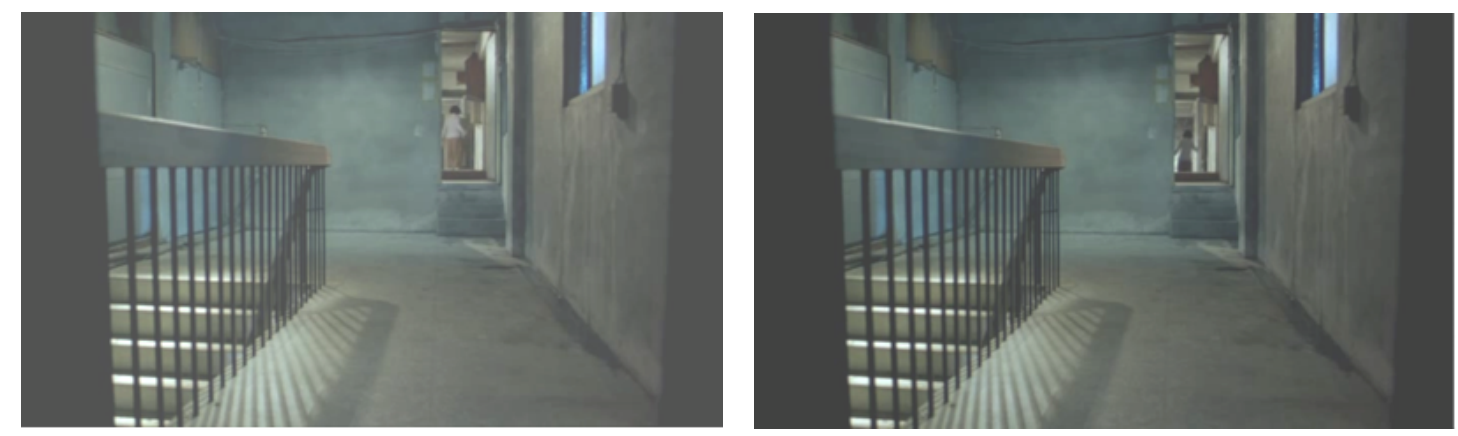

Stretching space in Goodbye Dragon Inn
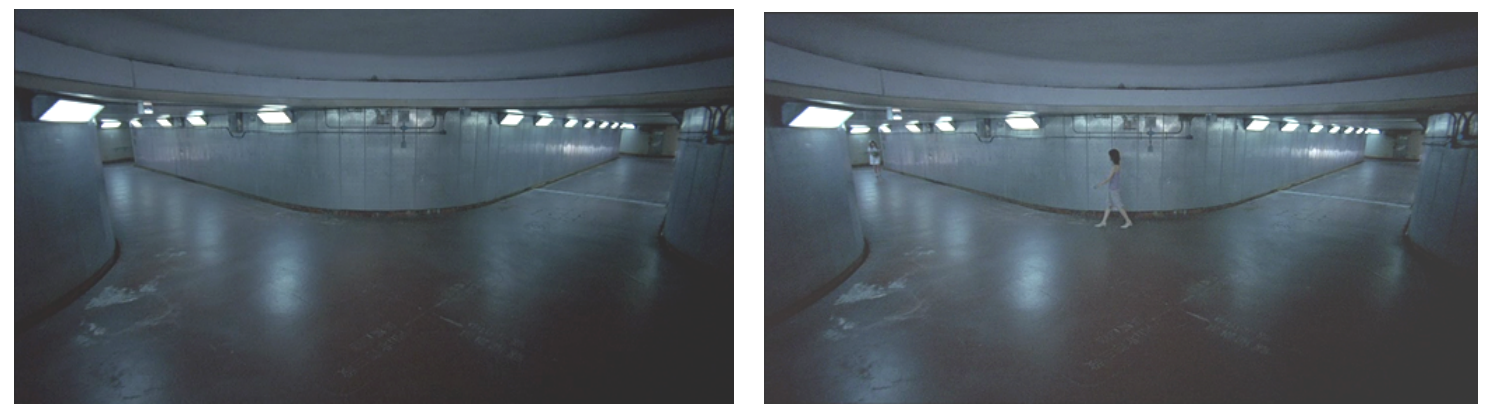

Doubling spatial depth in The Wayward Cloud

As these examples attest, Tsai's films pay an excessive allegiance to linear perspective: theirs are images whose vanishing points are monstrously visible, as fully demonstrated by the highly symmetrical shots of interminable corridors which unfailingly 
appear in his films (see pictures below). Framed centrally and through wide-angle lenses, the parallel lines of these settings seem to converge at one clearly discernable point in the image, creating an explicit, indeed vertiginous, sense of depth by bringing the image's concealed perspective to the fore. Often empty or else inhabited by solitary characters, these endless corridors, framed in protracted static shots, convey an overwhelming, superabundant sense of spatial fullness.

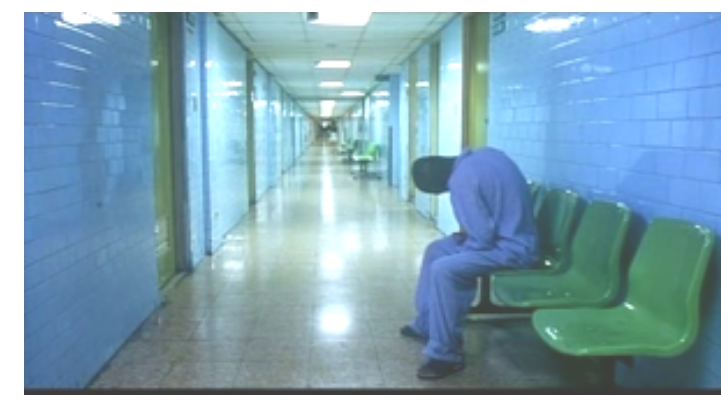

The River

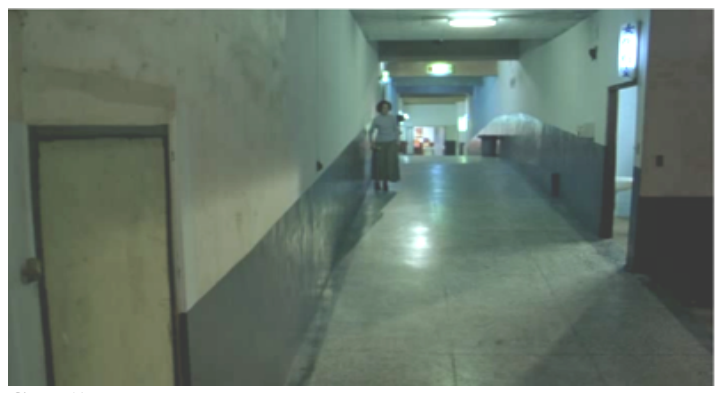

Goodbye Dragon Inn

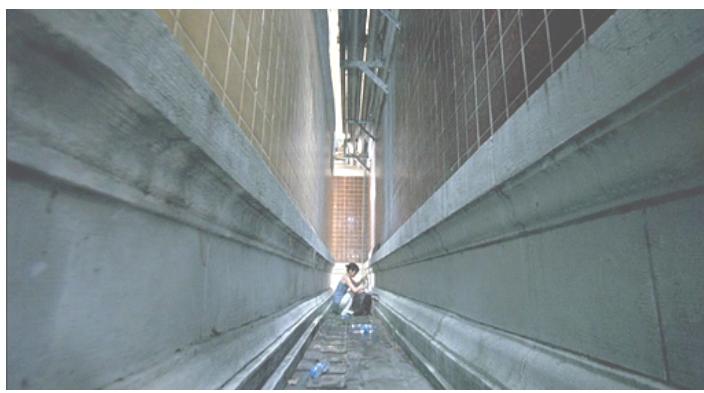

The Wayward Cloud

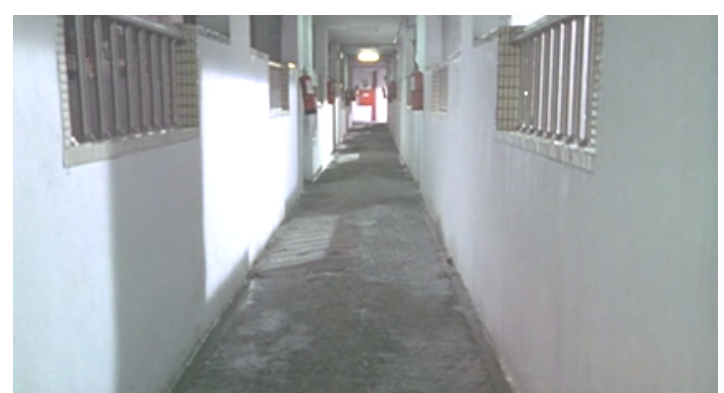

The Hole

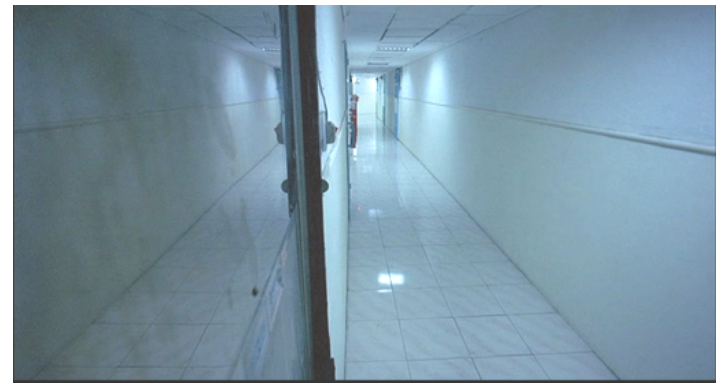

The Wayward Cloud

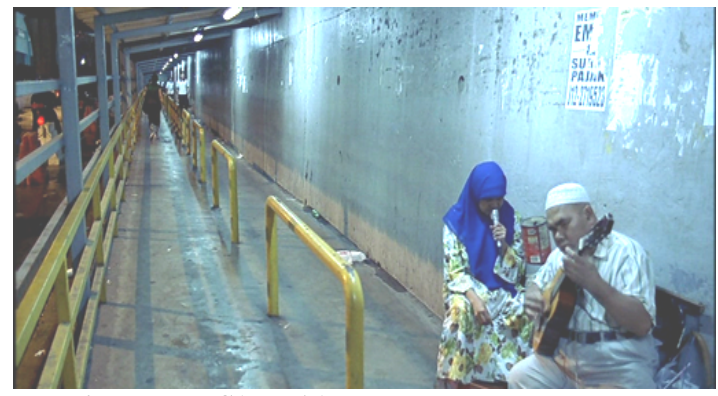

I Don't Want to Sleep Alone

Vertiginous Perspectives

Now this exposure of linear perspective, which the camera lens automatically 
reproduces, is worth examining in the light of the perspective system, which, first devised by Renaissance painters and perpetuated by film, was viewed by the apparatus theory of the 1970s as reinforcing an 'impression of reality' in tune with bourgeois ideology - a notion famously theorised by Baudry. Interestingly, the laying bare of this device in Tsai's cinema seems to respond to Baudry's tirade against cinematic illusionism, itself resonant with Brechtian notions of distanciation. In his seminal essay 'The Ideological Effects of the Basic Cinematographic Apparatus', Baudry argues that the linear perspective enshrined in the camera reinforces the bourgeois notion of a unitary, free and transcendental subject because it optically secures a central spectatorial position. Speaking of a Renaissance monocular perspective, he writes:

Based on the principle of a fixed point by reference to which the visualized objects are organized, it specifies in return the position of the 'subject', the very spot it must necessarily occupy...It lays out the space of an ideal vision and in this way assures the necessity of a transcendence - metaphorically (by the unknown to which it appeals - here we must recall the structural place occupied by the vanishing point) and metonymically (by the displacement that it seems to carry out: a subject is both 'in place of' and 'a part of the whole') (Baudry 1974: 41).

Baudry goes on to argue that classical editing devices are predicated on the same principle, namely: the mobilisation of a transcendental spectatorial position. Because conventional editing techniques are predicated on a multiplicity of changing viewpoints, 
it produces a fundamentally disembodied gaze:

[I]f the eye which moves is no longer fettered by a body, by the laws of matter and time, if there are no more assignable limits to its displacement - conditions fulfilled by the possibilities of shooting and of film - the world will not only be constituted by this eye but for it. The movability of the camera seems to fulfil the most favourable conditions for the manifestation of the transcendental subject (Baudry 1974: 43).

What is thus startling here is the pertinence of these remarks with reference to the formal strategies animating Tsai's cinema, which seems intent on denying the viewer this very transcendental position which, in Baudry's view, the classical text produces. Through hyperbolisation - in the case of perspective, camera fixity and temporal elongation - and refusal - as regards editing work - of techniques intrinsic to narrative film, Tsai's cinema programmatically reminds the viewer of its constructedness: it gives the apparatus its material, physical weight. The hyperbolic symmetry of its visual compositions stands out for its geometric, artificial, indeed pictorial quality. The unwavering stare of its fixed camera destabilises the representational dimension of the image, calling attention instead to the film medium, as well as the material density of the profilmic event. Unlike the cinema which Baudry dissects, in which the 'eye... is no longer fettered by a body', in Tsai the eye is obstinately fettered by a body, that of the actual camera. Here, sensory realism is produced through the materiality of the film medium, which, endowed with a stubborn, solid immobility, enhances the sheer physicality of minimalist, sometimes 
empty, interior spaces.

Indeed, the camera here demonstrates a certain indifference to human presence and onscreen action, meaning that it often remains firmly in place before or after characters have entered or left the screen, an obvious example being the scene in Goodbye Dragon Inn, mentioned in the Introduction, in which the camera continues rolling for nearly three minutes after Shiang-chyi leaves the frame. Elaborating on the everyday cinema of Yasujiro Ozu, Alain Bergala defines it as one in which 'the technique precedes the action, and never follows it' (Bergala 1990: 104), which, among other things, gives rise to Ozu's so-called 'empty spaces' or 'still lifes', that is, domestic spaces devoid of human presence through which one feels 'the absolute anteriority of the beingthereness of things, of their physical presence' (Bergala 1990: 107). Something similar happens in Tsai, in which the momentary lack of human presence gives objects and domestic spaces a heightened physicality. In his work, however, such autonomy of the camera over the onscreen action is far more extreme when compared to the short length of Ozu's shots, indeed more akin to an experimental film such as Chantal Akerman's Jeanne Dielman, 23 Quai du Commerce, 1080 Bruxelles (1975; henceforth Jeanne Dielman), yet another cinematic take on the everyday, as we follow the obsessive domestic routine of the protagonist Jeanne in minute detail. Here, extremely long static shots precede the onscreen entering of characters or else refuse to follow them as they leave the screen. Elaborating on the defamiliarising and sensory effects produced by this camerawork, Margulies notes how

the camera's poised stare placates the curiosity for human presence through what 
visibly becomes a hyperreality. Displaced onto sets and objects, the camera's extended gaze enhances the effect of defamiliarisation... [It] imposes a sense of gravity and physicality on both people and objects as they are anchored on screen. And as these images stimulate our awareness of the texture of domestic objects, it is as if we had gained an extrasensorial dimension (Margulies 1996: 70).

This is also what happens in Tsai, in whose films the architectural, minimalist, arrangement of spaces, as well as objects, appear in their perceptual literalness and factual existence, being therefore conveyed as sensory and phenomenological experience, that is, realism of the senses.
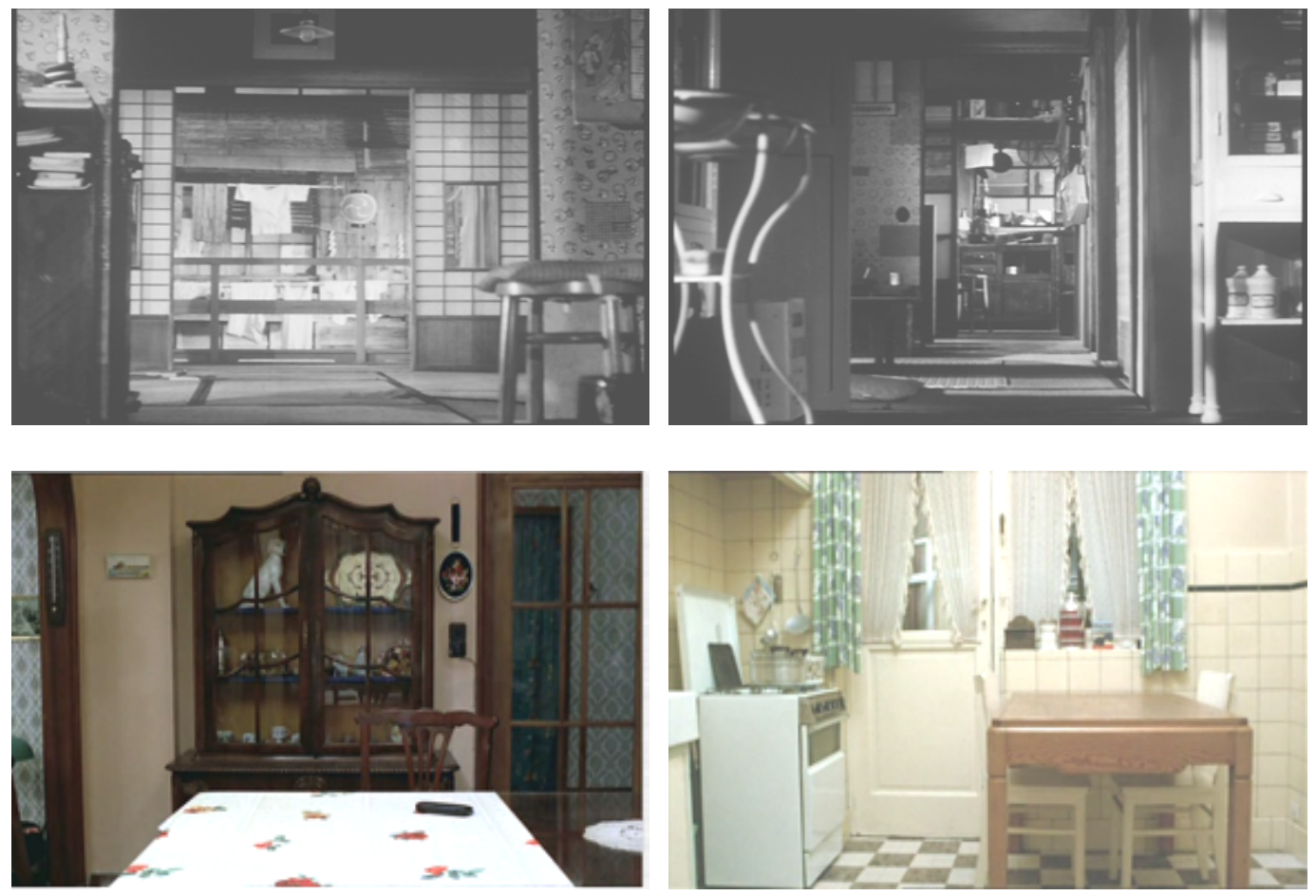

Empty domestic spaces in Ozu's Tokyo Story (Tôkyô Monogatari, 1953) and Jeanne Dielman 
This in fact is also the case when characters are onscreen, given that Tsai rarely uses close-ups, opting instead for long shots that naturally emphasise the materiality and design of settings, not to mention the self-evidence of his geometric visual compositions, as analysed above. As Cyril Neyrat notes in his review of I Don't Want to Sleep Alone, 'Tsai's sensuality...attaches itself to the cold materials of the contemporary world: the concrete of buildings and corridors, and above all the plastic of bottles' (Neyrat 2007). Unlike a filmmaker such as Reygadas, whose attention to materiality is distributed between rural and urban (but predominantly exterior) spaces, as analysed in Part I, Tsai's exclusive focus on urban materiality is not restricted to cityscapes but extends to interior spaces and objects as well, all emphasised by an imperturbably stationary camera that restores, inflates and expands their materiality.

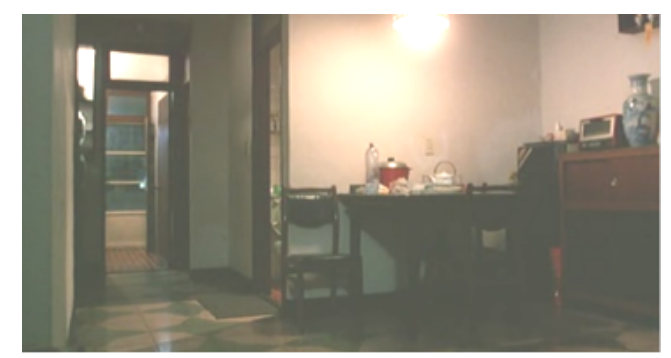

Rebels of the Neon God

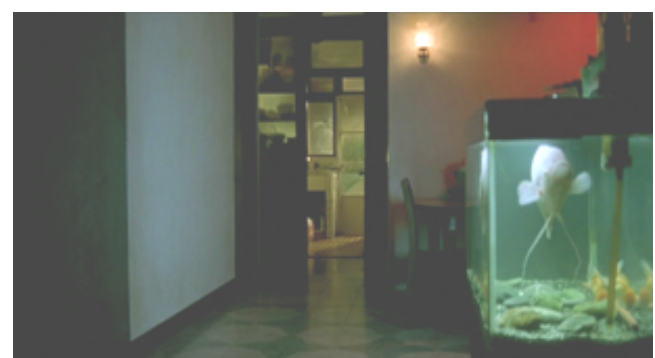

What Time Is It There?

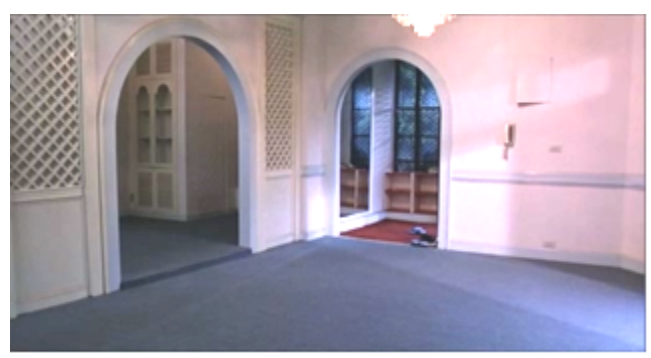

Vive l'amour

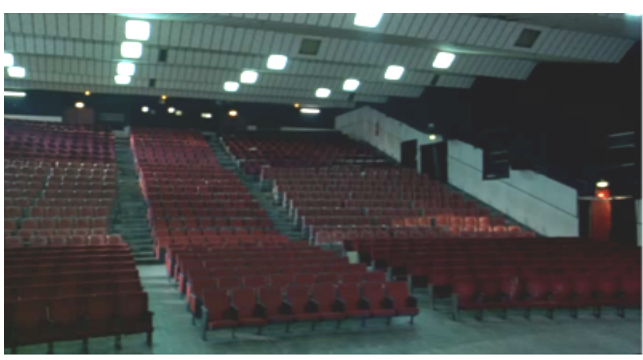

Goodbye Dragon Inn

\section{Empty spaces}

It is, furthermore, this scrupulous attention to domestic spaces and objects that 
connects Tsai's cinema to a cinematic tradition of the everyday, as exemplified by Jeanne Dielman and Ozu's cinema. The negotiation of everyday phenomena in his work is however far more complex and distinctive, compelling us now to examine this aspect more closely.

\section{A (Bath)room of One's Own}

Before I proceed with my analysis, it is useful to ask what is, after all, this slippery category we call everyday. French philosopher Maurice Blanchot set out to answer this question in 1962 in his essay 'La parole quotidienne', according to which the everyday is indeterminate, ambiguous and insignificant, in short, unrepresentable: 'Whatever its other aspects, the everyday has this essential trait: it allows no hold. It escapes. It belongs to insignificance, and the insignificant is without truth, without reality, without secret, but perhaps the site of all possible signification' (Blanchot 1987: 14). Yet, if the everyday cannot be circumscribed by the limits of representation, we have come nonetheless to associate certain discursive features with it. Whether in paintings, novels or films, attempts to lay claim to the quotidian are expressed through a focus on ordinary details in a quest to grasp the purely material riches of things and beings outside their functional status. As such, the everyday is firmly subscribed to the notion of an individual and private realm and, consequently, attached to tropes of domesticity. Speaking of the attention to domestic affairs and daily rituals on display in the novels of Honore de Balzac, Charles Dickens and George Eliot, Ruth Bernard Yeazell observes that their everyday impulse, harking back to the eighteenth-century Dutch paintings of Nicolas 
Maes and Johannes Vermeer, encompasses:

The representation of ordinary people and acts rather than heroic and mythical ones; the attention to everyday customs and habits, especially those that change with relative slowness over the centuries; the detailed rendering of material objects and settings, particularly the domestic interiors of the lower and middle classes (Yeazell 2008: xv).

One encounters in these paintings quotidian activities against domestic backdrops, as indicated, for example, by titles such as Maes's A Girl Sewing or his Young Girl Peeling Apples. In their turn, realist writers converted this pictorial attention to material detail into a descriptive rhetoric that scrutinised daily activities, décor, furniture, clothes, etc. And this was further explored by photography and, more significantly, film, which automatically captured the materiality of quotidian events and material settings in its minutest nuances. The Lumière brothers' fascination with household trivialities is now a commonplace in film history. We need only remember their famous Le repas de bébé (1895) in which we see Auguste Lumière and his wife feeding their baby. In narrative film, the everyday would also prove one of cinema's most fertile tropes, as canonised by the aforementioned cinema of Ozu, film movements such as Italian Neorealism, the new cinemas of the 1960s and 1970s, among many others. Speaking of this vocation to depict everydayness, Italian neorealist scriptwriter Cesare Zavattini would contend that "no other medium of expression has the cinema's original and innate capacity for showing things, that we believe worth showing, as they happen day by day - in what we might call 
their “dailiness", their longest and truest duration' (Zavattini 2004: 43).

As far as the work of Tsai is concerned, it partakes in a particular moment in Taiwan film production whose focus on a contemporary 'private I' (Lim 2006: 128), as mentioned earlier, followed on a cinematic inspection of the country's troubled colonial history. As Taiwan matured into a phase of economic prosperity and stability, filmmakers turned to everyday matters against the urban backdrop of contemporary Taipei, as epitomised, for instance, by Edward Yang's Yi Yi (A One and a Two 2000), a bittersweet portrayal of a middle-class family in the city. In fact, as Rey Chow argues, the everyday is a convention of contemporary Chinese cinema as a whole. She examines the 'manners in which the everyday emerges in a network of filmic elements' (Chow 2002: 641) in Wong Kar-wai's In the Mood for Love (Fa yeung nin wa, 2002) and Zhang Yimou's The Road Home (Wo de fu qin mu qin, 2000), each filling this fundamentally 'open, empty category' (2002: 639) with their own agendas.

And, indeed, insofar as the everyday can be viewed as 'the site of all possible signification', to cite Blanchot again, it easily lends itself to quite distinct projects. How is this trope negotiated in Tsai's oeuvre? Unlike Wong and Zhang, whose everyday aesthetics is meant to evoke the past, Tsai's everyday is coded as now in view of its documentary inflection and creative appropriation of real life occurrences, being further informed by its own, idiosyncratic set of aesthetic and thematic rules deriving from his cinema's auteurist imprint. On the one hand, his is an everyday that perpetuates a focus on customs and habits normally coded as quotidian and mundane, such as eating, cooking, cleaning, etc. On the other, the domestic activities focused on by his cinema impresses for their excessively private dimension, as observed in characters engaged in 
an array of intimate and physiological situations. Indeed, as I will now endeavour to demonstrate, Tsai's cinema steps into those domestic rooms where general cultural convention has it one should lock the door behind oneself upon entering, and where cinematic etiquette demands one not to cross such a door with a camera. It depicts situations in which, finding oneself alone in a room of one's own, one does things which only the delights of secrecy allow.

If Reygadas is interested in the purely material surface of bodies as enabled by extreme close-ups, as analysed in Chapter 2, Tsai foregrounds a body reduced to sheer physiology. Here, characters' bodily needs are on full, unrelenting display. As noted by many commentators, they eat, drink, urinate, defecate, copulate, vomit, burp, bathe, moisturise themselves, masturbate, etc. In most, if not all, Tsai films, a considerable portion of it will be devoted to the concatenation of these physiological activities. Rather than being subordinated to dramatic purposes, these intimate situations are often the focus of attention themselves and together comprise the bulk of episodic narrative structures. That is, these are films that take their time to show these activities, rendering them with a precision of aural and visual details that far extrapolate the demands of narrative economy. Tsai himself explains his concern with filming private situations in their most concrete dimensions:

[I]f I've filmed scenes with people pissing...that's because for me that's a very important part of real life. Only it's true that these are things that traditionally don't get shown in films because they are considered to be private. But that's just the point: what I want to show, what I feel I can and must show, is a very 
important part of our daily lives. For instance, what was very important for me in the scene where May [Mei-mei in Vive l'amour] pisses was simply - as she is in an empty room on her own - whether she would close the toilet door or leave it open (laughter). While I was preparing for that scene I asked a lot of women: 'What do you do when you are alone in a room and want to piss? Do you close the door or leave it open?' (Tsai apud Rehm et al 1999: 114).

As this statement demonstrates, Tsai's films offer situations so insignificant from a narrative perspective that one is likely to be amused by seeing them onscreen for such protracted length of time. Take for example the scenes in The Hole in which Yang's character gets frustrated as she struggles with a pen that refuses to work; or when, in the same film, we see Hsiao-kang simply cutting his nails; or indeed when Mei-mei, in Vive l'amour, attempts, without success, to catch a mosquito flying around her face for nearly two minutes. Consider also the scene, also in Vive l'amour, in which we see in close-up Mei-mei's foot opening the bath tap, a detail so minor, which, incidentally, evokes the scene of the maid getting up in Umberto $D$ (1951), in which 'she shuts the door with the tip of her outstretched foot' as canonised by Bazin's loving analysis of this film's famous quotidian drive (Bazin 2005b: 82). These films' devoting of time to such minute detail reveals an everyday focus on triviality that bridges them across time and space. But whereas the maid is in the kitchen, Mei-mei is in the bathroom, and from the kitchen to the bathroom domestic privacy is taken to a whole new level. 

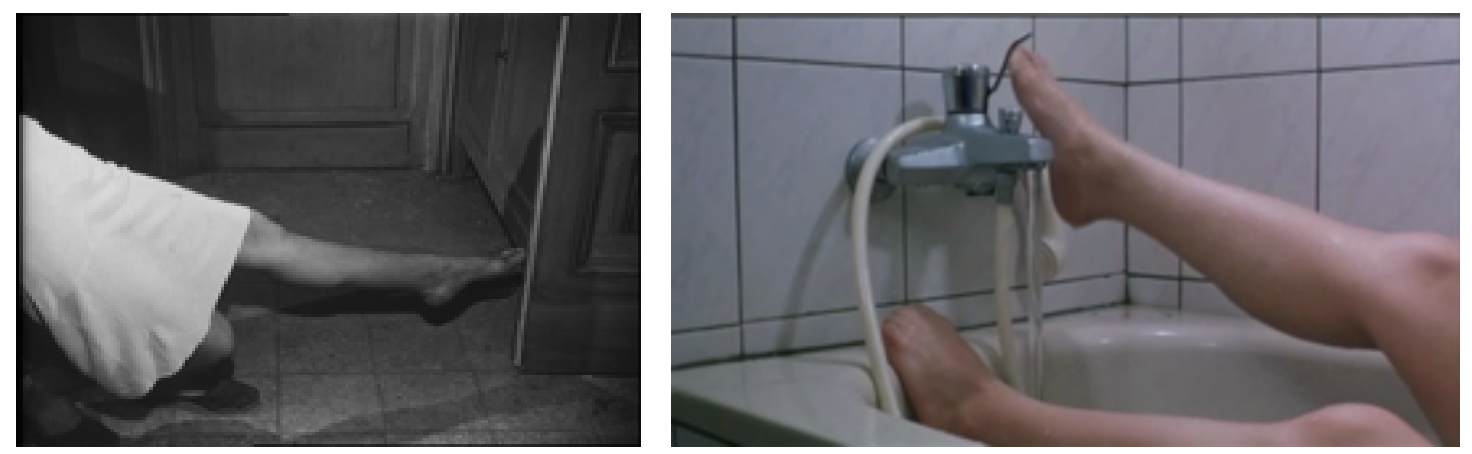

The Everyday Foot of Umberto D and Vive l'amour

Here, the bathroom is as visible and ordinary as any other room in the house. Characters sitting on a toilet vase (see pictures below) are a recurrent visual trope, often shown doing some other activity concomitant to their physiology, such as smoking (Hsiao-kang in The Skywalk Is Gone) or applying make up (Mei-mei in Vive l'amour). Though these actors never defecate in front of the camera, they do occasionally urinate, as performed, for example, by Miao Tien in The River and Lee Kang-sheng in What Time Is It There?, who takes to urinating in plastic bottles during the night as he is scared to go to the toilet and run into his father's spirit. That the director is interested in the Buddhist doctrine explains in part his attention to bodily waste processes. Buddhist philosophy, stressing the ephemerality of life, attaches great importance to its private dimension and the functioning of the body in every respect. Mindfulness of all bodily functions, including defecation and urination, is a crucial aspect of the doctrine insofar as this is said to strengthen awareness of the transience of one's own body. And here we are again compelled to revisit a filmmaker such as Ozu, whose cinematic everyday was also informed by Buddhism. 


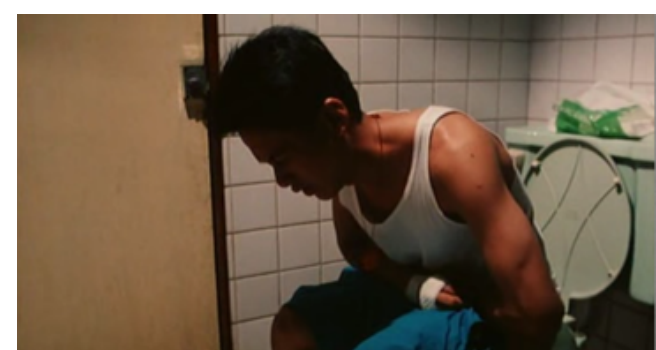

Rebels of the Neon God

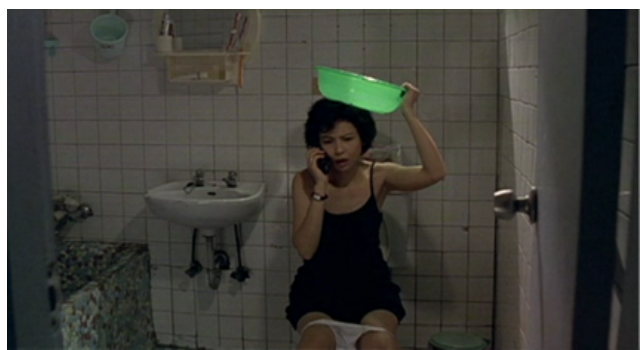

The Hole

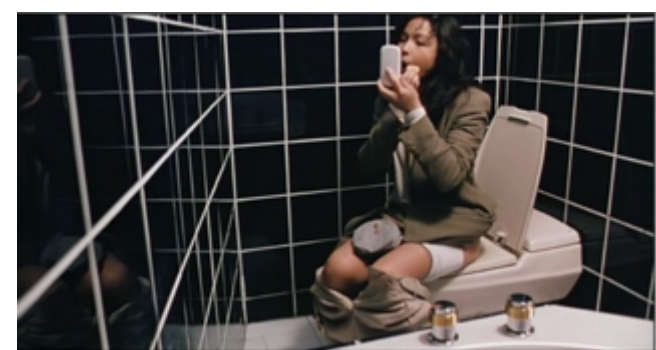

Vive l'amour

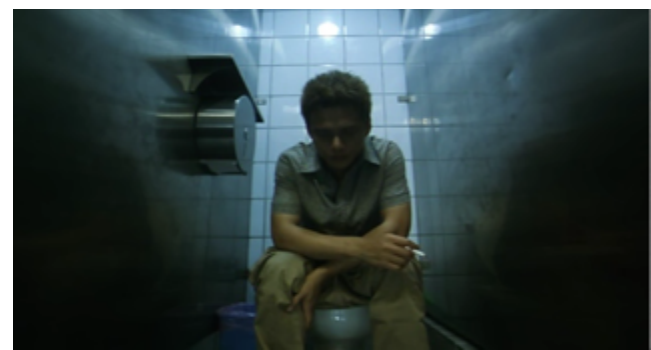

The Skywalk is Gone

Bodily privacy

Indeed, to link the cinemas of Tsai and Ozu makes sense not only in view of their aesthetic similarities, as discussed in the previous section. More than technically, their everyday projects are connected through attention to human physiology. Ozu, whose career spanned four decades, built a body of work which has for some time now been hailed as the quintessence of the everyday in cinema. Working all his life for Shochiku studios, the Japanese director engaged for most part of his career with the gendai-geki genre: films concerned with working and middle-classes in contemporary urban surroundings (Bordwell 1988: 18). In his post-war phase, he settled in the 'home drama' subgenre, with his films tackling strictly domestic matters against the backdrop of Japan's modernisation. Informed by a Buddhist perspective, Ozu's everyday is notably cathexed on bodily functions, which, as Bordwell tells us, harks back to the ero-guronansensu artistic movement predominant in Japan in the 1920-1930s, with its emphasis on grotesque subject matter (Bordwell 1988: 154). His films are famous for their 
scatological sense of humour, characters dashing to toilets, farting jokes and, not least, long eating gatherings.

Eating is also pervasive in Tsai's everyday, which, of course, can be attributed to the deep-seated Chinese tradition of enjoying this activity, symbolic as it is of the communal character of the family and represented in countless Chinese and Taiwanese films. One could cite, for example, the early work of Hou Hsiao-hsien, freighted with eating scenes, or, more significantly, Ang Lee's Eat Drink Man Woman (Yin shi nan nu, 1994), which explicitly thematises the ritualistic, familial dimension of eating in Chinese culture. In Tsai's cinema, however, eating is stripped of this communal character, being instead depicted as a physiological imperative. Granted, we do occasionally see eating gatherings but these are not only sparse but also reduced to the modicum number of two: Hsiao-kang and Ah-Jung in Vive l'amour; Hsiao-kang and his father at an outdoor restaurant in The River; Hsiao-kang and his mother in What Time Is It There? Incidentally, the last scene offers a telling example as the mother, convinced that her husband's spirit remains in the house, also dishes up a plate for him in what used to be his seat. But like most activities in Tsai's universe, eating is predominantly performed by characters alone, and the repetition of this particular bodily need in all his films can reach a significant degree. Throughout Vive l'amour, for example, we see Mei-mei eating alone on four different occasions with considerable screen time devoted to each of them. In fact, an emblematic image of Tsai's universe is that of characters in front of half-open refrigerators swallowing something, a situation we find, for instance, in Rebels of the Neon God, Vive l'amour, The River, and The Wayward Cloud (see pictures below). Moreover, these are characters for which the quality of food is no longer relevant. They 
eat fast-food, takeaways in polystyrene boxes, leftovers, canned food, which refers to a real situation as these new eating habits increasingly displace traditional Chinese eating customs and become the norm in late-industrialised Taipei.

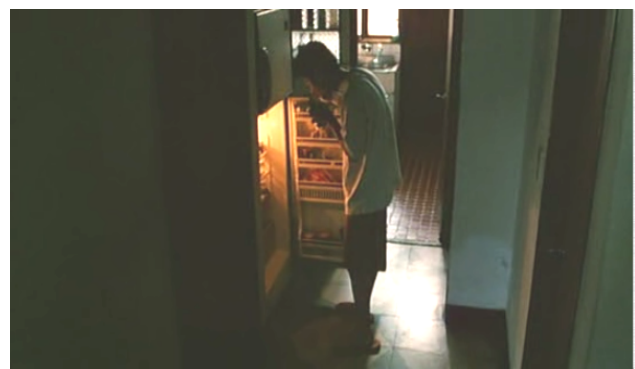

Rebels of the Neon God

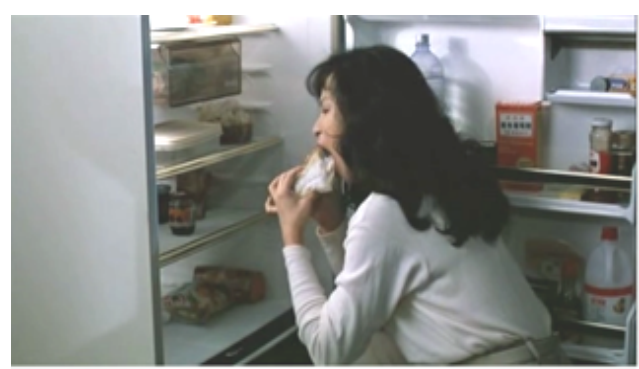

Vive l'amour

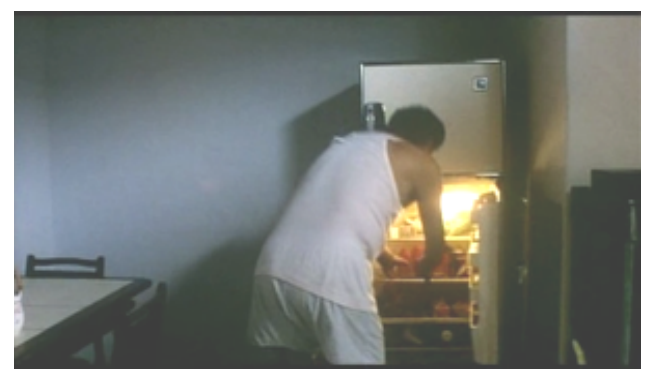

The River

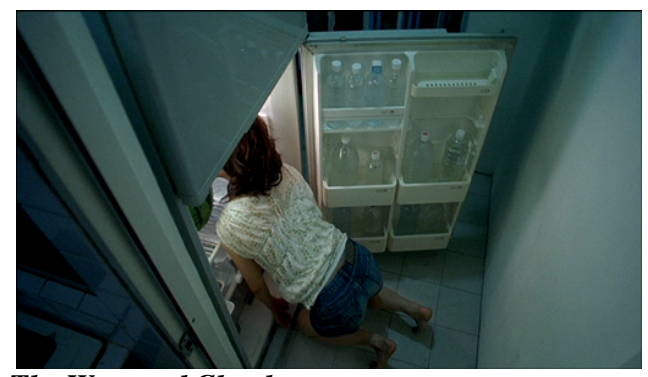

The Wayward Cloud

\section{Ravenous Characters}

These are, furthermore, ravenous characters. Consider the single shot in What

Time Is It There? in which Shiang-chyi, alone in her hotel room in Paris, swallows three biscuits and a whole banana in less than a minute. Or the scene in The River in which Hsiao-kang, even though contorting himself and grunting with neck pain, gulps down some rice with the help of an enormous tablespoon. Superlative hunger can also be found in The Wayward Cloud, as in the scene in which Shiang-chyi downs an immense glass of watermelon juice in no more than ten seconds and, later, scoops up half of a watermelon with an equally huge spoon. Not to mention that these are equally thirsty characters constantly in need of water, Tsai's ever-recurrent motif. 


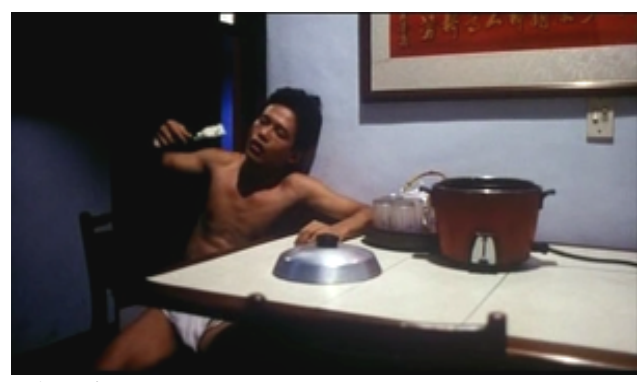

The River

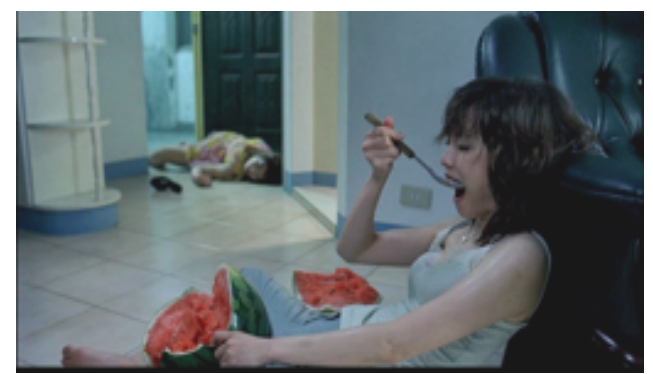

The Wayward Cloud

Superlative hunger

Physiology in the context of a private realm is further emphasised through the sight of other corporeal secretions, including vomit (Shiang-chyi in What Time Is It There?; Hsiao-kang in The Hole), semen (Hsiao-kang in The Wayward Cloud) and tears. Concerning the latter, we need only remember the famous ending of Vive l'amour in which Mei-mei cries incessantly for over five minutes in an unbroken shot. Excessive crying is also performed by Lee both in The Hole and What Time Is It There? in scenes that recall Mei-mei's convulsive tears. Despite the fact that sadness can, of course, be read into these events (loneliness in the case of Mei-mei in Vive l'amour and Hsiao-kang in The Hole; the death of Hsiao-kang's father in What Time Is It There?), it is interesting to note how sobbing appears as one more variant of the array of physiological situations on show here. As these crying scenes are intercut with those of eating, drinking, urination, etc., these events are rendered equivalent, as different expressions of human physiology. And that these actors can sob in long takes of five minutes underlines, beyond their representational dimension, the literal physiology of this act.

In fact, this stress on crying as a physiological product comes to a head in the controversial ending of The Wayward Cloud, in which Hsiao-kang violently thrusts his penis into Shiang-chyi's mouth and keeps it there for one and a half minute until she 
chokes on it, shedding a tear as a result. Of course, this tear is rich in its symbolic nuances, considering that the couple's sexual relation remains unconsummated throughout the film, not to mention that Taipei is here beset by a drought. But what is striking is the physical quality of this close-up, which, through its protracted duration, underlines the actress's drop of tear as a purely, real physiological response. This in turn resonates with the drops of sweat we see streaming down Lee's buttocks just a few shots before in the same scene, also in close-up. Close-ups are rare in Tsai's films: this foregrounding of distinct corporeal secretions, a few shots away from each other, seem to deliberately underline their equivalence as bodily products.
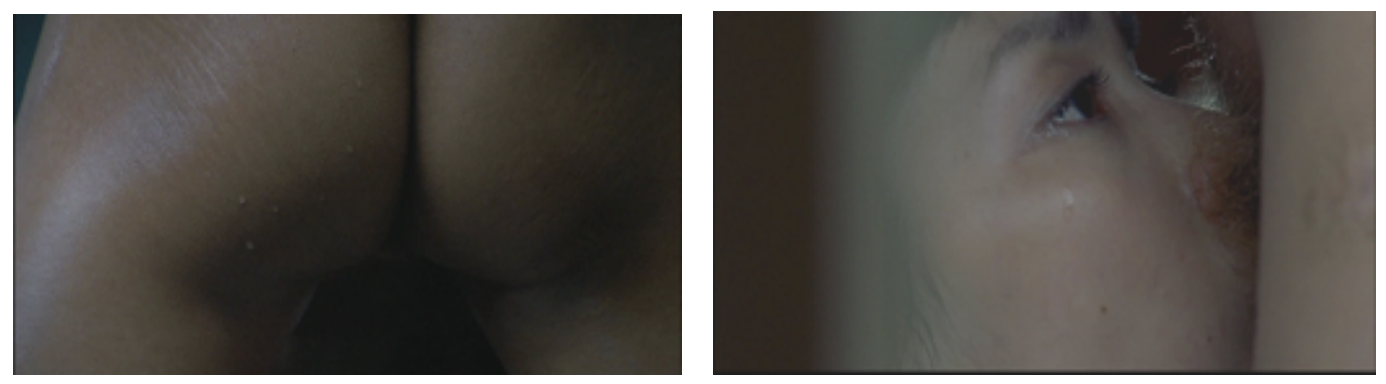

Bodily Excretions: sweat and tears in The Wayward Cloud

Bodiliness is also emphasised through these films' distinctive treatment of sound. But here let me briefly make a detour so as to expose how diegetic sound is utilised in general in Tsai's work. Tsai acoustically emphasises what Michel Chion calls 'materializing sound indices', which he defines as 'the sound's details that cause us to "feel" the material conditions of the sound source and refers to the concrete process of the sound's production'. Chion mentions, for example, the sound of footsteps, which, depending on how a given film acoustically renders it, 'can contain a minimum of 
materializing sound indices...or, on the contrary, many details of texture, giving the impression of leather and cloth, and cues about the composition of what is being walked on' (Chion 1994: 114-5). As Tsai's mise-en-scène is structured around characters alone in domestic spaces, the sounds of the activities in which they are engaged are often intensified, calling attention to their concrete source, a procedure attained through microphone amplification ${ }^{9}$ and which matches and enhances the visual stress on concrete materials displayed here. In this respect, furthermore, one is again reminded of Jeanne Dielman in which Jeanne's systematic and solitary routine is also highlighted through sound. We hear in crystal-clear registers her handling of household objects such as cutlery, dishes and, notably, the clicking sounds of light switches as she relentlessly turns it on and off upon entering and leaving rooms.

These material, sensory qualities of sounds are also emphasised in Tsai's cinema, for example, in I Don't Want to Sleep Alone, when Rawang (Norman Atun) washes the mattress on which Hsiao-kang recovers from physical injuries and which becomes the symbol of their newly formed union. As Rawang incessantly scrubs the mattress with a sponge, the produced friction is rendered in tactile, limpid registers, being further emphasised through long onscreen time. This is further echoed, later in the film, by the scene in which Shiang-chyi cleans Hsiao-kang's unresponsive comatose body. As she vigorously scrubs his shaved head and cleans his facial orifices, including his nose, mouth and ears, there is a heightened acoustic quality which, in this case, derives from the body itself. Such analogy thus demonstrates the equivalence accorded to animate and inanimate matter in Tsai's work, which portrays an excessively material body.

\footnotetext{
${ }^{9}$ Tsai himself provided me with this information (De Luca 2010).
} 

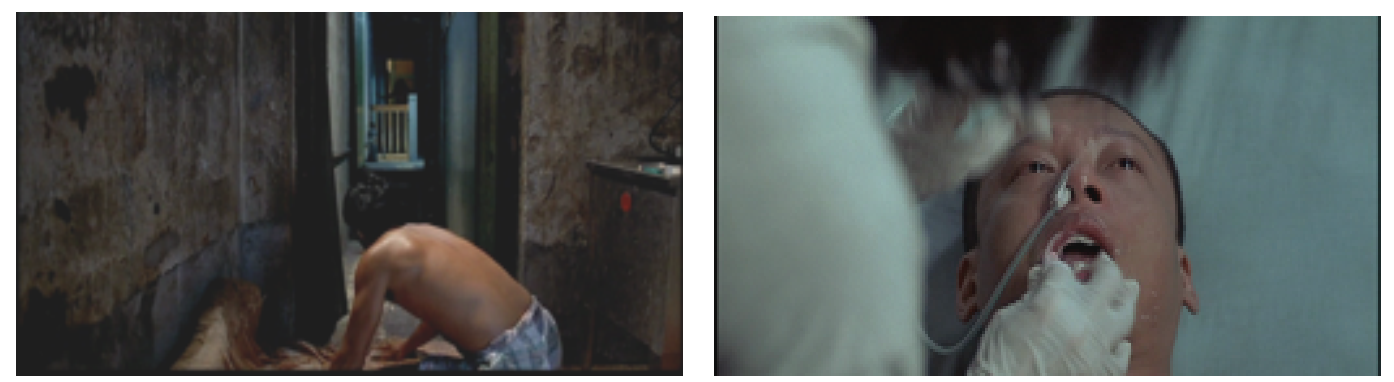

Material Sounds: a mattress, a Body... (I Don't Want to Sleep Alone)

Corporeal materiality is further mobilised through sounds emitted by the body. Take the aforementioned scene in The River in which we only hear Miao Tien urinating as he has his back to the screen. Consider also when Shiang-chyi emits a sonorous burp after drinking up a huge glass of watermelon juice in The Wayward Cloud. As she drinks the juice, moreover, we hear in limpid registers the liquid going down her throat, as is also the case whenever characters are chewing and swallowing food in Tsai's work. The Wayward Cloud also provides another privileged example in the scene in which Shiangchyi and Hsiao-kang are shown devouring some crabs. We see alternate shots of both characters' face shadows projected on walls and hear them chewing and sucking the crustaceous carapaces with overwhelming noise.
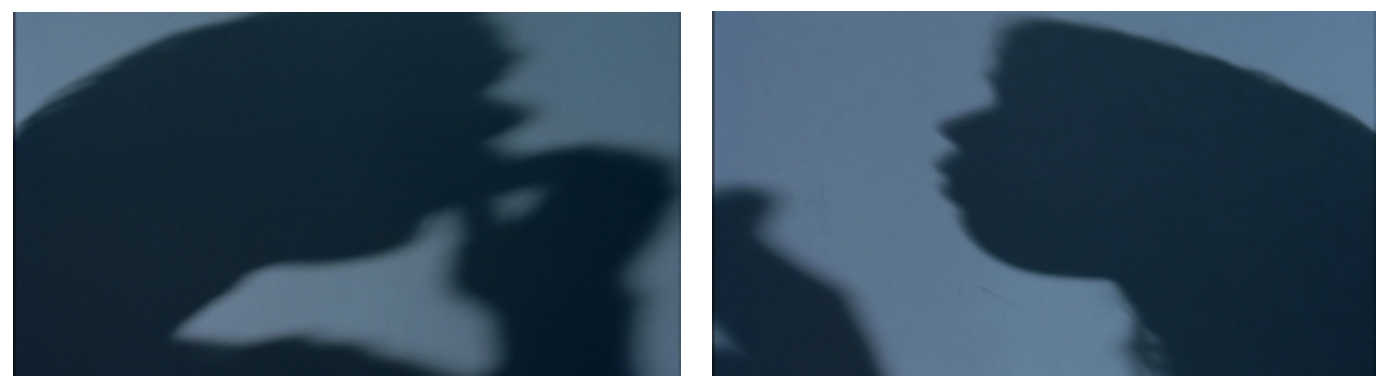

The sounds of eating in The Wayward Cloud 
Tsai reveals that in the scene in Vive l'amour in which Mei-mei and Ah-Jung have sex he 'took things to extremes' and 'wanted to show the noise of their breathing' (Tsai apud Rehm et al 1999: 103). Respiration, the quintessential signifier of human life, is also highlighted in his oeuvre as a whole. In this respect, I Don't Want to Sleep Alone provides yet another eloquent example, as the only indication that the comatose character is still alive is the breathing sounds he emits with the help of respiratory devices. These sounds are heightened in the film as they resonate against the plastic sheet that covers him, sensuously underlining to the viewer a body reduced to mere physicality. Davina Quinlivan, elaborating on Lars von Trier's Breaking the Waves (1996), argues that the 'sound of breathing creates another dimension of the lived body on screen for the viewer; it lends it volume and shape through the suggestions of a human physicality that can almost be felt and, as a kind of rough, sonic object, touched' (Quinlivan 2009: 161). Her remarks on the sound of breathing as producing a 'hyperrealist corporeality' is indeed fitting here, as it is extendable to all the other bodily noises we encounter in Tsai's oeuvre.

In short, both through sound and image, Tsai's work overexposes the irreducible bodily dimension of human beings. In so doing, it gives audiovisual expression to what French philosopher Paul Ricoeur defines as 'the corporeal involuntary'. Revoking the Cartesian dualism of body and mind, Ricoeur stresses instead the corporeal prevalence of incarnated existence, drawing attention to the inescapable bodily spontaneity governing human needs and waste processes, such as thirst, hunger, excretions, secretions, etc needs which, as emphasised by Tsai's cinema, escape conscious control. As Ricoeur puts it, 'my body is the most basic source of motives, revealing a primordial stratum of values: 
organic values'. As such, it is 'the initial existent': 'the "I am" or "I exist" infinitely overwhelms the "I think"” (Ricoeur 1966: 85).

As hopefully demonstrated, this corporeal prevalence is fully present in Tsai's everyday, which magnifies bodily functioning in the context of a private realm. Not only do we have here a far-reaching array of physiological functions but these are depicted as ruling these characters' lives. The acts of eating and drinking are emphasised as bodily needs rather than ritualistic activities. That characters are here seized by an urge to defecate or urinate further emphasises a body that seems to act on its own accord, as epitomised in What Time Is It There?, in which Hsiao-Kang wakes up repeatedly during the night to relieve himself.
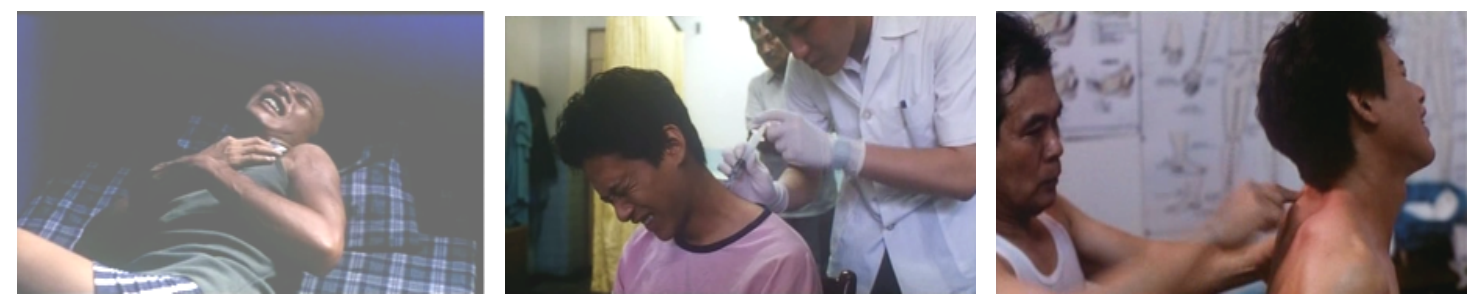

Corporeal prevalence: The River

Yet nowhere is corporeal prevalence granted more visibility than in The River, in which Hsiao-kang, as mentioned earlier, inexplicably develops a severe neck pain which makes him resort to a number of medical and ritualistic sessions. This mysterious pain literally takes over his body as he becomes unable to move his neck, with his head increasingly tilted to one side, going through massage, acupuncture and chiropractic sessions. This corporeal pain that inexplicably debilitates Hsiao-kang's body allegorises the physical supremacy of this singular everyday project, distributed between the brute 
materiality of animate and inanimate matter. Far from restricted to customs and events generally coded as mundane, Tsai opens the doors of domestic privacy wide open through an implacable focus on the bodily spontaneity of beings. As such, his is a cinema which extrapolates the representational tropes traditionally associated with the everyday. Indeed, as the next chapter will endeavour to demonstrate, this overexposed physiology of characters, coupled with their unrelenting sexual drive, signals a move away from an everyday realm and into that of the grotesque. 


\section{Chapter 8}

\section{Undomesticated Bodies}

Characters' need for sex in Tsai's cinema is often interpreted as a search for love, a view endorsed by the director himself (see Rehm et al 1999: 100). Be that as it may, closer inspection of his films attests that sex, as with the bodily functions analysed in the previous chapter, is another physiological variant of a prevalent body. This is immediately identified, for example, in the masturbating scenes on display in nearly all his films, with characters often resorting to the help of porn films, magazines and other objects, an example being the large cushion used by Hsiao-kang's mother in What Time Is It There?.
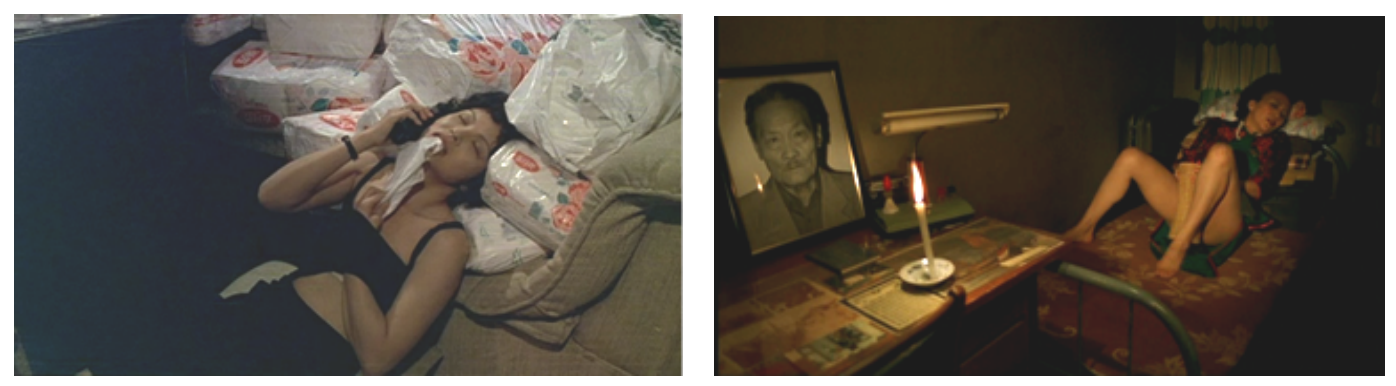

Touching themselves: Yang Kuei-mei in The Hole and Lu Yi-ching in What Time Is It There?

These are, furthermore, characters that leave the private sphere of home in search of sexual partners. In this regard, the ending of Rebels of the Neon God, which finds Hsiao-kang in a phone-in dating club where people meet anonymously, anticipates a 
theme which was to be fully developed across Tsai's work. In The River, for example, this same character, as well as his father, is shown frequenting gay saunas. It is in one of these that both characters will unknowingly have sex at the film's end. Hsiao-kang's father is also shown cruising with a young man (Chen Chao-jung) in a shopping arcade in the same film. Cruising is further on display in Vive l'amour as we see Mei-mei and Ah Rong exchanging looks in the street, being also depicted as the main activity going on within the decadent cinema in Goodbye Dragon Inn, both in its toilets and back areas. It is also in this setting that Hsiao-kang is chased by a chubby young man looking for sex in What Time Is It There?, the ending of which finds the former having sex with a prostitute.

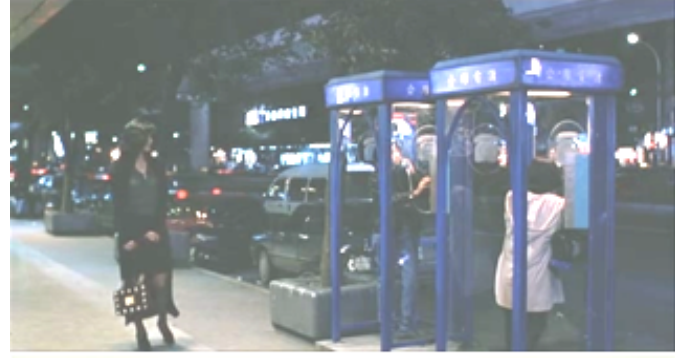

Vive l'amour

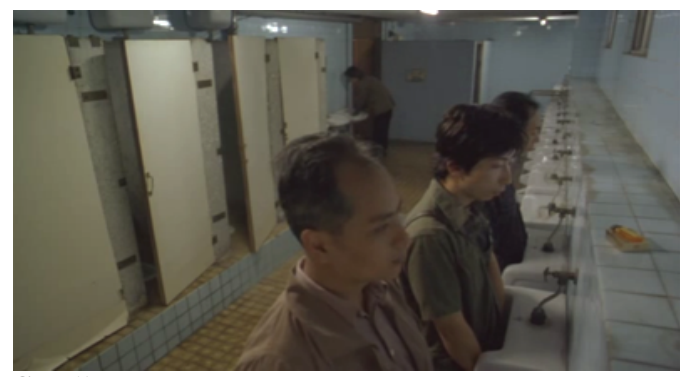

Goodbye Dragon Inn

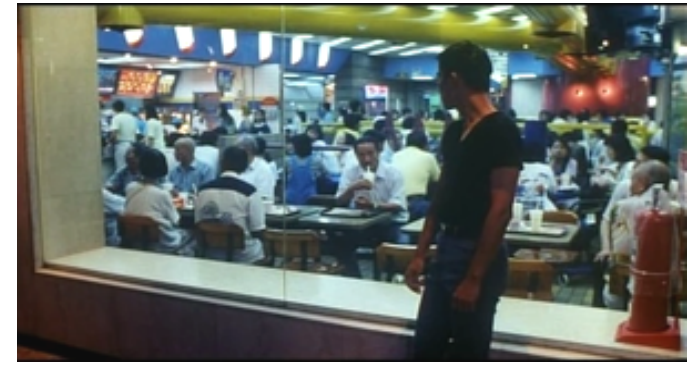

The River

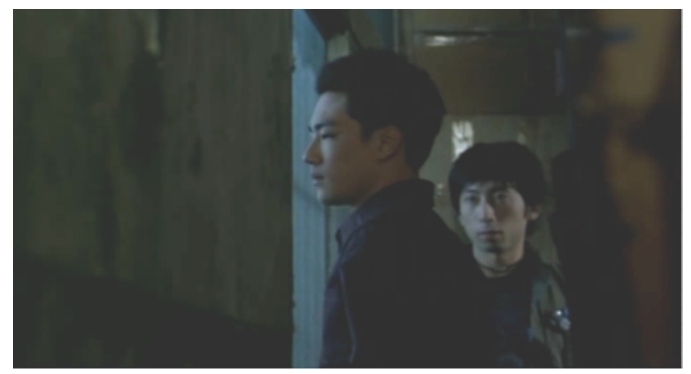

Goodbye Dragon Inn

The Dynamics of Cruising

In my view, this is therefore a universe peopled by characters whose overexposed physiology and superlative lust resonate with the grotesque body. Though it does not feature the best-known characteristic of the grotesque, namely, corporeal hyperbolism - 
as illustrated, for example, by the obese bodies of Battle in Heaven, analysed in Part I - it largely complies with Mikhail Bakhtin's definition of this canon to the extent that this line of argument is worth pursuing. Drawing on Bakhtin, I shall examine in this chapter the way in which grotesque tropes are granted audiovisual expression in Tsai's oeuvre, devoting in the process particular attention to The Wayward Cloud. I will then proceed to analyse his work's highly physical acting style, as well as its depiction of weird private behaviour in the context of an everyday film aesthetics. I conclude by stressing the political significance of these 'undomesticated bodies'.

\section{Grotesque Bodies}

According to Bakhtin, the fundamental trait of the grotesque body, as represented in medieval literature and, in particular, the work of François Rabelais, is its malleable permeability with the material world and other bodies. As opposed to the finished, immutable, self-enclosed body privileged by classical aesthetic canons, Bakhtin argues, the grotesque body is in perpetual alliance with its material surroundings in a ceaseless process of becoming. This is therefore a body highlighted in its points of aperture, that is, the orifices and protuberances which enable it to extrapolate its own confines, namely the gaping mouth, the bowels, the genital organs and the anus:

All these convexities and orifices have a common characteristic; it is within them that the confines between bodies and between body and the world are overcome: there is an interchange and an interorientation. This is why the main events in the 
life of the grotesque body, the acts of the bodily drama, take place in this sphere. Eating, drinking, defecation and other elimination (sweating, blowing of the nose, sneezing), as well as copulation, pregnancy, dismemberment, swallowing up by another body - all these acts are performed on the confines of the body and the outer world, or on the confines of the old and new body (Bakhtin 1984: 317).

The physiological accent of Tsai's oeuvre immediately connects it to a grotesque tradition, from which it also incorporates several visual motifs. For example, Bakhtin expounds on how the outer world is appropriated for bodily analogies in the grotesque, appropriating 'images of nature and of objects in which depths (holes) and convexities are emphasized', a statement he further extends to phallic imagery (Bakhtin 1984: 318). Phallic analogies and sexual iconography are notorious in most Tsai films. Lim, for example, draws attention to the sexual intimations in Hsiao-kang's inserting of glue into Ah Tze's motorbike in Rebels of the Neon God, as well as the electronic massager the character uses in The River so as to alleviate his neck pain, which 'looks and works like a vibrator' (Lim 2006: 146). In a similar vein, we also find here objects whose prominent circular depth evokes the human body's orifices, such as the recurrent drains on display in Rebels of the Neon God. Another example, among many others, can be found in The Hole as we see Hsiao-kang, intoxicated, embracing a phallic fire extinguisher.

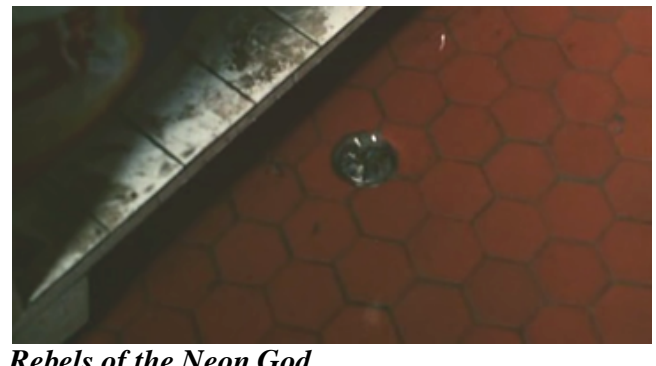

Rebels of the Neon God

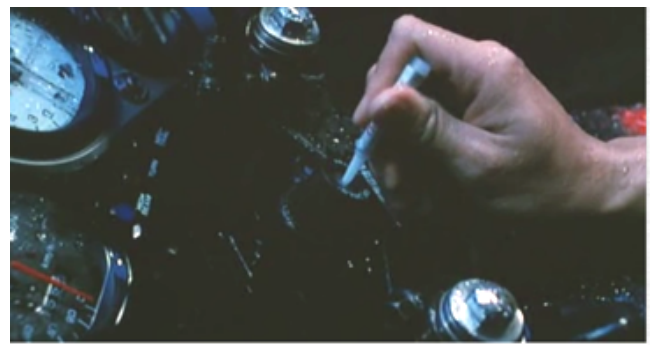

Rebels of the Neon God 


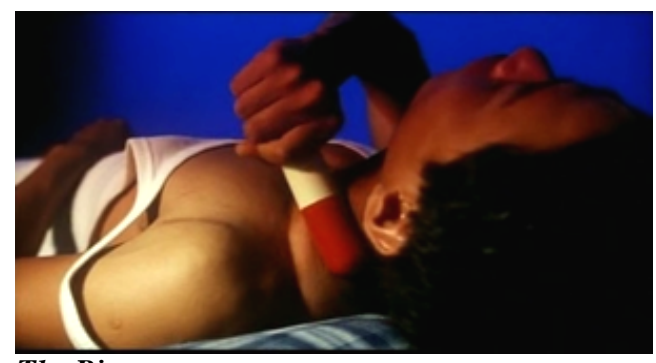

The River

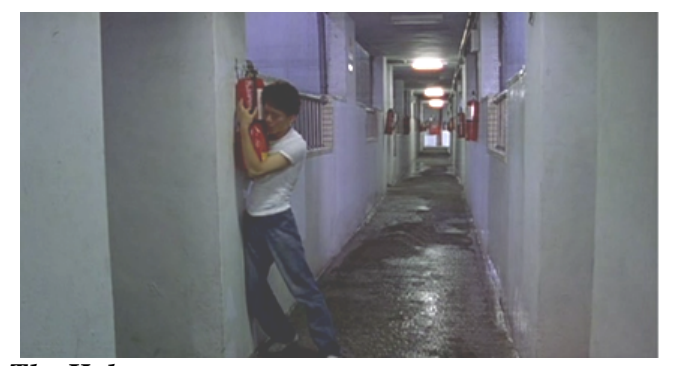

The Hole

Grotesque Motifs

In fact, as indicated by its very title, The Hole is highly emblematic of the grotesque. Linking the apartments of Hsiao-kang and Yang, this circular crack clearly stands for an enlarged human orifice through which both characters attempt to connect with each other. In one telling shot Hsiao-kang holds a plastic bottle perpendicularly to his crotch while spilling water into the hole, an image thus freighted with intimations of a sexual order, as he appears to be ejaculating or urinating into the orifice with an enormous phallus. Such visual metaphor is also mobilised later in the film when he inserts his leg into the fissure, evoking a penetrative act. In the film's final shot Yang is pulled up by Hsiao-kang into his apartment through this hole, perfecting this sexual metaphor in a gesture which visually echoes Michelangelo's famous The Creation of Adam, the overstretched arms of both characters, as in the fresco's depiction of God and Adam, trying to touch each other. This architectural hole, interestingly, is further revisited in The Wayward Cloud's ending, as Shiang-chyi watches the shooting of a porn scene through a circular hole in the wall. As Hsiao-kang thrusts his penis through the hole into Shiang-chyi's mouth, the fissure takes on the quality of a hyperbolised, doubled image of a human orifice, in this case her gaping mouth. 

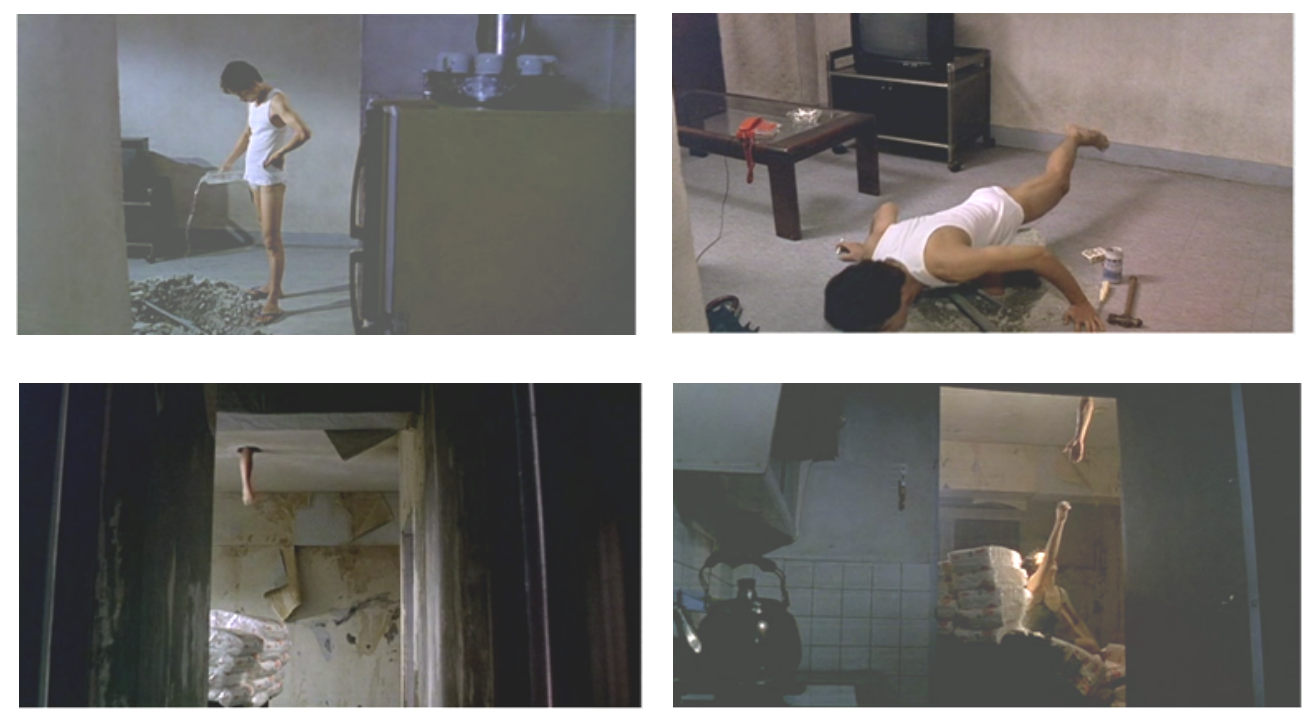

The grotesque hole in The Hole
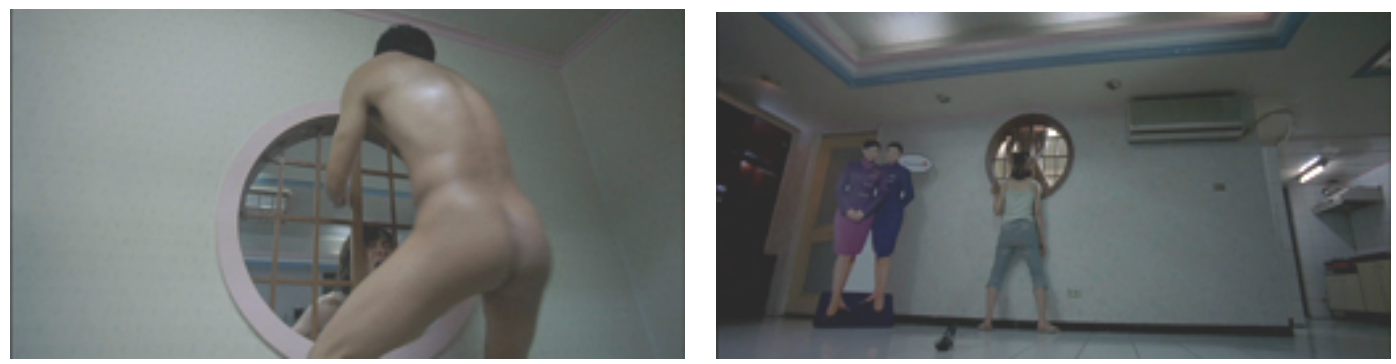

The grotesque hole in The Wayward Cloud

As well as through holes, grotesque hyperbolism, according to Bakhtin, is materialised through natural images such as 'mountains and abysses' or 'in architectural terms, towers and subterranean passages' (Bakhtin 1984: 318). The long subterranean corridors we encounter in Tsai's films, framed centrally and in extreme accordance with perspectival principles, not only echo bodily depths but also the phallus itself as viewed horizontally. Actually, The Wayward Cloud, a film which, as mentioned in the previous chapter, presents instead V-shaped subterranean corridors, makes explicit this architectural analogy with the human body. As Weihong Bao notes, the V-shape of these corridors 'resemble that of parted human legs' (Bao 2007: 146), an aspect also noted by 
Vivian Lee, who goes on to demonstrate how this analogy is overtly constructed in the film's first sequence through the juxtaposition of shots of the corridors and Shiang-chyi's parted legs (Lee 2007: 121).
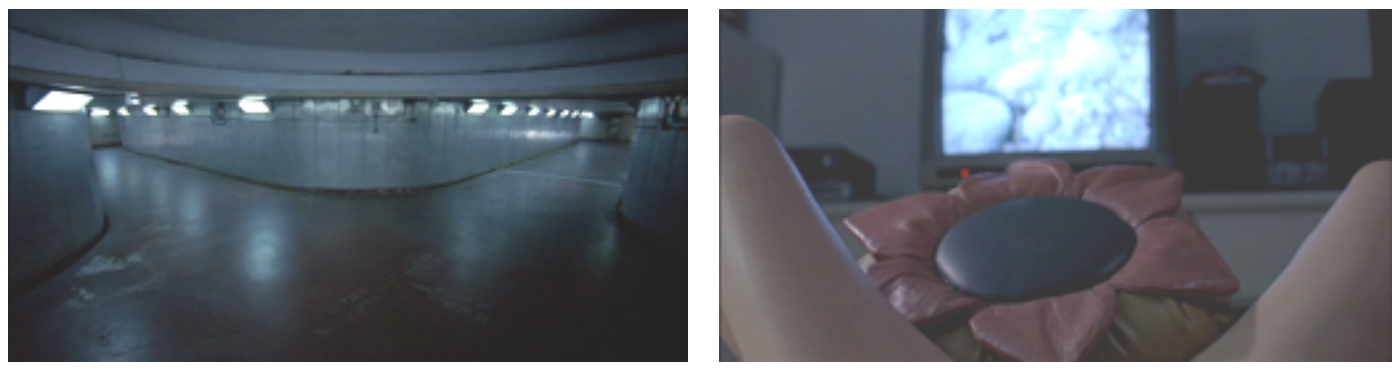

Bodily Analogies in The Wayward Cloud

Even more literal is the gigantism of forms as achieved through wide-angle lenses distortion in Tsai's work. This is what happens in the scene in The River in which Hsiaokang's hand acquires an oversized dimension because framed from too close a distance. This distortion can also be found in The Wayward Cloud, as Shiang-chyi's feet appear disproportionate, as the picture below illustrates.
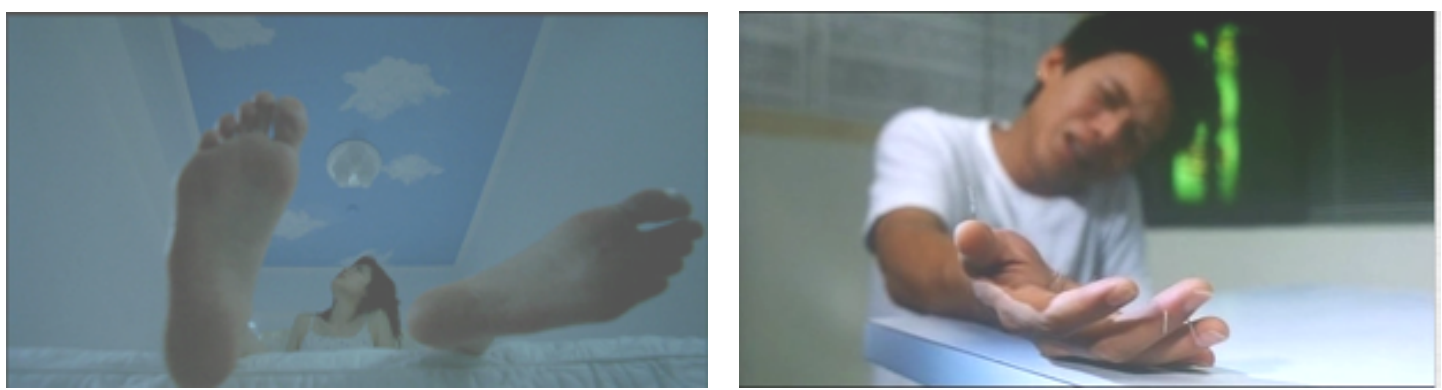

Gigantic Limbs in The Wayward Cloud and The River

In many respects, The Wayward Cloud indeed epitomises an aesthetics of the 
grotesque. This is all the more interesting given that it has been considered an exception in Tsai's career. As Bao points out, it 'befuddled Tsai's critics, divided his fans, and received both raves and grumps' (Bao 2007:139). No doubt, this furore was largely due to the film's sexual explicitness, as it depicts the shooting of a porn film. Though sex had always been pervasive in the work of the director, it was never so graphic. This divided response also stemmed from the film's extravagant collage of discrepant genres such as pornography and the musical, all wrapped up in a stridently camp style. It is true, Tsai had already flirted with the musical in The Hole, a film also composed of tacky, amateurish musical numbers accompanied by the 1950s songs of mandarin pop-star Grace Chang, thus prefiguring The Wayward Cloud in some respects. Yet the latter pushes a camp aesthetics to a new, openly grotesque, level in his work.

Indeed, this is a film that often dispenses recourse to grotesque metaphors, meaning that it literally embraces it. In one of its first scenes, for example, we see Hsiaokang in bed with a Japanese-looking woman, both wearing medical uniforms. The viewer does not know yet this is a shoot for a porn film. She has her legs parted and a watermelon between them stands for her genitalia. Hsiao-kang licks the melon to begin sticking his finger into it. He carves pieces out of the fruit, shoving them into her mouth. A few shots later, we now see this Japanese woman entirely naked in bed, fully covered in watermelon juice as Hsiao-kang licks it off her body. The sequence ends with Hsiaokang having sexual intercourse with her, half of the melon's skin atop his head. This scene therefore embodies the fundamental tenets of the grotesque: 'the delights of endless gluttony, creative obscenity, and indefatigable sexuality' (Stam 1995: 158). Not only does it show physiological activities such as eating and sex, but these are intermingled in 
a process which playfully transgresses the cultural separation of these bodily functions. The mouth and the female genitalia thus become interchangeable orifices in which the body's openness to the world is emphasised and 'the essential topographical element of the bodily hierarchy turned upside down' (Bakhtin 1984: 309).
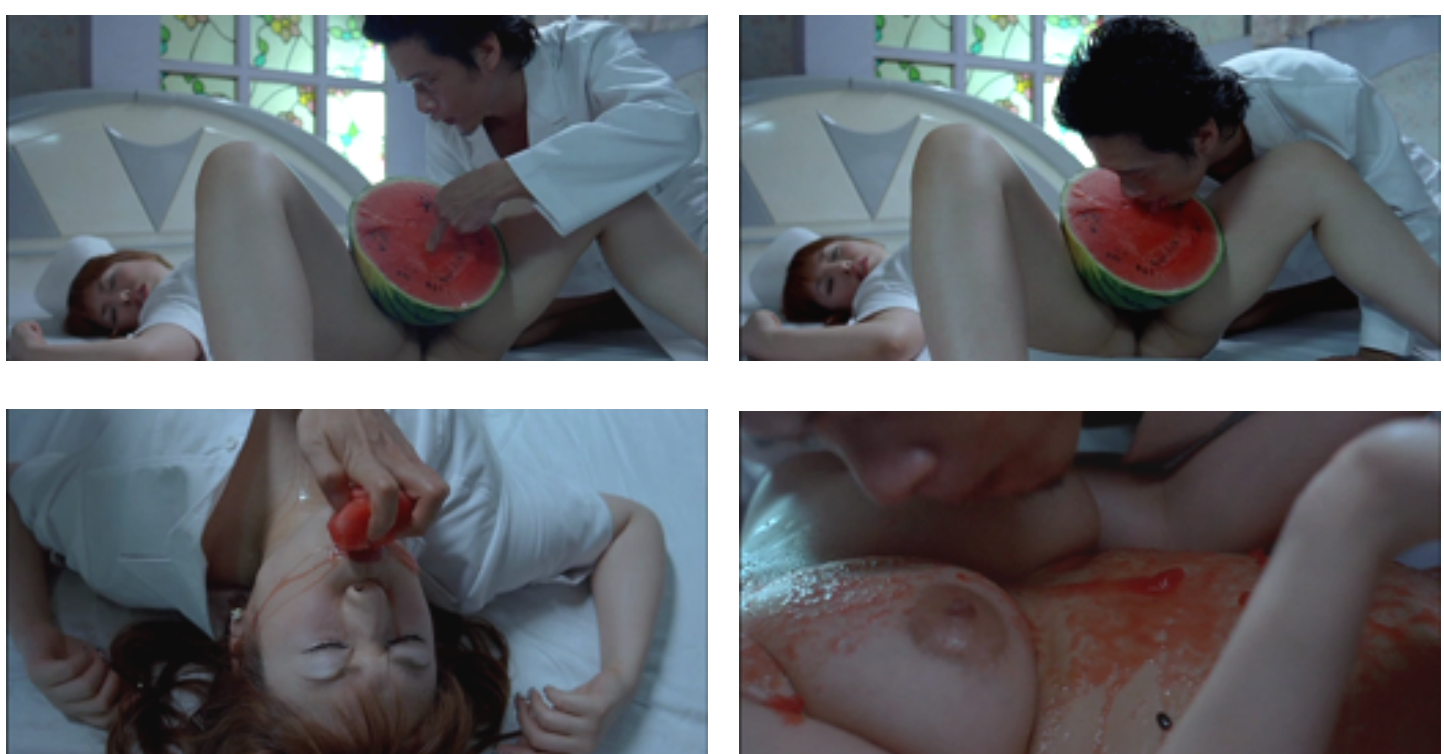

Interchangeable Orifices

Grotesquery can be similarly found in The Wayward Cloud's musical numbers.

As in The Hole, these sequences are in discordance with the generic conventions of what Barry Langford defines as the classical, 'integrated musical'. In the latter, musical numbers, performed by characters unexpectedly breaking into song-and-dance numbers within the intradiegetic universe, 'are woven into the narrative structure, motivated by character psychology and/or plot development and expressive of the emotions, opinions or state of mind of the singer(s)' (Langford 2005: 85). Instead, The Wayward Cloud resonates with the 'non-integrated musical', in which, as Langford goes on to analyse, 
'numbers simply accumulate serially, and are effectively stand-alone spectacles connected only loosely...either to each other or to the narrative in which they are embedded' (Langford 2005: 85). This is what happens in The Wayward Cloud, whose autonomous numbers (it is also unclear whether they derive from the characters' minds) offer a grotesque, extravagant mirror of the unfolding narrative, for example in the musical in which Hsiao-kang is, quite literally, an immense penis chased by a swarm of girls, which refers to his failing to consummate his romance with Shiang-chyi due to his inability to have an erection. Here the fantastic, humorous gigantism of forms characteristic of the grotesque acquires an explicit coloration. Moreover, this giant phallus, as noted by Vivian Lee (2007: 135), resonates with the phallic statue of the exparty leader of the Kuomintang, Chiang Kai-shek, displayed in another musical number earlier in the film. This sequence also resonates with the festive, carnivalesque spirit characteristic of the Bakhtinian grotesque, which, as Robert Stam argues, 'is more than a mere festivity; it is...the symbolic, anticipatory overthrow of oppressive social structures' (Stam 1995: 173). The rendition of Chiang Kai-shek - an authoritarian leader figure in Taiwan - as echoing an enormous phallus is symptomatic of this anarchic spirit. Featuring female dancers in flamboyant flowery costumes dancing around the statue, this camp musical sequence debauches the despotic figure in true grotesque fashion. 

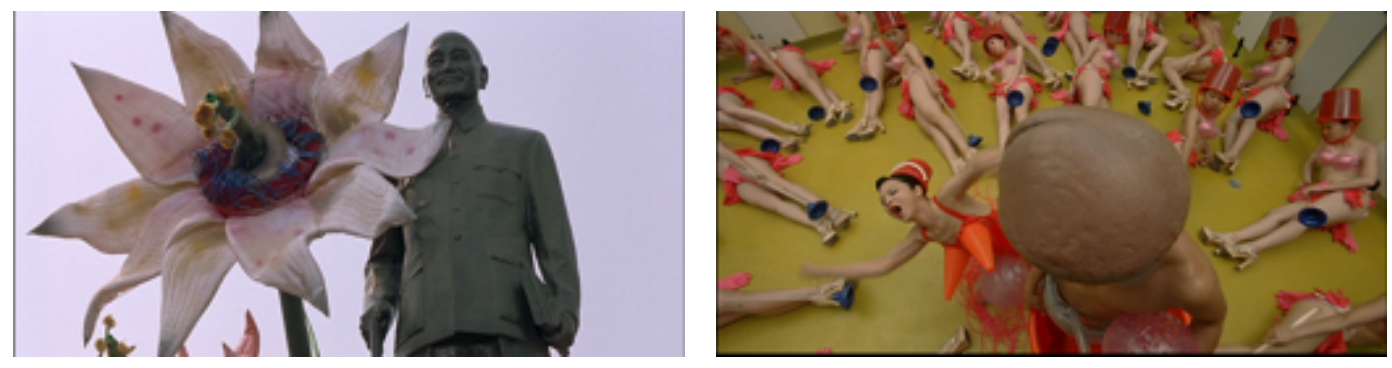

The Giant Penis

What thus impresses in The Wayward Cloud's musical numbers, which, like The Hole's, reappropriate Mandarin 1950s songs, is this carnivalesque ethos, here updated through a high-camp aesthetics. The palette of colours is much more vibrant than in other Tsai films. Its numbers, featuring characters in outlandish costumes awkwardly lipsynching (often de-synchronised with the songs), are tacky, raucous, obscene. If grotesque tropes run through all Tsai's work, they lack the out-and-out flamboyance they are endowed with here. In a certain sense, this is a film that invites a retrospective look on his oeuvre for it crystallises a number of grotesque motifs that, though pervasive in his previous works, had not materialised with such extravagance. Take for example the musical in which we see Hsiao-kang and Shiang-chyi, entirely cross-dressed, singing and dancing in a theme park filled with grotesque motifs such as phallic towers and giant animals with gaping mouths (see pictures below), which again resonates with the notion of carnival. Featuring an army of extras carrying umbrellas with a red and green watermelon print, this sequence playfully takes up one of Tsai's most recognisable motifs while parodying Jacques Demy's celebrated musical Les parapluies de cherbourg (1964). Accompanied by Hung Chong's Qi Miao De Yue Hui (Wonderful Rendezvous), this number is punctuated by the strident, high-pitched laughter of this song's chorus, which 
lends it a singularly comic-festive quality.
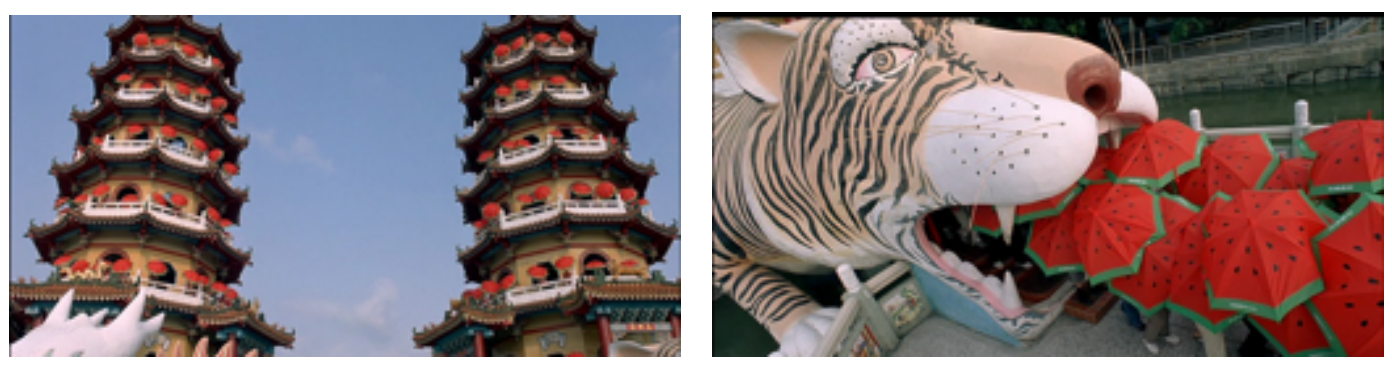

Grotesque Motifs: phallic towers and gaping mouths

This sequence also takes up transvestism, another quintessential grotesque trope (Bakhtin 1984: 81), which, incidentally, goes back in time to the scene in Vive l'amour in which Hsiao-kang, alone in the unoccupied apartment, dresses up as a woman, shedding light on Tsai's take on gender and sexuality. Preceded by the scene in which Shiang-chyi attempts, without success, to sexually arouse Hsiao-kang, this musical, like the one in which he is a giant penis, refers to his inability to consummate their relationship. Crossdressed, Hsiao-kang dances and sings with feminine gestures while Shiang-chyi, in a grey suit and hat, acts out the masculine role. Building on Judith Butler, Vivian Lee argues that this sequence therefore exposes the taken-for-granted performativity of heterosexual gendering. As both characters appear cross-dressed, their ambivalent sexuality is overtly underlined, suggesting, particularly in Hsiao-kang's case, a 'fluidity, one that deliberately blurs the boundary between being gay and being straight' (Lee 2007: 135). 

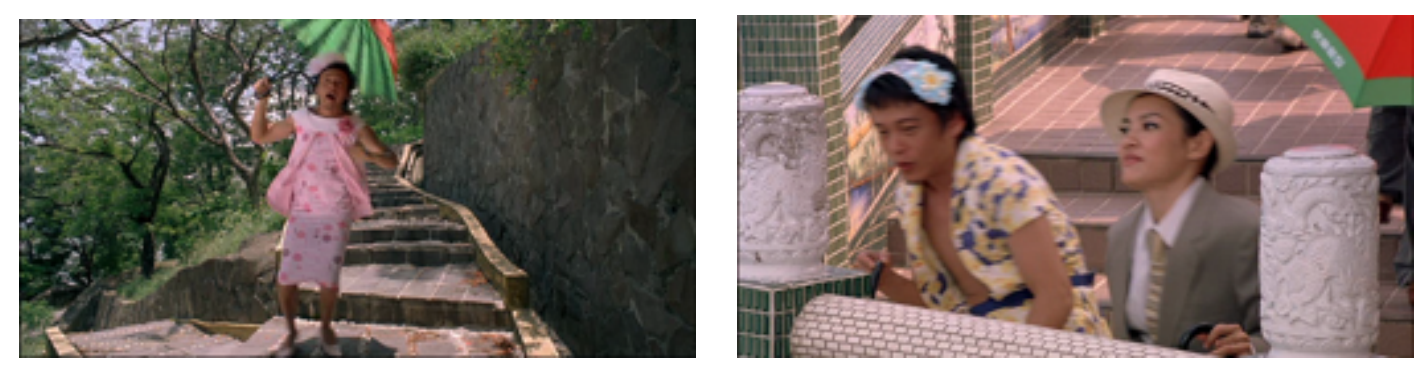

Ambivalent Genders

Lee is certainly right to read in this scene the subversion of gender expectations. Yet, I cannot follow her contention that Hsiao-kang is sexually ambivalent only in The Wayward Cloud, 'unlike his alter egos in Vive l'amour and The River' (Lee 2007: 135). If his sexual ambivalence is perhaps more overt here, it remains ambivalent in most, if not all, Tsai films. In Rebels of the Neon God, for example, one is unable to pinpoint whether Hsiao-kang is jealous of Ah Tze or his girlfriend, Ah Kuei; or if he is instead envious of Ah Tze's heterosexuality. The most-commented facet of The River is, of course, its depiction of incestuous homosexual sex in a gay sauna. Yet in one of its first scenes Hsiao-kang has sexual intercourse with a girl, Shiang-chyi, a scene which therefore marks the beginning of their 'history' across Tsai's oeuvre. If we are to take What Time Is It There? as a sequel to The River (as the same family and settings suggest), what are we to make of Hsiao-kang here, as we see him obsessed with Shiang-chyi and later having sex with a female prostitute, and find little, if at all, vestiges of his previous queerness? Indeed, if we are to view Hsiao-kang as the same character, as his unchanging name would seem to attest, his sexuality is resolutely ambivalent. Take also Shiangchyi's behaviour in The Wayward Cloud, which, as previously examined, picks up from What Time Is It There?. In the latter film she is depicted as open to having a lesbian 
sexual intercourse with a Hong-Kong woman she runs into in Paris. In the former she plays what is normally held to be the masculine role in a heterosexual couple, taking the initiative to have sex with Hsiao-kang and even attacking him in a porn video rental shop. In most films Hsiao-kang similarly fails to correspond to the stereotypical images of the hetero and/or homosexual, as does his father, who in The River, for instance, performs strictly domestic chores generally coded as feminine, such as ironing and cooking.

Tsai's characters resist unambiguous gendered identities and the roles expected from this distinction, an aspect which The Wayward Cloud playfully illustrates. In this respect, I Don't Want to Sleep Alone is also emblematic: here we find Hsiao-kang undecided between a woman (Shiang-chyi) and a man (Rawang). In the film's last shot this conflict seems solved as we see the three characters sleeping together, Hsiao-kang in the middle, on a mattress floating over a flooded construction site. This shot epitomises the sexual malleability of Tsai's characters, their resistance to pre-established, socially imposed sexual identities and the roles expected from such identities. Again, this resonates with a grotesque overturning of sexual norms and conventions, a grotesque body, to use Stam's words, which, 'against a patriarchal ideology of innate difference...exalts the blurring and shifting of gender distinctions...open to the circulation of multiple drives and desires' (Stam 1995: 163).

Brazilian writer Caio Fernando Abreu once said: 'The thing is that homosexuality does not exist, has never existed. What exists is sexuality - and directed to any object whatever of desire. Which may or may not have identical genitalia, and this is a mere detail' (Abreu 2009: 59). Is this not what Tsai's characters debunk: the myth of an inborn, unchanging and binary sexuality? As Deleuze and Guattari put it, 'sexuality...is 
badly explained by the binary organization of the sexes, and just as badly by a bisexual organization within each sex...Sexuality is the production of a thousand sexes, which are so many uncontrollable becomings' (Deleuze \& Guattari 2004: 307). In symmetry with this, Tsai's oeuvre depicts sexual conduct which confrontationally defies representational logic and normative sexual behaviour, such as the homosexual incest depicted in The River. The Wayward Cloud, in its turn, depicts an atypical threesome involving necrophilia, when Hsiao-kang, in front of the cameras, has sex with the Japanese porn actress who appears to be dead. The shoot is watched by Shiang-chyi, who, sexually stimulated by the sight, starts grunting and vocally 'stands in' for the actress' unresponsive body, establishing with her and Hsiao-kang a threesome of an unexpected sort. An equally unusual threesome can be found in I Don't Want to Sleep Alone in the scene in which the mother (Pearly Chua) of the comatose character (also played by Lee Kang-sheng), a teahouse owner, applies moisturiser to her bed-ridden son, occasionally slipping her hands into his pants. Later in the film, she stimulates his genitals through Shiang-chyi, who is grabbed by the mother and forced to masturbate her son.

These deeply unconventional sexual encounters are thus animated by a grotesque drive which overturns the repressive and reproductive sexual mandates of patriarchal ideology. Reproduction, in these three cases, is not only undesirable but wholly unattainable. As Chow argues, furthermore, the mere recognition that Hsiao-kang and his father are practicing incest in The River is already telling insofar as it implies the recognition that

the categories of the kinship family (upon which the norm of heterosexual 
marriage rests with its set relations of filiation) and the categories of heterosexuality (upon which the norm of kinship family rests with its set of mechanisms of biological reproduction) are unstable cultural inventions (Chow 2004: 124).

Sexual taboos are further broken here through characters whose predisposition for anonymous, casual, one-off sex encounters is remarkable, an unrelenting sexual drive that frontally contradicts the repressive dictates of sexual abstinence put forth by discourses on sexuality in the age of AIDS. In fact, AIDS has been pervasive in Tsai's career since his documentary My New Friends (Wo xin renshi de pengyou, 1995), in which the director interviewed two gay men diagnosed with the virus. He further approached the subject in Rebels of the Neon God whose opening shows Hsiao-kang accidentally cutting his wrists while blood drips across a map of Taiwan, which, as Lim notes, suggests the massive spread of the disease in the country (Lim 2006: 140), a visual metaphor later reinforced in the scene in which Hsiao-kang, bearing Ah Tze a grudge, sprays the word AIDS across his motorbike. Though Tsai's following films would refrain from openly engaging with the theme, they depict the very universes - cruising areas, gay saunas, decrepit cinemas - and (promiscuous) behaviour that have become severely stigmatised by the disease. His films could also be viewed as allegorising AIDS through the mysterious, invisible illnesses affecting his characters, such as Hsiao-kang's neck pain in The River or the inexplicable epidemic besetting Taipei in The Hole. 

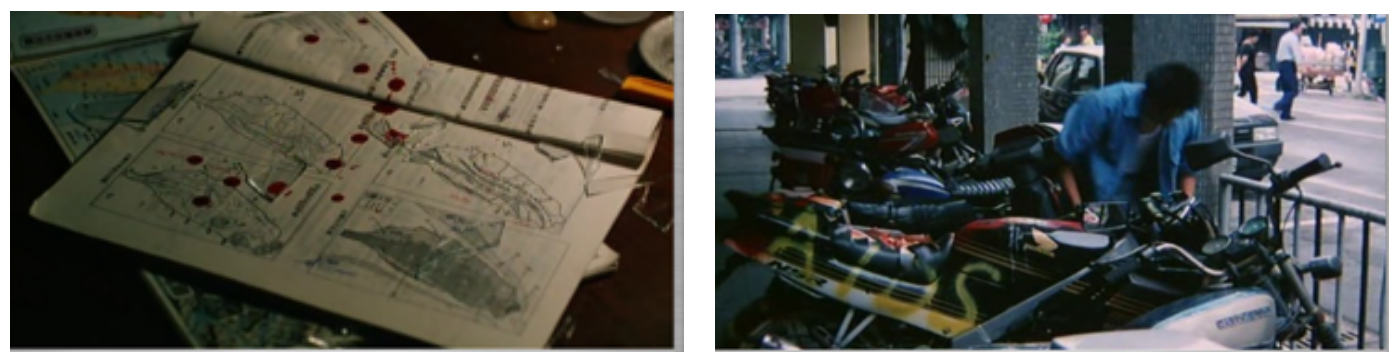

AIDS in Rebels of the Neon God

Of course, Tsai's universe is not all roses: we are talking here of deeply solitary, marginalised and isolated characters plagued by spiritual and physical pain, living in callous conditions and on the fringes of society. In many respects, his films are decidedly pessimistic about the possibility of human connection in modern life. But as in Reygadas's work, these unconventional sexual encounters and behaviour are refreshing, if only because they expose the historically constructed character of discourses on sexuality. Michel Foucault speaks of the need for inventing new sexual forms, which, in my view, sums up what is at stake here:

We have to dig deeply to show how things have been historically contingent, for such and such reason intelligible but not necessary. We must make the intelligible appear against a background of emptiness, and deny its necessity. We must think that what exists is far from filling all possible spaces. To make a truly unavoidable challenge of the question: what can we make work, what new game can we invent? (Foucault 1996: 312).

Tsai's cinema frontally confronts this question. Despite its dystopian outlook on modern life, there is an affirmative principle, informed by a grotesque impulse, underlying this 
grim world, materialised in its depiction of a liberating, indecent and outrageous sexuality.

\section{Performative Realism}

In tune with this grotesque drive, Tsai's characters are defined by a 'combination of human and animal traits', a trope qualified by Bakhtin as 'one of the most ancient grotesque forms' (Bakhtin 1984: 316). As Chow sums up, 'the features that distinguish human definitely from animals - that make humans human, as it were: features such as language, speech, thought, and narrative - are typically reduced to a minimum' in Tsai's work (Chow 2004: 126). Indeed, we hear them drinking, eating, sneezing, coughing, moaning, grunting, groaning, screaming, burping, etc., but rarely articulating speech as a form of communication. In fact, their movements and gestures resemble those of animals, notably insects (and cockroaches are a recurrent visual motif across Tsai's work). This insect-like behaviour has in fact been thematised in The Hole, in which, as previously mentioned, Taipei is crippled by an epidemic that causes the population to behave like cockroaches, crawling and scuttling in search of dark, hiding places. Likewise, 'the grotesque character of the transformation of the human element into an animal one' (Bakhtin 1984: 316) is given visible form in The Wayward Cloud's musical numbers in which, for example, we see Hsiao-kang singing in a crocodile costume and, later, his porn actress colleague (played by Lu Yi-ching, his mother in the family trilogy), dressed up as a spider.

Yet even without narrative motivation, Tsai's characters move like insects all the 
same, crawling and crouching about their apartments, performing weird and exaggerated gestures and uttering paralinguistic sounds. These overt intimations of animality are in consonance with their being depicted as physiological creatures, being moreover grounded in an eminently physical acting style. Devoid of psychological nuances and engaged in unorthodox, gymnastic corporeal movements that challenge the mechanicity of the everyday body, I would thus argue that these characters instead highlight an unfinished body in continuous becoming.

In Tsai's films we are constantly confronted with characters engaged in physical contortionisms. Take for example the scene in Rebels of the Neon God in which Hsiaokang starts to convulsively jump about while uttering unintelligible sounds in a hotel room as he observes Ah Tze's finding his vandalised motorbike.
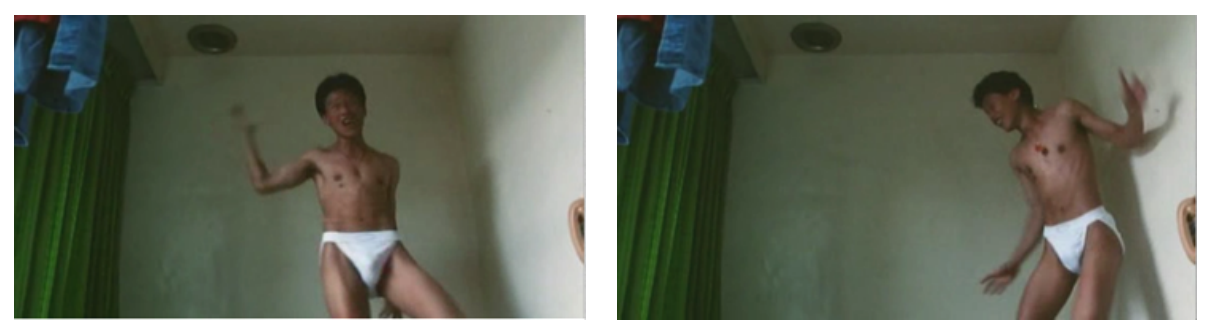

Jumping with joy: Hsiao-kang in Rebels of the Neon God

Consider also the scene in Vive l'amour which finds the same Hsiao-kang bowling a watermelon against the wall. He smashes the fruit and rubs its inside against his face. Then, he dresses up as a woman, wearing a strapped black dress, high-heeled shoes and a feathery scarf. He looks at himself in the mirror while impersonating feminine gestures and starts executing acrobatic feats and physical exercises, such as cartwheels and press-ups. 

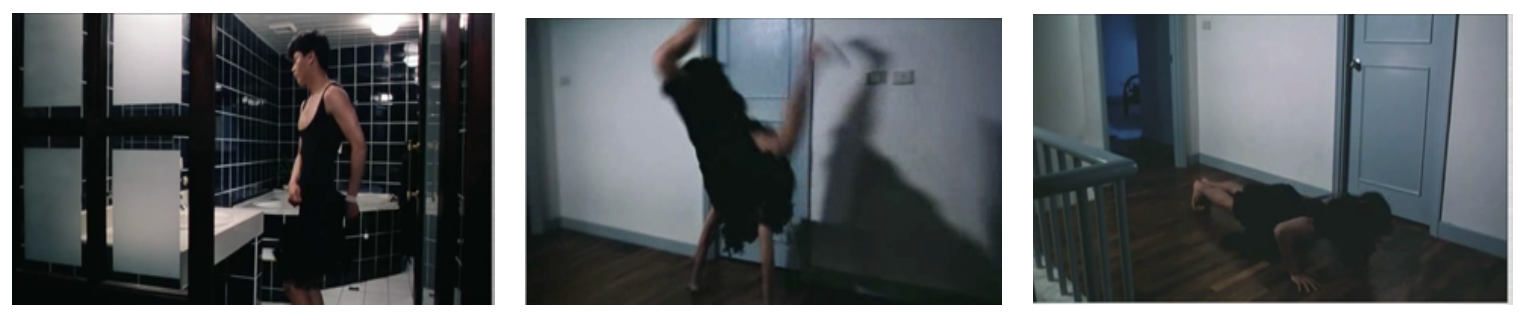

Wacky physical exercises in Vive l'amour

As with his mise-en-scène tactics, this gymnastic acting style can be traced back to Tsai's theatrical background. As Weihong Bao tells us, in the 1980s Tsai was part of the theatre group Xiaowu Theatre, itself representative of the 'The Little Theatre Movement' in Taiwan, which 'borrowed from an eclectic range of western avant-garde theatre since the 1960s as well as miscellaneous Chinese dramatic and performance traditions' (Bao 2006: 144). Though the Xiaowu Theatre would come to an end in 1985, with Tsai embarking on a career in television and, later, filmmaking, Bao charts the resonances between the acting style on display in Tsai's cinema and that of Jerzy Grotowski's theatrical practices, which made its way into the performative-theatrical scene of Taiwan through Liu Jing-ming's You Theatre group. Grotowski's 'paratheatre', itself indebted to, among other influences, Antonin Artaud's famous 'Theatre of Cruelty', was premised on the abolition of naturalistic performance and dramaturgic representation as a means to concentrate solely on 'the actor's body in non-narrative situations' and ‘intense physical actions' (Bao 2007: 145). As such, rather than representations of emotional or psychological states, Grotowski’s paratheatrical practices were performative, improvisational 'presentations' cathexed on the sheer expressivity and literalness of the human body.

Bao analyses this paratheatrical acting style in The Wayward Cloud, "when the 
intensity of acting no longer needs narrative justification' (Bao 2007: 146). She cites, for example, when Hsiao-kang climbs up and forms an arch with his body against the corridor's walls and just below the ceiling while Shiang-chyi feeds him some fruits, as well as the scene in which Shiang-chyi, carrying a watermelon underneath her top emulating a pregnant belly, performs the 'birth' of this watermelon in the staircase of her building while screaming with labour pain.
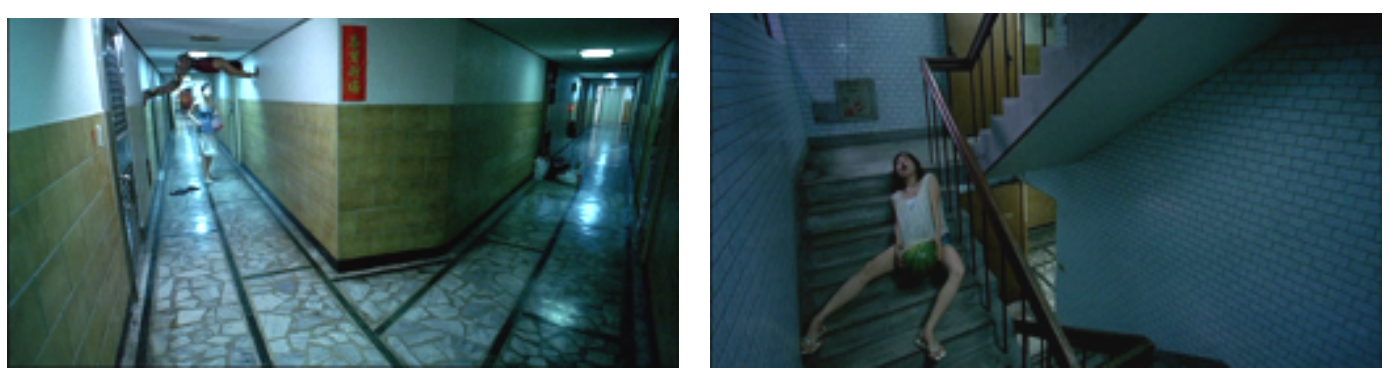

Paratheatrical acting in The Wayward Cloud

In this respect, moreover, these peculiar physical stunts, recorded by a stationary camera in long unbroken shots and performed in interior spaces, bear an interesting analogy with the work of someone such as American artist and performer Bruce Nauman who, in a manner similar to Grotowski, focused on the physical expressivity of the body as a performative act in itself, that is to say, away from the realm of representation. In the late 1960s, Nauman produced videos and 16mm films (recorded without interruption for ten minutes to be repeated on loop for an hour) in which he is shown performing random and serialised physical exercises in his own studio. Works such as Walking in an Exaggerated Manner around the Perimeter of a Square (1967-68), Bouncing in the Corner, No. 1, 2, 3 (1968), Bouncing Two Balls between the Floor and the Ceiling with 
Changing Rhythms (1967-1968) and Stamping in the Studio (1968), are illustrative of the arbitrary, idiosyncratic corporeal work pursued by him at the time, which, as their explicative titles further indicate, resonate with Tsai's highly physical vignettes. Expounding on the sensorial mode of address of these works, Nauman says that 'if you're honestly getting tired, or if you are honestly trying to balance on one foot for a long time, there has to be a certain sympathetic response in someone who is watching you. It is a kind of body response, they feel that foot and that tension' (Nauman 2003: 148).

This would also apply to Tsai's cinema, which is aimed at heightening the physicality of the viewing experience through a presentational focus on the actors' own bodies. Consider for instance the scene in The Wayward Cloud in which Shiang-chyi finds the Japanese porn actress lying unconscious. As she carries the actress across a long corridor in an unbroken shot, the visible physical effort summoned up by Chen Shiangchyi is brought to the fore. Or Hsiao-kang's neck pain in The River, which, as Margulies puts it, "takes over every scene contaminating more "dramatic" moments with an overwhelming physicality', this pain being a 'constant reminder of the actor's body, of its literalness' (Margulies 2003: 18). Or indeed Goodbye Dragon Inn, which forces the viewer to endure Shiang-chyi limping across interminably long corridors in static unbroken shots of several minutes. More than any representational function they may have, these scenes convey the actress's physical performance in their own right, that is, as sensory presentations, while at the same time enhancing the concealed corporeality intrinsic to unconscious and automatic acts such as walking.

On another note, this performative vein of Tsai's cinema is also responsible for its humorous ethos, often predicated on the distressed emotional states of its solitary 
characters. Overall, their sadness, frustration and anger, because performed with veritable physical energy, appear as highly comical, an example being the mourning demonstrations of Hsiao-kang's mother in What Time Is It There?, which, being so exaggerated, take on hilarious overtones. Another example can be found in The Hole in which we see, in two successive scenes, Yang's character sobbing in despair while crawling about her flooded bedroom, and then Hsiao-kang, crying and screaming while spasmodically ramming a hammer into the floor. In both cases their emotional states are portrayed so physically and intensely by these actors that, rather than fostering spectatorial empathy, they elicit a comical quality resulting from the openly presentational aspect of their performance.

Often referred to as 'eccentric' (Bao 2007: 146) and 'weird' (Chow 2004: 126), these are characters whose behaviour, prone to peculiar manias and intense physical demeanour, defies normative assumptions of private conduct and fixed categories of identity and subjectivity. Characterised by unexplained idiosyncrasies of behaviour, they summarily debunk the notion of a universal human Subject and the prevailing models of normality upon which such notion relies. As Jared Rapfogel puts it, Tsai's characters behave 'the way people generally behave (but are rarely portrayed behaving) when they're alone - that is to say, very oddly' (Rapfogel 2002). Consider for instance the scene in Vive l'amour in which Hsiao-kang, using washing up liquid, does his laundry in a bathtub. Or The River, in which he brushes his teeth in the shower to then start brushing his own body, including his armpits and nipples, with the same toothbrush. In The Hole Yang's character swallows paper while masturbating. Later in the film we see Hsiaokang, with his back to the camera, urinating into the toilet bowl to, in the middle of the 
act, start inexplicably pissing into the bathroom sink. Other examples of odd conduct occur in The Wayward Cloud in which, as previously mentioned, Shiang-chyi 'kisses' a watermelon, thereby replicating the same act performed by Hsiao-kang in Vive l'amour, not to mention his wacky cross-dressing stunt, as previously described.
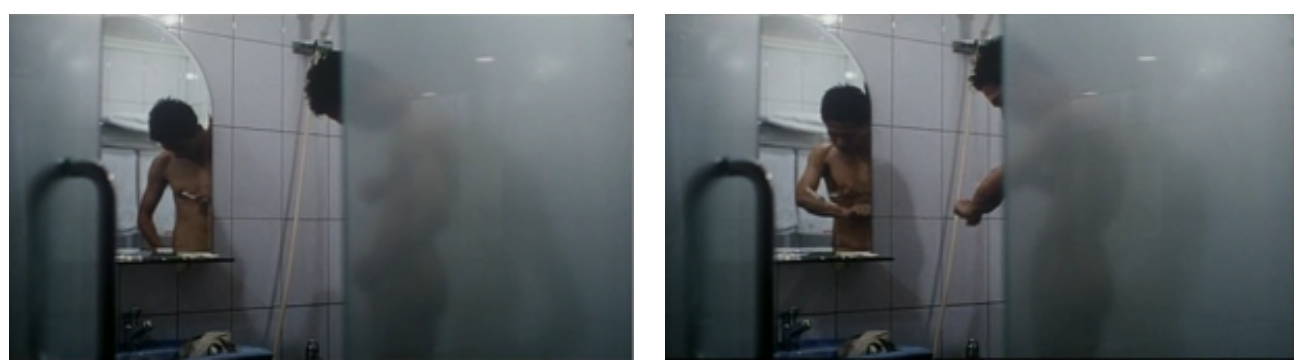

Odd Behaviour: Hsiao-kang in The River

In the same way Tsai's private everyday is cathexed on bodily functioning, it depicts singular behaviour which one only, and perhaps necessarily, adopts when entirely alone. Of course, I am not suggesting that the aforementioned examples are identified in general human conduct. What they demonstrate, precisely, is that one's private behaviour might be so particular, varied and peculiar, that the very concept of 'normal behaviour' is an empty category. Marcel Proust eloquently sums this up when he writes that "no one we know ever resembles a straight path; and we will always be astonished by every person's twists and turns, idiosyncratic, unavoidable, and irksome as they may be' (Proust 2005: 475). Which is to say that behind closed doors one's personal behaviour is likely to strike as eccentric to the outside. Tsai's work emphasises that which is incommensurable in one's behaviour, highlighting the particularities of behaviour which make one unique idiosyncrasies that can range from the outlandish aforementioned examples to more 
ordinary ones, such as Mei-mei's opening the bathtub tap with her foot or her applying make up while urinating, as displayed in Vive l'amour.

On the one hand, Tsai thus gives continuity to an everyday tradition in film through a focus on domestic spaces and solitary characters engaged in trivial chores chief everyday staples that give scenes a purely presentational quality. Devoid of narrative significance, these images impel the viewer to focus on the materiality of settings, as well as on the actors' own body, their movements and gestures, which, consequently, take on a performative aspect. Speaking of the scene of the maid's awakening in Umberto $D$, for example, Bazin would describe it as constituting 'the ultimate in "performance" of a certain kind of cinema' in which

the scenario [is] based entirely on the behavior of the actor. Since the real time of the narrative is not that of the drama but the concrete duration of the character, this objectiveness can only be transformed into a mise en scène (scenario and action) in terms of something totally subjective. I mean by this that the film is identical with what the actor is doing and with this alone... We are dealing here with a cinematographic 'report', a disconcerting and irrefutable observation on the human condition (Bazin 2005b: 77-8).

Deleuze also highlights the presentational aspect of Ozu's everyday cinema, in which, according to him, the 'action-image disappears in favour of the purely visual image of what a character is, and the sound image of what he says' (Deleuze 2005b: 13). Binding together these distinct everyday projects is therefore the same scrupulous inspection of 
private human behaviour through an emphasis on the literalness of the body (that of the actor) and its dynamics in domestic spaces.

As far as Tsai is concerned, to speak of his cinema as blurring the lines between character and actor also makes perfect sense, not least because of the ubiquitous presence of Lee Kang-sheng in his films, which have by now become documents of the actor's ongoing aging process. Yet, if here it is also the case of a 'cinematographic...observation on the human condition' (Bazin 2005b: 78) in the context of a private realm, the human behaviour on display in Tsai's work, far from restricted to universally recognisable household chores and habitual movements, is materialised through an idiosyncratic and highly corporeal conduct which reveals a decidedly anti-essentialist thrust. In this respect, it resonates, again, with a film such as Jeanne Dielman, as well as other Akerman's works, in which Margulies locates 'the politics of the singular': the foregrounding of extremely particularised bodies which, as such, resist the centrifugal impetus of representational logic. Herself indebted to performance art, 'Akerman avoids the pitfalls of totalizing representation by making her characters present gendered, individual singularities in tension with an implied category, a collective entity...their peculiar behaviour challeng[ing] the notions of generic type', an example being Jeanne's obsessive-compulsive domestic behaviour (Margulies 1996: 17).

Tsai certainly conforms to this description, yet the 'everyday theatricalization of the body' (Deleuze 2005b: 185) is here taken to extreme heights through an insistence on physiology, grotesquery and physical behaviour. While his oeuvre is cathexed on bodily functioning - universal attributes of human beings - it concomitantly focuses on the particularities of behaviour that comprise one's distinctive and irreducible subjectivity, 
even if such characters are entirely devoid of psychology. The complexity of these characters indeed resides in their extreme individualisation and resolute animality. As such, not only do they challenge and question notions of generic type, personal identity and models of normality but, as I will now argue by way of conclusion, humanness itself.

\section{Becoming Animal}

In her analysis of The River, Chow argues that Tsai's characters invite a reading which sees them as 'human remains of some previous social arrangement, apparently long since defunct...the walking exhibits of a collective order that has survived in the form of ruins' (Chow 2004: 130). Taking this reading a step further, I would like to conclude this chapter by suggesting that in many ways these characters seem to be indeed recovering from a deeply traumatic event which is not explained but whose after-effects are clearly discernable in their physical, laconic and animal-like behaviour. This reading finds immediate substantiation in their being constantly likened to cockroaches, famous for its astonishing survival abilities under catastrophic circumstances, an aspect, incidentally, overtly allegorised by The Hole, as mentioned earlier. Equally telling are the deserted, decrepit, desolate urban spaces through which these characters listlessly traverse: Where did all the people go? Why are these characters so alienated? This in turn resonates with Deleuze's definition of the 'cinema of the seer', discussed in the Introduction, whose origins the philosopher attributes to a real traumatic event, namely the Second World War. For Deleuze, the wandering, listless character which the aftermath of the war gives rise to in film is symptomatic of a post-traumatic situation in which 'the character does 
not know how to respond, abandoned spaces in which he ceases to experience and to act' (Deleuze 2005b: 261).

It is in this respect, moreover, that Tsai comes closest to one of his avowed cinematic influences, namely Antonioni. Speaking of his films, Deleuze notes how 'they reap the consequences of the effect of a remarkable event which is reported only through itself without being explained' (Deleuze 2005b: 7). In his turn, Angelo Restivo, in his book Cinema of Economic Miracles, argues that 'Antonioni can only be fully understood in light of the fundamental trauma of modernization undergone by Italy', his being a cinema arriving at 'narrative's limit point, the point where temporality itself collapses in face of historical trauma' (Restivo 2002: 143). Something similar is going on in Tsai's cinema, whose post-trauma universe seems to be an enlarged mirror of the places it depicts and in which it is so embedded, exposing the sordid underside of Taiwan's (and, more recently, Malaysia's) 'economic miracle'. Here, the trauma of modernisation is materialised through environmental catastrophes and alienated characters, who, summarily excluded from the benefits of economic development and urban modernity, are relegated to the fringes of society and seem at loss to cope with the new, industrial society in which they now find themselves. Lonely and longing for the possibility of some form of human contact, they are driven out of domestic isolation and into public space. Whether in deserted neon-lit streets and alleys, gay saunas, decadent cinemas or unoccupied apartments, they attempt, not always with success, to connect with someone else. Telling in this respect is the recurrence of places whose function is to bridge private and public realms, most notably elevators and building corridors, often the exclusive site on which some contact is initiated between otherwise isolated creatures. These 
'transitional places' epitomise the postmodern limbo in which these characters find themselves: trapped in their apartments but eager to embrace the slightest opportunity of human contact.

But if this post-traumatic universe may impress for its bleak and dystopian outlook, these are nevertheless resourceful characters. As Fran Martin argues, Tsai’s cinema seems to be an exploration of 'new ways of being in Taiwan's emergent, postindustrial, culturally hybrid society', offering, 'rather than a nostalgic lament for the lost plenitude of the past, ...the faint inkling of novel possibilities produced out of the difficult conditions of the present' (Martin 2000). In line with this, I would like to suggest that Tsai's characters, as a result of their undisciplined, grotesque and spontaneous bodies, indeed carry within themselves the seeds of change.

To see Tsai's characters as emerging from the vestiges of a traumatic event makes sense in light of their extreme isolation and linguistic inarticulacy, not to mention their previously examined idiosyncratic and extreme corporeal movements. This is a body ungoverned by automatic, mechanical, daily movements as conditioned by habit and cultural conventions but one which instead insinuates animality - crawling, laconic and insatiable bodies overtaken by primal instincts and an outpouring physicality. It is precisely in this sense, furthermore, that these are bodies in stark contrast with what Foucault defines as the 'docile bodies' subjugated by techniques of power and domination and accordingly assessed on the basis of their efficiency, productivity and submissiveness. He writes: 'the body is...directly involved in a political field; power relations have an immediate hold upon it; they invest it, mark it, train it, torture it, force it to carry out tasks, to perform ceremonies, to emit signs' (Foucault 1979: 25). Thus, 
'discipline produces subjected and practised bodies, "docile" bodies. Discipline increases the forces of the body (in economic terms of utility) and diminishes these same forces (in political terms of obedience). In short, it dissociates power from the body' (Foucault 1979: 138).

By contrast, the bodies on display in Tsai's cinema challenge these disciplinary dictates. Instead of emitting readable and predictable signs, these are characters whose ungoverned sexuality and untamed animal-like behaviour seem to grant audiovisual form to what Deleuze and Guattari, elaborating on the 'minor literature' of Franz Kafka and its half-human, half-animal characters, call 'becoming-animal', which they define thus:

To become animal is to participate in movement, to stake out the path of escape in all its positivity, to cross a threshold, to reach a continuum of intensities that are valuable only in themselves, to find a world of pure intensities where all forms come undone, as do all the significations, signifiers and signifieds, to the benefit of an unformed matter of deterriorialized flux, of nonsignifying signs (Deleuze \& Guattari 1986: 13).

According to Deleuze and Guattari, the becoming-animal, both as a trope but also as a real possibility, dismantles stratified, 'oedipalized' and normative notions of personal identity and human subjectivity through a 'deterrorialization' of the fixed forms, signs and categories upon which such notions rely. On the threshold of humanness and animality, the becoming-animal points to uncharted possibilities of psychic and corporeal selfhood in the world, allowing unsuspected self-transformations and social relations to 
come into life. It challenges the commonsensical, gendered, predictable view of what a body is and what a body does, what Foucault calls its obedient 'docility-utility' (Foucault 1979: 137). It shows, precisely, that our bodies carry within themselves a multiplicity of ways of being yet to be explored. As Tasmin Lorraine puts it, 'the becoming-animal engages the subject at the limits of the corporeal and conceptual logics already formed and so brings the destabilization of conscious awareness that forces the subject to a genuinely creative response' (Lorraine 1999: 182). As a result, Deleuze and Guattari go on,

there is an entire politics of becomings-animal... which is elaborated in assemblages that are neither those of the family nor of religion nor of the State. Instead, they express minoritarian groups, or groups that are oppressed, prohibited, in revolt, or always on the fringe of recognized institutions, groups all the more secret for being extrinsic, in other words, anomic (Deleuze \& Guattari 2004: 272).

This is certainly what happens in Tsai's universe, whose becoming-animal characters give embodiment and form to a marginalised population denied the benefits of urban modernity and economic development. Deprived and disaffected, these are characters whose dysfunctional and quasi-animal private behaviour confrontationally challenges the status quo and its discursive foundations. These are undomesticated bodies, it appears, discovering their own, nascent corporeality as they go along. Family structure is no longer defined a priori but instead characterised by a malleability which exposes its 
historically constructed character. The same applies to these characters' sexuality and gendered roles which, far from being fixed and predetermined, are instead flexible, unfinished and open. Sex, identities and the body in Tsai's cinema know no numbers, names, barriers or rules: they are anarchic, inventive and outrageous.

And yet, as previously mentioned, these characters do not experience this rupture of traditional social structures in a celebratory manner. In addition, if these are bodies that defy prevailing models of normative behaviour, such defiance takes place secretively, that is to say, in a private realm. This however does not diminish the political significance of their acts. As Brian Massumi, building on Deleuze and Guattari, puts it:

Even if a body becomes in the privacy of its own home, with no one else around, not even the dog, it is still committing a social act. Becoming performs an operation on collectively elaborated, socially selected, mutually accepted, and group-policed categories of thought and action. It opens a space in the grid of identities those categories delineate, inventing new trajectories, new circuits of response, unheard-of futures and possible bodies such as have never been seen before (Massumi 1992: 101). 9

This is best exemplified by the aforementioned scene in Vive l'amour in which Hsiaokang, alone and bored in an unoccupied apartment, bowls a watermelon against the wall. Transforming this fruit into his object of desire, he passionately licks it to, shortly after, inexplicably rub its inside all over his face. Then, high-heeled and dressed up as woman, he poses in front of the mirror while admiringly swinging his skirt. Cross-dressed, he 
starts executing physical exercises such as somersaults and press-ups outside the bathroom. Defying commonsense logic, this series of actions performed by Hsiao-kang, rather than an everyday body performing domestic tasks, testifies to an untamed body in all its spontaneous freedom of becoming. Here, in the solitude of a private space, a body tears itself away from its allocated roles and functions so as to creatively embark on unknown voyages of becoming. Becoming-fruit, becoming-animal, becoming-woman, this is a body laid open in all its invigorating creativity and, as such, a political body that, against all odds, asserts its right to invent new ways of being in the world. 


\section{PART III}

\section{GUS VAN SANT AND VISIONARY REALISM}

In 2002 the American director Gus Van Sant released Gerry, an experimental film which stood in stark contrast with his previous Hollywood films. Though Van Sant started within the American independent film scene, being associated with cult classics such as Mala Noche (1985) and Drugstore Cowboy (1989), nothing anticipated the formal leap of Gerry, a direction that was later cemented with Elephant (2003) and Last Days (2005). These three films comprise what the press nicknamed as the 'trilogy of death', alluding to their reenactment of real life stories involving young demises. While Gerry was loosely based on the little known story of a desert murder, the last two instalments garnered more attention thanks to their reconstruction of widely broadcast events: the Columbine massacre and the death of rock star Kurt Cobain respectively. More specifically, these three films are bound together through a marked formal unity and adherence to cinematic realism.

On the one hand, these films resort to realist devices such as non-professional acting, location shooting and long takes. Yet, on the other, they complicate their focus on the objective real through experimental strategies that evoke, through their form, mental processes of perception and cognition, that is to say, altered states of mind. While Gerry seems to convey desert mirages, Elephant frames the Columbine killings through the 
memory of trauma. In its turn, Last Days emulates a drug-induced state of mind. As will be argued in the following chapters, these altered states are materialised in these films through a hyperbolic assertion of the film medium's recording ability, which, coupled with traditional realist techniques and conceptual strategies, yields sensory cinematic experiences.

Chapter 9 analyses the tension between realist and postmodernist styles that has, to different extents, animated Van Sant's oeuvre, with a view to contextualising his move into the 'trilogy of death'. I then proceed to examine each of the trilogy films in detail. In Chapter 10, I investigate the way Gerry, shot entirely in deserted landscapes, channels physical and improvisational realism into an aesthetics of silence and contemplation, resonating with a landscape painting tradition, as well as the 'visionary' American avantgarde cinema. Chapter 11 looks at Elephant's rendition of the Columbine massacre, which, rather than providing a moral revision of this tragedy through narrativisation, highlights instead the experiential dimension of this event - what I call 'the reality of trauma' - and, in so doing, its bewildering social complexity. Last Days comprises the focus of Chapter 12, in which I analyse its reenactment of Kurt Cobain's suicide in the light of surrealism, minimal art and the American 'structural film'. Emulating a druginduced state of mind, Last Days preserves the sheer mystery of this event, converting cinematic reflexivity into realism of the senses. 


\section{Chapter 9}

\section{Realism and Postmodernism}

Understood as styles, realism and postmodernism are at least in principle antithetical. Realism involves a search for authenticity, as well as the foregrounding of an existing, historical and contextual reality. In its turn, postmodernism is predicated on the lack of a 'real' referent, privileging instead pastiche, intertextuality and a citational impetus which aims at displacing the focus on reality as such in favour of simulation. Theoretical debates concerning the postmodern condition, and the epistemological shift it elicited in the arts, germinated in different guises as of the late 1970s, notably associated with names such as Jean-François Lyotard in France and Fredric Jameson in the US. In 1984 Jameson published his seminal essay 'Postmodernism, or The Cultural Logic of Late Capitalism', declaring, among other things, the demise of high modernist art and its replacement by a new aesthetics characterised, in his words, by a 'new flatness and depthlessness, a new kind of superficiality in the most literal sense', in which reality is replaced by 'a set of texts or simulacra' (Jameson 1984: 60).

As will be argued in this chapter, Van Sant's oeuvre seems to stand at the frontier of these seemingly incompatible styles. In contrast with Tsai's work, as analysed in Part II, his oeuvre is devoid of uniformity. His independent beginning is characterised by films displaying, on the one hand, a postmodern aesthetics of irony and pastiche and, on the other, an adherence to realism as a means to provide a social commentary on the marginalised - a stylistic conflation that resulted in strongly hybrid works. This period 
was followed by the director's famous shot-by-shot remake of Psycho (1998), which, sandwiched between two extremely similar and conventional films (Good Will Hunting, 1997; Finding Forrester, 2000), signalled a postmodern saturation in the director's career.

Let us start with Van Sant's debut, Mala Noche (1985). Released one year after Jameson's essay, this is a film that in many ways subscribes to a postmodern aesthetics. Mala Noche was adapted from a novella by Walt Curtis (a representative of the Beat movement, itself emblematic of postmodern literature and a strong influence on the director) on the unrequited love between a homosexual shop-clerk for a young illegal Mexican immigrant. More than treating the book as a source upon which to construct an autonomous cinematic work, the film hyperbolises intertextuality through an overfaithful intersemiotic translation. For example, the film closely reproduces the book's first-person narration through the showing of condensed events as they are simultaneously described by the protagonist (Tim Streeter). Likewise, it displays the self-conscious aestheticisation characteristic of postmodern art, here conveyed through a black and white cinematography whose reliance on chiaroscuro and unusual framing angles emulate a film noir style, thereby approaching " "the past” through stylistic connotation' and 'the glossy qualities of the image' (Jameson 1984: 67).

And yet, Mala Noche's textual and stylistic collage is offset by realist techniques which, aimed at social commentary, ground the film in a very specific reality and time frame. The film was shot in the poor neighbourhoods of Portland, being entirely selffinanced and filmed with a crew of four people including the director himself. This spontaneous shooting style allowed a great deal of improvisation and the concomitant 
surfacing of chance elements, lending the film a veritable documentary and improvisational quality. Starring non-professional actors, including actual tramps from Portland, as well as real immigrants with no English skills, the film's realist take on the marginalised earned Van Sant an instant reputation in the American independent film scene.

The lumping together of realist and postmodern devices can also be found in $M y$ Own Private Idaho, the director's third film, focused again on a group of outcasts, this time gay street hustlers. Van Sant's first original screenplay (his second film, Drugstore Cowboy [1981] was adapted from James Nogle's then unpublished novel), the film is an extravagant pastiche of literary and cinematic texts, opening, for example, with a direct reference to The Wizard of $\mathrm{Oz}$ (1939), as we see a house crashing down on an empty road. Like Mala Noche and Drugstore Cowboy, My Own Private Idaho is also a selfconscious reworking of the road movie. More remarkably, intertextuality is here mobilised through a revision of Shakespeare's Henry IV in the light of Orson Welles's Chimes at Midnight (1965), merging both texts into a highly baroque and patchwork-like structure. According to Van Sant, the film in fact resulted from the conflation of three different scripts, jumbled up and put together in the manner of William Burroughs's cutup technique. A key step in the development of postmodern literature, the cut-up device as formulated by Burroughs consists in fragmenting and rearranging different texts at random, producing as a consequence a non-linear and disjointed structure. And yet, whereas all of the above is in accordance with postmodern aesthetic staples, revelatory realism can also be found here. Starring River Phoenix and Keanu Reeves, My Own Private Idaho also sees Van Sant resorting to a non-professional cast who thoroughly 
authenticate the social reality of gay male prostitution. This is particularly the case in the scenes, scattered throughout the film, in which these actual street hustlers speak directly to the camera.

Van Sant's postmodern exercises continued with Even Cowgirls Get the Blues (1993). Yet another adaptation, the film is faithfully based on Tom Robbins's eponymous novel, itself a pastiche of the literary Western genre and which here finds its cinematic equivalent. Even Cowgirls Get the Blues proved a tremendous commercial and critical failure, pushing the director into mainstream films in which the social-realist dimension of his work - Portland-set narratives focused on minorities such as drug-addicts, homosexuals and the poor - would be less discernable. Subsequently, due to the critical acclaim and commercial success of the more conventional Good Will Hunting (more of which shortly), Van Sant was able to stretch intertextuality to its limits through the remake of Psycho, a personal project the director had in mind for some time which obviously needed studio backing to be carried out. Let us now devote some time to this film for, as I will endeavour to demonstrate, it sheds some light on the direction his career would gear towards thereafter.

Psycho is a final exercise in postmodern pastiche and intertextuality. As has been noted, what stands out in this remake is its hyperbolic, extreme textual fidelity to Hitchcock's film. The director had the script revised by Joseph Stephano, Psycho's original screenwriter, who updated it to a present-day context. It is a minute reconstitution of the original, including Bernard Hermann's score, Saul Bass's opening credits and the timing, mise-en-scène and visual design of almost every single shot. Moreover, such fidelity was extended to Hitchcock's filming and production 
circumstances. As Thomas Leitch notes, the film followed 'the same six-week shooting schedule as Hitchcock' and used 'a budget of \$20 million - the 1998 equivalent of the original film's shoestring $\$ 800.000$ budget' (Leitch 2003: 250). The remake's settings were further built in a lot opposite the ones used in the original and many scenes shot in the exact same locations, such as the motorway off which Marion (Anne Heche) is caught sleeping in her car.

Psycho generated an extraordinarily negative critical reception, which, in general lines, condemned the film's shot-by-shot approach as a pointless emulation of a classic whose perfection could not be matched. This view was epitomised by James Naremore, who, defining Hitchcock as 'the major figure in the auteurist movement and the most influential director in Hollywood history', concludes that his most successful film 'can never be remade' and 'shouldn't be slavishly imitated' (Naremore 2000: 5-12). Naremore considers the film a fiasco because it 'strikes [him] as academic and not at all scary', further conceding that its 'chief value is on the pedagogical or theoretical level, where it functions, intentionally or not, as a metafilm' (Naremore 2000: 4-5). Now it seems obvious that Psycho is intentionally a metafilm. Regardless of whether it succeeds or not in this endeavour, it can only be read and criticised on these grounds. In my view, this is a film that does not attempt to be a mere forgery of the original but, quite simply, a copy. Speaking of cinematic remakes in a postmodern era, Jameson argues that the very word 'remake' becomes

anachronistic to the degree to which our awareness of the pre-existence of other versions, previous films of the novel as well as the novel itself is now a 
constitutive and essential part of the film's structure: we are now, in other words, in 'intertextuality' as a deliberate, built-in aesthetic effect, and as the operator of a new connotation of 'pastness' and pseudo-historical depth, in which the history of aesthetic styles displaces 'real' history (Jameson 1984: 67).

This is certainly the case apropos of Psycho, whose excessive fidelity to the original is indeed achieved at the expense of contextual and historical verisimilitude. For example, the remake reproduces most of the original screenplay, even though its plotline is very much outdated for a contemporary audience. Indeed, a film which has single-handedly influenced a whole genre and generated its own sequels, Hitchcock's Psycho is now a text whose features, incessantly replayed, expanded and recycled, have become a foundational collection of clichés. But nowhere is the textual more privileged over the contextual - the postmodern raison d'être - than in the remake's shots which reproduce the original's use of rear projections. Once a convention of classical Hollywood cinema, and one that Hitchcock was noticeably fond of, the application of this device, now entirely in disuse, is telling as it exposes this film's hyperbolic, self-reflexive postmodern impulse.

This being said, of course the remake had to introduce changes, among them a whole new cast, slightly modernised settings, as well as colour cinematography. In this respect, moreover, it is interesting to note how some of these changes reveal Van Sant's own authorial signature. For example, the violence is more graphic: in the shower scene not only we see the red blood but also the open wounds on Marion's back, digitally created in post-production. In this same scene, a cut-in showing a bank of passing clouds, 
the director's hallmark (more of which later), flashes on the screen. Auteurist signature is also arguably found in the film's opening, when Marion and Sam (Viggo Mortensen) enjoy a moment of intimacy in a hotel room. The original made fame for its decision to show Janet Leigh in her brassiere, with Hitchcock later admitting to Truffaut he wished Janet Leigh was in fact topless (Truffaut 1993: 226). Van Sant does not realise Hitchcock's wish, preserving Marion's costume. He shows us instead Mortensen's buttocks as he walks about the room entirely naked, an ironic touch which relates to the director's open homosexuality and focus on gay themes and male beauty. Also in tune with the above is Vince Vaughn's effeminate portrayal of Norman Bates, which, whether intentional or not, resonates with a rumour surrounding the original, namely that Hitchcock cast Anthony Perkins due to his widely suspected homosexuality.

In short, one is always confronted with a troubled and split authorship in Psycho. Is this still a Hitchcock film given that most features of the original are still in place? To what extent does Van Sant's appropriation of these features and introduction of others complicate Hitchcock's auteurist signature and his own? Does one voice overpower the other? There is obviously no definitive answer to these typical postmodern problems: what we find in Psycho is one film inescapably caught up with another, two tangled-up voices battling for authority. In fact, this clash is wittily epitomised in the remake, when Hitchcock's cameo appearance, his ultimate auteurist signature, is reproduced through digital manipulation with a telling twist, as he is seen accompanied by none other than Van Sant. What is more, the former is pointing the finger and seemingly scolding the latter, an ironic touch which reflexively materialises the postmodern conflict 
underpinning this film and prefigures the reproachful attitude critics were more than likely to take.
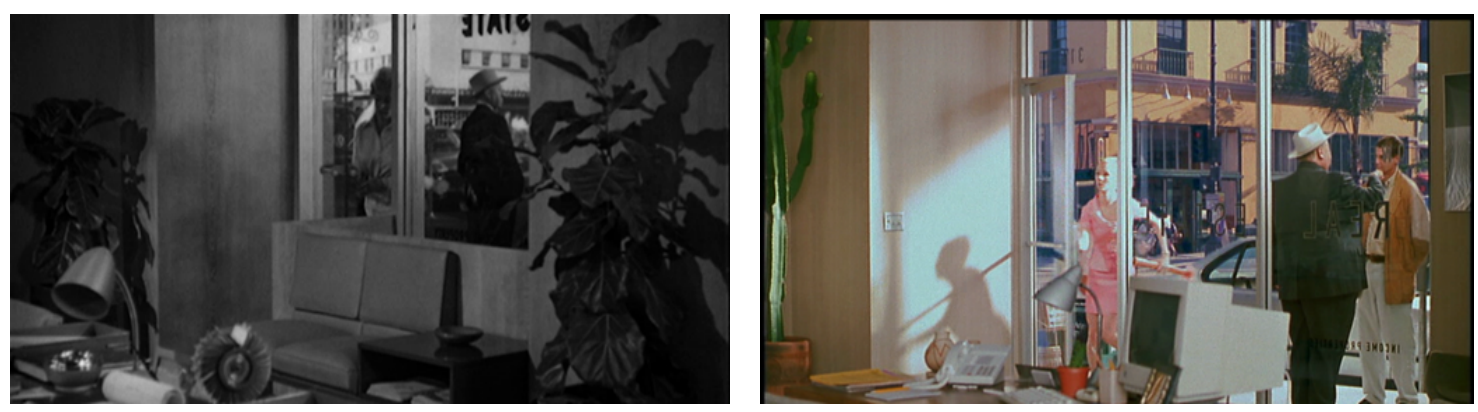

Telling off: Psycho and the remake

Psycho thus appears as the ultimate word in cinematic postmodernism, indeed signalling its own exhaustion. By deconstructing, dissecting and reassembling a film which has in many ways become the epitome of narrative film, it further reveals a filmmaker willing to arrive at a theoretical understanding of the film language canonised by one of Hollywood's most skilful directors. This is revealing considering that Van Sant's follow-up was Finding Forrester, the biggest-budget film of his career and one which was telling if only because yet another cinematic copy, this time of the director's own harvest: Good Will Hunting. In the latter Matt Damon is Will Hunting, a selfdestructive young genius who finds solace in a friendship with an older man, his therapist (Robin Williams). In the former we have a similar storyline: an intellectually gifted, black teenager becomes close to a reclusive, much older writer (Sean Connery), who becomes his mentor. These three films, which together comprised Van Sant's mainstream phase, thus suggested a career reaching its saturation point, exposing a director faced 
with typical postmodern conundrums, such as the impossibility of authenticity and aesthetic originality.

This was indeed what Van Sant himself expressed soon after in an essay on the Hungarian filmmaker Béla Tarr. Entitled 'The Camera is a Machine', this was included in the catalogue of a Tarr retrospective at The Museum of Modern Art (MoMA) in New York in 2001. In it, Van Sant describes his encounter with Tarr's work as a turning point in his career, as he found himself 'attempting to rethink film grammar' and what he calls the 'Industrial Vocabulary', of which he highlights its absolute inertia: 'The cinematic vocabulary of a 2001 television show like Ally Mcbeal is virtually the same as Birth of Nation's' (Van Sant 2001). Rather than 'separate fragments...placed together to form meaning', Van Sant goes on, Tarr's work, steeped in endless long takes, acrobatic camerawork and slow tempo, is 'organic and contemplative in their intentions', so much so that 'it is like seeing the birth of a new cinema' (Van Sant 2001). And so it is that in 2002 the director releases Gerry, a film which signals a move away from narrative terrain and postmodern fragmentation and into an experimental realism embedded in the long take and the reenactment of real, historical events. 


\section{Chapter 10}

\section{Gerry}

The films comprising the 'trilogy of death', based on real life events, resulted from similar realist modes of production: they were all entirely shot on location on the basis of improvised scripts and anchored in long takes, with Elephant and Last Days also featuring non-professional actors. Their uniformity was further accomplished through Van Sant's reliance on the same collaborators, in particular cinematographer Harris Savides, with whom the director first worked in Finding Forrester, and sound designer Leslie Shatz, whose partnership harks back to Mala Noche. In this chapter, I shall analyse the trilogy's first instalment, Gerry. As I will endeavour to demonstrate, rather than narrative interaction and meaning, Gerry strives for an aesthetics of reduction, silence and opaqueness, stretching contemplative cinema to its limits. I begin with a discussion of what I call the film's 'improvisational realism', whose skeletal and unfinished script left considerable room for chance elements during the shoot. I proceed to examine its focus on grandiose natural landscapes in the light of Van Sant's own oeuvre, canonical cinematic texts in film history, as well as a landscape painting tradition, moving on to investigate the film's debt to the American 'visionary' avant-garde cinema.

\section{Improvisational Realism}


Gerry's contemplative drive, as stated in the previous chapter, stemmed in part from a quest to break with narrative cinema, a rupture that Van Sant saw materialised in Tarr's endless tracking shots. As well as embracing his characteristic long takes, Van Sant pays open homage to the Hungarian director with 'special thanks' in Gerry's final credits. Moreover, the film cites, through compositional resemblance, emblematic scenes of Tarr's oeuvre. For example, a protracted shot of the bobbing heads of Matt Damon and Casey Affleck, the film's protagonists, evokes an identical visual composition we find in Werckmeister Harmonies (Werckmeister harmóniák, 2000). The same applies to another shot in which both characters, followed from behind on a Steadicam, walk against a strong wind, which cites one of Sátántangó's (1994) best known sequences. In view of this, Gerry could be viewed as merely perpetuating the intertextual impetus of Van Sant's cinema. This however does not stand close scrutiny, for here postmodern simulacrum is largely overridden by realist modes of production and address.
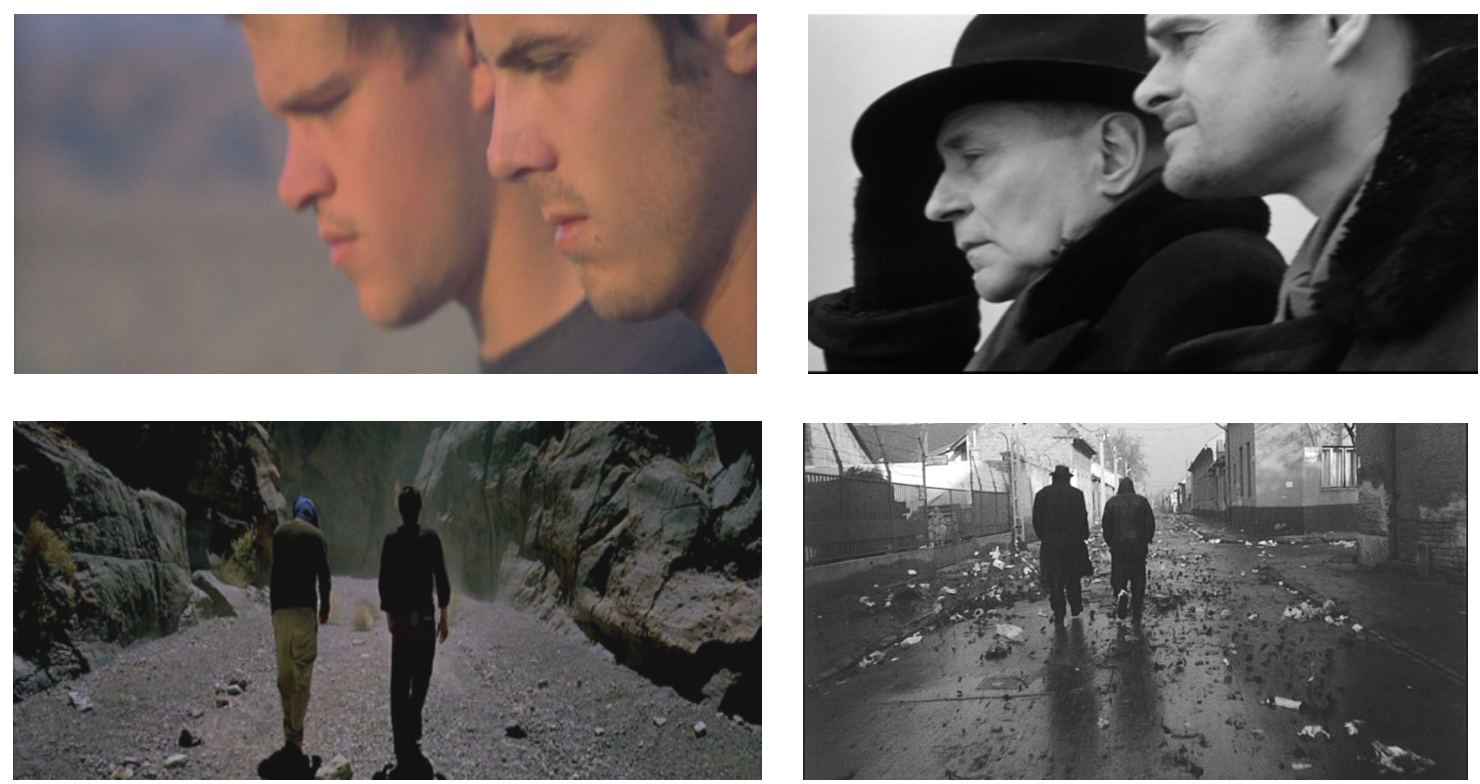

Gerry's nod to Tarr: shot citations of Werckmeister Harmonies (above) and Sátántangó 
Aiming at a more authentic project, Van Sant saw Gerry as an opportunity to go back to the unplanned, spontaneous shooting style of his self-financed debut Mala Noche. He teamed up with Damon and Affleck, personal friends with whom he had first worked in Good Will Hunting, and the trio started sketching the script for the film based on the news of a boy who murdered his friend in a desert in Mexico. This however never made it into a standard screenplay, nor is a plotline faintly discernable in Gerry. We follow these two young men arriving by car at a desert, both of whom inexplicably refer to each other as Gerry (as a result I shall be using the actors' names preceding those of the characters heretofore). We do not know who they are, their possible kinship and what has brought them to this desert, nor are we further enlightened as the film unfolds. Indeed, the only information conveyed is that they are looking for, in their words, 'the thing', yet this search is abandoned as soon as they realise they are lost. We follow, unaware of time lapses within the film, their unsuccessful attempt to find their way back while they wander across monumental landscapes, eventually pausing, talking and bickering. At the film's end, Damon-Gerry inexplicably chokes Affleck-Gerry to death, and manages to find his way off the desert and be rescued by a car.

For most of Gerry, the viewer is confronted with these characters, weak and hopeless, dragging their way across harsh landscapes and struggling to find water under a blistering sun. In this respect, the film's realism derives in part from the extreme temperatures and ruthless environmental conditions to which cast and crew were subjected. Though filmed in three distinct locations, each with its own peculiar landscape, these pass for the same desert in the film. At first, Gerry was shot in the Andes, Argentina, due to a logistical reason, namely to avoid the Screen Actors Guide 
(SAG) strike, which was a concrete threat at the time in the US. Having stayed in the Argentinean desert for nearly 3 weeks, the crew travelled back home as the strike never happened and temperatures proved too cold in the Andes. By contrast, the film's subsequent location was Death Valley, whose scorching weather (over 50 degrees Celsius) resulted in a few casualties during the shoot, with the director describing the experience as 'filming on the inside of a furnace' (Van Sant apud Tobias 2003). The film was finalised in the Utah salt flats, which, offering equally extreme conditions, prompted some crew members to abandon the shoot.

Granted, onscreen physical exertion is certainly conveyed through artifice in Gerry. One needs only consider the large make-up crew credited at the film's end, which contributed to the despairing, sunburnt look of both actors. In a similar vein, the slack, sluggish pace at which these actors walk throughout most of the film is most likely a performance. Yet, in many respects Gerry attests to what Nagib has recently theorised as 'physical realism', that is, films which attest to an actor's 'physical engagement with the profilmic event' (Nagib 2011: 12), as mentioned in the Introduction. This is what happens, for example, in the scene in which Affleck, stranded atop a rock, jumps off to the ground after hesitating for nearly eight minutes. Avoiding the use of montage trickery, this scene is presented in a long shot which highlights the physical reality of Affleck's jump, even though a jump cushion had been set up on the ground so as to prevent major injuries.

Realism is further mobilised through the film's semi-improvised script. In fact, Gerry was shot in chronological order as the director had even no idea as to how or when the film would actually end. With a view to endowing the film with a spontaneous 
quality, its script, sketched by director and actors, was composed of only two pages containing around sixty lines. With each of them counting as a scene, these were very brief, most of them one-word, descriptions which aimed at leaving room for chance happenings during the shoot. Examples include: 'taking a break', 'getting bored', 'panicking', 'looking for trail', 'returning the way they came', 'writing', 'discuss direction, which way is east', 'wandering', 'talking', 'walking' etc. (Ballinger 2004: 174). This skeletal, open-ended structure thus reveals the anti-narrative thrust informing this realist project, as well as the importance of Damon and Affleck in the film's creative process. Close friends in real life, they deliver a highly improvisational acting style grounded in absurdist dialogue.

Theirs is indeed a whimsical, obscure rhetoric full of made-up jargon such as 'dirt-mattress', 'rock-marooned' and 'mountain scout-about'. Their conversations, moreover, come across as inconsequential and nonsensical, which occasionally lends the film a humorous quality. At the film's beginning, for example, the Gerries engage in a three-minute conversation about the television programme 'Wheels of Fortune', recalling with amusement a contestant who 'had every letter except for L' in the word 'barreling' but who thought it was a Y. Later on, Affleck-Gerry claims that he 'conquered Thebes...two weeks ago', going on to give the details of the ancient Greek city's conquest to an attentive Damon for over three minutes, a baffling monologue which, the viewer concludes, can only refer to a video game. In another scene Damon suggests to Affleck, in a serious tone, that they should not go to the 'mating grounds' for what if the animals 'see [them] and they get self-conscious and then they don't mate?'. 
This absurdist dialogue, delivered by two solitary characters in the midst of nowhere, is in many ways reminiscent of Samuel Beckett's famous existentialist play Waiting for Godot, an aspect largely picked up by the press upon Gerry's release. Originally written in French as En attendant Godot and representative of the 'Theatre of the Absurd', the play presents two characters engaged in obscure conversations throughout while waiting for the eponymous Godot, which in Gerry finds its cryptic equivalent in 'the thing'. The word 'Godot', as noted by Lawrence Graver, encompasses moreover a multitude of meanings and puns, both in English and French, among them the obvious 'God' but also 'godillot' and 'godasses', French words, respectively, for 'shapeless old shoes' and 'military boots', recurrent visual motifs in the play (Graver 2004: 41). Interestingly, in Gerry it is the word 'Gerry' which is endowed with a puzzling interchangeability, a usage supposedly incorporated from the way the actors speak between themselves in real life. Not only they refer to each other as Gerry but this word, the spectator learns as the film unfolds, has a semantic and semiotic versatility in their vocabulary: it is used as a verb, an adjective and a noun, with varying meanings. Hence, in order to express his luck when 'conquering Thebes', Affleck-Gerry exclaims that that was 'such a gerry'. In another scene, Damon-Gerry explains that they 'gerried off to the animal tracks', using the word as a substitute for the verbs 'wander' or 'walk'. Most notably, Gerry stands for the word 'fuck' or 'screw', as illustrated when DamonGerry concludes that they 'totally gerried the mountain scout-about' or when Affleck accuses Damon of having 'gerried the rendezvous' they had arranged. The highly thin, cryptic plot of Gerry is therefore encapsulated in the slippery word 'Gerry', whose definite meaning, like this film's narrative, is impossible to pinpoint. 
One could argue, however, that the film's meagre narrative does lend itself to interpretation. It is telling, for example, that these characters' sparse conversations are predominantly centred on video games and television shows, which suggest an indoors, mediated lifestyle in which virtual realities take the upper hand over real experiences. In this respect, the desert in which these characters find themselves signals a move into a more physical experience, here authenticated by the film's realist mode of production. Moreover, does the fact that both characters are named Gerry imply that they are the two sides of a single person going through an existential crisis? This is not a far-fetched possibility, especially as we learn that they have opposed personalities: Affleck-Gerry is fragile and fearful, Damon-Gerry is strong and bold. What is more, the latter despises the former for these traits, as in the scene in which he reprimands him for crying. This opposition is also underlined in these characters' positioning: Affleck walks behind Damon, who invariably takes the lead. Should we then interpret Affleck-Gerry's death as a metaphorical coming-of-age or rebirth? The film's final scene seems to suggest as much when we see that Damon-Gerry has been rescued by a car. Starting with a close-up of Damon's sunburnt face, the camera gradually pans $180^{\circ}$ to the right, revealing first a blonde young boy seating by him and then a man in his forties, driving the car and looking at the back seat through the mirror. This half-circle carried out by the camera, from the child to the adult, could be viewed as foreshadowing the movement which Gerry himself is halfway through to complete, with his experience in the desert marking the threshold between both phases. Finally, when Affleck-Gerry is choked, this involves a highly sexualised, homoerotic battle between the two as they wrestle over the salted ground. Is Gerry's inner turmoil caused by a denial of his own homosexuality? 
Suggestive though these readings may be, let us not overstate these psychological interpretations, unable as they are to elicit any solid analysis in view of this film's nonsensical and rarefied narrative. Besides, as I will now show, Gerry's real protagonists are not its characters but, rather, the landscapes in which they find themselves.

\section{Contemplating Landscapes}

Gerry's aversion to psychology and drama is matched, on a visual level, by its disdain for anthropomorphic dimensions. Here, landscapes dwarf human presence so much so that Damon and Affleck often appear as insignificant dots within the frame. Their miniaturised scale renders in turn impossible the reading of facial expressions, gestures and movements, enhancing, by contrast, the enormity of the deserts they traverse. Take for instance one of Gerry's first scenes. After following the Gerries walking and talking in medium-long shots, the viewer is offered an extreme establishing shot taking in the Argentinean desert. Both characters, in infinitesimal dimensions, are located at the bottom right of the frame, being only discernable as we see them walking in a straight line to the left. The camera gradually pulls back, increasing the visual field and dwarfing the characters even further. It then starts panning to the left so as to lose sight of human presence and focus on the vast green vegetation and mountains further away in the horizon. This camera movement away from the characters and into the wilderness epitomises Gerry's disregard for human presence and deference to landscapes. Of course, the viewer continues to follow the characters' trajectory during the film, being 
occasionally confronted with dialogue and short-distance shots. But these are exceptions in a film which severely downplays human presence.
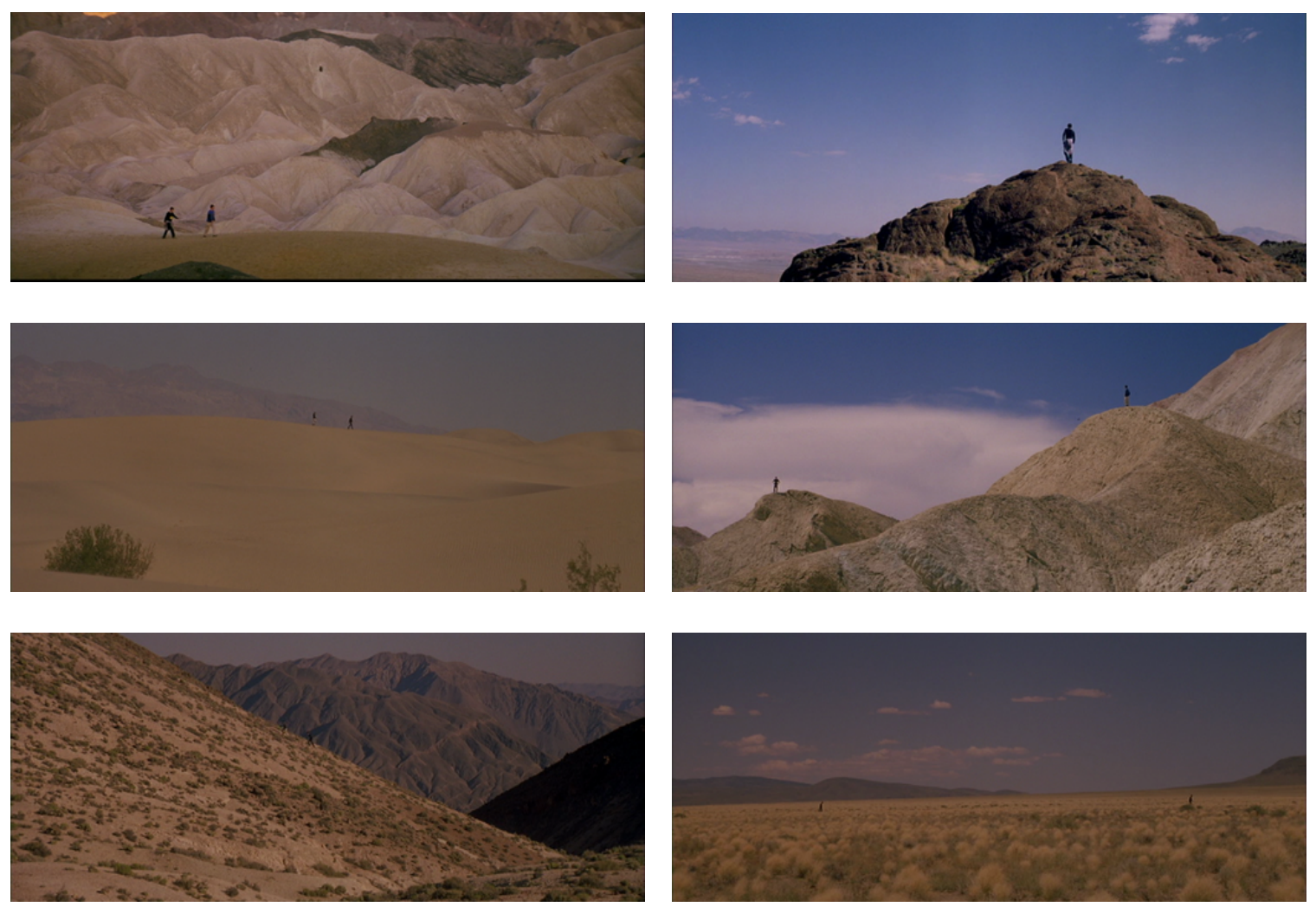

Dwarfing the human in Gerry

As a matter of fact, Savides's landscape cinematography is by far Gerry's most impressive feature. This however is certainly not the first film to convey a fascination with majestic landscapes. Vast dimensions and open expanses, as we know, are the defining geographical features of the US, featuring moreover in countless American films and being a constitutive staple of genres such as the road movie and the western. Speaking of the latter, for example, Bazin notes its 'predilection for vast horizons, allencompassing shots that constantly bring to mind the conflict between man and 
nature... and restore to space its fullness' (Bazin 2005b: 147). Likewise, and away from American genres, the desert landscape prominently featured in new cinemas across the globe in the 1960s and 1970s. As Matthew Gandy summarises:

By the 1970s the cinematic desert had become a kind of tabula rasa around which countercultural discourses could develop in opposition to the perceived hegemony and cultural inauthenticity of industrial capitalism. In the case of European and North American cinema the shifting relationship between landscape and popular culture combined with the cinematic legacy of the classic western to produce a new sensitivity toward the philosophical and political possibilities of desert space as a locus for cultural critique (Gandy 2006: 328).

Indeed, filmmakers such as Werner Herzog, Michelangelo Antonioni, Glauber Rocha, Pier Paolo Pasolini, among others, turned to the desert as a means to critique capitalism or else express social concern. Antonioni’s Zabriskie Point (1970), for example, was partly shot, like Gerry, in Death Valley. (The Death Valley has in fact an illustrious cinematic history, featuring also in Erich von Stroheim's Greed [1924] and John Ford's 3 Godfathers [1948], among others). Zabriskie Point contrasts a frantic, billboard-littered Los Angeles with the depopulated spaces of the Californian desert, thereby providing a commentary on the excessively materialist culture pervading the US. Herzog is likewise a director who appropriated the desert so as to expose capitalism's destructive drive. Fata Morgana (1971), shot predominantly in the Sahara desert and the Sahel savannahs, stitches together disconnected images of devastation found in these locations (plane 
wreckages, car carcasses, slums, weaponry, etc.), in which, as Nagib notes, 'the connection of war with destructive capitalism could not be clearer' (Nagib 2011: 91).

The representations of the desert we encounter, on the one hand, in a genre such as the western and, on the other, in these modern films, could moreover be profitably understood in light of Deleuze's distinction between the 'movement-image' and the 'time-image' regimes, as discussed in the Introduction. In the former case, Deleuze argues, characters are inserted within 'sensory-motor schemata' which unequivocally progress the narrative and to which all filmic elements, including space, are subordinated. Here, 'objects and settings...had a reality of their own, but it was a functional reality, strictly determined by the demands of the situation' (Deleuze 2005b: 4), the western genre being an eloquent example of this dynamics. In modern cinema, on the contrary, settings and landscapes 'take on an autonomous, material reality which gives them an importance in themselves' (Deleuze 2005b: 4). This is indeed what happens, to different degrees, in the films of Antonioni, Pasolini and Herzog, among others, in which landscapes call attention to their physicality as such and, as a result, ask to be contemplated for their own sake. And it is precisely this aspect which Gerry seems intent to carry to its ultimate consequences, pushing a cinema of contemplation to new heights.

To be entirely accurate, Gerry is in fact the culmination of a landscape sensibility which has always informed Van Sant's work, being a reflex of his roots in the Beat movement. As Jack Sargeant notes, films such as Mala Noche, Drugstore Cowboy, My Own Private Idaho and Even Cowgirls Get the Blues 'all reveal an interest in America and the vastness of the American landscape - which is similar to that manifested in [Beat writer] Jack Kerouac's writing' (Sargeant 1997: 219). Not only that, these are works also 
flirting, in postmodern fashion, with the road movie and the western genre. In them, characters are always on the road, which provides the cue for the foregrounding of the US's infinite expanses, notably the North and Mid-West. Yet, their display of vast landscapes is not only momentary but somewhat peripheral to their diegetic worlds. In Gerry, by contrast, postmodern fragmentation gives way to contemplative realism, meaning that landscapes become the central focus of attention. Their scale is either in monstrous contrast with that of characters or else they are displayed entirely on their own in extended shots. In this respect, the film resonates with a landscape painting tradition.
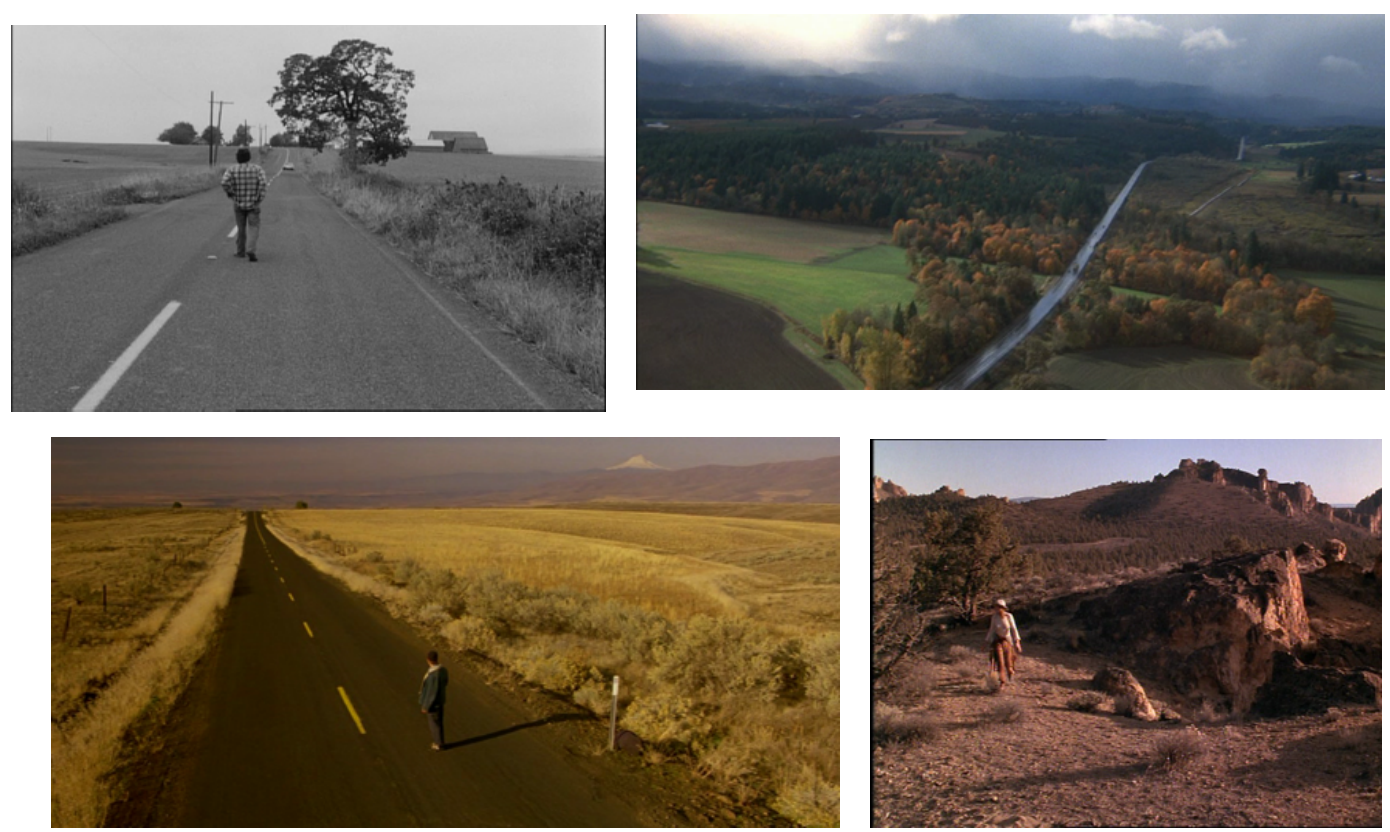

On the road: vast expanses in Van Sant's films (in clockwise order, Mala Noche, Drugstore Cowboy, My Own Private Idaho, Even Cowgirls Get the Blues)

In his study of spatial representation in cinema, Martin Lefebvre asks whether there is such a thing as 'landscape' in film, in the contemplative sense this term has acquired apropos of a Western painting tradition. Distinguishing between 'settings' space subordinated to narrative function - and 'autonomous landscapes', Lefebvre argues 
that the spectator may well choose to read a given image against the grain and adopt an 'autonomising gaze', taking in, for example, a western setting 'in its own right', and thereby transforming it into a 'landscape' (Lefebvre 2006: 29). On the other hand, one may find 'landscapes' momentarily, as in the 'temps morts' of Antonioni's films. Without a doubt, Gerry sets new parameters vis-à-vis a landscape tradition in film, being composed as it is of nothing but temps morts. If, as Malcolm Andrews contends, a landscape painting tradition emerges, among other reasons, as a quest 'to celebrate the awesome beauty of the natural world' (Andrews 1999: 48), Gerry is similarly a film which seems in awe of its own ability to record the phenomenological real as materialised in stunning landscapes.

Lefebvre charts the birth of a landscape tradition in the visual arts as the historical moment these locations cease to be a 'spatial "accessory" to a painted scene' and become 'the primary and independent subject matter of a work' (Lefebvre 2006: 23). This meant the literal spatial increase of landscapes in the surface of a painting and the inversely proportional decrease in the size of human beings. (Such process, interestingly, would thus be inverted with cinema whose over-reliance on the human body as the common denominator for its framing measures are well documented [see Doane 2009; Lefebvre 2006: xi]). This dwarfing of the human figure culminated in the Sublime painting tradition, a tendency with which Gerry specifically resonates.

The defining characteristics of the Sublime were famously proposed by the English philosopher Edmund Burke in his Philosophical Enquiry into the Origin of our Ideas of the Sublime and Beautiful, a book which, as Andrews notes, 'had an immense influence on aesthetics in Europe and North America in the latter part of the [eighteenth] 
century' (Andrews 1999: 132). Burke defined the Sublime as that which divests the human being of control and reasoning, the experience of which, usually found in nature, is inexpressible and unrepresentable. To encounter the Sublime is thus to confront superlative, abstract concepts such as 'Vastness', 'Infinity', 'Light', 'Magnificence', materialised in the natural world (Burke 1827). This notion was pictorially translated into landscapes whose monumentality loomed over powerless, minuscule human figures. Thus, in William Henry Bartleett's View Below Table Rock (1837), the painting's vertical surface is dominated by colossal falls cascading down upon three extremely small human figures at the bottom right of the picture. In Caspar David Friedrich's The Monk by the Sea (Der Mönch am Meer, 1809) we encounter over two thirds of the surface occupied by an immense and formless white sky, which weighs down upon the infinitesimal monk at the bottom. Gerry's scenes filmed in the Utah salt grounds, in particular, evoke Friedrich's painting. The whiteness of the salt flats are mirrored by the purplish white sky, resulting in visual compositions whose uniform, expansive paleness is counterpointed only by the diminutive presence of Damon and Affleck at the bottom of the frame (see pictures below).
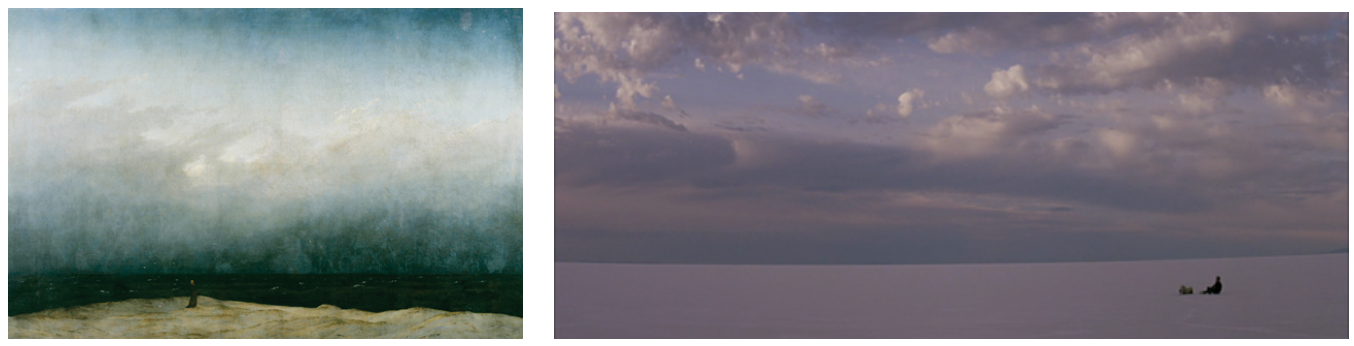

The Sublime in Caspar David Friedrich's The Monk by the Sea (1809) and Gerry 
But here we are also compelled to examine this visual resemblance more closely. For a Romantic painter like Friedrich, the contemplation of nature - mirrored in his paintings by subjects seen from behind and contemplating views themselves - was the means by which to enter into communion with a spiritual dimension. His paintings, as The Monk by the Sea illustrates, are freighted with religious allusions. In Gerry, this metaphysical dimension is not so clear-cut. More than communing with Nature, these characters are estranged by it, suffering from its sheer physicality and cruel indifference, an aspect epitomised, for example, in the splendid yet merciless salt flats. Granted, these characters' search for 'the thing' could suggest a spiritual journey. But in the same way that Godot never comes in Beckett's absurdist play, 'the thing' is never found in this film either. Which is to say that if these grandiose images may well lend themselves to metaphysical readings, they perhaps more pointedly convey emptiness, nothingness and meaninglessness, testifying not to God but to the sheer mystery of existence and the physical world, as well as our epistemological and specular limits in attempting to comprehend it.

\section{Visionary Images}

As well as looming over defenceless humans, landscapes in Gerry seem to convey a subjective consciousness. We see, in lengthy shots, immense skies, rising suns, sped up clouds and shadows, sand dunes and monumental rocks - autonomous images that arbitrarily halt Gerry's rarefied narrative and whose extended duration lend the film a hypnotic quality. As viewers, furthermore, we are unable to locate their place within the 
diegesis. Are they purely objective images conveying the passing of time? Are they being 'seen' through the eyes of these characters? Or are they 'mirages' in their own right, that is, audiovisual expressions of a pure consciousness? While these questions remain unanswered, the fact remaining is that these oneiric images resonate with the American avant-garde tradition and its 'visionary' quest as famously theorised by P. Adams Sitney (2002), whose representatives include names such as Maya Deren, Stan Brakhage, Michael Snow, among others. Sitney defines the visionary tradition in film as an attempt to reproduce dream states and (altered) mental processes through the juxtaposition of non-correlated, literal images, its greatest aspiration being 'the mimesis of the human mind in a cinematic structure' (Sitney 2002: 305), which seems to be the case in Gerry.
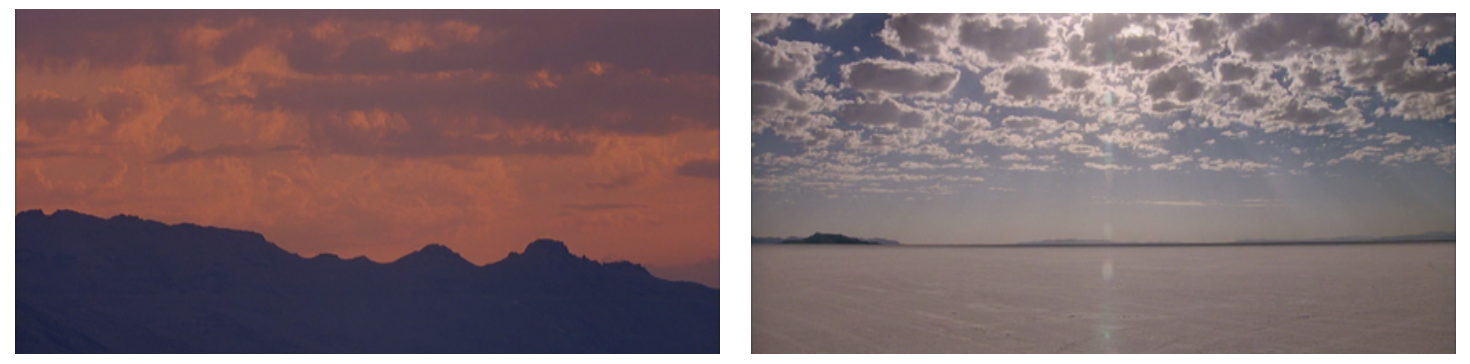

Visionary Images in Gerry

Van Sant's rapport with the American avant-garde goes back to his student days at the Rhode Island School of Design in the 1970s where he studied experimental cinema and became engaged with this filmmaking strand. Though he later veered into narrative cinema, 'visionary' images are however pervasive, if in subdued form, in many of his films, arguably comprising one more facet of their postmodern collages. Most notably, they appear in his films in the form of passing clouds which, either slowed down or sped 
up, interrupt the narrative flow, offering instead moments of contemplation. This visual motif has in fact become the director's hallmark, being found in most of his films to date, even as a flashing cut-in in the shower scene in Psycho, as mentioned in the previous chapter. In films such as Drugstore Cowboy and My Own Private Idaho, moreover, sped up clouds stand for the characters' altered perception of reality. In the former they appear, together with surreal objects floating in the air, as a means to convey the characters' drug-induced state of mind. In its turn, the latter's narcoleptic protagonist, played by River Phoenix, provides the cue for dreamlike images of empty roads and passing clouds whenever he falls into deep sleep.
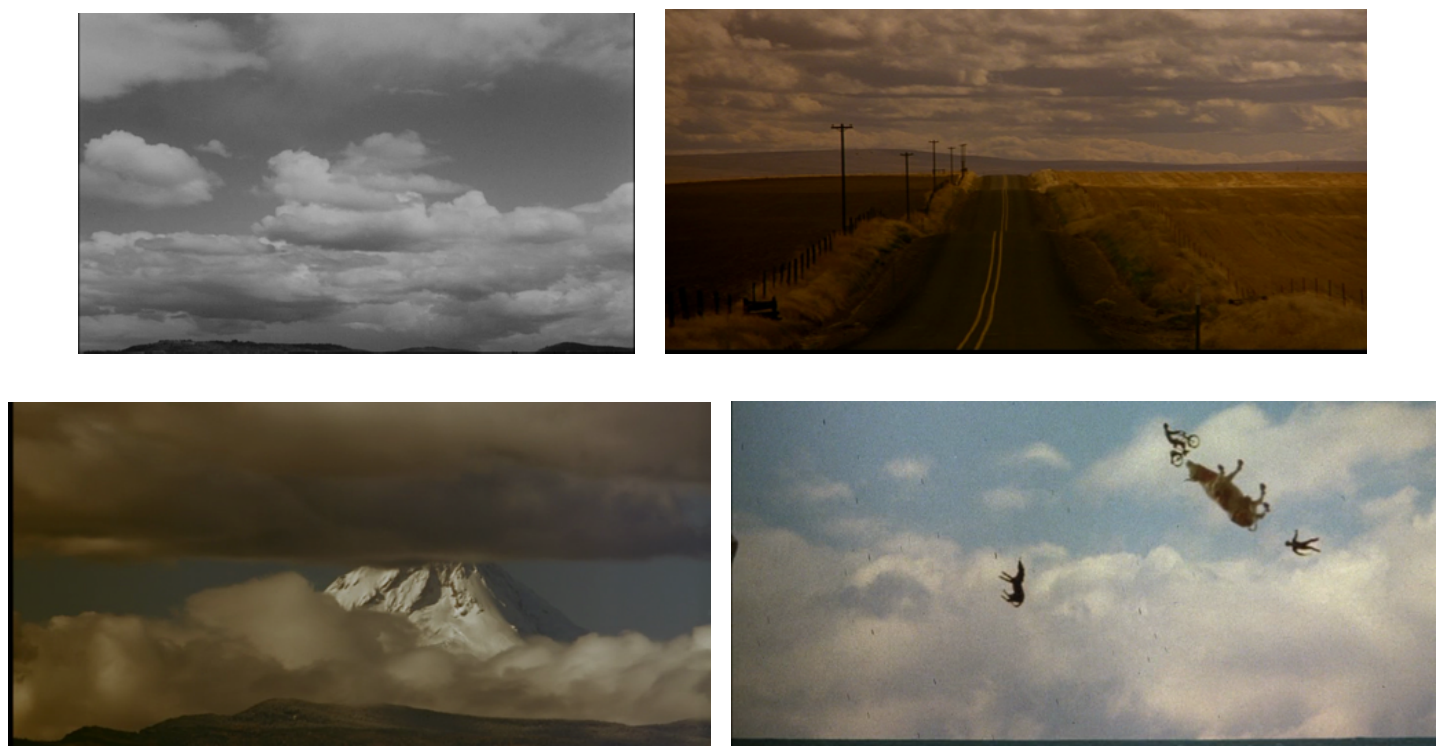

Visionary Images: (in clockwise order) passing clouds in Mala Noche, My Own Private Idaho Drugstore Cowboy and My Own Private Idaho

However, visionary images are onscreen in these films for a few seconds. Moreover, the altered states of mind they convey are acknowledged as such within the narrative, which clearly demarcates the reality of its intradiegetic universe and the 
distorted cognition of this same reality as experienced by characters. In Gerry (as well as Elephant and Last Days, as will be examined), this demarcation is nowhere to be seen, meaning that objective and subjective perspectives become indistinctly blurred. Deleuze's definition of modern cinema's narratives is applicable to this film:

We run...into a principle of indeterminability, of indiscernibility: we no longer know what is imaginary or real, physical or mental, in the situation, not because they are confused, but because we do not have to know and there is no longer even a place from which to ask (Deleuze 2005b: 7).

Gerry conforms to this indetermined quality. In it, the real and the imaginary irresolvably conflate, as epitomised in the scene showing a mirage, the quintessential desert trope. We initially see both Gerries from behind talking to each other as they sit on the ground, while noticing that a person, entirely out of focus and in the distance, walks towards the camera. As the scene cuts to a frontal shot of both characters and then back to a shot from behind, the camera starts closing in on Affleck's back and we realise that the person coming in his direction is actually Damon and that this film operates at the intersection of the real and the imaginary.
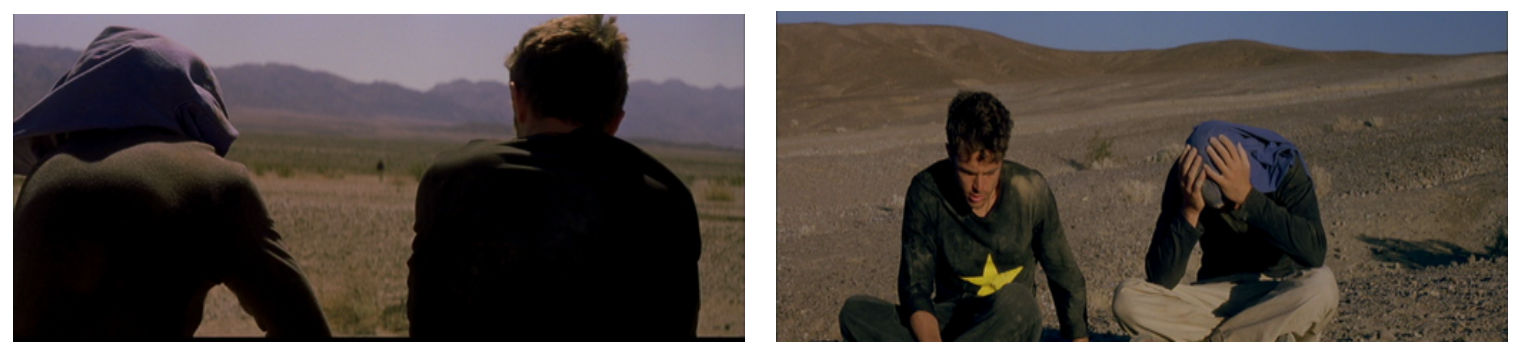

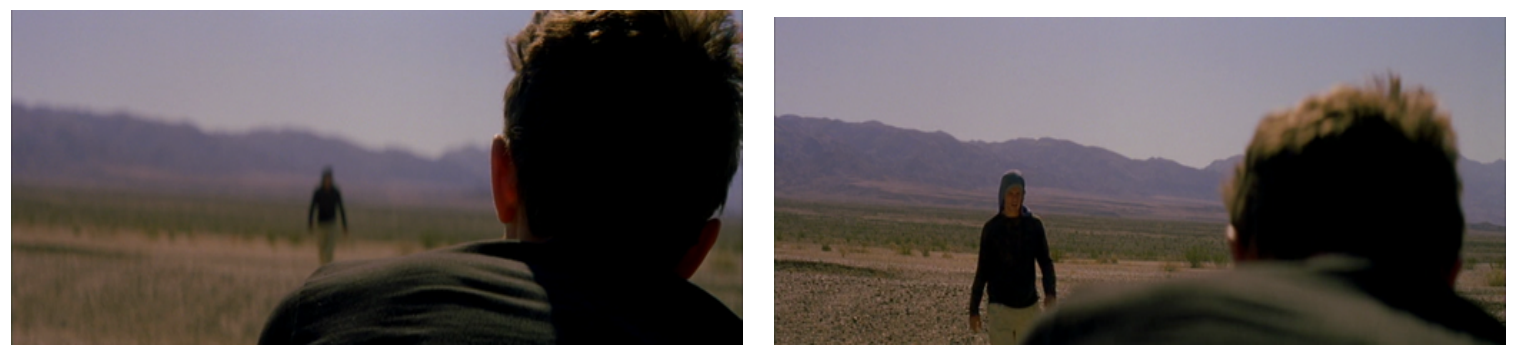

\section{Confronting a mirage in Gerry}

Even more remarkably, conflation of subjective and objective perspectives is mobilised here through the film's form, which, thanks to a discontinuous montage of mirage-like landscape images, evoke 'more directly states of consciousness and reflexes of the imagination in the viewer' (Sitney 2002: 306). Onscreen for minutes in extended shots, these images resist signification and are conveyed as sensory experience, requiring from the viewer a contemplative mode of attentiveness. We are given plenty of time to study the phenomenal, textural, tactile, in short, the affective qualities these landscapes radiate: the solidity of rocks, the gaseousness of passing clouds, the whiteness of salted grounds, the blueness of skies. Let me resort to Deleuze's definition of the 'affectionimage' to clarify my point. Drawing on Peirce's concept of 'Firstness' - a mode of being in which qualities have not been actualised in a state of things and thus emerge 'in their own suchness' (Peirce 1950: 86) - Deleuze defines affect as the pure expression of a pure quality or power: 'It is that which is as it is for itself and in itself' (Deleuze 2005a: 100). In film, he goes on, affect is 'expressed' when the image loses its spatio-temporal coordinates, enabling qualities to appear for themselves. This, he contends, is accomplished mostly through the facial close-up and what he calls the any-spacewhatever (espace quelconque) or qualisigns, of which he distinguishes two types: 
There are...two states of any-space-whatever, or two kinds of 'qualisigns', qualisigns of deconnection and of emptiness. These two states are always implied in each other, and we can only say that the one is 'before' and the other is 'after'. The any-space-whatever retains one and the same nature: it no longer has coordinates, it is a pure potential, it shows only pure Powers and Qualities, independently of the state of things or milieux which actualise them (Deleuze 2005a: 123).

Gerry's spaces come close to these definitions, displaying a conspicuous emptiness through which the sentient qualities of landscapes come to the fore. In the same vein, its framing strategies produce images which often threaten to overflow the borders of the figurative, attaining, like the time-lapsed dawn in Reygadas's Silent Light (described in the Introduction), the sensuous quality of abstract paintings in motion. This is what happens, for example, in the shot showing an immense blue sky under which we see triangular summits and, on the right, formless white clouds whose changing shape is rendered visible through time-lapse procedures; or when we see the surface of rocks above which grey, heavy storm clouds swiftly pass through the screen (also the effect of time-lapse procedures). Though one obviously perceives these things for what they are, these images fluctuate between their real, individuated state and their sheer plasticity: their movement, forms, texture and colours are liberated from that which actualises them. In this respect, Gerry seems to answer Stan Brakhage's famous call for a pure perception, freed from language and automatisms: 'Imagine an eye unruled by man-made laws of perspective, an eye unprejudiced by compositional logic, an eye which does not respond 
to the name of everything but which must know each object encountered in life through an adventure of perception' (Brakhage 2002: 46). Gerry is such an adventure of perception.
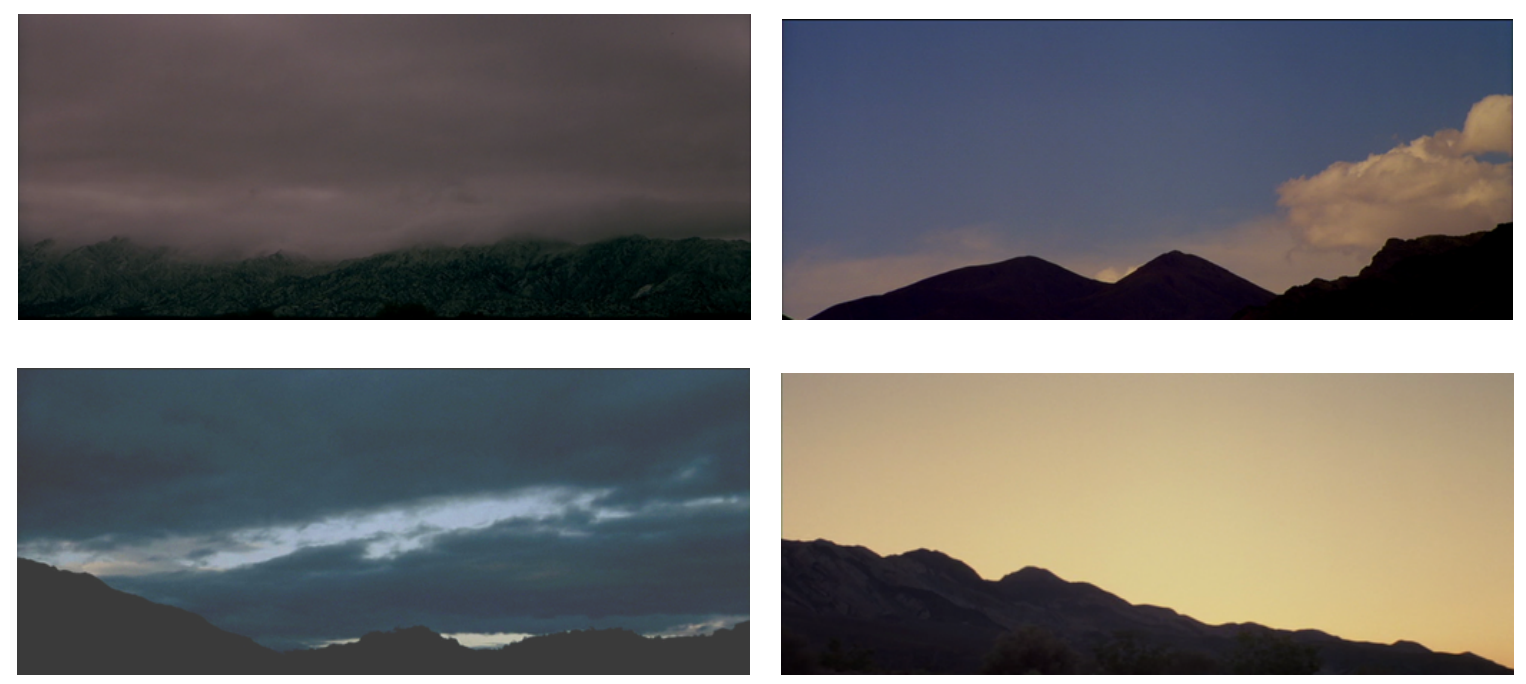

Affective landscapes

By way of concluding this chapter, I would like to reframe some points already made. Gerry is all the more striking in view of its predecessors in Van Sant's career. After the hyperbolic intertextuality of Psycho and the unremarkable Finding Forrester, similar in form and content to Good Will Hunting, the director's career seemed to have reached a creative stasis. He then turned to a cinema steeped in silence and contemplation, and one which exposes a director enamoured with the film medium's ability to record visionary images. At the same time, Gerry sees Van Sant adhering more firmly to realism, a style with which the director had variously flirted since his debut Mala Noche. That he chose the desert on which to carry out this project is telling. For if the desert has given rise to numerous realist landmarks in film history, as discussed 
earlier, this is so because it offers a germinal, primordial locus. A space of sheer authenticity, wilderness and physicality, it is by nature resistant to representation; a 'tabula rasa', to cite Gandy again, in which one can restart a filmmaking career anew.

Before Jameson, Sontag had already observed, in 1969, the representational saturation which would come to be viewed as typical of postmodernism, though without using this term. In her famous essay 'The Aesthetics of Silence', she discusses art which, rather than fostering meaning, turns to 'opaqueness', 'blandness', and 'alogicality', citing, among others, Beckett and minimal art. This silent turn she attributes to a general scepticism towards language and the concomitant appeal of a cultural and perceptual cleansing process in the context of a world overfilled with readily available representations and 'furnished with second-hand perceptions' (Sontag 2009: 5). As the artist is faced with the daunting prospect that whatever he or she creates 'will remind...of something already achieved', silence promises a more immediate and 'unalienated art' (Sontag 2009: 14-5). Van Sant was certainly after this artistic purification and authenticity when making Gerry. Rather than embracing collage and pastiche, he devised an experimental-realist approach which attests to the film medium's ability to enhance perception and, in so doing, evacuate consciousness of what we traditionally call 'thinking'. Sontag compares silent art with the perceptual appeal of landscapes, an operation which is literally conflated in Gerry:

The spectator would approach art as he does a landscape. A landscape doesn't demand from the spectator his 'understanding', his imputations of significance, his anxieties and sympathies; it demands, rather, his absence, it asks that he not 
add anything to $i t$. Contemplation, strictly speaking, entails self-forgetfulness on the part of the spectator: an object worthy of contemplation is one which, in effect, annihilates the perceiving subject (Sontag 2009: 16).

An annihilated perceiving subject, however, is denied thinking only in the traditional, Cartesian sense of this term. For, as Sontag herself observes, in contemplation 'the silence of eternity prepares for a thought beyond thought, which must appear from the...familiar uses of the mind as no thought at all - though it may rather be the emblem of new, "difficult" thinking' (Sontag 2009: 17). In its advocacy for perceptual literalness and silence, Gerry strives to be this contemplative kind of art. As such, the aesthetic sensations it conjures are not disconnected from thinking but are the very vehicles through which a new thinking - that which is yet to be thought - comes into being. 


\section{Chapter 11}

\section{Elephant}

On April 20 1999, two American students embarked on a series of shootings at their school in Colorado, killing one teacher, 12 students and injuring 21 others. After the massacre, Eric Harris and Dylan Klebod committed suicide by shooting themselves. This deeply traumatic event, televised in real time to millions of viewers across the globe, was the culmination of a string of 'school shootings' in the United States which had become insidiously frequent in the late 1990s. Yet the proportions of the Columbine massacre gave a new dimension to a problem which seemed to have suddenly materialised with an unprecedented, explosive dimension. Why did these two students, armed with a multitude of rifles and bombs, carry out these shootings? Debates centred on bullying, the role of violence in video games and films and, notably, gun control and culture in the country, aimed at providing the rationale for a situation which, far from restricted to this specific incident, pointed to a larger social problem. As if to prove this, in 2006 the country witnessed its yet deadliest school massacre, in Virginia, where one single serial killer gunned down 32 people.

In 2003, when Gerry was still being finalised, Van Sant started shooting Elephant, loosely based on the Columbine massacre and initially conceived as a television drama for the network company HBO. The film's title is a reference to Alan Clarke's 1989 BBC television short film of the same name, which depicts eighteen killings in Northern Ireland during the Troubles and whose title refers to the expression 
'Elephant in the room': a self-evident problem of gigantic proportions to which everyone turns a blind eye. Like Clarke's strongly political film, Van Sant's Elephant aims at unveiling and exploring an enormous social issue. Moreover, unlike Gerry, whose real life story was virtually unknown, Elephant reenacts a widely broadcast event, which immediately adds to it a historical and factual weight, raising questions informed by an ethics of representation. That is, this being a deeply upsetting incident and very alive in the country's psyche, its reenactment immediately poses questions of a moral order: is it accurate and respectful towards its object? Is it faithful to their factual aspects? In what ways does it elicit a better understanding of the causes of the event? And yet, as will be my contention in this chapter, Elephant adopts the same experimental approach of Gerry, rejecting a representational carapace that would justify its choice of subject matter as in service of an outlined moral message. This, I will argue, is a political choice.

In what follows, I start with an analysis of the film's realist foundations, indebted in part to an observational documentary approach. Yet, Elephant's realism is a much more complex matter, which I proceed to investigate. Rather than evolving in a logical fashion, the film portrays the massacre in its elusiveness, shattering its linearity and depriving it of a causal logic. It further complicates its semi-documentary focus through formal and narrative strategies which lend it a disquieting and hallucinatory quality, conjuring instead what I call 'the reality of trauma'. I then examine the film's social dimension, arguing that its political power resides in the way its reenactment eschews the routes of a moral representation, shedding a new, revelatory light on this event and current American youth. 


\section{Observational Realism}

Like Gerry, Elephant was entirely shot in chronological order and on location, its script being only an outline to be developed and improvised during the shoot. Yet, unlike Gerry, Elephant features a large ensemble cast, the majority of whom were nonprofessional actors who actually study in the high school where the film was shot, in Portland. The film devotes considerable time to following, in overextended tracking shots, these students engaged in trivial activities or else walking through the school's facilities, notably interminable and empty corridors. At the film's beginning, for example, we are introduced to the photographer Elias (Elias McConnell) as he takes pictures of a punk-gothic couple in the school's yard. Later on, we follow him walking through the school corridors, as well as developing negatives in a dark room. We are also introduced to Michelle (Kristen Hicks), whom we first see in a gym class, continuing to follow her into the changing room. She is further shown traversing an empty gymnasium, walking through the school corridors and finally arriving at the library where she works. In another sequence, the film focuses on Nathan (Nathan Tyson), the camera tailing him through the school's corridors until he meets his girlfriend Carrie (Carrie Finklea).

The film is divided into several sections, each of which is named after, through title cards, the character or group of characters whom a peripatetic camera steadfastly tails. However, this division proves deceptive for each section does not limit itself to focusing on the character which titles it, but includes scenes involving previously shown students and replays the same situations from different vantage points. This renders a non-linear and looping narrative structure that fragments a seemingly ordinary day at 
school. However, the film also devotes some time to showing the massacre's perpetrators, Alex (Alex Frost) and Eric (Eric Deulen), which builds a suspenseful narrative of sorts. We see, for example, Alex taking notes of the spatial coordinates of the school's refectory, as well as ordering the guns over the Internet. Such information, coupled with particular formal strategies, imbues ordinariness with an acute sense of the uncanny and foreboding, lending the film an insidiously disquieting tone. I will discuss these aspects in detail in the next section; for now let us note that Elephant's aesthetic foundations are grounded in an observational approach whose main focus are these real youngsters and their environment.

Elephant perpetuates a fascination with documenting youth which is discernable across Van Sant's entire work, indeed going back to his debut Mala Noche, at the core of which stands two young Mexican immigrants played by non-professional actors. As mentioned earlier, My Own Private Idaho also features real street kids, which gives this cinematic pastiche a welcoming authenticity. Even when working for major Hollywood studios, youngsters would also be at the fore, as in the black comedy To Die For (1995) the director's foray into the mainstream. Based on the real story of a teacher (Pamela Smart, played by Nicole Kidman) who seduces one of her students into killing her husband, the film focuses on the high school arena and features actual students from the school in which it was filmed. As such, not only does it foreshadow the trilogy's reenactment of real life death stories but also Elephant's thorough exploration of the high school universe. In fact, the director's oeuvre, more often than not discussed with reference to its queer vein, is characterised by an accent on male adolescent beauty, from the likes of young Hollywood actors such as River Phoenix and Casey Affleck through to 
graceful young amateur actors. In his work, the scopophilic drive which Laura Mulvey famously theorised as animating Hollywood's stress on woman as spectacle is, perversely, directed at young men. Indeed, Mulvey's contention that in classical Hollywood film women's 'visual presence tends to work against the development of a storyline, to freeze the flow of action in moments of erotic contemplation' (Mulvey 1989: 19) finds its reverse materialisation in Van Sant's work, in which narratively unjustified close-ups of young men abound.

In contrast with his previous work, the contemplative stakes in Elephant are, however, much higher. Deprived of a causal narrative flow and composed of extremely long takes, the film mainly evolves by showing these students in their full presence, that is to say, as aesthetic objects in their own right. We as viewers are invited to minutely study their bodies, faces, gestures and, notably, their way of walking. Here it is not so much the case of freezing the flow of action in favour of contemplation, as in Mulvey's seminal analysis, but indeed that of a film shamelessly enraptured by its objects of attention. Of course, young girls also feature in Elephant, which devotes some time to depicting them, such as the geek Michelle and a group of three bulimic girls (more of whom later), as well as others. As a general rule, however, and in tune with the director's previous films, Elephant focuses predominantly on young men, reinforcing the director's image as a gay auteur. In this respect, a film such as Paranoid Park (2007), the follow-up to Last Days and composed of fetishizing slow motions focusing on Gabe Nevins's angelical complexion, further corroborates this view.

Furthermore, the students on show in Elephant did not receive any acting training but only a few instructions of what to do in each scene, being further allowed to 
improvise the dialogue. With a few exceptions, their characters carry their real names, which authenticates the film's realism. In several occasions their unfamiliarity with the camera and, consequently, awareness of being filmed, surfaces on the screen. Their performance is either clumsy or else inhibited, indirectly acknowledging the camera's presence or indeed directly, inadvertently breaking the film's fourth wall. Their lines are delivered in discordance with the common standards of naturalistic acting, as are their untrained, somewhat mechanical gestures and movements. In a manner similar to Reygadas's directorial take on acting, analysed in Chapter 3, Van Sant privileges the spontaneous, fresh quality characteristic of unprofessional acting and the contingent element which it inevitably brings about. This is further reinforced by the director's preference for the spontaneous quality of the first take, an aspect also privileged by Reygadas, as we have seen. As Van Sant himself puts it, the film was 'designed so that whatever [he and cinematographer Savides] shot was what was going to end up in the film' (Van Sant: n/d).

In order to highlight the profilmic event, Elephant further appropriates some techniques traditionally associated with the observational tradition of American documentary. In particular, the film evokes the work of Frederick Wiseman, notably his two films devoted to the high school universe: High School (1968), shot in the Northeast High School, Philadelphia, and High School II (1994), filmed in the Central Park East Secondary School, New York. The observational approach in documentary film flourished in the United States during the 1960s, being understood, as Anna Grimshaw and Amanda Ravetz note, 'as a commitment to 'showing', not telling - that is... audiences were now to be presented with materials generated from recording events, situations and 
relationships as they unfolded in specific social and cultural contexts' (Grimshaw \& Ravetz 2009: 24). Wiseman's films became emblematic of this approach, focused as they are on institutional microcosms: mental institutions, hospitals, schools, etc. In his work one finds a juxtaposition of seemingly disconnected images, with no sense of opening or closure, unguided by structuring devices, such as voice-over commentary or causal editing. Rather, they appear as fragmentary, autonomous moments seemingly recorded by a fly-on-the-wall, often inquisitive camera, which captures spontaneous situations within clearly delimited environments, as in High School's recurrent stationary shots showing the school's student-filled corridors.

This fly-on-the-wall approach is emulated in Elephant, as in the scenes whose framing composition conveys the impression that the camera simply happened to be there, recording whatever happened to be in front of it. An eloquent example is the sequence in which a stationary camera takes in a vast green field: further in the background, on the top right corner of the frame, we see a group of cheerleaders, while in the foreground no focus of attention is immediately discernable. As the camera remains immobile for over two minutes, we are offered seemingly incidental occurrences in passing: a line of boys, and then girls, jogging past the camera; a group of boys playing American football, constantly entering and leaving the frame; Michelle briefly stopping and looking up at the sky. As these events only momentarily appear on the screen, being off-centre within it, we are left with the impression that the camera has captured these ordinary occurrences by chance. 

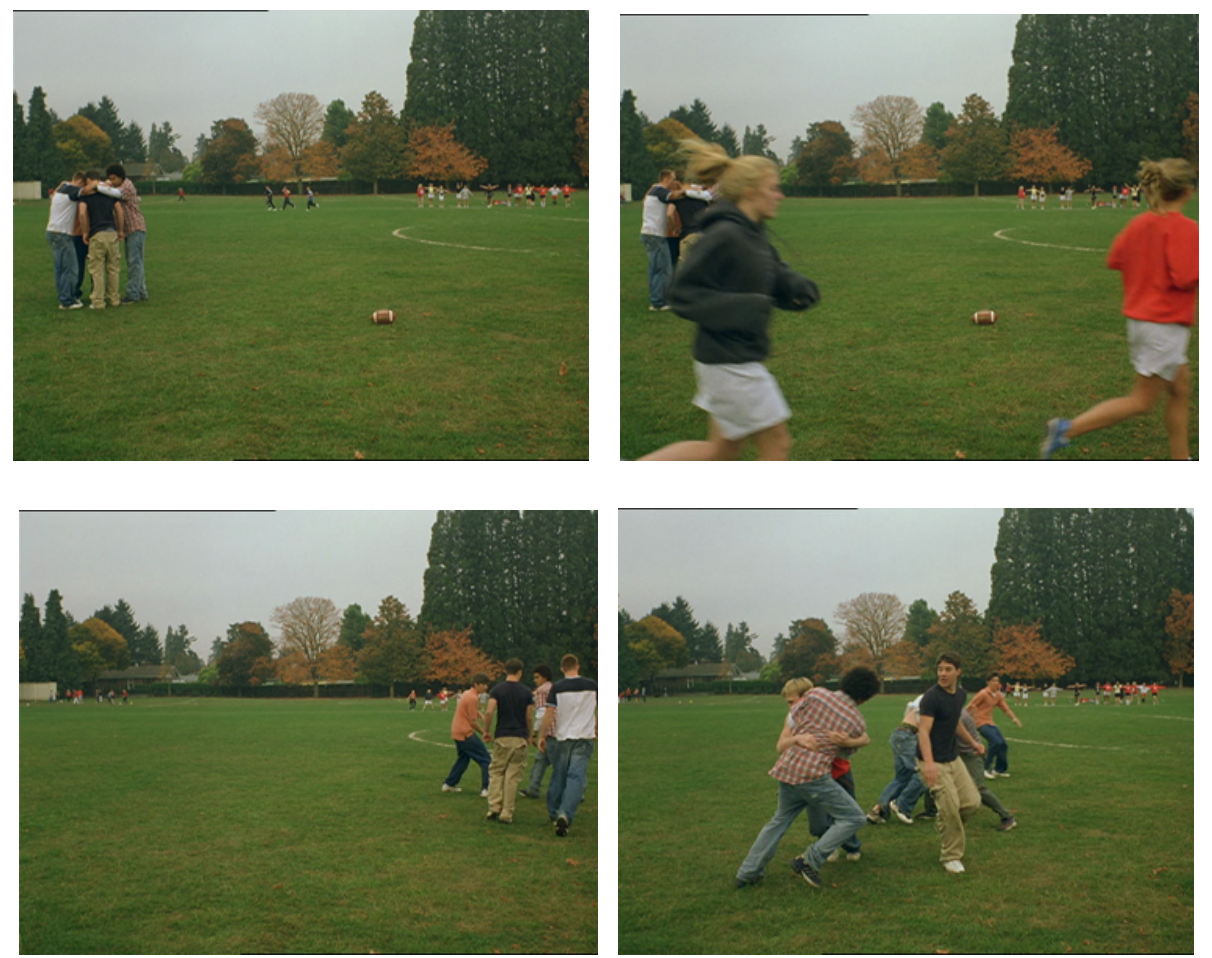

Whatever happens

An observational rhetoric is also found in the scene which shows the Gay-

Alliance school's group discussing whether one can tell whether someone is gay. As with Wiseman's fondness for facial close-ups, this scene proceeds, in an unbroken shot, by unhurriedly panning across the student's faces while they voice their opinions about the subject and even look into the camera, positioned at the centre of a circle. In these scenes, as in many others, Elephant becomes endowed with a documentary quality, conveying what Grimshaw and Ravetz, in their Bazinian reassessment of the observational approach, define as a 'sensuous... and phenomenologically inflected mode of enquiry' (Grimshaw \& Ravetz 2009: xi). Indeed, this is a film in which the phenomenological and sensory real fully surfaces on the screen, not least in view of its inclination for long takes that preserve the spatiotemporal integrity of events. 

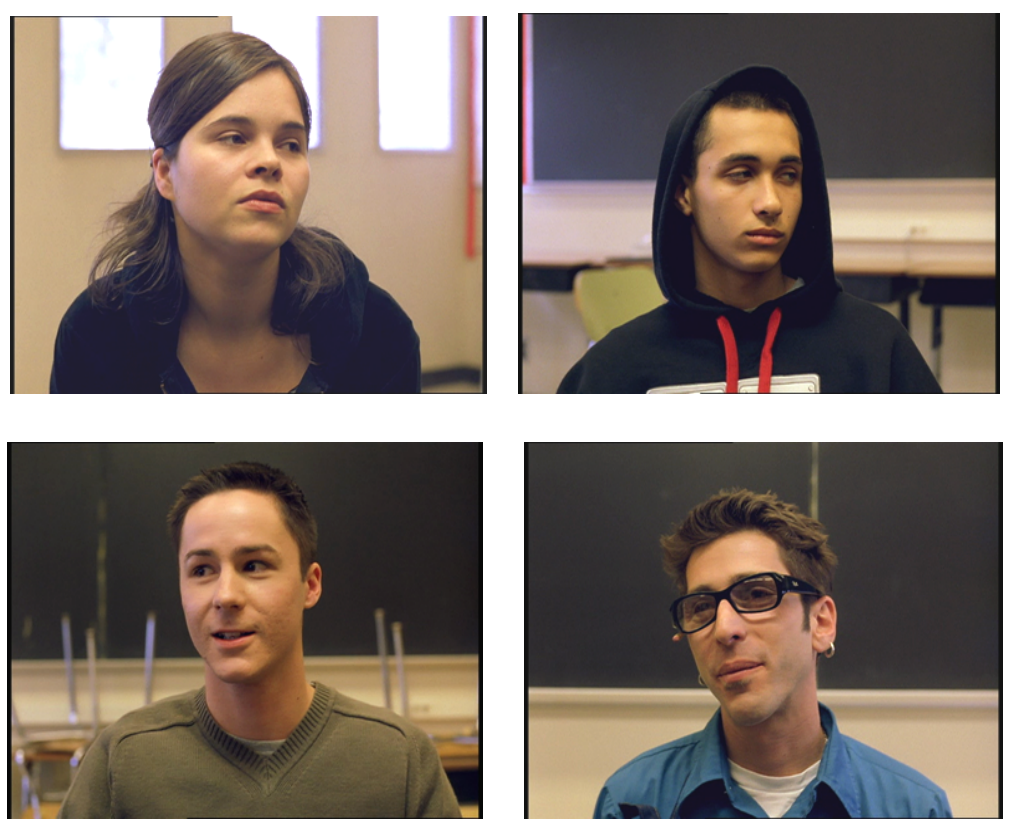

Observational approach in Elephant

But, of course, Elephant's situations, however spontaneously filmed or

phenomenologically dense, are prearranged. Besides, its style does not limit itself to the emulation of a documentary approach. On the contrary, superimposing this film's allegiance to the profilmic event, that is to say, its realist mode of production, is a highly formalist carapace which, as we will now see, works against its documentary aspect, lending the film a pronounced uncanny quality.

\section{The Reality of Trauma}

If Tsai, as discussed in Part II, depicts a universe seemingly recovering from a trauma whose after-effects are clearly discernable in the characters' behaviour, Elephant confronts the memory of trauma itself. Through a variety of formal strategies, this is a 
film that complicates its focus on objective reality, suggesting instead a subjective, experiential and hallucinatory recollection of this traumatic event. As Anna Backman Rogers puts it, 'many of the film's techniques undermine our common sense of reality in order to create an evocation of the experience of trauma and its aftershock' (Rogers 2009: 86). In this section, I shall attempt to demonstrate how this is constructed in the film, beginning with an analysis of its creative use of montage and sound, and moving on to examine its meticulously choreographed camerawork in light of the horror genre. We have seen that Gerry's 'visionary' images foreground perception itself, conveying the mirages of a pure consciousness in the desert and, in so doing, operating at the intersection of the real and the imaginary. Along similar lines, Elephant plays on the notion of an altered cognition of reality, here filtered through a post-traumatic mind. Rather than evolving in a linear, chronological fashion, time in Elephant is constantly circling back on itself, as if in an endless loop, replaying situations from different vantage points. Thus, we are made aware as the film unfolds that the activities in which we see these students engaged are not sequential but simultaneous. For example, at the film's beginning we follow John walking through one of the school's corridors and bumping into Elias: they greet each other and the latter takes a picture of the former. Meanwhile, Michelle runs past both students at the precise moment we hear the flash of the photographic camera. To the viewer's surprise, this same situation is replayed later in the film when the camera follows Elias through the school, and yet again when following Michelle running through the corridor past the two boys. Another example occurs when we follow Nathan walking past a group of three girls, who openly eye him up. This same 
situation is replayed later in a different section of the film, the camera now focused on the girls.

Though highly innovative in the way it is utilised in Elephant, this structure was lifted from Tarr's tour-de-force Sátántangó, based on László Krasznahorkai’s eponymous novel. The film replicates the structure of the book, which depicts a collective farm in Hungary near the end of Communism told from the different but temporally overlapping perspectives of each of the characters, thus producing a back-and-forth narrative pattern similar to that of the tango dancing movements, as the book's title indicates. But while Sátántangó's story unfolds in 24 hours, Elephant focuses on the last minutes preceding the massacre, with a few exceptions, such as when the two future killers are shown in Alex's house, which presumably took place the day before the killings. As far as the events set in the school are concerned, the viewer is only allowed a glimpse of the last ten minutes or so prior to the massacre, from a multifarious and shuffled perspective.

On the one hand, these time loops suggest, as Amy Taubin notes, 'a longing to stop time, to prevent the inevitable tragedy from ever taking place' (Taubin 2005: 18). More pointedly, they resonate with the temporal mechanisms of a traumatised mind. Recent scholarship has indeed stressed the inherently dissociative character of trauma when stored in consciousness. Cathy Caruth, for example, building on Freud, argues that the traumatic experience, being too overwhelming, cannot be mastered cognitively, returning in the form of images which resist meaning or narrative logic. As she puts it, 'the event is not assimilated or experienced fully at the time, but only belatedly, in its repeated possession of the one who experiences it. To be traumatized is precisely to be possessed by an image or an event' (Caruth 1995: 4). As such, the memory of trauma 
precludes representational logic, materialising instead in the form of dreams, hallucinations, flashbacks - autonomous images whose 'literality and nonsymbolic nature' (Caruth 1995: 5) preserve the purely sensory and experiential character of the event. Bessel A. van der Kolk and Onno van der Hart, in their turn indebted to neuroscience, strike a similar note, arguing that the traumatic event is translated into a particular form of bodily memory. Rather than unfolding in a sequential fashion, the traumatic memory lives in a state of simultaneity:

This simultaneity is related to the fact that the traumatic experience/memory is, in a sense, timeless. It is not transformed into a story, placed in time, with a beginning, a middle, and an end (which is characteristic for narrative memory). If it can be told at all, it is still a (re)experience (Kolk \& Hart 1995: 177).

Hence, the traumatic recollection entails an inability to recount the event in a linear fashion, as well as a '(re)experience' of the disturbing and discomforting sensations associated with the originary trauma.

Elephant's formal and narrative strategies, it appears, aim at conveying this experiential and discomforting dimension of trauma, drawing in the viewer as an active participant in the attempt to make sense of this ungraspable event. Thanks to an intricate and conceptual montage, chronology is shattered and perspectives shuffled, which, as a result, highlights the structural relation between images. Not so much in the manner of an Eisensteinian montage, in which the audience is invited to complete images as they are juxtaposed so as to generate contextual meanings, but indeed like the completion of a 
puzzle. Indeed, the spectator has to reconstruct this event by putting together pieces of information which the film's form renders disconnected, as though emulating a traumatised consciousness at great pains to narrativise this event, which is instead framed through repetition, simultaneity and circularity.

The literality that Caruth deems intrinsic to the memory of trauma also finds here its cinematic translation in extremely long takes which highlight events in their unexplained literalness. More than representing this event or telling a story, then, this is a film interested in rendering it as a sensorial and dreamlike recollection. Nowhere is this better illustrated than in the moments - as when Nathan is eyed up by the three girls, or when John, walking out of the school, plays with a dog - played in slow motion, which, coupled with the film's use of light, gives Elephant ethereal, dreamy overtones. Though shot predominantly with natural lighting, Savides brought in more light in certain scenes, such as those set in the school's corridors. Here, light floods in, producing not only flares and spectral discs in the image, but also giving it a bright, airy and translucent look which contributes to an oneiric quality. In this respect, the film's ingenious use of sound also asks for elaboration.

Elephant's soundtrack ranges from Beethoven's 'Moonlight Sonata' to Hildegard Westerkamp's soundscapes 'Doors of Perception' and 'Beneath the Forest Floor' (also utilised in Last Days, as we shall see). The former is first heard in the scene, mentioned earlier, in which a stationary camera records ordinary events in the school's green field, lending the film a poignant tone as it highlights the doomed fate of these characters (as noted by Rogers 2009: 87). In its turn, Westerkamp's soundscape compositions stand out for the disquieting atmosphere they convey. Mixed by sound designer Leslie Shatz, with 
whom Van Sant first worked in Mala Noche, we hear in the film multilayered soundtracks made up of tactile sounds as distinct as door hinges, trickling water, orchestral music and train departures, which, edited over non-correlated images, creates a disjunction between the film's visual and aural tracks, meaning we are unable to locate the sources of these sounds within the diegesis. Instead, as Randolph Jordan puts it, 'what we hear often becomes a surface which frustrates a coherent understanding of the spaces given to us on the image track' (Jordan 2007: 1). And as these tactile sounds are played over images showing mundane events such as Nathan or Elias perambulating through the school, the film takes on hallucinatory overtones.

This use of sound, in some respects, is reminiscent of that found, for example, in the cinema of Tarkovsky, as previously mentioned in relation to Reygadas's films. Tarkovsky relied on the autonomous, physical quality of sounds 'so that they no longer correspond with the image' (Tarkovsky 2005: 162). In his work, non-diegetic sounds, notably trickling water, are often heard in disagreement with the visual track, which produces a dreamlike quality. Elephant conforms to this usage, yet it also pushes it to new heights. Its originality resides in the way it concatenates and superimposes distinct sounds on one single aural track, even preserving the ambient sound. More than a mere oneiric quality, this device thus produces a disorienting acoustic experience which effectively conjures the sensations of fear and confusion associated with the recollection of trauma. Resisting imputations of meaning and in disjunction with the image, these sounds preserve their literal, concrete and nonsymbolic aspect.

In her analysis of Alain Resnais's Hiroshima Mon Amour (1959), a film focused on the trauma of the World War II, Caruth argues that it opens up 'a new mode of seeing 
and of listening - a seeing and a listening from the site of trauma' (Caruth 1996: 56). This is also what happens in Elephant, which is intent on producing a sensory rendition of the massacre as filtered through a subjective consciousness. And this is not only attained through the above examined montage and use of sound but also through its ominous, subjective-inflected camerawork, to which I will now turn.

To begin with, Elephant's peripatetic camera owes much of its style to Clarke's Elephant. Showing eighteen different killings and containing virtually no dialogue, Clarke's film proceeds by following, on a Steadicam, characters from behind wandering through empty spaces. This device generates tension insofar as each segment varies its focus of attention, meaning that we are unable to tell whether the person being followed in each vignette is a killer or else a victim about to be violently and abruptly murdered. By placing the viewer in the position of an active, stalking voyeur, as well as implying the killer's own point of view, this is therefore, as noted by Dave Rolinson, a camera freighted with subjective connotations (Rolinson 2005: 114). As with Clarke's film, Elephant stalks characters from behind on a Steadicam, a physical support in which the camera is indeed literally attached to a human body (here that of Savides) and whose resulting images viewers have arguably learnt to associate with a subjective, if preternatural, point of view. The epitome of this is Alexander Sokurov's Russian Ark (Russkiy kovcheg, 2002) in which we are invited to assume the point of view of a timetravelling visitor who is the camera itself. More significant for our purposes, a subjective camerawork is a chief staple of the thriller and horror genres. Let me substantiate this claim to then analyse its significance in Elephant. 
It is well known that one of Hitchcock's main strategies to heighten suspense was the extensive use of subjective shots which implicate the viewer in the restricted diegetic space as seen through the eyes of a character. In Rear Window (1954), the viewer shares the perspective of a wheelchair-bound photographer who spies on his neighbours in the opposite building. In Vertigo (1958), the spectator observes events, in an equally secretive fashion, through the eyes of Scottie (James Stewart), who trails the mysterious Madeleine (Kim Novak) across San Francisco. This first person camera became one of the aesthetic staples of the horror genre and its ramifications, being further theorised as such. Carol J. Clover, for example, calls it a 'predatory gazing' (Clover 1995: 193), analysing its effects in John Carpenter's 'slasher' Halloween (1978), itself a tribute to Hitchcock - among other nods, the film starred Jamie Lee Curtis, the daughter of Janet Leigh, canonised in her role in Psycho, in its turn the precursor of the slasher.

In contrast with Hitchcock's use of a dolly as a means to convey a moving subjective vision, Halloween made pioneering use of the Panaglide support, an early, Panavision clone of the Steadicam which enabled a much more flexible and wider range of smooth camera movements in space. In Halloween, as in countless horror films ever since, the camera conveys the victims' shifting perspectives, stalks characters and houses as seen through the eyes of the killer, and plays on the ambiguity of points of view, meaning we are more often than not unable to tell whether it is an objective or subjective perspective. Aiming for a heightened emotional response from the viewer, this camerawork confers on events an ominous quality, highlighting a fundamentally unstable and menacing diegetic space. As Clover puts it, 'inasmuch as the vision of the subjective 
camera calls attention to what it cannot see...it gives rise to the sense...of vulnerability' (Clover 1995: 196).
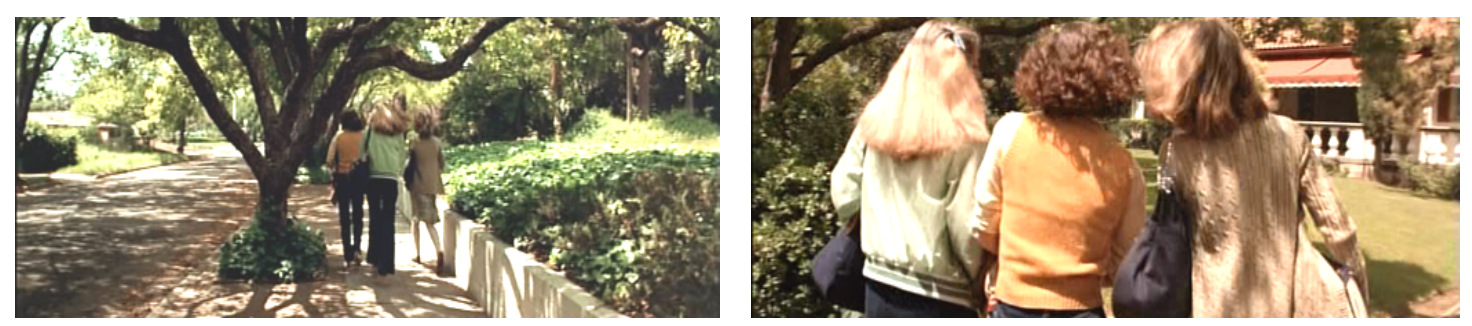

Stalking Camera in Halloween

From the outset, Elephant strongly evokes the slasher film through its very settings and characters. Since Halloween, high schools, suburbia and adolescents are fundamental and constitutive elements of the slasher, as recently exemplified by Wes Craven's Scream (1996), itself a self-reflexive take on the genre. More specifically, Elephant dialogues with the slasher, and Halloween in particular, by depicting the massacre during the seasonal period in which this annual holiday, yet another convention of the horror film, takes place (in reality, the Columbine shootings happened during Spring, in April). This is identified in the first scene, as the camera follows John's car from behind through a typical American suburb lined with autumnal trees and fallen leaves on the ground. Later in the film, we see in Alex's house the traditional pumpkins representative of this festivity, tellingly placed atop a television monitor showing a documentary about Nazism. 

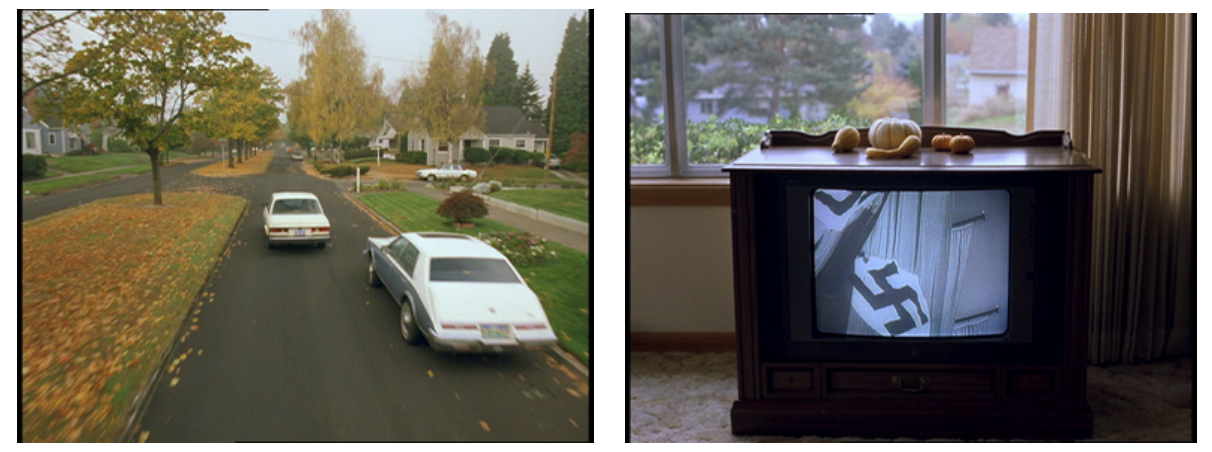

Halloween time in Elephant

This being said, Elephant's Steadicam camerawork is not unambiguously presented as an embodied agency in the film, as is largely the case in Halloween and the horror film. Still, its self-reflexive camera produces a stalking vision which itself underlines the horror awaiting these characters and creates a haunting sense of unease throughout. Such a strategy can arguably be found in Stanley Kubrick's The Shining (1980), yet another canonical horror film reliant on Steadicam and tracking shots and which proceeds, like Elephant, by following characters from behind in ominously empty corridors, here that of a hotel. In fact, The Shining was shot by Gareth Brown, himself the inventor of the Steadicam. Though not conveying an unequivocal subjective vision, the film capitalises on the disquieting effects produced by a camerawork whose 'smooth glide', as Anna Powell notes, intimates that 'of a preternatural pursuer' (Powell 2005: 48). (Coincidentally, The Shining is also set in Denver, Colorado). Something similar is going on in Elephant in which a free-floating camera spectrally embodies the impending danger which is about to shatter its objects of attention, an aspect particularly pronounced in those scenes in which it becomes insidiously close to the students' backs and necks. 

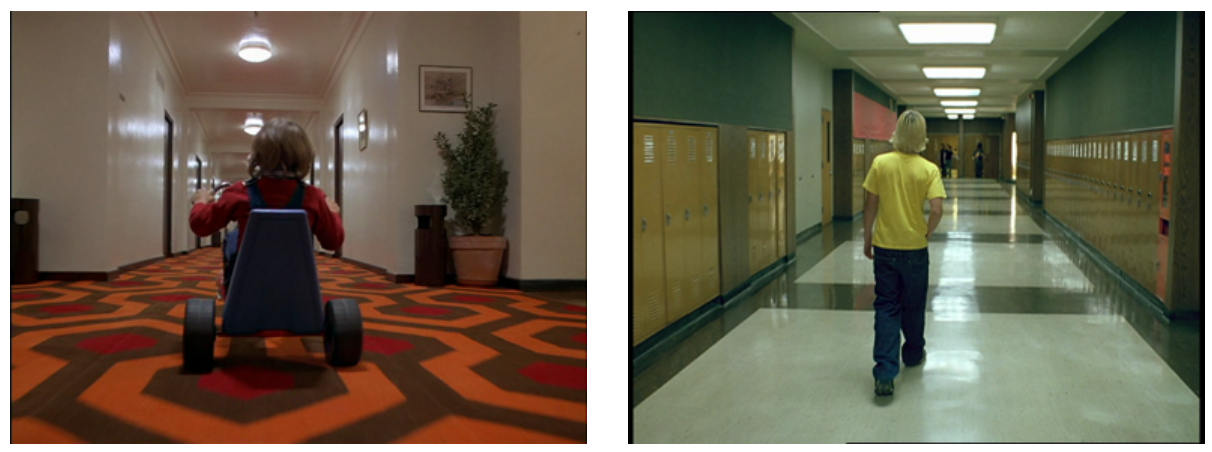

Stalking camera and ominous corridors in The Shining (left) and Elephant

In like manner, these characters are often observed through a detached gaze which, in predatory fashion, watches its prey from a reasonably safe distance and, in so doing, intimates their doomed fate. Take for instance one of the film's first scenes, in which the camera records Elias taking some pictures of a punk couple in the school's yard, panning to the left as they walk. As Elias finishes with the pictures and walks by himself farther away in the horizon, the camera pans to the right and there it remains immobile behind a large tree, continuing to record the character for over a minute until he is no longer visible in the frame. This spectral fixed stare, hidden behind a tree and watching the character from a distance, conveys a subjective vision full of deadly implications. This is also what happens in the scene, analysed in the previous section, in which ordinary occurrences take place in the school's vast green field before an immobile camera. Here, this shot's initially indifferent point of view is transformed into an active and stalking one as soon as Nathan stops in front of the camera and puts his jumper on. The camera immediately frees itself from the tripod, tailing the character from behind as he walks through the field, to then brusquely stop as he approaches one of the school's doors. It continues, motionlessly, to observe the character until he steps into the school, which, as in the aforementioned scene, suggests a predatory pursuer. 

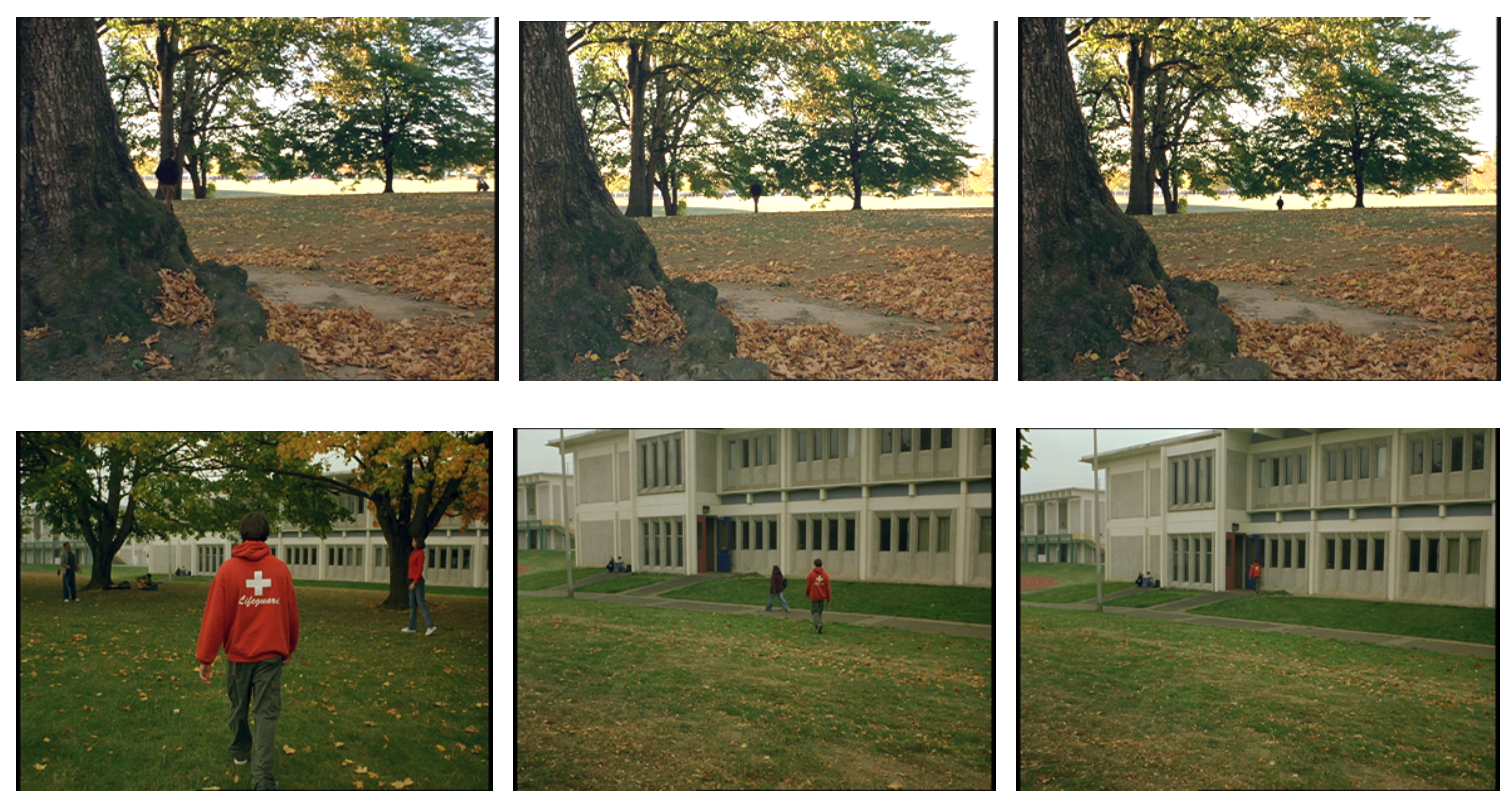

Predatory vision in Elephant

A subjective-inflected camerawork also comes into fruition through a camera which, like that of Reygadas's work, is resolutely independent, monitoring its own speed and directions at will, and even going on autonomous 'journeys' in the school. An example is the long scene, comprised of one continuous Steadicam shot, in which the camera follows Brittany (Brittany Mountain), Jordan (Jordan Taylor) and Nicole (Nicole George) as they walk through the school refectory. The camera leaves the three girls and glides into the kitchen, registering a man washing up the dishes, two employees furtively smoking marijuana, another carrying trays, to then come out, 'find' the girls on their way to sit down and stop by their table. As the girls barely touch their food and get up, the camera follows their way out to, yet again, lose sight of them and randomly focus on a girl talking to a boy about her singing skills at a table, even slowing down while it moves past so as to, it appears, better overhear the conversation. Such independent quality can also be found in the scene in which the camera initially follows Elias, who runs into John 
and takes a picture of him in the school's corridor. As they part ways, the camera seemingly changes its 'mind' and begins to stalk John instead.

Though it remains unconnected to a particular agency throughout, the killing intimations of this subjective gaze finds its diegetic embodiment in one telling shot towards the film's end, when we see the shootings as being perpetrated from an unequivocal first person perspective. This appears as a brief flash-forward cut-in, when the future killers discuss the logistics of the massacre, its subjective dimension being clearly identifiable. Not only the camera is shakier here as we also see the tip of the rifle facing forwards on the frame's foreground, which intimates the weapon is being carried by one of them. This shot is further significant in view of its visual design, which is a citation of that of so-called 'first person shooter' (FPS) video games, itself blamed by the media as one of the main causes behind the Columbine massacre and commented by Elephant through a graphic match: earlier in the film we are offered a shot of a FPS video game as being played by Eric (this, moreover, being a computerised version of Gerry). The similarities between these games - whose visual kernel is also defined by spatial exploration through a subjective perspective - and the horror film are, furthermore, not coincidental. The visual idiom of FPS games is itself indebted to the horror and thriller genres, indeed bringing us back full circle to Hitchcock. This is indeed what Alexander R. Galloway demonstrates in his study of gaming, showing that a FPS perspective appears, for example, in some Hitchcock's films, such as the finale of Spellbound (1945), as well as the alternative ending of Topaz (1969), as the pictures below further illustrate (Galloway 2006: 58-9). 

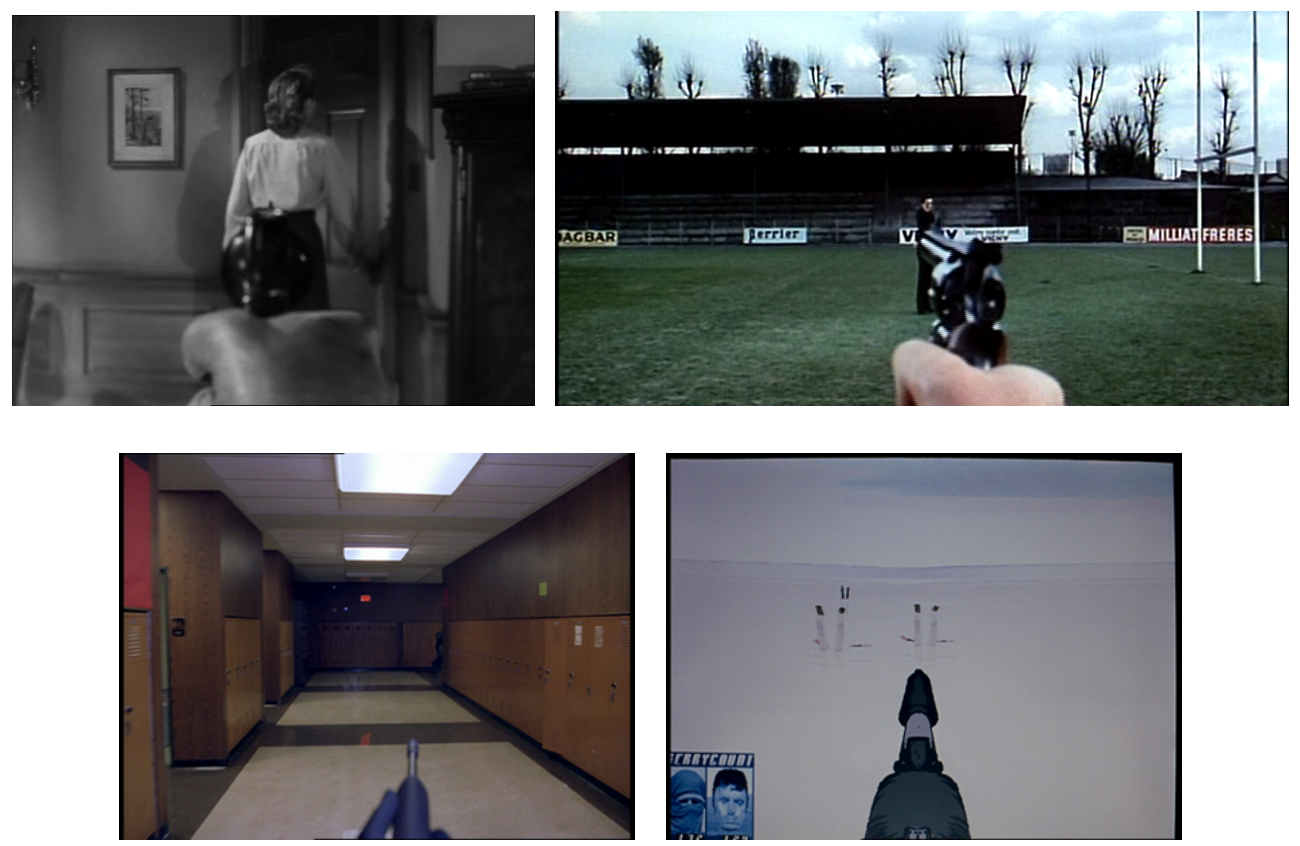

(In clockwise order) FPS perspective in Spellbound, Topaz and Elephant (below)

And yet, if the killings found in the horror film and its audiovisual ramifications are meant to provoke 'a roller-coaster ride of sadomasochistic thrills', to cite Linda Williams (1991: 7), Elephant is an altogether different case. The threat that this film explores is not a supernatural or fictitious one but instead a pressing, explosive and complex social issue. There is no room here for the sensational, thrilling spectatorial rewards of the horror or thriller genre insofar as this is a film which refers to a factual reality in urgent need to be addressed. Elephant thus updates the genre into a hitherto unexplored, and indeed far more frightening, realm, appropriating its formal devices so as to enhance a real horror. In so doing, it also comments on a visual culture whose fascination with violence, serial killings and weapons is far from constituting a recent phenomenon. As will be now examined, it indeed suggests a much more complex rationale for this befuddling event. 


\section{A Complex Reality}

As hopefully demonstrated, Elephant does not explain the massacre through a moral, edifying and revisionary glass. In fact, this was the main accusation it received upon its release: that its highly aestheticised reenactment provided no answers about this event. By way of conclusion, I will argue that the film's political power resides precisely in the way it averts a representational logic, opting instead to 'present' a problem which simply cannot be accommodated into a neat, problem-solving narrative but which instead demands a formal treatment that acknowledges its overwhelming complexity.

Elephant frames the Columbine shootings through the memory of trauma while appropriating devices from the horror film, conveying this event as a sensory and disquieting cinematic experience. This does not mean, however, that it shies away from confronting the issues which this event so urgently raises. On the contrary, what this film suggests is that this massacre is not an isolated incident but only the tip of the iceberg of a social malaise. This is indeed a film highly critical of the society it portrays, touching upon some of the most pressing problems connected to American youth, including alienation, bulimia, bullying, homosexual repression, gun culture and parental ineptness. If anything, Elephant conveys the strong impression that something is rotten in the American high school universe.

Take for instance the aforementioned scene in which we follow the group of three girls, with exactly the same haircut, having lunch in the refectory and planning their shopping afternoon. They are, the viewer soon learns, bulimic, as we see them locking themselves in the toilet's cubicles and hear their vomiting spasms. At this very moment, 
bulimia is a growing epidemic in the US (as well as many other developed countries), an eating disorder resorted to as a means to attain the unhealthily thin body image as reproduced and celebrated in commercial films, fashion magazines and advertisements. Such image obsession is also touched upon through the character of Michelle, the opposite of 'the perfect look' as pursued by these young girls. Always on her own, utterly alienated from the other pupils, Michelle is herself the personification of the 'nerd' and the 'loser' as we hear some students calling her behind her back. She is also clearly uncomfortable with her own physique. When she is first introduced in the film, for example, we see her being reprimanded by a teacher for wearing pants rather than shorts in the gym classes, which discloses her being ashamed of her own body.

Elephant further comments on parental neglect. Consider for instance the film's opening: we are introduced to John, who sees himself forced to replace his intoxicated father at the wheel, when driving to the school. Upon arrival, John takes the car keys to the school's office and calls his brother to pick them up and drive their father home, which suggests an inverted parental relationship in which it is the teenager son who looks after the father. Take also the scene in which we see the killers-to-be eating at Alex's house, his father getting ready to go to work while his mother cooks pancakes. In this brief glimpse of familial gathering we get the sense of a cold, loveless and alienated relationship between parents and son as they barely speak or interact with each other. This is further conveyed through the framing, which literally cuts off the parents' heads, thereby underlining their insignificance and absence in Alex's life. Indeed, for most of the time Alex is shown entirely by himself at home and doing whatever he wants, including ordering guns over the Internet with baffling ease and speed on a website 
revealingly titled 'GUNS USA', as well as testing these same guns in the house's garage with Eric.
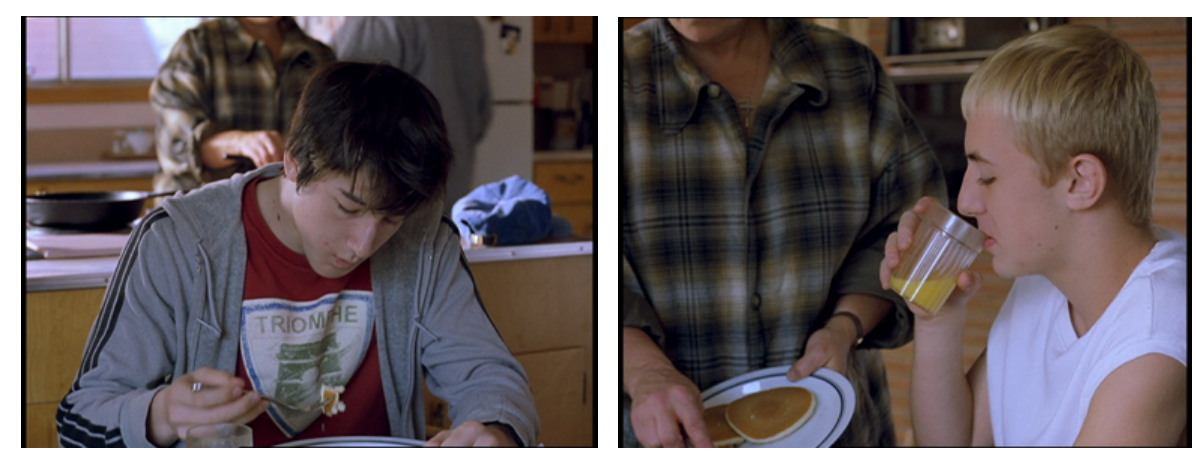

Headless Parents in Elephant

Homosexual repression is also hinted at here. We see Eric and Alex kissing in the shower on the morning of the shootings (in a previous scene Eric confides to Alex he has never kissed anyone), which resonates with the scene, mentioned earlier, in which student members of the Gay-Alliance school's group discuss whether one can tell if a person is gay. Alex is also shown as being abused in the school environment, as Nathan and his friend throw spit wads at him during a science class. Was it bullying the trigger for the massacre? Was it the violent video games and Nazi documentaries we see Eric and Alex engaged with? Was it homosexual repression? Was it the ease with which one can purchase guns in the US? 

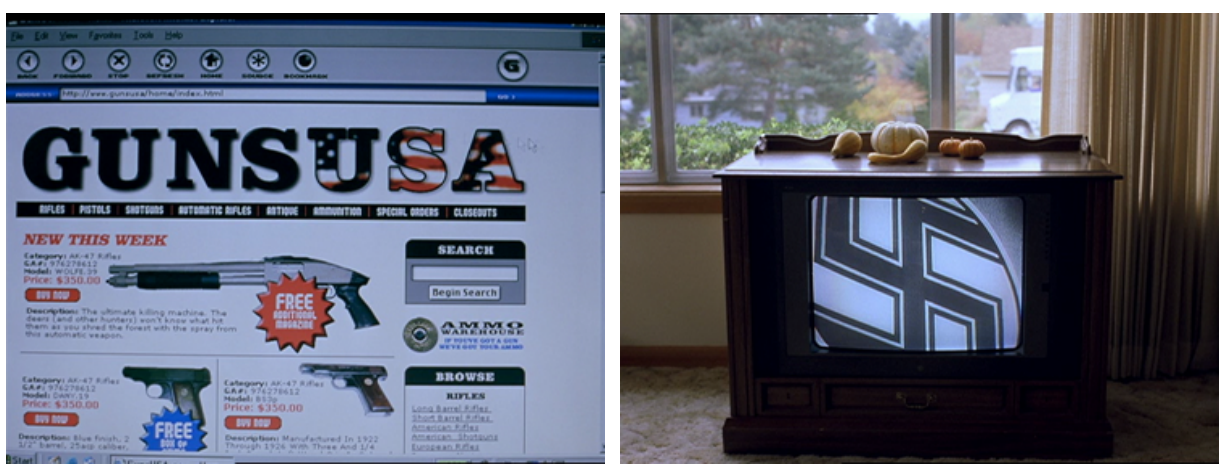

Reasons to kill?

The fact remains that Elephant refuses to weave these social problems into a logical narrative. On the contrary, they are presented in an episodic and matter-of-fact fashion, never being developed or congealing into a story. Rather than a deterministic structure, the viewer is offered several vignettes which, in many cases, do not even relate to the killers or the massacre, such as the bulimic girls and John's alcoholic father. Taken together, however, these distinct social problems reveal the impossibility of reducing this tragedy to a single cause, unveiling instead a much bigger picture. This could not be further from the approach found in Michael Moore's documentary Bowling for Columbine (2002), which, though with the best of intentions, exclusively attributes this event to gun culture and control in the US. This, as stated above, is also touched upon by Elephant but here such aspect becomes only one more piece of an intricate puzzle which the film refuses to transform into a problem-solving narrative.

A brief comparison with two recent American films, which similarly reenacted a topical historical trauma, the 9/11, is helpful here. Oliver Stone's World Trade Center (2006) and Paul Greengrass's United 93 (2006), though formally different and focusing on different aspects of the event, clearly fashion a moral fable out of it. In both films, as 
Robert Burgoyne notes, historical trauma is reframed as 'a narrative of heroic [human] agency....in a much larger landscape of victimization' and self-sacrifice (Burgoyne 2008: 149). By contrast, in Elephant there is no demonisation, victimisation or heroism. Instead, the film plunges the viewer into the American high school while confining itself to showing the numerous social problems permeating it on many levels. As such, it impels the viewer to identify these problems not as self-contained and unconnected, but as symptoms of a much larger, more intricate and problematic social landscape. In his study of cinematic realism, John Hill argues that 'social problem' films which conform to a problem-solving narrative pattern, betrays a "presumption, built into the very conventions of the narrative, that "problems" can be "overcome"" without the need of a whole 'transformation of the social structure'. He defends instead 'an alternative account of social problems' which would stress 'their intractability, their inability to be resolved, at least within the confines of the present social order' (Hill 1986: 55).

This is precisely what happens in Elephant, which, as its titles indicates, reveals the enormity of a problem whose answers only a thorough inspection of the current social order might provide. And, indeed, the overall, and revelatory, impression which this film conveys is that these bewildering outbursts of violence, perpetrated not by foreign terrorists but young, white and wealthy Americans, may well result from a listless postmodern lifestyle afforded by a young generation living in complete welfare and freedom. Nowhere is this better illustrated than in the scenes involving Eric and Alex, shown in a series of situations in Alex's home, which convey their lives as untethered by authority and pervaded by an insidious sense of boredom and apathy: Alex plays the piano, Eric reads a magazine, they both play a video game, watch television, eat and 
sleep. Their needs also seem to be immediately satisfied: they have the money to easily purchase guns over the Internet and these are delivered in the comfort of Alex's spacious suburban house a few hours later. The same applies to the group of bulimic girls whose conversation topics include the fat contents of a salad dressing and their shopping afternoon. Overall, as noted by some commentators (see, for example, Rogers 2009), these students indeed resemble sleepwalkers, somnambulists traversing aimlessly, endlessly and freely through a school which seems bereft of authority. There is indeed a permanent sense of purposelessness in the way these students seem to merely drift through the school which conveys the impression we are before a young generation immersed in sheer ennui.

The high school universe has been long dear to Hollywood and American television programmes and series, whose audiovisual productions capitalise on the onscreen presence of teenagers as an obvious means to attract this highly profitable niche market. Comedies, musicals and, as we have seen, the horror film, all feed on the interactions of adolescents within the high school environment. And yet, what these school shootings glaringly show is that this is a reality which is yet to be fully confronted. Rather than representing this universe, as well as this event, Elephant presents it in an entirely new light, enabling us to look at them anew. This is the result, in the first place, of its realist commitment to this environment insofar as it restores to this endlessly reproduced microcosm - so much so that it has become a parody of itself - its real contours and social issues. Elephant gives real voices and bodies to these adolescents, a project which Van Sant would continue in Paranoid Park, a film also played by nonprofessional teenagers and shot in an American high school. In its turn, Elephant's 
experimental form, which complicates its documentary dimension, attests to a commitment not to the objective real but to the experiential reality of trauma and the social complexity of this event. Its formalist realism is justified by the very event it portrays, which, rather than narrativisation, requires an approach that does justice to its perplexing intricacy.

Caruth argues that in the encounter with trauma, one might begin to recognise 'the possibility of a history that is no longer straightforwardly referential (that is, no longer based on simple modes of experience and reference)...permitting history to arise where immediate understanding may not' (Caruth 1996: 11). This is what happens in Elephant, which, frontally confronting this event, reveals the irruption of a yet incomprehensible history. In its attempt to provide a revelatory insight into this young generation and microcosm, this is a film which, furthermore, conveys what Raymond Williams calls 'structures of feeling', which he defines as 'that particular quality of social experience and relationship, historically distinct from other particular qualities, which gives the sense of a generation or of a period' (Williams 1977: 131, my emphasis). Thus, the structure of feeling of a generation conveys 'what is actually being lived, and not only what is thought is being lived' (Williams 1977: 131). Rather than an established social formation, it relates to an embryonic new generation or period which only art, and not without difficulty, may express:

Art reflects its society and works a social character through to its reality in experience. But art also creates, by new perceptions and responses, elements which the society, as such, is not able to realize...We find..., in certain 
characteristic forms and devices, evidence of the deadlocks and unsolved problems of the society: often admitted to consciousness for the first time in this way (Williams 2001: 86).

Elephant conforms to this description, laying bare a social reality which is yet to be properly understood. And while recognising its own limitations for an understanding of this reality and generation, it attests that it is art that might provide the tools to that end. 


\section{Chapter 12}

\section{Last Days}

Last Days was loosely based, like Elephant, on a much-reported event, namely the death of Kurt Cobain, the vocalist of grunge rock band Nirvana. Cobain was found dead at the age of 27 at his home in Seattle, Washington on 8 April 1994, with autopsy ruling a selfinflicted jaw gunshot as the cause of death. His suicide note was published a few days later. As is often the case with rock and roll stardom and its tragic young deaths, Cobain's spawned numerous conspiracy theories, the most widespread being that he was in fact murdered at the behest of his wife Courtney Love. His death became an event, which, to this date, has generated a voluminous number of biographies, television films and programmes. In the same way that Elvis Presley is still believed to be alive, or that the causes of Jim Morrison's death are constantly challenged, Cobain's suicide comprises one more chapter in the mythological history of rock stars' premature and mysterious deaths, including the likes of Janis Joplin, Jimi Hendrix and Ian Curtis.

Born in Washington in 1967, Cobain reached fame in 1991 when the Seattlebased Nirvana burst into the mainstream. Nirvana was part of the Pacific Northwest grunge rock musical scene (composed, among others, of bands such as Pearl Jam, Mudhoney and Soundgarden) and catapulted into the spotlight upon the release of its second album, Nevermind. In the following years Cobain was assigned by the media the role of spokesperson for a disaffected youth whose grunge musical movement was said to be its embodiment. This was dubbed the 'Generation X' (also referred to as the 'baby 
bust generation'), a term borrowed from Douglas Coupland's 1991 eponymous novel. Parallel to his rising popularity, Cobain started to suffer from severe stomach ailments, heroin addiction and depression. Famous for his self-deprecating character, his lyrics reflected emotional angst, as well as his inability to cope with the adoration lavished upon him, which led to fanaticism after his death. Indeed, his demise witnessed a hysterical flurry of coverage, which, as Sharon R. Mazzarella notes, was comparable to that of 'the Kennedy assassination some 30 years earlier' (Mazzarella 1995: 49).

How to portray this heavily televised event, which, like the Columbine massacre, resists facile answers? As I will endeavour to show in this chapter, Last Days does not attempt to make sense of this tragedy, opting instead for a highly conceptual approach that not only preserves the mystery surrounding this event but which furthers, and in many ways concludes, Van Sant's cinematic explorations of mental processes of perception, here materialised in the form of a drug-induced state of consciousness. I first analyse the film's biopic character, demonstrating how it conforms, in principle, to some conventions of the genre. Yet, as I move on to argue, Last Days extrapolates generic confines through a realist mode of production. I proceed with an investigation of Van Sant's roots in drug culture and art, moving on to analyse the film's original rendition of an expanded state of consciousness in the light of surrealism, minimal art and the American structural film.

Rock star biopics constitute an established sub-genre in American cinema. From the likes of The Doors (Oliver Stone, 1991), the story of the eponymous band, through to the more recent Walk the Line (James Mangold, 2005), the biopic of singer Johnny Cash, the troubled lives of rock singers seem to provide rich material for the screen. In some 
respects, Last Days conforms to the conventions of the genre, constructing for instance a replica image of Kurt Cobain's phenotype and appearances. This, according to Van Sant, was in fact suggested by Michael Pitt, who plays Cobain in the film and whose impersonation of the singer is indeed impressive. Usually displaying a rounder figure, the actor lost substantial weight in order to attain the musician's skinny physique, further adopting his bleached hairstyle. Fans of Cobain also cannot fail to notice that the garments on display in Last Days emulate, if with minor variations, those famously worn by Cobain: the spaceman sunglasses, flannel checkered shirts, the fur coat, the army boots, the stripy baggy jumper, the hunting cap - objects which acquired an iconic status after the singer's death. Such fidelity to the star's clothing even extends to the reproduction of Cobain's cross-dressing habit. The singer notably played on his gender identity and sexuality, eventually showing up in interviews and concerts entirely crossdressed. In the film, we see the character inexplicably making himself up and putting on a strapless black dress.
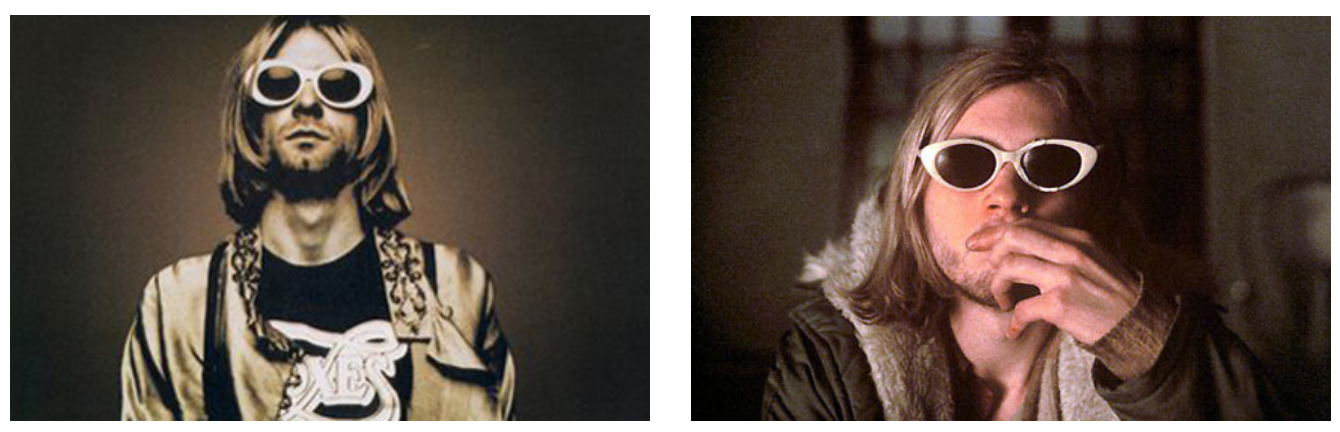

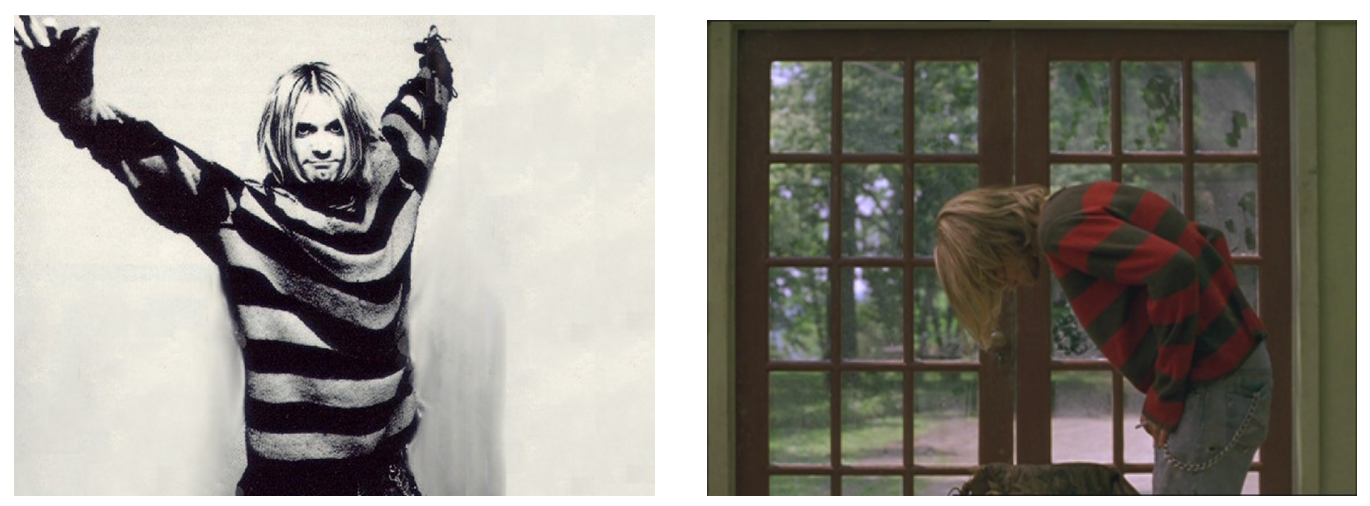

In the mould of Cobain

As well as his visual attire, Last Days cites widely disseminated photographs of Cobain, whose idolatry derived from the relentless propagation of his image. In one scene, for example, we see the musician cuddling some kittens, which refers to a string of famous pictures in which Cobain is playing with these animals. Even more telling is Van Sant's reference to the most circulated photograph of the singer's death, in which his corpse, lying on the floor, is framed from a distance through the bars of a glass door, an image emulated in Last Days, as the pictures below illustrate.
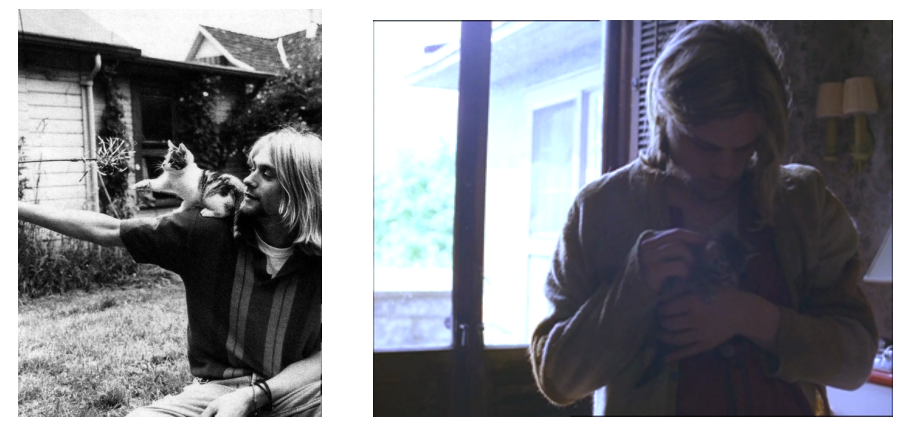

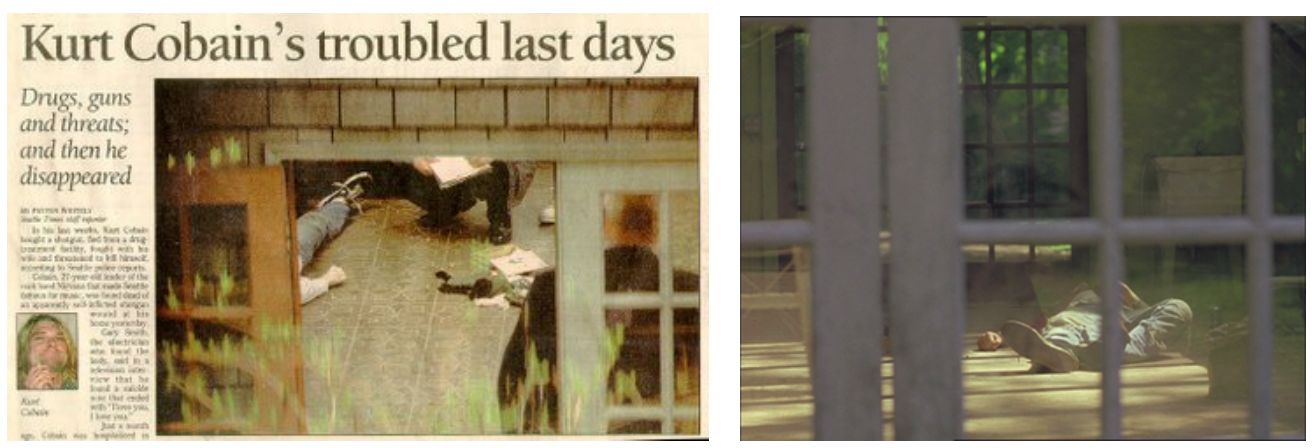

Reproducing Cobain in Last Days

In addition, Van Sant authenticates his rendition of Cobain's death by casting personal friends of the singer, such as Kim Gordon, member of the American band Sonic Youth, which was crucial in propelling Nirvana onto the music circuit. Shortly before Nirvana's breakthrough, in 1991, the band travelled on a tour around Europe as the opening act for Sonic Youth. In the film, Gordon plays an unspecified part (the film credits it as 'record executive' but this is not evident), attempting to rescue the singer from his downward spiral. For those who know Gordon and her friendship with Cobain, this scene obviously acquires an added significance.

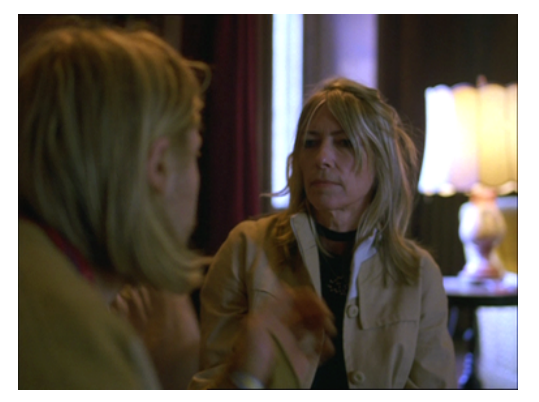

Kim Gordon in Last Days

This being said, Last Days proved a deeply unconventional biopic, if such a term can indeed be applied at all here. This is a film unconcerned with what actually happened 
during Cobain's last days. In stark contrast with the news media discourse, which constructed murder-mystery and psychological narratives around the singer's death, Last Days does not attempt to provide a logical rationale for this tragedy. Instead, as will be now examined, it opts for a largely fictionalised, as well as improvised, account through a non-narrative approach.

One finds no story or psychology in Last Days. In it, we are offered a deeply isolated musician, named Blake, who is depicted throughout in a constant state of agitation, sleeplessness and despair, visibly trapped in a profound haze. This, we assume, has been caused by the use of drugs, though drug taking is not on show here. Onscreen entirely by himself for most of the time, we follow Blake, in overextended shots, staggering his way in and around the countryside stone mansion in which he presumably lives and in which a group of four people (actors Lukas Hass, Scott Patrick Green, Asia Argento, Nicole Vicius) are staying. In their turn, these characters are not psychologically nuanced either, their relationship with the singer remaining unspecified. Are they members of his band or friends feeding on his wealth, as we see Scott asking Blake for some money? As the film unfolds, we are introduced to even more obscure characters mostly played by untrained non-professional actors, and I will return to this - whose unexplained and inconsequential appearance lends the film a surrealist quality. Blake and his friends receive the visit of a Yellow Pages salesman, two Mormon congregants, a private investigator accompanied by a friend, but none of these episodes are developed, contributing to a permanent sense of confusion and obscurity. Dialogue does not provide any insight into these characters either, for they often verge on absurdity, as in Gerry, or else is inexistent. As far as Blake is concerned, he is incommunicable. In the rare 
conversations with which he engages, he is a numb, catatonic listener whose mind is somewhere else. When he speaks, it is with himself, in unintelligible, incoherent mumblings.

Like the trilogy's previous instalments, Last Days authenticates this fictional universe through a realist mode of production. Filming entirely on location, Van Sant again relied on a script simply outlined, enabling a great deal of improvisation on the part of the cast, who even moved to the house, located in Garrison in New York state, during the four-week period in which the film was shot. The actors, most of them close friends of the director, were further allowed to bring their own experiences into their characters, whose real names, with the exception of Blake, are also preserved. In one scene, for example, Luke tells Blake the story of a girl whom he has met in Tokyo, which happened in reality. Other scenes, such as the unexpected sexual encounter between Luke and Scott, were suggested by the actors themselves, who thought it interesting for their characters.

Realism is further mobilised in Last Days through the performance of Michael Pitt. Though in the film Pitt is the carbon copy of Cobain, who is moreover on the verge of unconsciousness, the lines separating fiction from reality, that is to say, character from actor, are occasionally blurred. This is so because Pitt is also a musician, the vocalist of the band Pagoda, whose musical influences, in turn, include grunge rock. Pitt was given total freedom to improvise when playing instruments in the film, even playing his own, single-authored songs, such as 'Death to Birth', which, despite the fitting title and the fact that it evokes Cobain's own obsession with birth imagery (Nirvana's last album was called In Utero), was not composed for the film but many years before it. 
More specifically, the realist aspect of Pitt's impersonation resides in what is a highly physical performance. Though, as mentioned above, Last Days refrains from showing drugs, which is in contrast with, for example, Drugstore Cowboy's recurrent close-ups of piercing syringes, its take on the subject is far more realistic, opting for a scrupulous inspection of a slow and deteriorating death. In Gerry and Elephant death is a sudden irruption inflicted by external agents, in the former the character Gerry played by Matt Damon, in the latter the perpetrators of the massacre, Eric and Alex. In Last Days, on the contrary, the gunshot that kills Blake merely brings to a halt an agonising corporeal pain scrutinised during the film's entirety. In this respect, the film conforms to what Margulies theorises as reenactment films which resort to 'bodily discomfort' so as to authenticate their rendition of historical events, testifying, as a result, to 'how distant realism can be from a mere reproduction of appearances' (Margulies 2003: 5). For most of the time, Blake is hardly able to stand on his feet, conveying the impression he is in slow motion. We see him repeatedly stumbling, vomiting and, more often than not, collapsing. As his dishevelled hair covers his face for most of the time, or else his head is enclosed by giant hats or hooded jackets, the viewer is further denied reading of his facial expressions, their attention being constantly drawn to Blake's unsteady corporeal movements. This is all a performance, of course. But in a manner similar to the physical acting found in Tsai's cinema, analysed in Chapter 8, such performance required from Pitt a considerable level of corporeal engagement, authenticating the character's bodily discomfort through his own body, as in the film's opening, in which we see him plunging into what one assumes to be a freezing waterfall. 
As well as its corporeal effects, Last Days highlights, through its form, an entropic state of mind as supposedly derived from the use of drugs. However, this is not at all Van Sant's foray into the arena of drug culture, compelling us now to revisit his oeuvre and artistic roots as a means to better grasp Last Days's take on the subject.

\section{Death, Drugs and Rock and Roll}

Drug-addict characters are indeed a recurrent feature in Van Sant's oeuvre, including $M y$ Own Private Idaho, Even Cowgirls Get the Blues and, of course, Drugstore Cowboy, focused on American drug culture in the 1970s as it depicts a group of outcasts robbing pharmacies around Portland. This interest in drugs, in fact, testifies to Van Sant's roots in the American Beat movement, which, as stated earlier, exerted a great influence on the director. Including the likes of Burroughs and Allen Ginsberg (to whom Good Will Hunting is dedicated), the Beat generation became known for their depiction of drug addiction, as well as their own experimentation with drugs due to its inspirational and mind-expansive abilities. Prefiguring the psychedelic counterculture of the 1960s, which would heavily make use of lysergic drugs to this end, works such as Ginsberg's Howl (1956) and Burroughs's Naked Lunch (1959), among others, were the result of these writers' actual experience with drugs, aimed at emulating a drug-induced state of mind. Van Sant paid homage to the Beat movement in Drugstore Cowboy, in which Burroughs makes an appearance as an ex-junkie priest, an explicit reference to one of his short stories, The 'Priest' They Called Him, compiled in the writer's collection Exterminator! (1973). In the film, Burroughs, who in real life suffered from heroin addiction, is a priest 
whom the protagonist Bob (Matt Dillon) meets in a rehabilitation clinic when undergoing treatment. The collaboration between filmmaker and writer was then rehashed in 1990 in the music video 'A Thanksgiving Prayer', a promo for Burroughs's recited musical album Dead City Radio, which was directed by Van Sant. Interestingly, Nirvana's frontman Kurt Cobain was also inspired by Burroughs's work, including his famous cutup technique when composing his lyrics. In 1992, it was Cobain and Burroughs turn to collaborate in the record The 'Priest' They Called Him, with Burroughs reciting the words from his short story to the sound of Cobain's guitar.

And yet, Last Days makes no references to Burroughs. Instead, it nods to one of the forefathers of the Beat generation, as well as the hippie movement of the 1960s, namely English poet and painter William Blake. Representative of the English Romantic age, Blake stressed the power of imagination in its ability to disclose the perennial nature of things as opposed to an empirically verifiable reality, his illustrations being freighted with religious imagery seemingly derived from his own 'visions'. As Harold Bloom puts it: 'The universe according to Blake was not the objective outside ran by laws...but an internally perceived subjectivity which projected itself, through the agency of the material world, in vision' (Bloom 2006: 22). Hence, the poet highlighted the need to expand our perceptual faculties, as epitomised in these oft-quoted lines from his poem The Marriage of Heaven and Hell:

If the doors of perception were cleansed, everything would appear to man as it is, infinite. 
For man has closed himself up, till he sees all things thru chinks of his cavern. (Blake 1994: 36).

As a result of this mystical rhetoric, Blake was appropriated in the 1950s and 1960s by artists who connected his visionary stance to drug-induced mental processes. In fact, the aforementioned lines were single-handedly evoked in many drug-related projects, not least Aldous Huxley's famous recollection of a mescaline trip, titled The Doors of Perception (1954), as well as Jim Morrison's psychedelic rock band The Doors. As far as the Beat movement is concerned, Blake was also a decisive influence upon its leading figures, with Ginsberg even claiming that in 1946 he had a vision, similar to those claimed by Blake in his age, in which he saw the English poet in person.

In Last Days, Cobain is named Blake, in what is an obvious reference to the Romantic artist. To confirm this, the film also features Hildegard Westerkamp's soundscape ‘Doors of Perception' (more of which later), which, like Huxley's novel and Morrison's band, was named after Blake's aforementioned epigram. The reference to the poet is rounded off in the film's ending, which emulates the picture of Cobain's death. The static camera looks on into the garage as the naked body of Blake, or his 'spirit' if you will, rises up through a superimposition: we see him climbing up the doors, as though ascending to heaven while his dressed corpse remains on the floor. This visual imagery, as Jason Whitaker (2010) notes, is highly redolent of Blake's famous religious illustrations, such as those commissioned to illustrate Robert Blair's poem The Grave (1808), which depicts, as emulated in Last Days, spirits detaching themselves from bodies, as the pictures below exemplify. 

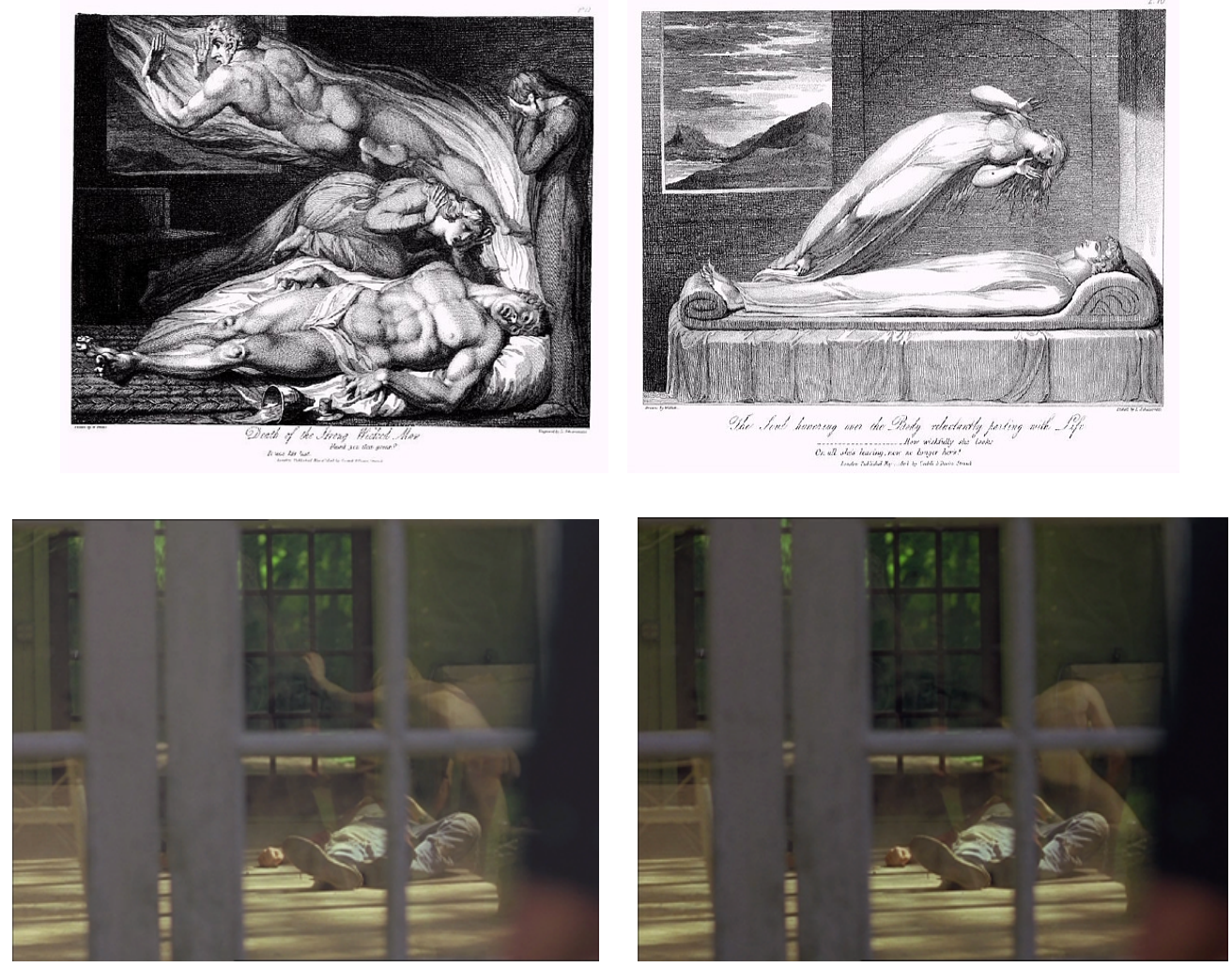

Detaching spirits in Blake's illustrations (above) and Last Days

To be more accurate, however, this is not the first time Cobain appears as 'Blake' in a work by Van Sant, going back to the director's literary (and thus far one-off) debut, the novel Pink (1997), itself an exploration of death, American youth and drugs. A love letter to Van Sant's protégée River Phoenix (in the book named Felix Arroyo), who starred in My Own Private Idaho and died a few years later of an accidental overdose, the book devotes two chapters to a rock star named Blake, whose allusions to Cobain, including illustrations, are unequivocal. In the novel, Blake is married to Blackie, in its turn a reference to Courtney Love that reappears in Last Days, as we learn that the private investigator searching for the singer has been hired by his wife Blackie. In some respects, the novel complements Last Days, not least because it tentatively provides a 
psychological, if brief and ironic, rationale for the singer's death, which is non-existent in the film. In a free indirect discourse style, Blake is described as someone who 'couldn't handle the rock star idolatry' and 'needed more space' (Van Sant 1998: 65-6), suffering from the worship of a purposeless young generation:

These crowds needed him. They needed his life, they needed his shit. Because they had no lives of their own. Sad but true.

They had no identity of their own. They needed Blake to tell them what to believe in. They needed someone to follow. Like sheep. And he was their shepherd... (Van Sant 1998: 21-2).

In the film, we do not see these crowds, except for one scene in the end in which a television in the background briefly shows hordes of people mourning the singer's death. However, aimlessness and purposelessness are certainly highlighted as youth characteristics through the group of four friends who stay in Blake's house, who seem to have no occupation in life and pass the time sleeping, pottering about, having sex or throwing parties. A particularly poignant sequence, also at the film's end, shows these characters, presumably running away from the police, inside a car. Scott drives the vehicle while Luke, in the back seat with Nicole, plays a melancholic melody on the guitar, both looking desolate and lost. Thus, if Gerry and, most notably, Elephant portray the current American youth generation as inserted in a vicious cycle of boredom and satisfaction, Last Days rounds off the trilogy by suggesting that such state of affairs is not a recent phenomenon but has for some time now permeated American youth. 
Yet, as is also the case with the trilogy's previous instalments, Last Days stops short of making moral judgments about its characters or their behaviour, confining itself to contemplating this reality and, even more so, the 'reality' of drug-induced mental processes. In tune with the mind-altering artistic legacy that Blake's visionary work has elicited, this is indeed a film aimed at conveying the sensory and perceptual reality of an altered consciousness. However, Last Days has none of the euphoric overtones of mind expansion which, to different extents, characterised the likes of Ginsberg, Burroughs, Huxley and psychedelic culture in general. As Whitaker puts it, here 'the hippie optimism of a Huxley-inspired personal liberation through LSD has become the despair of heroinaddicted, sold-out grunge' (Whitaker 2010). And, indeed, Last Days is in many ways a 'dark trip', portraying in scrupulous detail a solitary and painful death. In contrast with the trilogy's previous instalments, moreover, its form is more austere and minimalist, converting cinematic reflexivity into entropy of mind.

\section{The Doors of Perception}

If Last Days emulates a drug-induced state of mind, an altered consciousness is not overtly conveyed as such within its diegetic universe and defined against a state of normalcy, as is usually the case in drug films. Take once again, for example, Van Sant's own Drugstore Cowboy, in which drug 'trips' are given audiovisual materialisation through images of objects such as cows, clocks and spoons floating against shifting clouds - surreal imagery which is in stark contrast with the 'normal' diegetic reality as observed in the rest of the film. What is so puzzling in Last Days, precisely, is that such 
normalcy does not seem to exist at all, meaning that the spectator is gradually offered a series of situations to which they cannot apply sense-making tools. Reality is not offered a counterpoint against which to contrast, but instead made strange - or 'defamiliarised' to use Viktor Shklovsky's famous expression - through a number of formal and narrative strategies. As a result, we conclude that an altered state of mind may well be simply what there is. Let us first analyse the film's use of sound.

Here, as in Elephant, overlapping excerpts of Hildegard Westerkamp's 'Doors of Perception' imbue scenes with a disorienting quality, producing a multilayered audiovisual dissonance. But whereas in Elephant these concrete sounds are non-diegetic and unrelated to a specific character, Last Days offers a more complicated case, as sounds seem to originate either from an off-screen source within the diegesis or else directly from Blake's mind. Take for example the scene in which Blake walks up the stairs in the house as we hear some chimes. These initially seem to come from a clock inside the house but as they proliferate and become increasingly louder, the spectator is forced to dismiss this assumption. On other occasions, Blake's own consciousness seems to comprise the film's aural track. Michel Chion discusses what he calls the 'subjective sense of point of audition', which he deems analogous to the subjective shot in that we hear what 'a character, at a given moment of the story, is (apparently) hearing' (Chion 1994: 90). He argues that this subjective sense, or point of hearing, is often conveyed by the film's visual track, through close-ups, in that we can identify the sounds 'as being heard by the character shown' (Chion 1994: 91). This is what happens, for instance, when Blake is in the outhouse writing in what looks like a diary. As the camera slowly carries out a $360^{\circ}$ pan around his face, we hear, among others sounds, diffuse murmuring, bell 
chimes, a motorbike engine, shutting doors, all seemingly springing from Blake's mind. This impression is further reinforced when, a few moments later, his friends' leaving the house suddenly catches his attention and breaks his concentration, which is conveyed through an interruption of the soundscape. We then realise that the sound of footsteps we have also been hearing, which eventually superimposes upon all other sounds, come in fact from within the diegesis as the camera shows the group of friends walking towards the car, which we locate as their acoustic source.

This inability to locate sound sources, and the blurred cognition of reality its fluctuation entails, seem to materialise Blake's confused mind. Entropy is further conveyed through the film's montage, which, as in Elephant, fractures and shuffles temporal linearity, replaying situations from different perspectives. This looping structure renders a chronology which is anything but reliable, with the film leaving unspecified the number of days being shown, as well as the time elapsed between scenes. At one point, for example, we follow Asia through the house as she opens the door of a room and encounters Blake's unconscious body. This event, to the viewer's surprise, is later repeated from inside the room as we see Blake collapsing against the door and Asia subsequently opening it. In another occasion, we watch an enthralled Scott singing to Velvet Underground's hymn 'Venus in Furs'. He gets up and the camera follows him into the kitchen, where he finds Blake, asks for some money in a quasi-nonsensical rhetoric and goes back to the couch in which he was sitting. This is later replayed from Blake's perspective, as we watch him cooking an instant macaroni cheese in a sleepwalking state while Scott arrives asking for some money. The scene ends by replaying the previous shot, following Scott back to the place in which he was sitting. 
Sound and montage are certainly the most readily identifiable formal devices through which objective reality is estranged in Last Days. Yet, even when the film dispenses with these recourses, reality is made strange all the same through staged events which resist meaning, lending the film a surrealist quality. As is well known, surrealism is premised on the rejection of rationality and logic, aiming for a purely unconscious, free mental functioning. To this end, a technique often resorted to is the unexpected juxtaposition of unrelated objects or, in the words of foundational surrealist poet Pierre Reverdy, 'the conjunction of two more or less distant realities' (Reverdy apud Grant 2005: 78). In Last Days surrealist juxtapositions appear not so much in the form of a collage-like montage, as has been explored by the likes of Luis Buñuel and Maya Deren, among others, but in the profilmic event itself. In some respects similar to Reygadas, Van Sant produces strange juxtapositions in reality by casting non-professional actors who, playing exactly what they do in real life and given total freedom to improvise their lines, are plunged into bizarre fictional situations which, as a result, takes on an estranged documentary quality. This is what happens, for example, when Blake, visibly on drugs and entirely cross-dressed, receives the visit of the Yellow Pages salesman Thadeus A. Thomas. During a conversation that lasts six baffling minutes, recorded in a static unbroken shot, we watch the salesman nonchalantly enquiring a spaced-out and crossdressed Blake trivia such as the success of his previous ads. This proves utterly inconsequential within the film, as does the scene, onscreen shortly after, in which we are offered yet another bizarre juxtaposition: two twin missionaries of a Mormon congregation (Adam and Andy Friberg), are shown visiting the house and proselytising their religion to Blake's friends. 

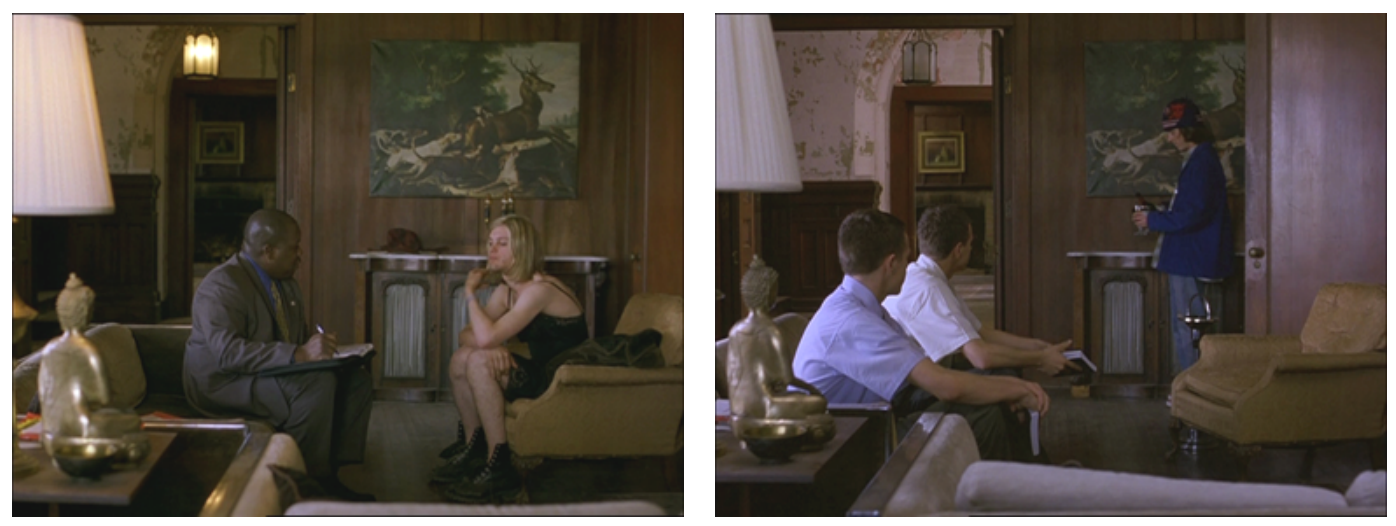

Surrealist juxtapositions

Important though they are, the aforementioned strategies alone cannot fully explain Last Days's exploration of an altered perception, prompting us now to revisit Van Sant's roots in experimental cinema, from which he also incorporates many formal devices. Like Gerry, this is indeed a film which owes much of its style to the American avant-garde cinema, and in particular its 'structural' offspring, whose concern with cognition and perception, as Noël Carroll tells us, reflected 'the obsession of the sixties with perception, an interest evinced as well by the drug culture' (Carroll 1998: 305). A term coined by Sitney, the 'structural film' came to be defined by ultra-reflexivity and rigorous form, intent to expose the medium's material and formal properties. The cinematic correlate of minimal art, with its quest for reduction and literality, structural cinema, in short, hyperbolises, and in so doing calls into reflection, the act of perception as enabled and enhanced by the film medium. To this end, it resorts to strategies such as duration, reduced visual content, as well as reflexive, notably stationary, camerawork. Sitney defines it as 'a cinema of structure in which the shape of the whole film is predetermined and simplified' (Sitney 2002: 348), these being films 'actively engaged in 
generating metaphors for the viewing or rather the perceiving, experience' (Sitney 2002: $351)$.

This is certainly what happens in Last Days, for example in the scene in which Blake collapses in the television room. A few shots earlier, the viewer had followed the character, in a strapless dress, switching on the TV set, which showed the music video of the saccharine song 'On Bended Knees' by RnB boy band Boys II Men. True enough, this video serves a temporal function, as it anchors the film in 1994, the year of the song's release and Cobain's death. This does not justify, however, the protracted attention that it subsequently receives. As Blake, in visible pain, seems to lose consciousness, the song gradually fades out and is superimposed by a disorienting soundscape, which, as in the previously analysed scene, conveys his subjective, altered point of hearing. As he collapses onto the door and is found by Asia, who checks he is still alive, corrects his position and leaves the room, the song begins to fade in again. The viewer is then offered a long shot of the TV set, by itself in the middle of the room - in a composition whose schematic and geometric spatial arrangement evokes an art installation - followed by an overextended close-up of the television showing the music video's final minute in its entirety.

By deliberately focusing on an object which by nature demands a perceiving recipient, these two shots immediately highlight the spectatorial act of perception. At the same time, they seem to convey Blake's subjective vision. What is thus so interesting here is that an altered perception is conveyed through a mere fixed, static gaze, which, insistently dwelling on an image resistant to meaning, underlines its resolute literality and, in so doing, perception itself. As a result, defamiliarisation is elicited in the strict 
sense of the term as formulated by Russian formalist Victor Shklovsky, who, noting that 'as perception becomes habitual, it becomes automatic' (Shklovsky 1965: 11), called for an art able to revitalise perception in its full sensory dimension:

[A]rt exists that one may recover the sensation of life; it exists to make one feel things, to make the stone stony. The purpose of art is to impart the sensation of things as they are perceived and not as they are known. The technique of art is to make objects 'unfamiliar', to make forms difficult, to increase the difficulty and length of perception because the process of perception is an aesthetic end in itself and must be prolonged (Shklovsky 1965: 12).

This scene thus seems to answer Shklovsky's call programmatically. Thanks to the medium's temporal properties, here perception is indeed literally prolonged, forcing the viewer to 'perceive' this television, as well as its seemingly random visual content, as a pure and heightened sensible presence, that is, as realism of the senses. 'Doors of perception' are opened up through a hyperbolic, unwavering assertion of the medium's recording ability. Speaking of the early films of one of Van Sant's avowed heroes, Andy Warhol, steeped as we know in duration, camera fixity and emptied-out content, Sitney argues that they 'outlast a viewer's initial state of perception. By sheer dint of waiting, the persistent viewer would alter his experience before the sameness of the cinematic image' (Sitney 2002: 351). Of course, Last Days is miles away from the radicalism of Warhol's works, many of which composed of one single frame onscreen on loop for hours on end, such as Sleep (1963) and Eat (1963). Still, its reliance on overextended 
fixed frames seems to aim for a similar foregrounding, and consequent distortion, of automatic modes of perception, here appropriated so as to crystallise a drug-induced state of consciousness.
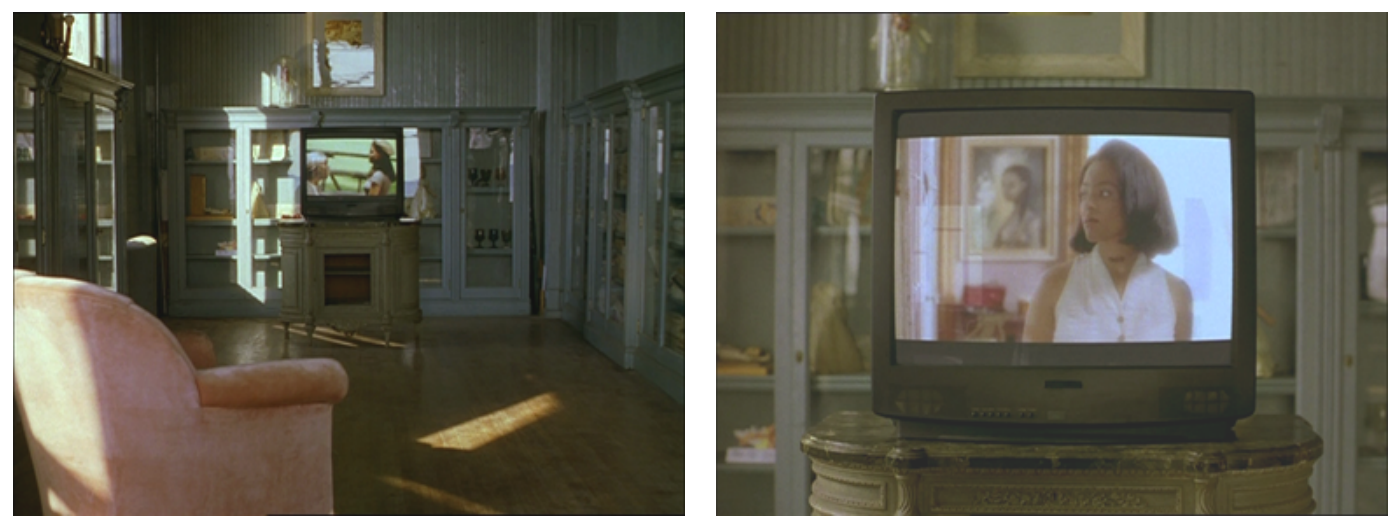

Prolonging and enhancing perception in Last Days

Perception is also explored in Last Days through the foregrounding of the medium itself as expanding the frame's visual field and, as a result, the viewer's own perceptual apprehension of time and space. Such strategy is arguably found in a landmark of yet another structural filmmaker, namely Michael Snow's Wavelength (1967), composed, through montage tricks, of a 45-minute forward zoom exploring an empty interior space. Initially taking in a loft in a long shot, the film gradually narrows its visual field until it closes in on a photograph of waves on the wall opposite, sided by two windows. In Last Days a reversed exploration of an outdoor space and a window is conveyed not through zoom, but in its famous tracking shot of six minutes, as mentioned in the Introduction. The camera, seemingly static, focuses on Blake's mansion from the outside, its half-open window revealing several musical instruments in an empty room. As Blake walks into the room, and consequently the frame, and begins to play these instruments with the help of a 
mixing equipment, the camera unhurriedly starts to recede, unveiling in time a previously concealed portion of phenomenological space: the house's full façade and its front area. What is remarkable, moreover, is that this receding camera movement is so subtle, steady and slow that its unveiling of space within the shot is almost imperceptible, prompting the spectator to question the reliability of their perception. That is, in order to certify that the camera is indeed moving, the viewer's perception is most likely centrifugally redirected to the borders of the frame, in which the continuous, smooth and slow expansion of this space is more readily visible. Here, perception is not only deautomatised as the viewer is made fully conscious of its process. The medium itself is highlighted as indeed expanding, in both senses of the word, the viewer's perceptual apprehension of such phenomenological space in time.
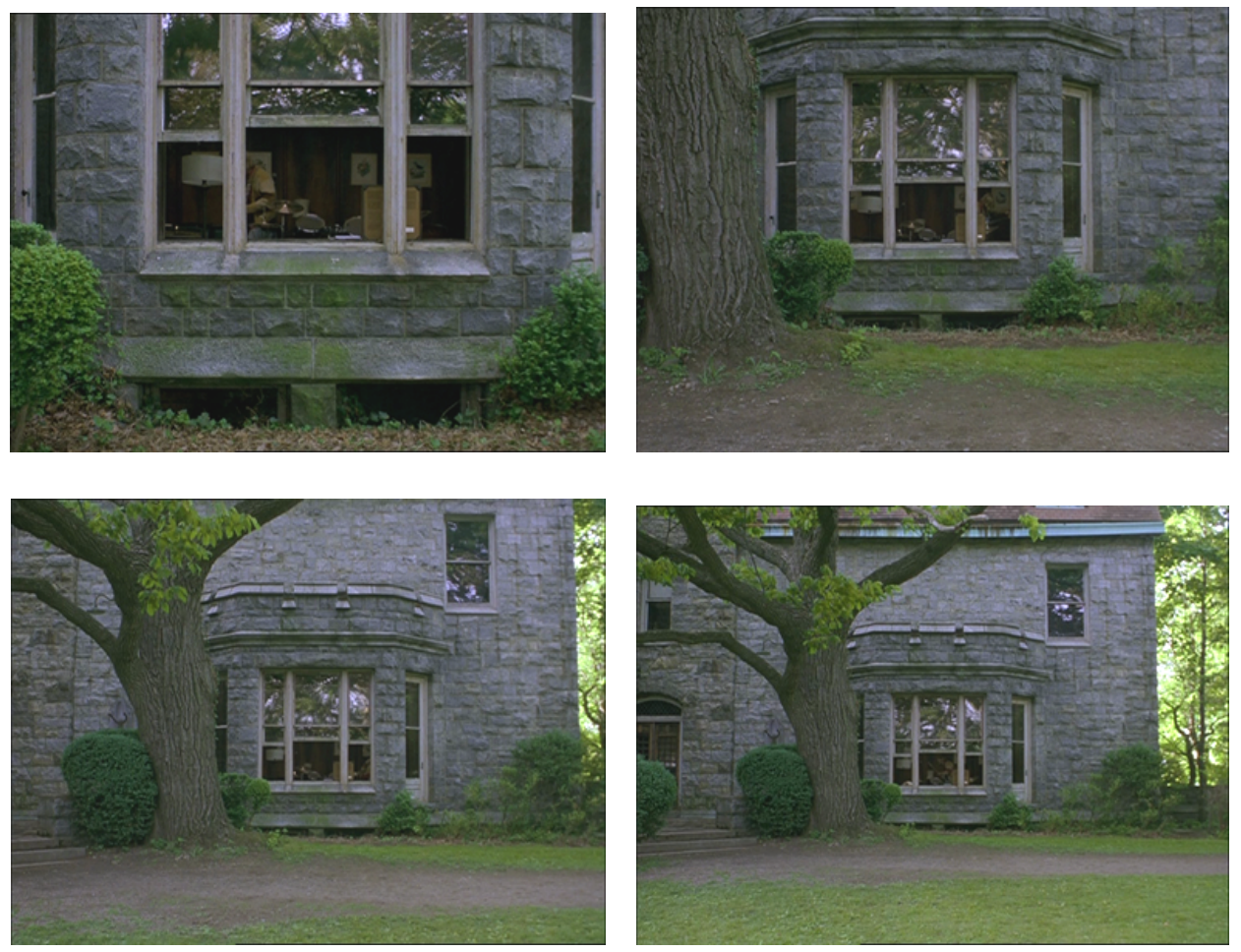

Expanding perception in Last Days 
Perception is also estranged through other structural-minimalist strategies, such as repetition and seriality. We have seen, for example, how the film repeats the same situations twice in time from different spatial perspectives. In symmetry with that, the same portions of space, rendered in virtually identical frames, are repeated throughout Last Days. That is, as the film unfolds, the viewer is offered the same fixed frames, each time with slight variations in its visual content. Several visual compositions recur throughout, most of which being static, frontal and geometric shots: Blake's room, framed from outside and through a centrally positioned, open door; the front area of the mansion, with the outhouse in which Blake commits suicide visible in the background; a flight of the house's stairs, its railing in the foreground (see pictures below). The latter frame, for example, appears every time we see a character walking up or down these stairs, whose perspective is almost entirely restricted to this angle. Another recurrent composition frames the mansion's door from outside, which appears, for example, when the Yellow Pages salesman, the Mormons, as well as other characters, enter or leave the house. We thus realise that the rendition of this particular filmic space obeys to a limited range of perspectives, their obsessive repetition calling attention to the film's predetermined form.
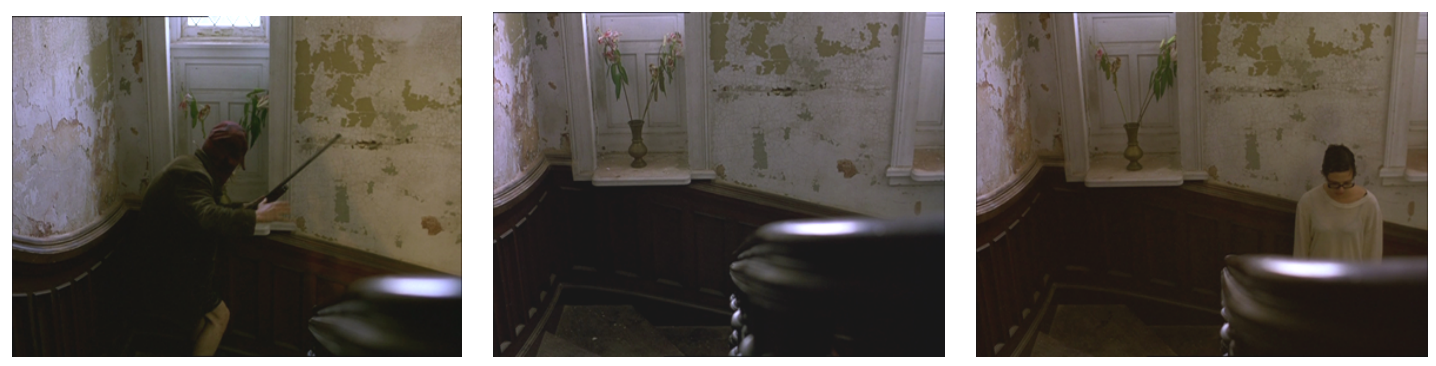

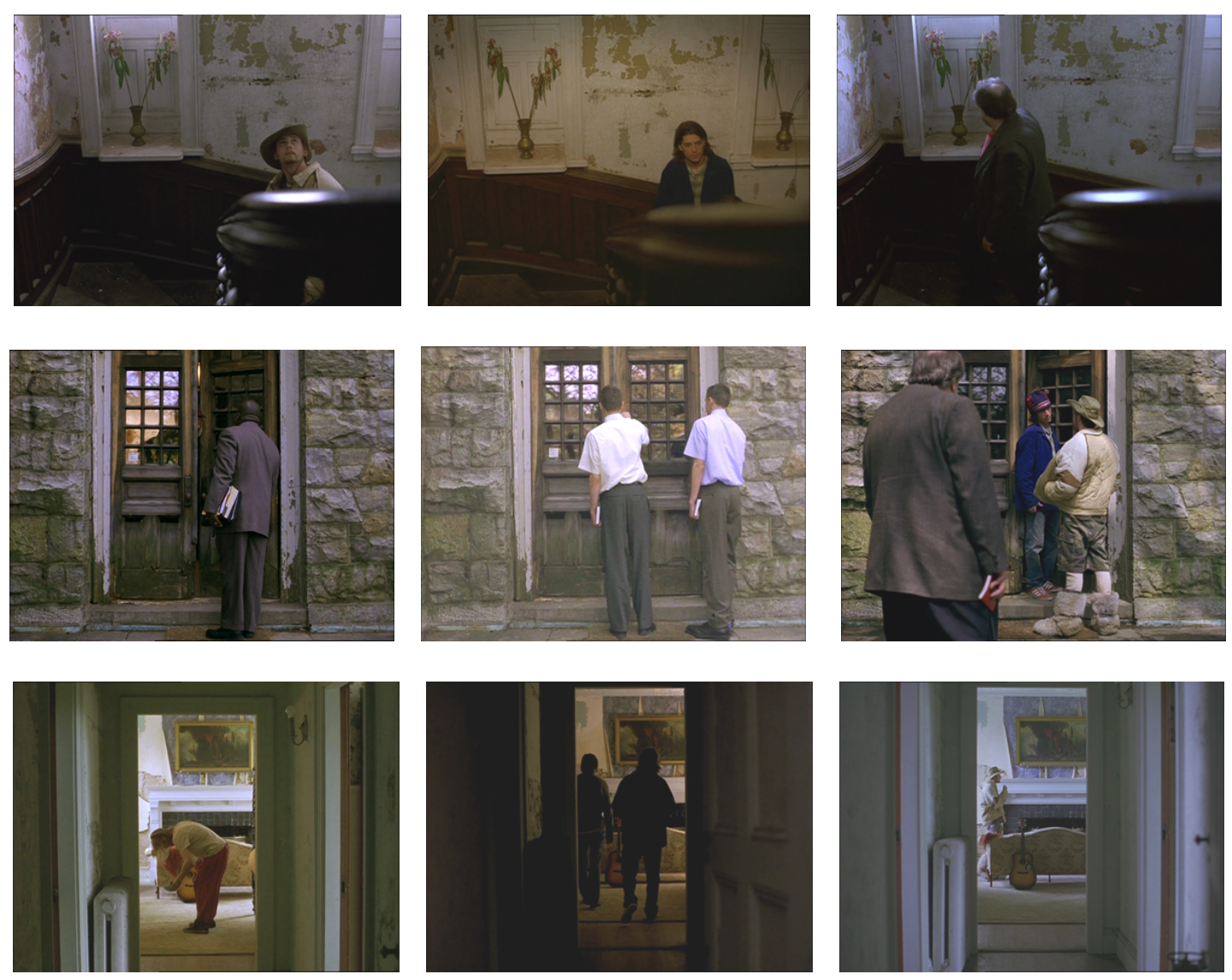

Repetition and seriality in Last Days

Savides has confessed that one of the inspirations for the trilogy's long take approach was Akerman's Jeanne Dielman, discussed in Part II in relation to Tsai's immobile camerawork and everyday aesthetics. Without a doubt, it is in Last Days that such influence is most forcefully felt, given that Gerry and Elephant privilege a much more itinerant camerawork. In Jeanne Dielman, a direct heir of the American structural tradition and minimal art, the protagonist's home is framed throughout from the same rigid, frontal and static angles, which, through endless repetition, effectively contributes to its description of an obsessive-compulsive behaviour. In Last Days, this repetitive strategy yields different effects. Its more limited choice of framing compositions means 
that the house's spatial coordinates, in which most of the film is set, are rendered entirely confusing and unclear. Insofar as the spectator is offered only a few predetermined, selected and tight angles of the house's interior, these shots, matching the film's temporally fractured structure, become pieces of a spatial puzzle which is ultimately impossible to complete.

From psychedelic landmarks such as The Trip (Roger Corman, 1967) and Easy Rider (Dennis Hopper, 1968), through to the more recent Trainspotting (Danny Boyle, 1996), Fear and Loathing in Las Vegas (Terry Gilliams, 1998) and Requiem for a Dream (Darren Aronofsky, 2000), a drug-induced perception is often conveyed through a disruption on the 'realistic' legibility of the cinematic image, whether through blurred focus, swooping camerawork, rapid-fire montage, fish-eye lens and, more recently, digital manipulation. By contrast, Last Days opts for a conceptual, minimal and reflexive visual approach in its exploration of cognition and perception, hyperbolising, through static long takes, the literality of the image as a means to enhance perception itself.

Its elaborate editing work and use of sound notwithstanding, Last Days is indeed a film of sparse means, being entirely reliant on the indexicality of the cinematic image, here foregrounded through duration and camera fixity. But more than the phenomenological real, such strategy aims at unveiling the durational and material properties of the medium and, notably, its capacity to make reality mysterious and strange. This is different for example from Gerry, whose long take cinematography calls as much attention to the objective real, materialised in stunning landscapes, as to the medium's ability to record it. An exploration of altered modes of cognition, Last Days is proof that the medium, even when reduced to its basic recording property, offers 
inexhaustible resources to be explored in anti-naturalistic ways. As discussed in the Introduction, discourses of the digital put forward the view, as noted by Rosen, that indexicality is a 'monolithic unity characterized by fixity of world, of representation, and of subject' (Rosen 2001: 348). Shaviro, for example, argues that this recent trend in world cinema, reliant on long takes and oblivious to 'digitalization', attests to 'a profound failure of imagination to continue to make films in the old way... when this "old way" has itself become nothing more than a nostalgic cliché' (Shaviro 2010). Responding to this, Last Days attests that indexicality is far more flexible than discourses hinging on its outmodedness imply, conveying a delirious perception through the medium's fundamental realist property.

The medium's recording ability is ultimately foregrounded in Last Days through the recurrence of a telling cinematic trope: the wind in the trees. Let me provide some examples to, by way of conclusion, draw its significance in the context of the trilogy. At first, it could be argued that the blowing leaves insistently on display in Last Days are simply the product of chance, given that the film was shot in a mansion encircled by woods and foliage. This however would fail to explain the central attention this trope receives in the film. To begin with, the green vegetation surrounding the mansion is highlighted in the film through the cinematography, which renders the colour green particularly vivid when set against the recurrent greys of the stone house and overcast skies. More significantly, moving leaves are on central display in several scenes. An example is the aforementioned tracking shot, in which swaying foliage is not only seen reflected on the upper half of the house window but also in the tree standing in front of it, which the camera unhurriedly reveals. Two shots are even more emblematic in this 
respect. The first finds the private investigator and his partner Donovan (Ryan Orion) driving towards the mansion to search for Blake. With the camera positioned outside the car in a high angle upon the front window, the spectator's attention oscillates between the passing trees reflected on the window surface and the two characters, partly concealed behind the reflection, engaged in an inconsequential conversation inside the car.

But nowhere is the swinging movement of leaves more foregrounded than in the scene in which Blake, in one of his perambulations, sets out to the woods. The camera pans to the left so as to follow the character but as he leaves the frame, it remains static for nearly 40 seconds simply recording the swaying foliage, as if suddenly magnetised by this particular image, which, it appears, compelled it to forget the character which it was following.
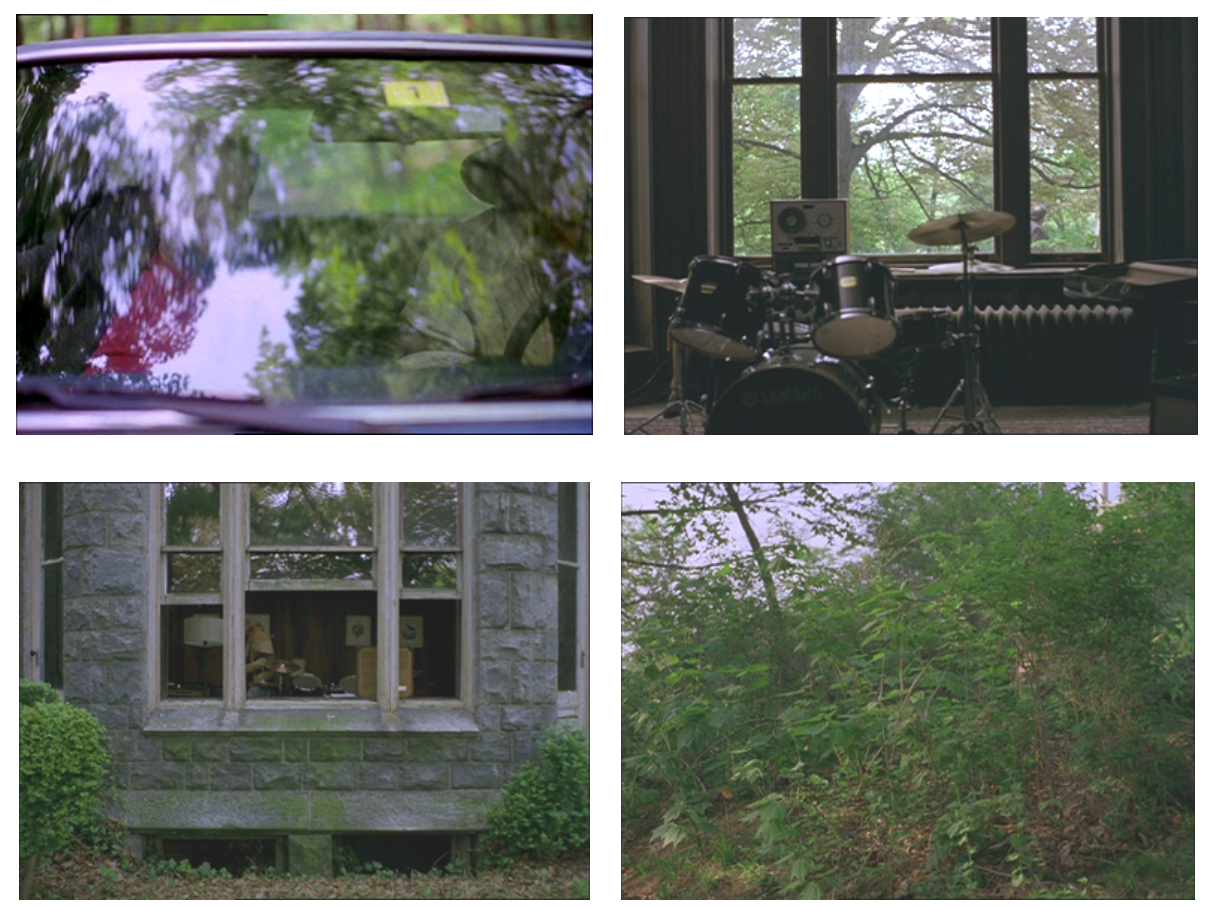

The wind in the trees in Last Days 
As we know, onscreen moving leaves have been extensively evoked in film history as a means to express the uncanny power of the film medium. As Jameson sums up, 'the fascination with leaves and their relationship to motion seems to have marked photography (and film) from their beginnings', such as 'the Lumière brothers' first highly praised shorts of "the ripple of leaves stirred by the wind"' (Jameson 1992: 196). As recent film scholarship has further stressed, early viewers were as much fascinated by the medium's ability to reproduce movement in a hitherto unseen lifelike manner as the actual visual content of films. Speaking of this uncanny effect, Mulvey stresses the dimension of the 'marvellous' in the Lumière films:

It is impossible to see the Lumière films as a simple demonstration of a new technology; every gesture, expression, movement of wind or water is touched with mystery. This is not the mystery of the magic trick but the more disturbing, uncanny sensation of seeing movement fossilized for the first time (Mulvey 2006: 36).

Now, such reproduction of reality, once a novelty in its own right, no longer conjures the same perceptual astonishment it once provoked. As Mulvey herself goes on to note, 'as cinema technology became integrated into everyday life...its workings were no longer mysterious' (Mulvey 2006: 36). And yet, what a film such as Last Days seems intent to reclaim is this very sense of mystery which so fascinated early viewers and whose allure is indissolubly connected to the medium's intrinsically realist properties. 
In many respects, this seems to be what Van Sant was after when embarking on this trilogy: to de-automatise perception and estrange reality, thereby restoring to the film medium its mysterious and sensorial power. These three films indeed attest to a director deeply enamoured with the cinematic apparatus, a rediscovery that 'the camera is a machine', to cite the title of Van Sant's piece on Tarr's work, freighted with unexplored possibilities. Taken together, they signal not to death but to a remarkable rebirth in the director's career, and one that testifies to the endless capacity of reinvention of the film medium and cinematic realism. 


\section{CONCLUSION}

In her seminal manifesto-essay 'Against Interpretation', Susan Sontag advocated a type of criticism that would stress the sensorial value of art rather than its semantic dimension. The year was 1964, as Sontag reacted to the upsurge of conceptual art in the US, as well as the ensuing tendency in American criticism to analyse art exclusively for its 'content', in the modes of the Platonic theory 'of art as mimesis or representation' (Sontag 2001: 4). She posited the need of reclaiming sensory experience in a world overloaded with stimuli:

Think of the sheer multiplication of works of art available to every one of us, superadded to the conflicting tastes and odors and sights of the urban environment that bombard our senses. Ours is a culture based on excess, on overproduction; the result is a steady loss of sharpness in our sensory experience. All the conditions of modern life - its material plenitude, its sheer crowdedness - conjoin to dull our sensory faculties... What is important now is to recover our senses. We must learn to see more, to hear more, to feel more (Sontag 2001:13-14).

Sontag's remarks on the excess of stimuli brought about by modernity in fact reword Walter Benjamin's famous concept of 'shock', according to which urban life radically altered traditional modes of human perception, now ineluctably anchored in a state of 'distraction'. In contrast to previous modes of experience of time, art and history - what 
Benjamin called Erfahrung - experience was now fragmentary, isolated and ephemeral (Erlebnis). As he writes: 'Historically, the various modes of communication have competed with one another. The replacement of the older narration by information, of information by sensation, reflects the increasing atrophy of experience' (Benjamin 1973: 113). As Leo Charney observes, Benjamin's writings were in turn only a subset of a prevailing line of thinking of this period, being developed in different but overlapping guises by the likes of Walter Pater, Martin Heidegger and Henri Bergson, writers who 'in the midst of this environment of fleeting sensations and ephemeral distractions...sought to rescue the possibility of sensual experience in the face of modernity's ephemerality' (Charney 1995: 279).

This culture of excess, overproduction and overstimulation is glaringly more pervasive now, in our globalised world. Technological developments, such as the digital, satellite technology, as well as new media platforms such as the Internet, increase the speed, reach and flow of images and information in circulation around the globe, as well as significantly alter the way we communicate with others. In this context, Rodowick argues that the long take work of artists such as Sharon Lockhart and Sam Taylor-Wood, exhibited in art galleries and museums, seem to reclaim the 'phenomenology of the viewing experience' long lost in cinematic practices. They convey, he suggests, a 'yearning for duration and uninterrupted time, for perceptual depth, and for a sensuous connection to physical reality in a universe dominated by simulation and information saturation' (Rodowick 2007: 158). What Rodowick overlooks however is that sensory realism can be currently found in theatrical cinema. As I have argued, the cinemas of Carlos Reygadas, Tsai Ming-liang and Gus Van Sant aim themselves to 'recover our 
senses' (Sontag 2001: 14) through the inspection of sheer physical phenomena, dilating our perceptual and durational apprehension of animate and inanimate matter.

On the one hand, as we have seen, their realisms are fundamentally cinephile projects, testifying to a self-conscious quest to rework and expand upon very distinct film schools: metaphysical realism in Reygadas, cinematic auteurism in Tsai, experimental film in Van Sant, among others. Still, despite their being in most cases indebted to unrelated influences and grounded in very specific realities, to put these directors on an equal footing makes sense not only in light of their unrestrained commitment to the long take. As hopefully illustrated, they also arrive at similar formal strategies and common tropes in their quest to enhance material reality. We have seen, for example, the way in which the trope of the wanderer, contended by Deleuze as one of the fundamental staples of modern cinema, is pervasive in equal measure in their work. In them, characters devoid of psychology, interminably walk, stroll and loiter, often aimlessly, which in turn provides the cue for a contemplative approach to landscapes and cityscapes. We are offered the sensory urbanity of Taipei, Kuala Lumpur, Mexico City, as well as the extreme physicality of desert landscapes such as Ayacatzintla, the Utah salt flakes, Death Valley, not to mention the concreteness of interior spaces in Tsai's cinema. This visual stress on materiality is further relayed by these cinemas' sonic design, which emphasises the physical, autonomous, three-dimensional quality of sounds: whether through Van Sant's disorienting soundscapes; the raw, heightened physicality of sounds as enabled by direct sound in Reygadas; or the physiological sounds we hear in crystalline registers in Tsai's work. These are cinemas equally cathexed on the human body, be it in the form of the obese, flaccid flesh on full, microscopic view in Reygadas; or the performative bodies 
reduced to sheer physiology and physicality in Tsai; or the bodily discomfort and adolescent bodies as foregrounded, respectively, by Van Sant's Last Days and Elephant.

We have also seen how similar tropes reverberate in different guises here, an obvious example being the way the grotesque is mobilised both in Reygadas and Tsai: in the former, through the monstrosity of the close-up and the gigantism of bodies; in the latter, in the form of carnivalesque motifs and the hyperbolisation of bodily functioning. Not to mention their portrayal of atypical sexual encounters, as observed in the unlikely couples at the centre of Japón and Battle in Heaven and the incestuous sexual acts on display in The River and I Don't Want to Sleep Alone. In their turn, Tsai and Van Sant, in addition to deploying minimalist mise-en-scène and ultra-reflexive strategies, offer distinctive takes on the notion of trauma. While the latter frames the Columbine killings through a traumatised mind at pains to narrativise this event, the former depicts a universe seemingly recovering from the trauma of modernisation. The work of Van Sant and Reygadas similarly afford comparative analyses, not least in their preference for the contingent element of the first take and untrained acting as performed by amateur actors.

At least in principle, these are thus cinemas in line with the realist style as foundationally theorised by Kracauer, who, among other reasons, championed its enabling 'the experience of things in their concreteness' (Kracauer 1997: 296), in his view a welcoming antidote to the technician and abstract thinking prevailing at his time. Bazin is even more relevant here in view of his defence of phenomenological spatiotemporal integrity, as well as his concern for the 'sensuous quality' and 'concrete tactility of realistic details' onscreen, as summarised by Keathley (2006: 70-1). However, as discussed in the course of this project, the films of Reygadas, Tsai and Van Sant 
radicalise such interest in material reality through de-dramatisation, temporal elongation and aestheticisation. In so doing, they challenge Bazin's cinematic phenomenology, attached in many respects to a dramaturgic and representational logic, itself informed by the moral, humanist ideology of his contemporaries. If Bazin indeed put forward the idea that realism is first and foremost an aesthetic endeavour, as exemplified by the 'aesthetic realism' of Citizen Kane (Bazin 2005b: 43), his definition of realism was nonetheless often articulated as a 'form of self-effacement before reality' (Bazin 2005a: 29), as he famously defined Neorealism, or indeed as a 'styleless style' (Bazin 1997: 9), as he argued with reference to William Wyler's The Best Year of Our Lives.

In its turn, rather than an effacement before reality, the cinemas of Reygadas, Tsai and Van Sant are expressions of an active and unconcealed commitment to reshaping it. Were we to single out the unifying principle connecting these filmmakers, we could say that they are divided between two seemingly paradoxical impulses that create an aesthetic tension. On the one hand, they privilege the phenomenological and contingent real through untrained amateur acting (Reygadas); merely outlined scripts to be improvised during the shoot by professional and non-professional actors (Van Sant); performative and physical acting (Tsai); preference for the first take and its spontaneous quality (Van Sant, Reygadas); location shooting (Tsai, Reygadas, Van Sant); real sex onscreen (Reygadas, Tsai), all enhanced by presentifying long takes. On the other, they contradict documentary authenticity through formalist strategies that precede, constrain and complicate their stress on the objectivity of recording, such as geometric framings, choreographed camerawork and mise-en-scène, unnaturalistic use of sound and, particularly in Van Sant's case, conceptual montage. At stake here is thus a 
predetermined and self-evident aesthetic form that circumscribes the sheer physical presence of things and beings as highlighted by realist modes of production. This resonates with what Rancière calls 'the aesthetic regime of art', which, as mentioned in Chapter 3, is 'distributed between two extremes: a pure creative activity... and the pure passivity of the expressive power inscribed on the very surface of things, independently of every desire to signify or create' (Rancière 2006: 8).

The cinemas of Reygadas, Tsai and Van Sant are different audiovisual facets of a systematic, rigid and austere style that impresses for the plastic, even painterly, beauty of its rigorously composed images. As such, these are cinemas that frame reality through an aesthetic gaze which itself restructures the sensory and perceptual experience of the sensible. And while this aesthetic impulse is certainly not polemical in itself, it becomes as much when we consider the subjects and social realities focused on by these cinemas. In their quest to aestheticise 'controversial' issues such as the socio-ethnic divide of Mexico (Reygadas), traumatic events in the US such as the Columbine massacre (Van Sant) and marginalised populations in late-capitalist cities such as Taipei and Kuala Lumpur (Tsai), these cinemas are more often than not deemed to offer an inappropriate expression of the social issues they portray.

At stake here is a disruption of representational logic, which, as Rancière has recently argued, is informed by the notion of the 'proper', which secures and perpetuates the normal, in his words the 'consensual', social order as arranged and maintained by the status quo. Representative art, in this context, abides to mimetic principles whose logic of verisimilitude is in consonance with the self-evidence of the visible world, reinforcing the hierarchical social order that allocates bodies to specific, unchanging and functional 
places and spelling out the ways in which subjects are to be portrayed. By contrast, aesthetic art upsets this logic by deploying 'dissensual' strategies 'intended to make the invisible visible or to question the self-evidence of the visible; to rupture given relations between things and meanings and, inversely, to invent novel relationships between things and meanings that were previously unrelated' (Rancière 2010:141). This, Rancière goes on, is therefore an art that reconfigures reality through a 'specific form of sensory experience, disconnected from the normal forms of sensory experience' (Rancière 2010: 173). And this is fundamentally political insofar as politics, like aesthetics, is concerned with reframing, reordering and rearranging the normal social order and the sensory and perceptual space it elicits.

It is no coincidence that Rancière chooses to illustrate his thesis with the work of a contemporary realist filmmaker such as Pedro Costa, whose In Vanda's Room (No quarto de Vanda, 2000), shot in a slum in demolition in Lisbon, he deems representative of the aesthetic regime. Rather than pedagogically explaining the social and economic factors that contributed to this situation of extreme poverty, Costa chooses to highlight the purely aesthetic effect of such reality as perceived, for example, in 'the strangely coloured architecture resulting from the demolition itself' (Rancière 2010: 151). Characterised by rigorously composed static silent shots, this film impresses for the artistic imprint of its visual compositions which reveal at the same time a terrifying reality. At stake here is an art which accepts its 'insufficiency', its limitations as art restricted to sensory experience. It is a political practice that, overturning the expectations bought into representations of social misery, 'invents new trajectories between what can be seen, what can be said and what can be done' (Rancière 2010: 149). 
It is precisely this representational logic that is confrontationally challenged when a film such as Battle in Heaven refuses to explain the hierarchical disruption which a couple such as Ana and Marcos - the phenotypical embodiment of the socio-ethnic divide of Mexico - performs in the social establishment. Instead, the film opts to highlight the aesthetic effect produced, for example, by the graphic conjunction of these segregated bodies through extreme close-ups and overstretched camera movements that inspect, dissect and magnify their purely fleshly quality. Here, as we have seen, these bodies are torn away from their assigned places and functions and rearranged in a new sensible order, which upsets the dominant codes while denouncing them as arbitrary and contextual.

The same is true of a film such as Elephant, which, rejecting a representational carapace that would justify its choice of subject matter as in service of a moral message, turns this event into an elusive, sensorial cinematic experience: the reality of trauma. Averse to demonisation and heroism, the film spends most of its time following real adolescents traversing the school's corridors through smooth, elegantly choreographed tracking shots to the sound of Beethoven's 'Moonlight Sonata', as well as disquieting soundscapes. Here, too, this event is framed through a contemplative and aesthetic sensibility whose political significance consists in the way it enables us to look at this reality anew, making us confront this event in its overwhelming complexity and harrowing terror.

Finally, consider Tsai's The River: focused on a marginalised working-class family in Taipei, its most notorious scene, as we have seen, shows an incestuous homosexual act. How to depict this shocking event? The River opts to give us a highly 
aestheticised scene. Framed in a static medium shot lasting nearly four minutes, the event is presented in almost complete darkness, the silhouettes of bodies only dimly visible. Positioned at the centre of the image, we occasionally get glimpses of the characters' skin as their bodies mutate into changing forms overflowing the borders of the figurative. The loaded representational character of this event, that is, the way in which it immediately questions all sorts of historical discourses and constructions, is not acknowledged as such but transformed into an aesthetic spectacle of contours, light and forms.

More than representations of social issues, these films are sensory explorations of realities yet to be properly understood. Averse to didacticism and univocal messages, they reveal the bewildering factual complexity of local, as well as global, events while producing unexpected configurations of the sensible that contravene the logic of the world and that of fiction. In so doing, they affirm the new. 


\section{BIBLIOGRAPHY}

Abreu, Caio Fernando (2009) Pequenas Epifanias: Crônicas (1986-1995). Rio de Janeiro: Agir/Ediouro.

Andrew, Dudley (2006) 'An Atlas of World Cinema' in Stephanie Dennison and Song Hwee Lim (eds), Remapping World Cinema: Identity, Culture and Politics in Film. London/ New York: Wallflower Press.

Andrews, Malcolm (1999) Landscape and Western Art. Oxford: Oxford University Press. Ayfre, Amédée (1969) 'The Universe of Robert Bresson’ in Ian Cameron (ed) The Films of Robert Bresson. London: Studio Vista. (1985) 'Neo-Realism and Phenomenology' in Jim Hillier (ed.) Cahiers $d u$

Cinéma Volume 1 - The 1950s: Neo-Realism, Hollywood, New Wave. London: Routledge.

Bakhtin, Mikhail (1981) The Dialogical Imagination. Austin: University of Texas Press. (1984) Rabelais and His World. Bloomington/Indianapolis: Indiana University Press.

Ballinger, Alexander (2004) New Cinematographers. London: Laurence King.

Bao, Weihong (2007) 'Biomechanics of Love: Reinventing the Avant-garde in Tsai Ming-liang' Wayward "Pornographic Musical"' in Journal of Chinese Cinemas $1: 2$, pp.139-160.

Bataille, Georges (2001) Eroticism. London: Penguin.

Baudry, Jean-Louis (1974) 'The Ideological Effects of the Basic Cinematographic 
Apparatus' in Film Quarterly 28: 2, pp. 39-47.

Bazin, André (1974) Jean Renoir. New York: Dell.

(1978) Orson Welles: a Critical View. New York/San Francisco/London:

Harper and Row, Publishers.

(1982) The Cinema of Cruelty. New York: Seaver Books.

(1997) Bazin at Work: Major Essays from the Forties \& Fifties, edited by

Bert Cardullo. New York/London: Routledge.

(2003) 'Death Every Afternoon' in Ivone Margulies (ed) Rites of Realism:

Essays on Corporeal Cinema. Durham/London: Duke University Press.

(2005a) What is Cinema? - Volume 1, essays selected and translated by

Hugh Gray. London/Berkeley: University of California Press.

(2005b) What is Cinema - Volume 2, essays selected and translated by

Hugh Gray. London/Berkeley: University of California Press.

Benjamin, Walter (1973) Charles Baudelaire: A Lyric Poet in the Era of High

Capitalism. London: NLB.

Berg, Charles Ramírez (1992) Cinema of Solitude: a Critical Study of Mexican Film, 1967-1983. Austin: University of Texas Press.

Bergala, Alain (1990) 'O homem que se levanta' in Lúcia Nagib (ed) Ozu:o extraordinário cineasta do cotidiano. São Paulo: Cinemateca Brasileira.

Berry, Chris (2005) 'Where is the Love? Hyperbolic Realism and Indulgence in Vive L'amour' in Chris Berry \& Feii Lu (eds) Island on the Edge: Taiwan New Cinema and After. Hong Kong: Hong Kong University Press.

Betz, Mark (2006) ‘The Cinema of Tsai Ming-liang: a Modernist Genealogy' in Maria N. 
Ng \& Philip Holden (eds) Reading Chinese Transnationalisms: Society, Literature, Film. Hong Kong: Hong Kong University Press.

Bird, Michael (2007) 'Religion in Film' in Jolyon Mitchell \& S. Brent Plate (eds) The Religion and Film Reader. London/New York: Routledge.

Blake, William (1994) The Marriage of Heaven and Hell. New York: Dover Publications.

Blanchot, Maurice (1982) 'Everyday Speech' in Yale French Studies (73), pp. 12-20.

Bloom, Harold (2006) 'Introduction' in Harold Bloom (ed) William Blake. New York: Chelsea House Publishers.

Bordwell, David (1981) The Films of Carl-Theodor Dreyer. Los Angeles/London: University of California Press. (1988) Ozu and the Poetics of Cinema. London: BFI.

Bradshaw, Peter (2007) 'Review: Silent Light' in The Guardian 7 December [Online]. Available at http://www.guardian.co.uk/film/2007/dec/07/romance.drama [Accessed May 2009]

Brakhage, Stan (2002) 'Metaphors on Vision' in S. Brent Plate (ed) Religion, Art and Visual Culture: a Cross-Cultural Reader. New York: Palgrave.

Brantes, Charles H. de (2006) 'Faith is the Only Thing that Can Save Man' in John Gianvito (ed) Andrei Tarkovsky: Interviews. Mississippi: University Press of Mississippi.

Brecht, Bertolt (1964) Brecht on Theatre: the Development of an Aesthetic. London: Methuen \& Co Ltd. Bresson, Robert (1986) Notes on the Cinematographer. London: Quartet Encounters. 
Brunette, Peter (1997) 'But Nothing Happened: the Everyday in French Postwar Cinema' in Lynn Gumpert (ed) The Art of the Everyday: the Quotidian in Postwar French Culture. New York/London: New York University Press.

Burgoyne, Robert (2008) The Hollywood Historical Film. Oxford: Blackwell.

Burke, Edmund (1827) Philosophical Enquiry into the Origin of our Ideas of the Sublime and Beautiful. London: J. F. Dove.

Burroughs, William (2001) Naked Lunch. London: Flamingo. (2008) Exterminator!. London: Penguin.

Butcher, Pedro (2005) 'Battle in Heaven' in Cinema-Scope, 23 [Online]. Available at http://www.cinema-scope.com/cs23/spo_butcher_battle.htm [Accessed May 2009].

Byrd, Lesley Simpson (1967) Many Mexicos. Berkeley/Los Angeles: University of California Press.

Carney, Raymond (1989) Speaking the Language of Desire: the Films of Carl Dreyer. Cambridge: Cambridge University Press

Carroll, Noël (1998) Interpreting the Moving Image. Cambridge: Cambridge University Press.

Caruth, Cathy (1995) 'Introduction' in Cathy Caruth (ed) Trauma: Explorations in Memory. London: Johns Hopkins University Press. (1996) Unclaimed Experience: Trauma, Narrative, and History. London: John Hopkins University Press. 
Charney, Leo (1995) 'In a Moment: Film and the Philosophy of Modernity' in Leo

Charney \& Vanessa R. Schwartz (eds.) Cinema and the Invention of Modern Life.

Berkeley/Los Angeles/London: University of California Press.

Chion, Michel (1994) Audio-vision: Sound on Screen. New York/ Chichester: Columbia University Press.

(2009) Film: a Sound Art. New York/ Chichester: Columbia University

Press.

Chow, Rey (2002) 'Sentimental Returns: On the Uses of the Everyday in the Recent Films of Zhang Yimou and Wong Kar-wai' in New Literary History 33:4, pp. $639-654$ (2004) 'A Pain in the Neck, a Scene of "Incest", and Other Enigmas of an Allegorical Cinema in Tsai Ming-liang's The River' in New Centennial Review 4:1, pp. $123-42$

Clover, Carol J. (1995) 'The Eye of Horror' in Linda Williams (ed) Viewing Positions: Ways of Seeing Film. New Brunswick: Rutgers University Press.

Cunneen, Joseph E. (2004) Robert Bresson: a Spiritual Style in Film. London/ New York: Continuum.

Dargis, Manohla (2003) ‘Movie Review: Japón’ in Los Angeles Time April 25 [Online]. Available at http://www.calendarlive.com/movies/reviews/cl-etmanohla25apr25,0,555441.story [Accessed May 2009]

Davis, Kenneth Ronald (1974) Anabaptism and Asceticism: a Study in Intellectual Origins. Pennsylvania/ Ontario: Herald Press. 
De Luca, Tiago (2009) Interview with Carlos Reygadas, September. Mexico City: unpublished.

(2010) Interview with Tsai Ming-liang, November. Leeds: unpublished.

Deleuze, Gilles (2005a) Cinema 1: The Movement-Image. London: Continuum. (2005b) Cinema 2: The Time-Image. London: Continuum.

Deleuze, Gilles \& Guattari, Felix (1986) Kafka: Toward a Minor Literature. Minneapolis: University of Minnesota Press. (2004) A Thousand Plateaus: Capitalism and

Schizophrenia. London/ New York: Continuum.

Doane, Mary Ann (2002) The Emergence of Cinematic Time: Modernity, Contingency, The Archive. Cambridge/ Massachusetts/ London: Harvard University Press. (2009) 'Scale and the Negotiation of "Real" and "Unreal" Space in the

Cinema’ in Lúcia Nagib \& Cecília Mello (eds) Realism and the Audiovisual Media. Basingstoke: Palgrave Macmillan.

Dyck, Cornelius J. (1993) An Introduction to Mennonite History. Pennsylvania/ Ontario: Herald Press.

Eliade, Mircea (1961) The Sacred and the Profane. New York: Harper \& Row.

Essick, Robert N. (1982) Robert Blair's The Grave Illustrated by William Blake: a Study and Facsimile. London: Scolar Press.

Foucault, Michel (1979). Discipline and Punish. New York: Vintage. (1989) Foucault Live (Interviews 1961-1984), edited by Sylvère

Lotringer. New York: Semiotext(e). 
Forgacs, David; Luton, Sarah \& Nowell-Smith, Geoffrey (eds) (2000) Roberto Rossellini: Magician of the Real. London: BFI.

Flanagan, Matthew (2008) 'Towards an Aesthetic of Slow in Contemporary Cinema' in 16:9 [Online]. Available at http://www.16-9.dk/2008-11/side11 inenglish.htm [Accessed July 2010].

Frampton, Daniel (2006) Filmosophy. London/New York: Wallflower Press.

Furst, Lilian R. \& Skrine, Peter N. (1971) Naturalism. London: Methuen.

Galloway, Alexander R. (2006) Gaming: Essays on Algorithmic Culture. Minneapolis/ London: University of Minnesota Press.

Gandy, Matthew (2006) 'The Cinematic Void: Desert Iconographies in Michelangelo Antonioni's Zabriskie Point' in Martin Lefebvre (ed) Landscape and Film. New York/London: Routledge.

Ginsberg, Allen (2006) Howl and Other Poems. San Francisco: City Lights Books.

Grant, Kim (2005) Surrealism and the Visual Arts: Theory and Reception. Cambridge/ New York: Cambridge University Press.

Graver, Lawrence (2004) Beckett: Waiting for Godot. Cambridge: Cambridge University Press.

Grimshaw, Anna \& Ravetz, Amanda (2009) Observational Cinema: Anthropology, Film and the Exploration of Social Life. Bloomington, Indiana: Indiana University Press.

Gunning, Tom (2004) 'What's the Point of an Index? Or, Faking Photographs' in NORDICOM Review 5: 1/2 (September), pp. 39-49.

Haddu, Miriam (2007) Contemporary Mexican Cinema, 1989-1999: History, Space, and 
Identity. Lewiston: E. Mellen Press.

Halliday, Jon (1997) Sirk on Sirk - Conversations with Jon Halliday. London: Faber. Hansen, Miriam Bratu (1997) 'Introduction' in Siegfried Kracauer, Theory of Film: The Redemption of Physical Reality. Princeton, New Jersey: Princeton University Press.

Haraway, Donna J. (2000) How Like a Leaf. London/ New York: Routledge.

Hill, John (1986) Sex, Class and Realism: British Cinema 1956-1963. London: BFI.

Hillier, Jim (1985) 'Introduction (Part Three: Italian Cinema)' in Jim Hillier (ed) Cahiers du Cinéma Volume 1 - The 1950s: Neo-Realism, Hollywood, New Wave. London: Routledge.

Hui, La Frances (2009) 'Tsai Ming-liang: “Cinema Has Its Own Realism”' in Asia Society [Online]. Available at http://asiasociety.org/arts-culture/film/tsai-mingliang-cinema-has-its-own-realism [Accessed November 2010]

Hummel, Volker (2004) 'The Missing: an Interview with Lee Kang-sheng' in Senses of Cinema 32 [Online]. Available at http://www.sensesofcinema.com/2004/32/lee_kang_sheng/ [Accessed November 2010]

Huxley, Aldous (2004) The Doors of Perception. London: Vintage.

James, Nick (2005) ‘Angels and Demons' in Sight and Sound 15 (11), pp. 30-33 (2008) 'New Crowned Despair' in Sight and Sound 18:3, pp. 5 (2009) 'Whose Cinephilia?' in Sight and Sound 19: 11, pp. 5 (2010) 'Passive Aggressive' in Sight and Sound 20: 4, pp. 5

Jameson, Fredric (1984) 'Postmodernism, or The Cultural Logic of Late Capitalism' in 
New Left Review 146, pp. 53-92.

(1992) Signatures of the Visible. London: Routledge.

Jones, Amelia (1998) Body Art: Performing the Subject. Minneapolis/London: University of Minnesota Press.

Jordan, Randolph (2007) 'The Work of Hildegard Westerkamp in the Films of Gus Van Sant: An Interview with the Soundscape Composer (and some added thoughts of my own)' in Offscreen 11:8-9 [Online]. Available at http://www.offscreen.com/index.php/pages/essays/jordan_westerkamp/ [Accessed December 2010].

Keathley, Christian (2006) Cinephilia and History, or The Wind in the Trees. Bloomington/Indianapolis: Indiana University Press.

Kolk, Bessel A. van der \& Hart, Onno van der (1995) 'The Intrusive Past: The Flexibility of Memory and the Engraving of Trauma' in Cathy Caruth (ed) Trauma: Explorations in Memory. London: Johns Hopkins University Press.

Kracauer, Siegfried (1997) Theory of Film: The Redemption of Physical Reality. Princeton, New Jersey: Princeton University Press.

Kraicer, Shelly (2000) 'Interview with Tsai Ming-liang' in East Asia Cultures Critique 8:2,pp. 579-588

La Garza, Armida de (2006) Mexico on Film: National Identity \& International Relations. Bury St. Edmunds: Arena Books.

Langford, Barry (2005) Film Genre: Hollywood and Beyond. Edinburgh: Edinburgh University Press.

Lee, Vivian (2007) 'Pornography, Musical, Drag, and the Art Film: Performing 'Queer' 
in Tsai Ming-liang's The Wayward Cloud' in Journal of Chinese Cinemas 1:2, pp. $117-137$

Lefebvre, Martin (2006) 'Between Setting and Landscape in the Cinema' in Martin Lefebvre (ed) Landscape and Film. New York/London: Routledge.

Leitch, Thomas (2003) 'Hitchcock without Hitchcock' in Literature/Film Quarterly 31:4, pp. 248-259.

Lim, Song Hwee (2006) Celluloid Comrades: Representations of Male Homosexuality in Contemporary Chinese Cinemas. Honolulu: University of Hawai'i Press. (2007) 'Positioning Auteur Theory in Chinese Cinema Studies:

Intratextuality, Intertextuality and Paratextuality in the films of Tsai Ming-liang' in Journal of Chinese Cinemas 1:3, pp. 223-245.

Lorraine, Tasmin (1999) Irigaray and Deleuze: Experiments in Visceral Philosophy. New York: Cornell University Press.

Lu, Tonglin (2002) Confronting Modernity in the Cinemas of Taiwan and Mainland China. Cambridge: Cambridge University Press.

Manovich, Lev (2001) The Language of New Media. Cambridge/London: The MIT Press. Marcus, Millicent (1986) Italian Film in the Light of Neorealism. Princeton: Princeton University Press.

Margulies, Ivone (1996) Nothing Happens: Chantal Akerman's Hyperrealist Everyday. Durham/London: Duke University Press. (2003) ‘Bodies Too Much’ in Ivone Margulies (ed) Rites of Realism: Essays on Corporeal Cinema. Durham/London: Duke University Press. Marks, Laura U. (2000) The Skin of the Film: Intercultural Cinema, Embodiment and The 
Senses. Durham/London: Duke University Press.

Marlow, Jonathan (2006) 'Carlos Reygadas and "A Perfect Universe"” in Greencine

February 15 [Online]. Available at https://www.greencine.com/central/node/257

[Accessed May 2009].

Martin, Fran (2000) 'Wild Women and Mechanical Men: a Review of The Hole' in

Intersections: Gender, History, Culture in the Asian Context, issue 4 [Online].

Available at http://intersections.anu.edu.au/issue4/holereview.html [Accessed

December 2010].

(2003) 'Vive l'amour: Eloquent Emptiness' in Chris Berry (ed) Chinese

Films in Focus: 25 New Takes. London: BFI.

Massumi, Brian (1992) A User's Guide to Capitalism and Schizophrenia: Deviations

from Deleuze and Guattari. Massachusetts: The MIT Press.

Matheou, Demetrios (2003) 'Interview: Carlos Reygadas' in Sight and Sound 13:2, pp.

$12-13$.

Mazzarella, Sharon R. (1995) “"The Voice of a Generation”? Media Coverage of the

Suicide of Kurt Cobain' in Popular Music and Society 19:2, pp. 49-68.

Mulvey, Laura (1989) Visual and Other Pleasures. Basingstoke: Palgrave Macmillan. (2006) Death 24x a Second: Stillness and the Moving Image. London:

Reaktion.

Nagib, Lúcia \& Mello, Cecília (2009) ‘Introduction’ in Lúcia Nagib \& Cecília Mello (eds) Realism and the Audiovisual Media. Basingstoke: Palgrave Macmillan. Nagib, Lúcia (2007) Brazil on Screen: Cinema Novo, New Cinema, Utopia. London/ New York: I.B. Tauris. 
(2011) World Cinema and the Ethics of Realism. London: Continuum.

Naremore, James (2000) 'Remaking: Psycho' in Hitchcock Annual 8 (1999-2000), pp. 312.

Nauman, Bruce (2003) Please Pay Attention Please: Bruce Nauman's Words (ed. by Kraynak, Janet). London/ Cambridge: The MIT Press.

Neyrat, Cyril (2007) 'Critique: I Don't Want to Sleep Alone by Tsai Ming-liang' in Cahiers du Cinéma 623 [Online]. Available at http://www.cahiersducinema.com/Critique-I-don-t-want-to-sleep,1169.html [Accessed November 2010].

Noble, Andrea (2005) Mexican National Cinema. London: Routledge.

Pasolini, Pier Paolo (1980) 'Observations on the Long Take' in October 13, pp. 3-6 (2005) Heretical Empiricism. Washington, DC: New Academia Publishing.

Peirce, Charles Sanders (1950) 'Logic as Semiotic: The Theory of Signs' in Justus Buchler (ed) The Philosophy of Peirce: Selected Writings. London: Routledge.

Powell, Anna (2005) Deleuze and Horror Film. Edinburgh: Edinburgh University Press.

Prince, Stephen (1996) 'True Lies: Perceptual Realism, Digital Images, and Film Theory' in Film Quarterly, 49:3, 27-37.

Proust, Marcel (2005) In Search of Lost Time: In the Shadow of Young Girls in Flower, translated by James Grieve. London: Penguin Books.

Quinlivan, Davina (2009) 'Breath Control: The Sound and Sight of Respiration as Hyperrealist Corporeality in Breaking the Waves' in Lúcia Nagib \& Cecília Mello (eds) Realism and the Audiovisual Media. Basingstoke: Palgrave Macmillan. 
Rancière, Jacques (2006) Film Fables. Oxford/ New York: Berg.

(2010) Dissensus: On Politics and Aesthetics. London/ New York:

Continuum.

Rapfogel, Jared (2002) ‘Tsai Ming-liang: Cinematic Painter’ in Senses of Cinema

[Online] Available at

http://archive.sensesofcinema.com/contents/02/20/tsai_painter.html [Accessed January 2010]

Rawnsley, Ming-yeh T. (2009) 'Observational Realism in New Taiwan Cinema' in Lúcia Nagib \& Cecilia Mello (eds) Realism and the Audiovisual Media. Basingstoke: Palgrave Macmillan.

Redekop, Calvin (1989) Mennonite Society. Baltimore/London: The Johns Hopkins University Press.

Rehm, Jean-Pierre; Joyard, Olivier \& Rivière, Danièle (1999) Tsai Ming-liang. Paris: Editions Dis Voir.

Restivo, Angelo (2002) The Cinema of Economic Miracles: Visuality and Modernization in the Italian Art Film. Durham/ London: Duke University Press.

Ricoeur, Paul (1966) Freedom and Nature: the Voluntary and the Involuntary. Northwestern University Press.

Rodowick, D. N. (2007) The Virtual Life of Film. London: Harvard University Press.

Rogers, Anna Backman (2009) ‘Elephant and Realism’ in Lúcia Nagib \& Cecília Mello (eds) Realism and the Audiovisual Media. Basingstoke: Palgrave Macmillan.

Rolinson, Dave (2005) Alan Clarke. Manchester: Manchester University Press.

Romney, Jonathan (2008) 'The Sheltering Sky' in Sight and Sound 18 (1), pp. $42-44$ 
Rosen, Philip (2001) Change Mummified: Cinema, Historicity, Theory.

Minneapolis/London: University of Minnesota Press.

Ross, Kristin (1997) 'French Quotidian' in Lynn Gumpert (ed) The Art of the Everyday: the Quotidian in Postwar French Culture. New York/London: New York University Press.

Sargeant, Jack (1997) The Naked Lens: a History of Beat Cinema. London: Creation.

Sartre, Jean-Paul (2003) Being and Nothingness. London/ New York: Routledge.

Sawatzky, Harry Leonard (1971) They Sought a Country: Mennonite Colonization in Mexico. Berkeley/London: University of California Press.

Schrader, Paul (1972) Transcendental Style in Film: Ozu, Bresson, Dreyer. London/Los Angeles: University of California Press.

Shaviro, Steven (1993) The Cinematic Body. Minneapolis/ London: University of Minnesota Press. (2010) 'Slow Cinema Vs Fast Films' in The Pinocchio Theory [Online] Available at http://www.shaviro.com/Blog/?p=891 [Accessed June 2010]. Shklovsky, Victor (1965) ‘Art as Technique’ in Lee T. Lemon \& Marion R. Reis (eds) Russian Formalist Criticism: Four Essays. Lincoln: University of Nebraska Press. Sitney, P. Adams (2002) Visionary Film: The American Avant-Garde, 1943-2000. New York: Oxford University Press.

Smith, Anthony D. (2003) Chosen Peoples: Sacred Sources of National Identity. Oxford: Oxford University Press.

Smith, Paul Julian (2003) 'Review: Japón' in Sight and Sound 13: 3, pp. 49-50. (2005) 'Review: Battle in Heaven' in Sight and Sound 15: 11, pp. 48- 
50.

Sobchack, Vivian (2000) 'What My Fingers Knew: The Cinesthetic Subject, or Vision in the Flesh' in Senses of Cinema [Online] Available at http://archive.sensesofcinema.com/contents/00/5/fingers.html [Accessed August 2010] (2004) Carnal Thoughts: Embodiment and Moving Image Culture. Berkeley/ London: University of California Press.

Sontag, Susan (2001) Against Interpretation. London: Vintage. (2002) On Photography. London: Penguin Books. (2009) Styles of Radical Will. London: Penguin Books.

Stam, Robert (1995) Subversive Pleasures: Bakhtin, Cultural Criticism, and Film. Baltimore/London: The Johns Hopkins University Press.

Tarkovsky, Andrey (sic) (2005) Sculpting in Time: Reflections on the Cinema. Austin: University of Texas Press.

Taubin, Amy (2003) 'Part of the Problem: Stepping into the Arena of High School, Gus Van Sant's Elephant Confronts the Specter of Columbine' in Film Comment 39:5, pp. 26-33.

Teodoro, José (2009) 'On Earth as It is in Heaven’ in Film Comment, 45: 1, pp. 48-51. Thompson, Kristin (1986) 'The Concept of Cinematic Excess' in Philip Rosen (ed) Narrative, Apparatus, Ideology: a Film Theory Reader. New York/Guildford: Columbia University Press.

Tobias, Scott (2003) 'Interview: Gus Van Sant' in The A.V. Club March 5 [Online]. Available at http://www.avclub.com/articles/gus-van-sant,13800/ [Accessed April 
2010].

Truffaut, François (1971) 'Tributes to Dreyer' in Carl Theodor Dreyer's Jesus. New York: The Dial Press.

(1993) Hitchcock/Truffaut: Édition Définitive (avec la collaboration de

Helen Scott). Malesherbes: Édition Gallimard.

Turner, Brian (1997) 'The Body in Western Society' in Sarah Coakley (ed) Religion and the Body. Cambridge: Cambridge University Press.

Valck, Marijke de (2005) 'Drowning in Popcorn at the International Film Festival Rotterdam: The Festival as a Multiplex of Cinephilia' in Marijke de Valck \& Malte Hagener (eds) Cinephilia: Movies, Love and Memory. Amsterdam: Amsterdam University Press.

Vallury, Raji (2009) 'Politicizing Art in Rancière and Deleuze: The Case of Postcolonial Literature' in Gabriel Rockhill \& Philip Watts (eds) Jacques Rancière: History, Politics, Aesthetics. Durham/London: Duke University Press.

Van Sant, Gus (1998) Pink. London: Faber and Faber. (2000) 'The Camera is a Machine' in MoMA Béla Tarr Retrospective Catalogue. Available at http://blogs.walkerart.org/filmvideo/2008/03/17/gus-vansant-light-bela-tarr/ [Accessed April 2010]. (n/d) Interview in the extras of the DVD Elephant. London: Optimum

Releasing.

Wang, Bang (2003) 'Black Holes of Globalization: Critique of the New Millennium in Taiwan Cinema' in Modern Chinese Literature and Culture 15: 1, pp. 90-106. Wartenberg, Thomas E. (1999) Unlikely Couples: Movie Romance as Social Criticism. 
Oxford: Westview Press.

Whitaker, Jason (2001) 'William Blake and Film' in Zoamorphosis: The Blake 2.0 Blog

[Online]. Available at http://zoamorphosis.com/2010/02/william-blake-and-film/

[Accessed November 2010].

Willemen, Paul (1994) Looks and Frictions: Essays in Cultural Studies and Film Theory.

Bloomington/Indianapolis: Indiana University Press.

Williams, Linda (1991) 'Film Bodies: Gender, Genre and Excess' in Film Quarterly

44:4, pp. 2-13.

Williams, Raymond (1977) Marxism and Literature. Oxford: Oxford University Press. (2001) The Long Revolution. Ontario: Broadview Press.

Wood, Chris (2007) 'Realism, Intertextuality and Humour in Tsai Ming-liang's Goodbye Dragon Inn' in Journal of Chinese Cinemas 1:2, pp. 105-116.

Wood, Jason (2006) The Faber Book of Mexican Cinema. London: Faber and Faber.

Wollen, Peter (1976) Signs and Meaning in the Cinema. London: BFI. (2004) 'Citizen Kane' in James Naremore (ed) Orson Welles's Citizen

Kane: A Casebook. Oxford/New York: Oxford University Press.

Xavier, Ismail (2003) 'Brazilian Cinema in the 1990s: the Unexpected Encounter and the Resentful Character' in Lúcia Nagib (ed) The New Brazilian Cinema. London/ New York: I. B. Tauris.

Yao, Kuang-Tien (2005) 'Social Commentary on the Marginalized Society: Tsai MingLiang's Films' in R. Yin-Wang Kwok (ed) Globalizing Taipei: The Political Economy of Spatial Development. New York: Routledge.

Yeazell, Ruth Bernard (2008) Art of the Everyday: Dutch Painting and the Realist Novel. 
Princeton/ Oxford: Princeton University Press.

Zola, Émile (1992) Thérèse Raquin. Oxford: Oxford University Press. 